Anatomical, morphological and physiological differences between different types of rice and wheat under water deficit conditions

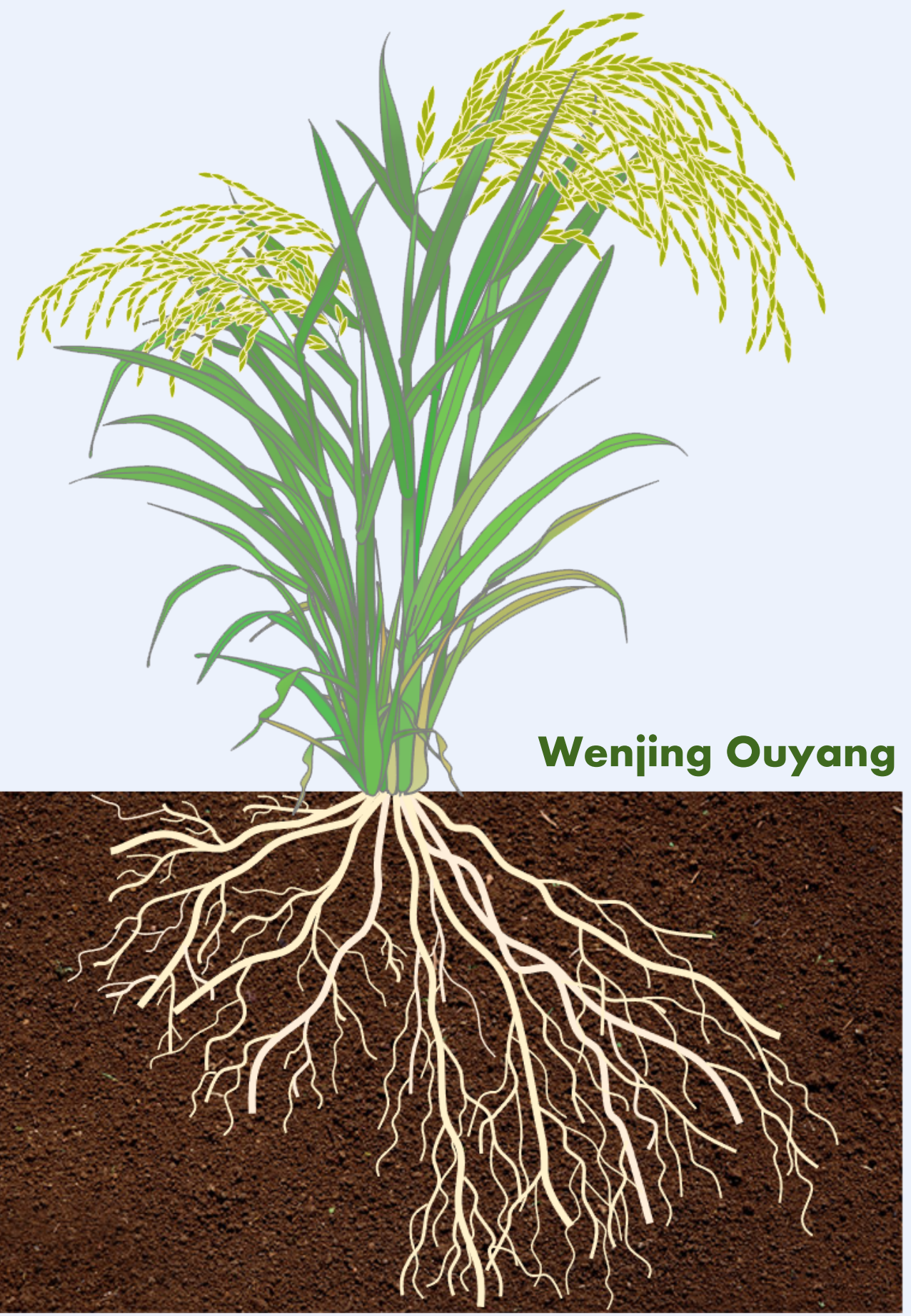





\section{Propositions}

1. Structural design of above- and below-ground organs of the rice plant is not suited for production under water deficit.

(this thesis)

2. Leaf-level water use efficiency in rice is not low.

(this thesis)

3. Outliers in scientific data should be challenged, not removed.

4. Experimental design should consider more the risk of failure than the chance of breaking-through.

5. Waste sorting should be implemented by guidance rather than by legal enforcement.

6. Online education is not the future.

Propositions belonging to the $\mathrm{PhD}$ thesis, entitled:

Anatomical, morphological and physiological differences between different types of rice and wheat under water deficit conditions

Wenjing Ouyang

Wageningen, October 26, 2021 
Anatomical, morphological and physiological differences

between different types of rice and wheat

under water deficit conditions

Wenjing Ouyang 


\section{Thesis committee}

\section{Promotor}

Prof. Dr P.C. Struik

Professor of Crop Physiology

Wageningen University \& Research

\section{Co-promotors}

Dr X. Yin

Senior scientist, Centre for Crop Systems Analysis

Wageningen University \& Research

Prof. Dr J. Yang

Professor of Crop Physiology

Agricultural College of Yangzhou University, China

\section{Other members}

Prof. Dr K.E. Giller, Wageningen University \& Research

Prof. Dr H.J. Bouwmeester, Swammerdam Institute for Life Sciences, University of Amsterdam

Dr V. Willemsen, Wageningen University \& Research

Prof. Dr L. Bentsink, Wageningen University \& Research

This research was conducted under the auspices of the C.T. de Wit Graduate School for Production Ecology and Resource Conservation 


\title{
Anatomical, morphological and physiological differences between different types of rice and wheat under water deficit conditions
}

\author{
Wenjing Ouyang
}

\section{Thesis}

submitted in fulfilment of the requirements for the degree of doctor at Wageningen University

by the authority of the Rector Magnificus,

Prof. Dr A.P.J. Mol, in the presence of the

Thesis Committee appointed by the Academic Board to be defended in public

on Tuesday 26 October 2021 at 11 a.m. in the Aula. 


\section{Wenjing Ouyang}

Anatomical, morphological and physiological differences between different types of rice and wheat under water deficit conditions, 206 pages.

PhD thesis, Wageningen University, Wageningen, NL (2021)

With references, with summary in English

ISBN: 978-94-6395-989-6

DOI: https://doi.org/10.18174/553705 


\begin{abstract}
Wenjing Ouyang, 2021. Anatomical, morphological and physiological differences between different types of rice and wheat under water deficit conditions. $\mathrm{PhD}$ thesis, Wageningen University \& Research, Wageningen, The Netherlands. 206 pp.

Rice (Oryza sativa) is one of the most important cereal crops with high economic and social values. Natural diversity in water-deficit tolerance has allowed rice genotypes to adapt to different edaphic conditions. While genotypes adapted to the irrigated lowland system are most productive, the growing scarcity of freshwater resources for agriculture calls for developing rice genotypes that can be gown like dryland cereals. This dissertation aims to understand why so far rice cannot perform well under drier conditions via studying the basic anatomical, morphological and physiological mechanisms that determine the comparative adaptability of rice and wheat (Triticum aestivum) to water deficit.
\end{abstract}

First, leaf anatomical and morphological attributes that affect leaf photosynthesis $\left(A_{\mathrm{n}}\right)$ and transpiration efficiency (TE) were investigated, using six representative rice genotypes and two wheat genotypes grown under long-term water deficit. Variations in $A_{\mathrm{n}}$ and TE were well explained by the $\mathrm{CO}_{2}$ diffusion components, i.e. stomatal conductance $\left(g_{\mathrm{s}}\right)$ and mesophyll conductance $\left(g_{\mathrm{m}}\right)$. Genotypic variation in $g_{\mathrm{s}}$ among rice genotypes resulted from the differences in stomal density and size. Compared with wheat, the lower $g_{\mathrm{m}}$ in rice was associated with its less optimized leaf mesophyll structures and anatomical properties.

Secondly, anatomical traits that affect the acquisition and transport of water in root and shoot were examined at two developmental stages of three rice and two wheat genotypes. Rice roots possess extensive aerenchym but much smaller xylem vessels than wheat roots, while the xylem area in stem and leaf was higher in rice than in wheat. Compared with wheat, water deficit clearly induced the apoplastic barriers for radial water flow in rice roots and strongly limited the root growth and lateral root proliferation in rice, whereas the shoot growth in rice was less affected by treatments. As a result, there was an imbalance between water acquisition and transpiration demand in rice plant when grown under water deficit.

Rice genotypes adapted to different edaphic conditions display diverse canopy architectures. To investigate how rice water-deficit adaptability is associated with canopy physiological and morphological characteristics, one irrigated-lowland (cv. IR64) and one aerobic (cv. Apo) rice 
genotypes were selected from the six rice genotypes based on their similar growth durations but contrasting above-ground architectures. Compared with cv. IR64, cv. Apo allocated less leaf area and less nitrogen to strongly shaded leaves and its leaf angles were less responsive to the long-term water deficit, allowing the vertical nitrogen distribution to better acclimate to light distribution within its canopy. The favourable above-ground architecture and canopy nitrogen profile relative to the light profile contributed greatly to the higher biomass gain and yield in cv. Apo under water deficit.

Findings in this dissertation for the anatomy, morphology and physiology of rice at organ, plant and canopy level suggest that several anatomical and morphological attributes need to be modified if rice is to grow like dryland cereals.

Keywords: Canopy light distribution; canopy nitrogen distribution; canopy structure; leaf anatomy; mesophyll conductance; rice; root anatomy; root morphology; stem anatomy; stomatal conductance; transpiration efficiency; water deficit; wheat 


\section{Table of contents}

Chapter 1 General introduction 1

Chapter 2 Stomatal conductance, mesophyll conductance, and transpiration 23 efficiency in relation to leaf anatomy in rice and wheat genotypes under drought

Chapter 3 Comparisons with wheat reveal root anatomical and histochemical constraints of rice under water-deficit stress

Chapter 4 Do shoot anatomical characteristics allow rice to grow well under water deficit?

Chapter 5 Roles of canopy architecture and nitrogen distribution in better performance of an aerobic than a lowland rice cultivar under water deficit

Chapter 6 General discussion

Summary

Acknowledgements

List of publications

PE\&RC Training and Education Statement 203

Curriculum Vitae 205

Funding 



\section{Chapter 1}

General introduction 


\subsection{General background}

Rice is a semi-aquatic Gramineae plant. It encompasses approximately twenty-two species of the genus Oryza, of which O. sativa (known as Asian rice) and O. glaberrima (known as African rice) are the most important cultivated species, grown for human consumption. These two species provide the primary food for over half of the world's population (Muthayya et al., 2014). Rice is considered among the most important caloric and nutritional sources and provides approximately $25 \%$ of all global calories. The demand for rice is continuously increasing due to the population growth in Asian countries as well as the steadily growing consumption of rice in sub-Saharan Africa and Latin America (IRRI, 2013). Therefore, increasing rice yield is crucial for solving the food shortage problem and ensuring food security.

\subsubsection{Rice cultivation systems}

Of the two most widely cultivated rice species, $O$. sativa is more widely grown and mostly cultivated in Asian countries, while the cultivation of $O$. glaberrima is confined to Africa. Thousands of O. sativa varieties are grown in more than 100 countries, and they are cultivated in diverse growing conditions: floating (deep-water) rice, irrigated rice, rice in mangrove swamps, rice in rain-fed lowlands and rice in upland environments (Khush, 1997). Of these rice production systems, irrigated lowland, rain-fed lowland and upland rice accounted for more than $90 \%$ of the global rice production area. Rice cultivated in irrigated lowland systems is grown in bunded fields that are continuously with a standing water layer of 5-10 cm from crop establishment to close to harvest. It is estimated that irrigated lowland rice accounts for approximately $55 \%$ of the total rice area and contributes nearly $75 \%$ of the global rice production (Maclean et al., 2013). Irrigated lowland rice consumes up to about $40 \%$ of the total world's freshwater resources used for irrigation (Barker et al., 2000; Bouman et al., 2007b). Rain-fed lowland is the second most important rice ecosystem. Rice in rain-fed lowland is grown in bunded fields with non-continuous flooding of variable depth and duration, depending on the frequency and quantity of rainfall available. Nearly $25 \%$ of the global rice area is occupied by rain-fed lowland system; but rain-fed lowland rice comprises less than one-fifth of the global rice produced (Portmann et al., 2010). Upland rice is grown in rain-fed, not bunded fields with naturally well drained soils, without surface water accumulation, and normally without extra water supply. Upland rice represents about $12 \%$ of total rice production area and is generally the lowest-yielding ecosystem. Upland rice is mostly produced by smallholder farmers and produces $4 \%$ of the world's total rice production (Bernier et al., 2008). The other 
rice ecosystems make up the remaining area and production, both in Africa and Asia.

The African indigenous rice, O. glaberrima, has evolved parallel to the Asian cultivated $O$. sativa species (Wang et al., 2014). Due to its low yield potential, O. glaberrima was being largely replaced by the higher yielding O. sativa varieties (Linares, 2002). Nevertheless, African rice embodies important cultural values and is continuously cultivated in West Africa (Teeken et al., 2012). Compared with O. sativa, O. glaberrima has the ability to grow in a wider range of difficult ecosystems, such as rain-fed upland as well as deep-water systems. Efforts to utilize $O$. glaberrima genes to improve $O$. sativa rice cultivars have intensified to develop NERICA (New Rice for Africa) genotypes that are expected to be high-yielding, and droughtand pest-resistant (Sarla and Swamy, 2005; Shaibu et al., 2018). Farmers have also spontaneously selected interspecific hybrids from their fields (Nuijten et al., 2009), which show greater robustness than O. sativa types under stressful West African conditions with poor, dry or eroded soils (Mokuwa et al., 2013).

\subsubsection{Global water shortage and impact on rice production}

Global climatic variables and water availabilities are continuously changing. Increase in global average temperature has been documented since 1950s (IPCC, 2007). An even more rapid rate of increase in global average temperature is expected over the next decades, likely in particular for cultivated land areas (Lobell et al., 2011). Global warming increases evaporation and leads to an increase in the frequency of droughts (Sheffield and Wood, 2008; Allan et al., 2010; Li et al., 2011; Chou et al., 2013). In addition, extreme high temperature during both day and night time will likely become more frequent and more intensive in the future (Mika, 2013; Stocker, 2014), especially in the tropical and subtropical areas of South and Southeast Asia. Climate models predict that the frequency and concurrence of weather and climate extremes will increase the severity and frequency of water shortage for agriculture (Dai, 2011; Smirnov et al., 2016; Madadgar et al., 2017; Prabnakorn et al., 2018).

Although the cultivation of rice extends from wetland to dryland, most of the annual rice production comes from the Asian irrigated lowland systems (Maclean et al., 2013). Irrigated lowland rice production requires ample water supply and, thus, is more vulnerable to the increasing agricultural water scarcity than other rice cropping systems (O'Toole, 2004; Peng et al., 2009). It has been estimated that 15-20 million hectares of irrigated rice will experience some degree of water scarcity by 2025 (Bouman et al., 2007a). Furthermore, rice grown in rainfed lowland and upland conditions does not receive irrigation, relying entirely on rainfall or 
drainage from higher lands in a watershed. Drought, caused by insufficient rainfall, is of common occurrence in rain-fed fields under present climatic conditions, and is likely to be more intense and more frequent in the future (Wassmann et al., 2009). It has been shown that the production of rice has declined in many parts of Asia in the past few decades, due to increasing water deficit stress, arising from increasing temperatures and decreases in the number of rainy days (Fukai et al., 1998; Tsubo et al., 2009; Sarker et al., 2012). Therefore, using less water to maintain or preferably even increase rice yield becomes a major challenge for global food security.

\subsubsection{Approaches to cultivate rice with less water}

While rice has been grown in flooded fields for thousands of years, the rice plant itself is not an aquatic species. The adaptation of rice genotypes to a wide range of edaphic conditions indicates the possibility of growing rice in the same way as dryland cereal crops such as wheat (Triticum aestivum). Actually, when grown under flooded conditions, modern rice varieties have similar water productivity (i.e. grain yield per unit of water input) as wheat with respect to transpiration (on average $2.0 \mathrm{~g}_{\text {grain } \mathrm{kg}^{-1}}$ water) and to evapotranspiration (on average $1.1 \mathrm{~g}$ grain $\mathrm{kg}^{-1}$ water) (Bouman and Tuong, 2001; Zwart and Bastiaanssen, 2004; Tuong et al., 2005; Singh et al., 2006). Yet, the water productivity of rice with respect to total water input (irrigation plus rainfall) is only about half that of wheat (Bouman and Tuong, 2001; Tuong et al., 2005). It has been estimated that irrigated rice requires about $3000-5000 \mathrm{~L}$ water to produce $1 \mathrm{~kg}$ grain (IRRI 2001). Exploring alternative solutions to reduce water use for lowland rice production is therefore of great strategic value for sustainable crop production for the world facing water scarcity.

To reduce water use in irrigated lowland rice while maintaining its high yield level, various water-saving practices have been introduced, such as the System of Rice Intensification (Stoop et al., 2002; Zhao et al., 2011), alternate wetting and drying (Carrijo et al., 2017; Menge et al., 2020), and controlled soil drying during grain filling (Yang et al., 2003; Yang and Zhang, 2006). Under accurate management, some of these practices can reduce water use without heavily compromising grain yield. Yet, these practices are not adopted by farmers as they incur too high risks, and different levels of yield penalties are unavoidable. More recently, genotypes that can grow under aerobic environments, i.e. aerobic rice (Bouman et al., 2005; Singh et al., 2008), have been developed. The aerobic rice system is a new cultivation system in which rice is grown under non-puddled, non-flooded and non-saturated soil conditions. Water input in 
aerobic conditions is less than 50\% of that in flooding conditions (Peng et al., 2006). Nevertheless, aerobic rice cannot replace lowland rice in most of the rice growing areas because of its lower grain yield and undesirable taste, and can only be an option for farmers in rain-fed lowlands with limited or erratic rainfall (Atlin et al., 2006). To sum up, these practices are largely management measures to reduce water use for rice production but do not solve the problem of the intrinsically high-water requirement by rice.

Obviously, there is a strong need for developing rice genotypes that can be grown like wheat under drier field conditions. In virtue of their relatively small water requirements, O. glaberrima and upland rice varieties have been applied as genetic resources for breeding for genotypes having better drought adaptation (Sarla and Swamy, 2005; Lyu et al., 2014; Shaibu et al., 2018; Luo et al., 2020). Choosing drought tolerant donors was normally based on direct selection for grain yield in stress environments (Venuprasad et al., 2007; Yuan et al., 2011; Raman et al., 2012). There is a lack of information on characteristics of rice varieties that are required for superior performance under water saving crop management.

\subsection{Literature review on water deficit tolerant determinants}

To develop new rice genotypes that can perform well under water-deficit conditions, it is important to understand why irrigated lowland rice needs more water to maintain yield while traditional upland and newly developed aerobic rice can grow in relatively drier (upland or aerobic) conditions (though with yield penalty). Moreover, it is also important to understand why in general rice production has higher water requirement than wheat, although the water productivity per unit of transpiration and per unit of evapotranspiration is similar between these two species. Breeding for drought tolerant crops has mainly focused on using genetic approaches to identify the functional genes that favourably influence water deficit tolerance (see review by $\mathrm{Hu}$ and Xiong, 2014).

Water deficit is a multidimensional stress and affects different plant organs over time and space. Plants have evolved multiple strategies to respond to water deficit and have evolved to adapt or acclimate to water deficit via anatomical, morphological and physiological changes. This means that in addition to the functional genes for crop performance, the importance of the intermediate physiological, morphological and anatomical characteristics in determining water uptake, water transport and thus water deficit tolerance cannot be overlooked. In the next part of this general introduction, I will describe several candidate mechanisms that merit specific attention at 
different scales, from leaf to canopy, and from plant to crop levels.

\subsubsection{Determinants at leaf level}

Water flow across a plant can be simplified as: water uptake by roots, long-distance transport in vascular systems in root and stem, and release back in the atmosphere from leaves. In terrestrial plants, about $90 \%$ of the root-absorbed water from soil is lost into the atmosphere by transpiration through stomata, the small pores distributed on the surfaces of leaves (Hetherington and Woodward, 2003; Sinha, 2004). Regulating stomatal transpiration to prevent unrestricted water loss plays a critical role in plant development especially when soil water availability is limited.

Leaf water loss is controlled by stomatal aperture (Chaves, 1991; Cornic and Massacci, 1996) and anatomical development (i.e. size and density of stomata) (Doheny-Adams et al., 2012; Franks et al., 2015; Li et al., 2020). When water escapes through stomata, $\mathrm{CO}_{2}$ enters the leaf simultaneously. Therefore, reducing transpiration under water shortage also means a decrease in the $\mathrm{CO}_{2}$ uptake from the atmosphere to the interior of the leaf for photosynthesis, i.e. the lower the stomatal conductance $\left(g_{\mathrm{s}}\right)$, the lower is photosynthesis (Chaves et al., 2002; Flexas et al., 2004). As stomata exert major controls on both water and $\mathrm{CO}_{2}$ exchange, the stomatarelated environmental acclimation would affect the instantaneous transpiration efficiency (TE), i.e. the ratio of net photosynthesis rate $\left(A_{\mathrm{n}}\right)$ to transpiration rate (Condon et al., 2004; Gu et al., 2012; Antunes et al., 2017). TE, known as leaf-level water use efficiency (WUE), has been proposed to be an attractive target to improve the water productivity of both irrigated and rainfed crop production (Fischer, 1981; Richards et al., 2002; Condon et al., 2004). Thus, a better understanding of the determinants affecting TE under water deficit may help elucidate how this trait could be used most effectively to develop tolerant rice genotypes.

After $\mathrm{CO}_{2}$ diffuses into the interior leaf, it has to enter the mesophyll cells and move across several subcellular barriers before it reaches the site of carboxylation in the chloroplasts. Mesophyll conductance $\left(g_{\mathrm{m}}\right)$ is viewed as leaf internal diffusion conductance of $\mathrm{CO}_{2}$ from substomatal cavities to the sites of carboxylation in the chloroplasts (Flexas et al., 2008). Increasing evidences indicate that $g_{\mathrm{m}}$ is sufficiently small to significantly decrease the $\mathrm{CO}_{2}$ concentration in the chloroplasts relative to that in the sub-stomatal cavities, therefore limiting photosynthesis (for a review, see Flexas et al., 2008). Therefore, the importance of $g_{\mathrm{m}}$ in affecting photosynthesis and TE under water deficit should not be underestimated. Factors affecting $g_{\mathrm{m}}$ comprise anatomical and biochemical components (Flexas et al., 2008). In particular, leaf 
anatomical characteristics play important roles in determining the variation in $g_{\mathrm{m}}$ between and within species with different leaf forms and growth habits (Oguchi et al., 2005; Niinemets et al., 2009; Terashima et al., 2011; Tosens et al., 2012). In addition, plants may modify their leaf anatomy during their development under water-deficient conditions. Therefore, investigation on the structural basis of variation in $g_{\mathrm{m}}$ among the contrasting rice genotypes as well between rice and wheat, and how those structures underpin genotypic differences in the response of $g_{\mathrm{m}}$ under water deficit are needed.

\subsubsection{Determinants of water transport}

Apart from regulation of water loss from transpiration, the supply side of the water balance of a plant, i.e. the acquisition of water from the soil, is worthy of attention when plants are facing water-limited conditions. Roots are the first point of contact with the soil in a plant. Because of the primary role in water uptake, root traits are of great interest for geneticists and breeders to explore avenues for increasing crop productivity under water deficit. Genetic variation in water uptake in water-deficit-stressed rice has previously been described (Lilley and Fukai, 1994; Henry et al., 2012), which is thought to be due in part to root architecture (reviewed by Gowda et al., 2011) and root function (water uptake per length of root and root hydraulic conductivity; Miyamoto et al., 2001). The composition of the root system depends greatly on soil texture, soil compaction and soil water status, and plays an important role in environmental adaptations (Pierret et al. 2005; Watt et al. 2008; reviewed by Gowda et al., 2011). As different rice types are adapted to various edaphic conditions, their root systems might respond differently to water deficit. Furthermore, due to its ability to grow under inundated conditions, rice develops several specific root characteristics compared with dryland species, such as aerenchyma. Although the difference is obvious, the direct comparison of the root traits in response to water deficit between rice and wheat will help to identify the general traits that responsible for the low tolerance to water deficit in rice.

There are two types of conductance that determine the uptake of soil water by roots: radial conductance, the conductance of water passing from root surface to the xylems in the stele; and axial conductance, the conductance of water passing from the root to the shoot through the xylems (Wasson et al., 2012). Given the complex, composite anatomical structure of roots, the radial water transport requires composite pathways: parallel apoplastic and cell-to-cell (symplastic and transcellular) pathways (Steudle and Peterson 1998). Experimental data indicated a predominantly higher contribution of apoplastic water transport to the overall 
hydraulic conductivity than that of cell-to-cell pathways in rice roots (Ranathunge et al., 2004). Generally, the radial path of water movement faces a series of barriers within the root cylinder: epidermis, exodermis, central cortex, endodermis, pericycle stele parenchyma, and tracheary elements. During water deficit stress, the anatomy and chemical compositions of those apoplastic barriers will change (Schreiber et al., 1999; Zimmermann et al., 2000; Henry et al., 2012). How those modifications influence the water uptake in different rice types is rarely studied. Unlike other cereal crops, rice roots in well-watered conditions feature some specific structures such as a sclerenchyma layer at the outer part of roots to form a barrier that reduces radial oxygen loss (Colmer et al., 1998); and an extensive intercellular space (i.e. aerenchyma) in the root cortex to provide a low internal resistance for gas movement within the roots (McDonald et al., 2002; Suralta and Yamauchi 2008). However, the roles of those features in water deficit response of rice are not clear.

In vascular plants, xylem vessels act as ducts which collect the water taken up radially in roots and rapidly distribute it throughout the plant (Kim et al., 2014). Under well-watered conditions, water moves passively through the xylem vessels in each organ in response to a water potential gradient set up by transpiration (Steudle 2000). It is clear that the resistance of the water flow in the axial path (xylem) is much smaller than that of the radial pathway across the root cylinder (Rowse and Goodman, 1981; Steudle 2000). However, the hydraulic resistance of xylem may become important under water deficit stress, when transpiration is low. In its most simplified representation, the hydraulic conductivity of xylem is proportional to the number of conduits in parallel and their diameters raised to the fourth power (Tyree and Ewers, 1991). The development (number and size) of xylem vessels can be different along the root axis and may change under water-limited conditions (Henry et al., 2012; Steinemann et al., 2015). Xylem vessels in stem and leaf were expected to influence the plant water status and could be modified according to the growth environment (Yatapanage and So, 2001; Sibounheuang et al., 2006; Ennajeh et al., 2010). Thus, xylem parameters along root, stem and leaf would play important roles in adjusting water balance in water deficit-stressed rice plants.

\subsubsection{Determinants at canopy level}

Plant architecture has major agronomic roles in determining the adaptation capability of plant to cultivation practices. One of the big successes of the Green Revolution in increasing the yield potential of rice was breeding for modified plant architecture (Khush, 2001). Rice varieties with shorter, stiff stems responded better to fertilizer than traditional varieties, and turned out to 
perform very well with good irrigation systems or reliable rainfall (Evenson and Gollin, 2003). However, it is uncertain if those characters are suitable for growing under water limited conditions.

In general, lowland rice varieties have many tillers, dwarf stature and narrow leaves with wide leaf angle while aerobic and upland rice varieties have fewer tillers, longer stems and broader leaves with erect orientation (Peng et al., 2000; Lafitte et al., 2002; Venuprasad et al., 2009; Matsuo et al., 2010). Plant architecture is determined by the genetic background but is also influenced by environmental factors such as light, temperature, plant density, nutrient availability and water regimes (Ross, 1981; Sperry et al., 1998; Ariyaratna et al., 2011). Farooq et al. (2010) reported rice cultivars maintaining broader leaves performed better than those with narrow and short leaves under water deficit. Nevertheless, limited information is available on the differences in the effects of water deficit on above-ground architecture between contrasting rice genotypes.

In a given environment, plants exhibit various growth strategies to maximize resource-use efficiency. In particular, nitrogen is important as it is involved in both meristematic and photosynthetic activities. Besides the total amount of nitrogen absorbed by the crop, the distribution of nitrogen in the canopy plays a key role in determining crop productivity (Evans, 1989). A vertical gradient of specific leaf nitrogen (SLN; leaf N/leaf area) within a canopy, with more nitrogen allocated to upper leaves and less nitrogen to shaded lower leaves, is classically considered as an adaptative strategy to the local light environment that would tend to maximize canopy photosynthesis and nitrogen utilization efficiency (Field, 1983; Goudriaan, 1995; Hasegawa, 1999; Tominaga et al., 2015). However, within a dense canopy, the actual vertical nitrogen gradient is not fully acclimated with the light gradient (Yin et al., 2003; Archontoulis et al., 2011; Hikosaka et al., 2016). Differences in light-leaf nitrogen relationship have been reported to be related to the differences in plant architecture (Anten et al., 1995; Lötscher et al., 2003). Therefore, rice cultivars with contrasting plant architecture may exhibit different light-leaf nitrogen relationships. Furthermore, a number of canopy structural characteristics that are associated with the variations in light-leaf nitrogen relationship could be modified in water-limited conditions (Archontoulis et al., 2011; Okami et al., 2016). So far, limited studies have investigated the variability of the light-leaf nitrogen relationship under water deficit stress between contrasting rice genotypes. Moreover, the impact of canopy architecture on biomass and yield differences under water deficit between different rice types 
is also limited. Hence, a study on the canopy architectural difference between contrasting rice types can provide a better view on how architectural alteration can contribute to water deficit tolerance.

\subsection{Research objectives}

The general hypotheses of the current study are that rice and wheat have developed specific anatomical, morphological and physiological adaptations to cope with their growth environments. Rice genotypes adapted in different water regimes have optimized their anatomical, morphological and physiological characters to thrive best in their growth environment. The differences in drought tolerance among various rice genotypes, as well as between rice and wheat are determined by those anatomical, morphological and physiological characters. The overall objective of this study, as a component of the "Growing Rice Like Wheat" (GRLW) programme, is to investigate the morphological and anatomical traits and related physiological characteristics that could explain the differences in growth and yield performance between rice and wheat and among various types of rice under water deficit. To achieve this objective, experimental research was designed that allows:

1) Analysis of leaf anatomy in relation to water use efficiency in rice and wheat,

2) Characterization of root system and root anatomical characteristics in different types of rice and wheat,

3) Characterization of shoot anatomical characteristics and its relationship with leaf water status in different types of rice and wheat,

4) Study on rice above-ground architectural traits,

5) Study on the crop physiological and agronomic performance of rice and wheat in response to different water regimes as determined by the above morphological and anatomical characteristics.

\subsection{Outline of the thesis}

This thesis consists of six chapters, including this chapter as general introduction that identifies the research objectives based on research questions of the GRLW programme and the literature information (Chapter 1). Following this chapter, there are four research chapters (Chapter 2 to Chapter 5) and a general discussion (Chapter 6). The structure of this thesis is illustrated in Fig. 1.1 . 


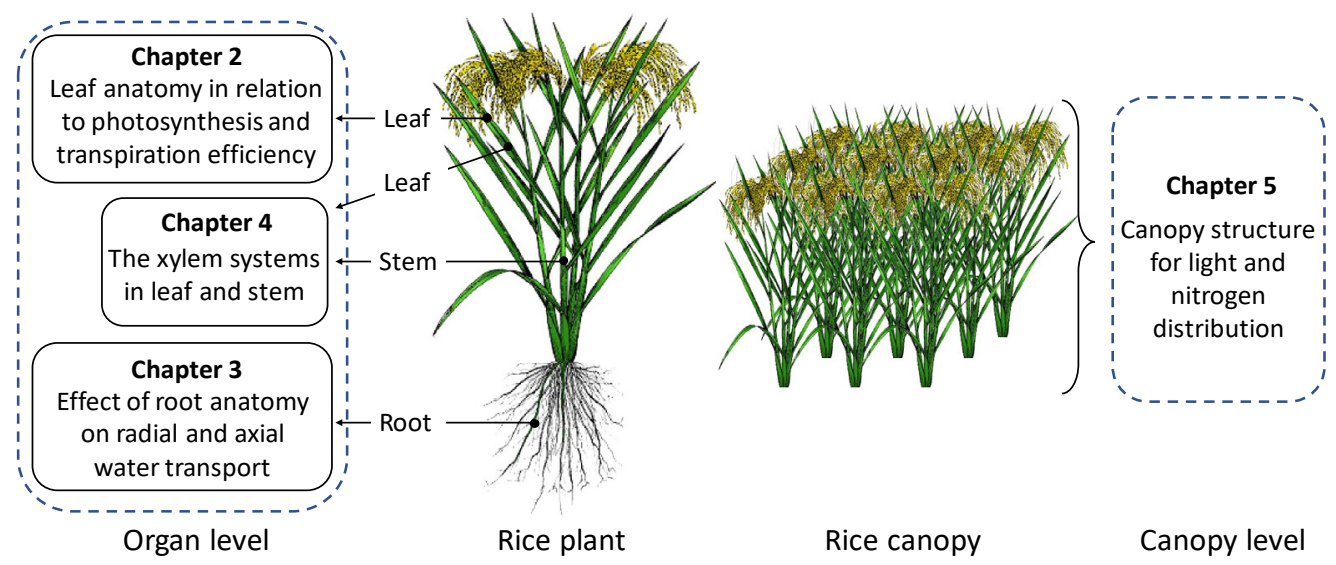

Fig. 1.1 Outline of the dissertation. Rice plant image is obtained and modified from the image collection of the International Rice Research Institute (IRRI).

Chapter 2 aims to unravel the mechanisms for improving leaf-level water use efficiency (TE) in rice. Anatomical drivers of variation in stomatal and mesophyll conductances are evaluated in two cultivars from each of lowland, aerobic, and upland groups of $O$. sativa, one cultivar of O. glaberrima, and two cultivars from wheat, under three water regimes. The importance of stomatal and mesophyll conductances in determine the variation in photosynthetic capacity and TE are discussed.

In Chapter 3 and Chapter 4, the morphological and anatomical traits that affect water acquisition and transport in root and shoot will be determined. In order to do so, root morphology and root cross-sectional structures will be compared between three rice cultivars and two wheat cultivars under three regimes in Chapter 3. Those rice cultivars are selected based on their performance in Chapter 2 and the two wheat cultivars are the same as those used in Chapter 2. Water deficit effect on anatomical and histochemical properties of each root tissues will also be tested. In Chapter 4, the same genotypes are used, but to understand how shoot anatomy responds to water deficit stress, and its relationship with leaf water status (indicated by leaf water potential). The importance of morphological and anatomical adaptations of root and shoot in determining the degree of water deficit tolerance in rice and wheat is discussed.

From the above studies, it was noticed that the above-ground architectural characters vary between different types of rice. Based on the observations from experiments conducted for the previous chapters, one cultivar from lowland and one from aerobic rice are selected due to their similar growth durations and contrasting above-ground architectures. Canopy morphological 
characters (i.e., leaf angles and leaf area allocation) and physiological characters (i.e., light and nitrogen distribution parameters) under three water regimes, and their relations are investigated in Chapter 5. Furthermore, the contribution of canopy physiological characters on biomass gain and yield response to water deficit of the two rice cultivars is emphasized.

Chapter 6 summarizes the main findings of this thesis, discusses the sensitivity of rice plant to water deficit and the importance of fundamental morphological and anatomical characteristics in determining water deficit tolerance. In this chapter, information from leaf to canopy are integrated from a broad perspective to get better understanding why rice plant cannot grow in drier conditions as wheat. The potential targets for improving rice tolerance to water deficit are discussed.

\section{References}

Allan RP, Soden BJ, John VO, Ingram W. Good P. 2010. Current changes in tropical precipitation. Environmental Research Letters 5, 025205.

Anten NPR, Schieving F, Medina E, Werger MJA, Schuffelen P. 1995. Optimal leaf area indices in $\mathrm{C}_{3}$ and $\mathrm{C}_{4}$ mono- and dicotyledonous species at low and high nitrogen availability. Physiologia Plantarum 95, 541-550.

Antunes WC, de Menezes Daloso D, Pinheiro DP, Williams TCR, Loureiro ME. 2017. Guard cell-specific down-regulation of the sucrose transporter SUT1 leads to improved water use efficiency and reveals the interplay between carbohydrate metabolism and $\mathrm{K}^{+}$accumulation in the regulation of stomatal opening. Environmental and Experimental Botany 135, 73-85.

Archontoulis SV, Vos J, Yin X, Bastiaans L, Danalatos NG, Struik PC. 2011. Temporal dynamics of light and nitrogen vertical distributions in canopies of sunflower, kenaf and cynara. Field Crops Research 122, 186-198.

Ariyaratna M, Takamure I, Kato K. 2011. Plant architecture and its responses to high planting density and low fertilizer of reduced culm number mutants in rice (Oryza sativa L.). Journal of Plant Breeding and Crop Science 3, 114-119.

Atlin G, Lafitte H, Tao D, Laza M, Amante M, Courtois B. 2006. Developing rice cultivars for high-fertility upland systems in the Asian tropics. Field Crops Research 97, 43-52.

Barker R, Dawe D, Tuong T, Bhuiyan S, Guerra L. 2000. The outlook for water resources in the year 2020: challenges for research on water management in rice production. International Rice Commission Newsletter 49, 7-21.

Bernier J, Atlin GN, Serraj R, Kumar A, Spaner D. 2008. Breeding upland rice for drought 
resistance. Journal of the Science of Food and Agriculture 88, 927-939.

Bouman BAM, Humphreys E, Tuong TP, Barker R. 2007a. Rice and water. Advances in Agronomy 92, 187-237.

Bouman, BAM, Lampayan RM, Tuong TP. 2007b. Water management in irrigated rice: coping with water scarcity. International Rice Research Institute, Manila, Philippines, 53.

Bouman, BAM, Tuong TP. 2001. Field water management to save water and increase its productivity in irrigated lowland rice. Agricultural Water Management 49, 11-30.

Bouman BAM, Peng S, Castaneda A, Visperas R. 2005. Yield and water use of irrigated tropical aerobic rice systems. Agricultural Water Management 74, 87-105.

Carrijo DR, Lundy ME, Linquist, BA. 2017. Rice yields and water use under alternate wetting and drying irrigation: A meta-analysis. Field Crops Research 203, 173-180.

Chaves MM.1991. Effects of water deficits on carbon assimilation. Journal of Experimental Botany 42, 1-16.

Chaves MM, Pereira JS, Maroco J, Rodrigues ML, Ricardo CP, Osório ML, Carvalho I, Faria T, Pinheiro C. 2002. How plants cope with water stress in the field. Photosynthesis and growth. Annals of Botany 89, 907-916.

Chou C, Chiang JC, Lan CW, Chung CH, Liao YC, Lee CJ. 2013. Increase in the range between wet and dry season precipitation. Nature Geoscience, 6, 263-267.

Colmer TD, Gibberd MR, Wiengweera A, Tinh TK, 1998. The barrier to radial oxygen loss from roots of rice (Oryza sativa L.) is induced by growth in stagnant solution. Journal of Experimental Botany 49, 1431-1436

Condon AG, Richards RA, Rebetzke GJ, Farquhar GD. 2004. Breeding for high water-use efficiency. Journal of Experimental Botany 55, 2447-2460.

Cornic G, Massacci A. 1996. Leaf photosynthesis under drought stress. In Photosynthesis and the environment. 347-366. Springer, Dordrecht.

Dai A. 2011. Drought under global warming: a review. Wiley Interdisciplinary Reviews: Climate Change 2, 45-65.

Doheny-Adams T, Hunt L, Franks PJ, Beerling DJ, Gray JE. 2012. Genetic manipulation of stomatal density influences stomatal size, plant growth and tolerance to restricted water supply across a growth carbon dioxide gradient. Philosophical Transactions of the Royal Society B: Biological Sciences 367, 547-555. 
Ennaje, M, Vadel AM, Cochard H, Khemira H. 2010. Comparative impacts of water stress on the leaf anatomy of a drought-resistant and a drought-sensitive olive cultivar. The Journal of Horticultural Science and Biotechnology 85, 289-294.

Evans JR. 1989. Photosynthesis and nitrogen relationships in leaves of $\mathrm{C}_{3}$ plants. Oecologia, 78, 9-19.

Evenson RE, Gollin D. 2003. Assessing the impact of the Green Revolution, 1960 to 2000. Science, 300, 758-762.

Farooq M, Kobayashi N, Ito O, Wahid A, Serraj R. 2010. Broader leaves result in better performance of indica rice under drought stress. Journal of Plant Physiology 167, 1066-1075.

Field C. 1983. Allocating leaf nitrogen for the maximization of carbon gain: leaf age as a control on the allocation program. Oecologia 56: 341-347

Fischer RA. 1981. Optimizing the use of water and nitrogen through breeding of crops. Plant and Soil 58,249-278.

Flexas J, Bota J, Loreto F, Cornic G. Sharkey TD. 2004. Diffusive and metabolic limitations to photosynthesis under drought and salinity in $\mathrm{C}_{3}$ plants. Plant Biology, 6, 269-279.

Flexas J, Ribas-Carbo MIQUEL, Diaz-espejo ANTONIO, Galmes J, Medrano H. 2008. Mesophyll conductance to $\mathrm{CO}_{2}$ : current knowledge and future prospects. Plant, Cell \& Environment 31, 602-621.

Franks PJ, Doheny-Adams TW, Britton-Harper ZJ, Gray JE. 2015. Increasing water-use efficiency directly through genetic manipulation of stomatal density. New Phytologist 207, 188195.

Fukai S, Sittisuang P, Chanphengsay M. 1998. Increasing production of rainfed lowland rice in drought prone environments. Plant Production Science 1, 75-82.

Goudriaan J.1995. Optimization of nitrogen distribution and of leaf area index for maximum canopy assimilation rate. In Nitrogen management studies in irrigated rice. 85-97. Los Baños, Philippines: International Rice Research Institute.

Gowda VRP, Henry A, Yamauchi A, Shashidhar HE, Serraj R. 2011. Root biology and genetic improvement for drought avoidance in rice. Field Crops Research 122. 1-13

Gu J, Yin X, Stomph TJ, Wang H, Struik PC. 2012. Physiological basis of genetic variation in leaf photosynthesis among rice (Oryza sativa L.) introgression lines under drought and wellwatered conditions. Journal of Experimental Botany 63, 5137-5153.

Hasegawa T. 1999. Changes in vertical distribution of leaf nitrogen with the growth stage and the influence on dry matter production in rice. Plant Production Science 2, 37-46. 
Henry A, Cal AJ, Batoto TC, Torres RO, Serraj R. 2012. Root attributes affecting water uptake of rice (Oryza sativa) under drought. Journal of Experimental Botany 63, 4751-4763.

Hetherington AM, Woodward FI. 2003. The role of stomata in sensing and driving environmental change. Nature, 424, 901-908.

Hikosaka K, Anten NP, Borjigidai A, Kamiyama C, Sakai H, Hasegawa T, Oikawa S. Iio A, Watanabe M, Koike T, Nishina K, 2016. A meta-analysis of leaf nitrogen distribution within plant canopies. Annals of Botany 118, 239-247.

$\mathrm{Hu}$ H, Xiong L. 2014. Genetic engineering and breeding of drought-resistant crops. Annual Review of Plant Biology 65, 715-741.

IPCC. 2007. Summary for Policymakers. S. Solomon et al., Eds. In Climate Change 2007: The Physical Science Basis. Contribution of Working Group I to the Fourth Assessment Report of the Intergovernmental Panel on Climate Change. Cambridge University Press, Cambridge, UK and New York, NY, USA.

IRRI (International Rice Research Institute). 2001. Annual Report 2000-2001: rice research: the way forward, 71-73. Los Banos (Phillipines): International Rice Research Institute.

IRRI (International Rice Research Institute). 2013. World Rice Statistics 2013. Los Banos, the Philippines: IRRI. June 29, 2013.

Khush GS. 1997. Origin, dispersal, cultivation and variation of rice. Plant Molecular Biology 35, 25-34.

Khush GS. 2001. Green revolution: the way forward. Nature Reviews Genetics 2, 815-822.

Kim HK, Park J, Hwang I. 2014. Investigating water transport through the xylem network in vascular plants. Journal of Experimental Botany 65, 1895-1904.

Lafitte HR, Courtois B, Arraudeau M. 2002. Genetic improvement of rice in aerobic systems: progress from yield to genes. Field Crops Research 75, 171-190.

Li L, Jiang X, Chahine MT, Olsen ET, Fetzer EJ, Chen L, Yung YL. 2011. The recycling rate of atmospheric moisture over the past two decades (1988-2009). Environmental Research Letters 6, 034018.

Lilley JM, Fukai S. 1994. Effect of timing and severity of water deficit on four diverse rice cultivars. I. Rooting pattern and soil water extraction. Field Crops Research 37, 205-213

Li S, Zhang J, Liu L, Wang Z, Li Y, Guo L, Li Y, Zhang X, Ren S, Zhao B, Zhang N, Guo, YD. 2020. SITLFP8 reduces water loss to improve water-use efficiency by modulating cell size and stomatal density via endoreduplication. Plant, Cell \& Environment 43, 2666-2679. 
Linares OF. 2002. African rice (Oryza glaberrima): history and future potential. Proceedings of the National Academy of Sciences 99, 16360-16365.

Lobell DB, Schlenker W, Costa-Roberts J. 2011. Climate trends and global crop production since 1980. Science 333, 616-620.

Lötscher M, Stroh K, Schnyder H. 2003. Vertical leaf nitrogen distribution in relation to nitrogen status in grassland plants. Annals of Botany 92, 679-688

Luo Z, Xiong J, Xia H, Ma X, Gao M, Wang L, Liu G, Yu X, Luo L. 2020. Transcriptomic divergence between upland and lowland ecotypes contributes to rice adaptation to a droughtprone agroecosystem. Evolutionary Applications 13, 2484-2496.

Lyu J, Li B, He W, Zhang S, Gou Z, Zhang J, Meng L, Li X, Tao D, Huang W, Hu F, Wang W. 2014. A genomic perspective on the important genetic mechanisms of upland adaptation of rice. BMC Plant Biology 14, 1-16.

Maclean J, Hardy B, Hettel G. 2013. Rice Almanac: Source book for one of the most important economic activities on earth. International Rice Research Institute.

Madadgar S, AghaKouchak A, Farahmand A, Davis SJ. 2017. Probabilistic estimates of drought impacts on agricultural production. Geophysical Research Letters 44, 7799-7807.

Matsuo N, Ozawa K. Mochizuki T. 2010. Physiological and morphological traits related to water use by three rice (Oryza sativa L.) genotypes grown under aerobic rice systems. Plant and Soil 335, 349-361.

McDonald MP, Galwey NW, Colmer TD. 2002. Similarity and diversity in adventitious root anatomy as related to root aeration among a range of wetland and dryland grass species. Plant, Cell \& Environment 25, 441-451.

Menge DM, Kano-Nakata M, Yamauchi A, Suralta RR, Makihara D. 2020. Root and shoot responses of upland New Rice for Africa varieties to fluctuating soil moisture conditions as affected by different levels of nitrogen fertilization. Journal of Agronomy and Crop Science 206, 322-337.

Mika J. 2013. Changes in weather and climate extremes: phenomenology and empirical approaches. Climatic Change 121, 15-26.

Miyamoto N, Steudle E, Hirasawa T, Lafitte R. 2001. Hydraulic conductivity of rice roots. Journal of Experimental Botany 52, 1835-1846

Mokuwa A, Nuijten E, Okry F, Teeken B, Maat H, Richards P, Struik PC. 2013. Robustness and Strategies of Adaptation among Farmer Varieties of African Rice (Oryza glaberrima) and 
Asian Rice (Oryza sativa) across West Africa. PloS One 8, e34801.

Muthayya S, Sugimoto JD, Montgomery S, Maberly GF. 2014. An overview of global rice production, supply, trade, and consumption. Annals of the New York Academy of Sciences 1324, 7-14.

Niinemets Ü, Díaz-Espejo A, Flexas J, Galmés J, Warren CR. 2009. Role of mesophyll diffusion conductance in constraining potential photosynthetic productivity in the field. Journal of Experimental Botany 60, 2249-2270.

Nuijten E, Van Treuren R, Struik PC, Mokuwa A, Okry F, Teeken B, Richards P. 2009. Evidence for the emergence of new rice types of interspecific hybrid origin in West African farmers' fields. PLoS One 4, e7335.

Oguchi R, Hikosaka K, Hirose T. 2005. Leaf anatomy as a constraint for photosynthetic acclimation: differential responses in leaf anatomy to increasing growth irradiance among three deciduous trees. Plant, Cell \& Environment 28, 916-927.

Okami M, Kato Y, Yamagishi J. 2016. Canopy architecture and leaf nitrogen distribution of rice (Oryza sativa L.) under chronic soil water deficit. Journal of Agronomy and Crop Science 202, 464-471.

O'Toole JC, 2004. Rice and water: The final frontier. In The first international conference on rice for the future. Bangkok, Thailand: The Rockefeller Foundation.

Peng S, Bouman B, Visperas RM, Castañeda A, Nie L, Park HK. 2006. Comparison between aerobic and flooded rice in the tropics: agronomic performance in an eight-season experiment. Field Crops Research 96, 252-259.

Peng S, Laza RC, Visperas RM, Sanico AL, Cassman KG, Khush GS. 2000. Grain yield of rice cultivars and lines developed in the Philippines since 1966. Crop Science 40, 307-314.

Peng S, Tang Q, Zou Y. 2009. Current status and challenges of rice production in China. Plant Production Science 12, 3-8.

Pierret A, Moran CJ, Doussan C. 2005. Conventional detection methodology is limiting our ability to understand the roles and functions of fine roots. New Phytologist 166:967-980.

Portmann FT, Siebert S, Döll P. 2010. MIRCA2000 - Global monthly irrigated and rainfed crop areas around the year 2000: A new high-resolution data set for agricultural and hydrological modeling. Global Biogeochemical cycles 24.

Prabnakorn S, Maskey S, Suryadi FX, de Fraiture C. 2018. Rice yield in response to climate trends and drought index in the Mun River Basin, Thailand. Science of the Total Environment 621, 108-119. 
Raman A, Verulkar S, Mandal N, et al. 2012. Drought yield index to select high yielding rice lines under different drought stress severities. Rice 5, 1-12.

Ranathunge K, Kotula L, Steudle E, Lafitte R. 2004. Water permeability and reflection coefficient of the outer part of young rice roots are differently affected by closure of water channels (aquaporins) or blockage of apoplastic pores. Journal of Experimental Botany 55, 433 447.

Richards RA, Rebetzke GJ, Condon AG, Van Herwaarden AF. 2002. Breeding opportunities for increasing the efficiency of water use and crop yield in temperate cereals. Crop Science 42, 111-121.

Ross J. 1981. The radiation regime and architecture of plant stands. The Hague, The Netherlands: Dr Junk W.

Rowse HR, Goodman D. 1981. Axial resistance to water movement in broad bean (Vicia faba) roots, Journal of Experimental Botany, 32, 591-598.

Sperry J, Adler F, Campbell G, Comstock J. 1998. Limitation of plant water use by rhizosphere and xylem conductance: results from a model. Plant, Cell \& Environment 21, 347-359.

Sarker MAR, Alam K, Gow J. 2012. Exploring the relationship between climate change and rice yield in Bangladesh: An analysis of time series data. Agricultural Systems 112, 11-16.

Sarla N, Swamy BM. 2005. Oryza glaberrima: a source for the improvement of Oryza sativa. Current Science-Bangalore 89, 955.

Schreiber L, Hartmann K, Skrabs M, Zeier J. 1999. Apoplastic barriers in roots: chemical composition of endodermal and hypodermal cell walls. Journal of Experimental Botany $50,1267-1280$.

Shaibu AA, Uguru MI, Sow M, Maji AT, Ndjiondjop MN, Venuprasad R. 2018. Screening African rice (Oryza glaberrima) for tolerance to abiotic stresses: II. Lowland drought. Crop Science 58, 133-142.

Sheffield J, Wood EF. 2008. Projected changes in drought occurrence under future global warming from multi-model, multi-scenario, IPCC AR4 simulations. Climate Dynamics 31, 79105.

Sibounheuang V, Basnayake J, Fukai S. 2006. Genotypic consistency in the expression of leaf water potential in rice (Oryza sativa L.). Field Crops Research 97, 142-154.

Singh S, Ladha J, Gupta R, Bhushan L, Rao A. 2008. Weed management in aerobic rice systems under varying establishment methods. Crop Protection 27, 660-671. 
Singh R, van Dam JC, Feddes RA. 2006. Water productivity analysis of irrigated crops in Sirsa district, India. Agricultural Water Management 82, 253-278.

Sinha RK. 2004. Modern plant physiology. CRC Press. Patna, India.

Smirnov O, Zhang M, Xiao T, Orbell J, Lobben, A, Gordon J. 2016. The relative importance of climate change and population growth for exposure to future extreme droughts. Climatic Change 138, 41-53.

Steinemann S, Zeng Z, McKay A, Heuer S, Langridge P, Huang CY. 2015. Dynamic root responses to drought and rewatering in two wheat (Triticum aestivum) genotypes. Plant and Soil 391, 139-152.

Steudle E. 2000. Water uptake by roots: effects of water deficit. Journal of Experimental Botany 51:1531-1542

Steudle E, Peterson CA. 1998. How does water get through roots? Journal of Experimental Botany 49, 775-788.

Stocker TF. Dahe Q, Plattner GK, et al. (eds.). 2014. Climate change 2013: the physical science basis: Working Group I contribution to the Fifth assessment report of the Intergovernmental Panel on Climate Change. Cambridge University Press.

Stoop WA, Uphoff N, Kassam A. 2002. A review of agricultural research issues raised by the system of rice intensification (SRI) from Madagascar: opportunities for improving farming systems for resource-poor farmers. Agricultural Systems 71, 249-274.

Suralta RR, Yamauchi A. 2008. Root growth, aerenchyma development, and oxygen transport in rice genotypes subjected to drought and waterlogging. Environmental and Experimental Botany 64, 75-82

Teeken B, Nuijten E, Temudo MP, Okry F, Mokuwa A, Struik PC, Richards P. 2012. Maintaining or abandoning African rice: lessons for understanding processes of seed innovation. Human Ecology 40, 879-892.

Terashima I, Hanba YT, Tholen D, Niinemets Ü. 2011. Leaf functional anatomy in relation to photosynthesis. Plant Physiology 155, 108-116.

Tominaga J, Yabuta S, Fukuzawa Y, Kawasaki S, Jaiphong T, Suwa R, Kawamitsu Y. 2015. Effects of vertical gradient of leaf nitrogen content on canopy photosynthesis in tall and dwarf cultivars of sorghum. Plant Production Science 18, 336-343. 
Tosens T, Niinemets U, Vislap V, Eichelmann H, Castro-Diez P. 2012. Developmental changes in mesophyll diffusion conductance and photosynthetic capacity under different light and water availabilities in Populus tremula: how structure constrains function. Plant, Cell \& Environment 35, 839-856.

Tuong TP, Bouman BAM, Mortimer M. 2005. More Rice, Less Water: Integrated Approaches for Increasing Water Productivity in Irrigated Rice-Based Systems in Asia. Plant Production Science 8, 231-241.

Tsubo M, Fukai S, Basnayake J, Ouk M. 2009. Frequency of occurrence of various drought types and its impact on performance of photoperiod-sensitive and insensitive rice genotypes in rainfed lowland conditions in Cambodia. Field Crops Research 113, 287-296.

Tyree MT, Ewers FW. 1991. The hydraulic architecture of trees and other woody plants. New Phytologist. 119, 345-360.

Venuprasad R, Dalid CO, Del Valle M, Zhao D, Espiritu M, Cruz MS, Amante M, Kumar A, Atlin GN. 2009. Identification and characterization of large-effect quantitative trait loci for grain yield under lowland drought stress in rice using bulk-segregant analysis. Theoretical and Applied Genetics 120, 177-190.

Venuprasad R, Lafitte HR, Atlin GN. 2007. Response to direct selection for grain yield under drought stress in rice. Crop Science 47, 285-293.

Wang M, Yu Y, Haberer G, et al. 2014. The genome sequence of African rice (Oryza glaberrima) and evidence for independent domestication. Nature Genetics 46, 982-988.

Watt M, Magee LJ, McCully ME. 2008. Types, structure and potential for axial water flow in the deepest roots of field-grown cereals. New Phytologist 178, 135-146.

Wassmann R, Jagadish SVK, Heuer S, Ismail A, Redona E, Serraj R, Singh RK, Howell G, Pathak H, Sumfleth K. 2009. Climate change affecting rice production: the physiological and agronomic basis for possible adaptation strategies. Advances in Agronomy 101, 59-122.

Wasson AP, Richards RA, Chatrath R, Misra SC, Prasad SVS, Rebetzke GJ, Kirkegaard JA, Christopher J, Watt M. 2012. Traits and selection strategies to improve root systems and water uptake in water-limited wheat crops. Journal of Experimental Botany 63:3485-3498.

Yang J, Zhang J. 2006. Grain filling of cereals under soil drying. New Phytologist 169, 223236.

Yang J, Zhang J, Wang Z, Liu L, Zhu Q. 2003. Postanthesis water deficits enhance grain filling in two-line hybrid rice. Crop Science 43, 2099-2108. 
Yatapanage KG, So HB. 2001. The relationship between leaf water potential and stem diameter in sorghum. Agronomy Journal 93, 1341-1343.

Yin X, Lantinga EA, Schapendonk AHCM, Zhong X. 2003. Some quantitative relationships between leaf area index and canopy nitrogen content and distribution. Annals of Botany 91, 893-903.

Yuan W, Peng S, Cao C, Virk P, Xing D, Zhang Y, Visperas RM, Laza RC. 2011. Agronomic performance of rice breeding lines selected based on plant traits or grain yield. Field Crops Research 121, 168-174.

Zhao L, Wu L, Wu M, Li Y. 2011. Nutrient uptake and water use efficiency as affected by modified rice cultivation methods with reduced irrigation. Paddy and Water Environment 9, 25-32.

Zimmermann HM, Hartmann K, Schreiber L, Steudle E. 2000. Chemical composition of apoplastic transport barriers in relation to radial hydraulic conductivity of corn roots (Zea mays L.). Planta 210,302-311.

Zwart SJ, Bastiaanssen WG. 2004. Review of measured crop water productivity values for irrigated wheat, rice, cotton and maize. Agricultural Water Management 69, 115-133. 



\section{Chapter 2}

Stomatal conductance, mesophyll conductance, and transpiration efficiency in relation to leaf anatomy in rice and wheat genotypes under drought

Wenjing Ouyang ${ }^{1}$, Paul C. Struik ${ }^{1}$, Xinyou Yin ${ }^{1}$ and Jianchang Yang ${ }^{2}$

${ }^{1}$ Centre for Crop Systems Analysis, Wageningen University \& Research, 6700 AK Wageningen, The Netherlands

${ }^{2}$ College of Agriculture, Yangzhou University, 225009 Yangzhou, Jiangsu, China 


\begin{abstract}
Increasing leaf transpiration efficiency (TE) may provide leads for growing rice like dryland cereals such as wheat (Triticum aestivum). To explore avenues for improving TE in rice, variations in stomatal conductance $\left(g_{\mathrm{s}}\right)$ and mesophyll conductance $\left(g_{\mathrm{m}}\right)$ and their anatomical determinants were evaluated in two cultivars from each of lowland, aerobic, and upland groups of Oryza sativa, one cultivar of $O$. glaberrima, and two cultivars of T. aestivum, under three water regimes. The TE of upland rice, $O$. glaberrima, and wheat was more responsive to the $g_{\mathrm{m}} / g_{\mathrm{s}}$ ratio than that of lowland and aerobic rice. Overall, the explanatory power of the particular anatomical trait varied among species. Low stomatal density mostly explained the low $g_{\mathrm{s}}$ in drought-tolerant rice, whereas rice genotypes with smaller stomata generally responded more strongly to drought. Compared with rice, wheat had a higher $g_{\mathrm{m}}$, which was associated with thicker mesophyll tissue, mesophyll and chloroplasts more exposed to intercellular spaces, and thinner cell walls. Upland rice, O. glaberrima, and wheat cultivars minimized the decrease in $g_{\mathrm{m}}$ under drought by maintaining high ratios of chloroplasts to exposed mesophyll cell walls. Rice TE could be improved by increasing the $g_{\mathrm{m}} / g_{\mathrm{s}}$ ratio via modifying anatomical traits.
\end{abstract}

Keywords: Drought, leaf anatomy, mesophyll conductance, rice, stomatal conductance, transpiration efficiency, wheat 


\subsection{Introduction}

Rice (Oryza sativa L.) is a major staple crop that adapts strongly to fully inundated conditions. Compared with other cereal crops, such as wheat (Triticum aestivum L.) grown on dry uplands, rice cultivation requires massive amounts of fresh water for irrigation. To minimise the total water requirement for rice cultivation, several water-saving regimes have already been introduced, such as alternate wetting and drying irrigation (Bouman and Tuong, 2001; Zhang et al., 2008) and controlled soil drying during grain filling (Yang et al., 2003; Yang and Zhang, 2006). However, these regimes are largely management measures to reduce water use for rice production. Solving the problem of the intrinsically high water requirement of rice would need breeding or genetic engineering approaches to develop new drought-tolerant rice genotypes with increased water use efficiency (WUE).

Genetic diversity in drought tolerance has long been explored to develop cultivars of $O$. sativa for diverse growing conditions: irrigated lowland, rain-fed lowland, and upland environments. More recently, genotypes suitable for aerobic environments (moderately dry conditions, not inundated lowland or dry upland conditions), i.e. aerobic rice (Bouman et al., 2005; Singh et al., 2008), have been developed. However, aerobic rice cannot replace lowland ('paddy') rice in most of the rice-growing areas because of its lower grain yield and is an option only for farmers in rain-fed lowlands with limited or erratic rainfall (Atlin et al., 2006). In addition, African rice (Oryza glaberrima Steud.) has evolved as a cultivated species in parallel with $O$. sativa, and is more drought-resistant (Sarla and Swamy, 2005). Natural interspecific hybrids between $O$. sativa and $O$. glaberrima are cultivated in West Africa (Nuijten et al., 2009). The adaptation of rice genotypes to a wider range of edaphic conditions indicates the possibility of growing rice in the same way as other dryland cereal crops such as wheat. Also belonging to the $\mathrm{C}_{3}$-crop type, wheat has a relatively higher WUE than rice (Kemanian et al., 2005; Haefele et al., 2009). Compared with rice, wheat shows higher plasticity in root morphological and anatomical adaptation to water-deficit conditions (Kadam et al., 2015). Further comparative analysis of the physiology and anatomy of rice and wheat in response to drought will facilitate the identification of the general traits and mechanisms required for breeding drought-tolerant yet high-yielding rice varieties (Praba et al., 2009).

Photosynthesis is the key process of primary metabolism, and its capacity can influence plant performance and productivity (Lawlor and Tezara, 2009; Pinheiro and Chaves, 2011). Photosynthesis under drought, despite being affected by Rubisco velocity, is often limited by 
the $\mathrm{CO}_{2}$ concentration at carboxylation sites $\left(C_{\mathrm{c}}\right)$ inside the chloroplast, which is determined by $\mathrm{CO}_{2}$ diffusion components, i.e. stomatal conductance $\left(g_{\mathrm{s}}\right)$ and mesophyll conductance $\left(g_{\mathrm{m}}\right)$ (Evans et al., 2009). Stomata regulate $\mathrm{CO}_{2}$ diffusion into, and water diffusion out of, plant leaves (Chaves et al., 2002). Under water-deficit conditions, plants close stomata to prevent major water loss; this, consequently, reduces photosynthesis via decreased influx of $\mathrm{CO}_{2}$ (Pinheiro and Chaves, 2011). In the long-term response to water deficit, $g_{\mathrm{s}}$ can be influenced by leaf anatomical traits such as stomatal density and size, which can vary to acclimate to the environment (Xu and Zhou, 2008; Franks and Beerling, 2009). As the inevitable consequence of $\mathrm{CO}_{2}$ entry through leaf stomata is water loss through transpiration, the stomata-related environmental adaptation may also affect plant instantaneous transpiration efficiency (TE), i.e. the ratio of net photosynthesis rate $\left(A_{\mathrm{n}}\right)$ to transpiration rate. In general, higher $g_{\mathrm{s}}$ results in a lower TE (Flexas et al., 2008; Gu et al., 2012).

Mesophyll conductance $\left(g_{\mathrm{m}}\right)$ has been viewed as the diffusion of $\mathrm{CO}_{2}$ from sub-stomatal cavities to the sites of carboxylation in the chloroplasts (Flexas et al., 2008). In contrast to $g_{\mathrm{s}}$, increasing $g_{\mathrm{m}}$ increases $A_{\mathrm{n}}$ at no costs of increased transpiration, because the $\mathrm{CO}_{2}$ diffusion pathway involving $g_{\mathrm{m}}$ is not shared with the diffusion pathway of transpired $\mathrm{H}_{2} \mathrm{O}$. Therefore, increasing $g_{\mathrm{m}}$ not only increases $A_{\mathrm{n}}$ but also increases TE (Barbour et al., 2010; Flexas et al., 2013). However, long-term drought stress reduces $g_{\mathrm{m}}$ (Scartazza et al., 1998; Gu et al., 2012; Han et al., 2016). Along the $\mathrm{CO}_{2}$ diffusion pathway inside leaves, the conductance through the liquid phase $\left(g_{\text {liq }}\right)$ is the most limiting factor for $\mathrm{CO}_{2}$ diffusion in the mesophyll in many species (Gorton et al., 2003; Flexas et al., 2008; Flexas et al., 2012). Growing evidence indicates that (i) genotypic differences in $g_{\mathrm{m}}$ exist within a given species (Evans and Vellen, 1996; Gu et al., 2012; Jahan et al., 2014), and (ii) leaf mesophyll structure and anatomical properties are important determinants of $g_{\mathrm{m}}$. Mesophyll thickness $\left(T_{\mathrm{m}}\right)$, surface area of chloroplasts exposed to the intercellular airspace $\left(S_{\mathrm{c}}\right)$, and mesophyll cell wall thickness $\left(T_{\mathrm{w}}\right)$ are suggested to be the most important structural components determining $g_{\mathrm{m}}$ (Evans et al., 1994; Evans et al., 2009; Scafaro et al., 2011; Tosens et al., 2012b; Tomás et al., 2013), as these parameters determine pathways for $\mathrm{CO}_{2}$ permeation into chloroplasts (Terashima et al., 2011). Therefore, investigating relationships between leaf anatomy and photosynthetic features could improve understanding of leaf structural features required to enhance drought tolerance in rice.

In this study, the photosynthetic diffusion components ( $g_{\mathrm{s}}$ and $\left.g_{\mathrm{m}}\right)$ and possibly related leaf anatomical properties were examined in three species, O. sativa, O. glaberrima and T. aestivum. 
$g_{\mathrm{s}}$ was measured from gas exchange, and combined gas exchange and chlorophyll fluorescence measurements were used to estimate $g_{\mathrm{m}}$. Leaf anatomical properties were examined through light and transmission electron microscopy. The objectives of this study were: (i) to evaluate the variation in photosynthetic capacity among the contrasting types of rice species as well as between rice and wheat in response to a long-term drought; and (ii) to assess the leaf anatomical determinants of $g_{\mathrm{s}}$ and $g_{\mathrm{m}}$ and how those determinants underpin genotypic differences in the response of $g_{\mathrm{s}}, g_{\mathrm{m}}$, and TE under drought.

\subsection{Materials and methods}

\subsubsection{Plant materials and treatments}

Six cultivars from O. sativa, one cultivar from O. glaberrima, and two cultivars from $T$. aestivum were used for the study of photosynthetic and leaf anatomical properties. The $O$. sativa cultivars represented rice types bred for lowland, aerobic or upland cultivation systems, respectively, whereas wheat cultivars were selected based on their drought tolerance (Table 2.1). The tolerance and susceptibility classifications were based on previous reports (Thanh et al., 1999; George et al., 2002; Sarla and Swamy, 2005; Atlin et al., 2006; Liu et al., 2006; Praba et al., 2009). Seeds of rice and wheat cultivars were obtained from the International Rice Research Institute (IRRI) and from the International Maize and Wheat Improvement Center (CIMMYT), respectively.

Pot experiments were conducted at Yangzhou University, Jiangsu Province, China $\left(32^{\circ} 30^{\prime} \mathrm{N}\right.$, $119^{\circ} 25^{\prime}$ E). Rice seeds were sown in saturated soil after pre-germination, and wheat seeds were sown directly in moist soil. The pots were placed in an open field sheltered from rain by a mobile transparent polyethylene shelter. Each pot $(30 \mathrm{~cm}$ in height, $25 \mathrm{~cm}$ in diameter, 14.72 liters in volume) contained $20 \mathrm{~kg}$ of sandy loam soil from the Yangzhou University rice/wheat rotated experimental field. One day before sowing, $1.1 \mathrm{~g} \mathrm{CO}\left(\mathrm{NH}_{2}\right)_{2}$ (urea) and $0.5 \mathrm{~g}$ $\mathrm{KH}_{2} \mathrm{PO}_{4}$ were pre-mixed through the soil per pot. Extra nitrogen $(2.5 \mathrm{~g}$ urea for rice and $1.5 \mathrm{~g}$ urea for wheat per pot) were split-applied during different plant growth stages.

We imposed three levels of soil moisture, i.e. control (CT), mild drought stress (MD), and more severe drought stress (SD). Across all species and treatments, three replications were maintained and pots were placed in a randomized design. Soil water potential was monitored by inserting a tension meter (Institute of Soil Sciences, Chinese Academy of Sciences, Nanjing, China) at $15 \mathrm{~cm}$ soil depth throughout the experiments. Because rice and wheat have different 

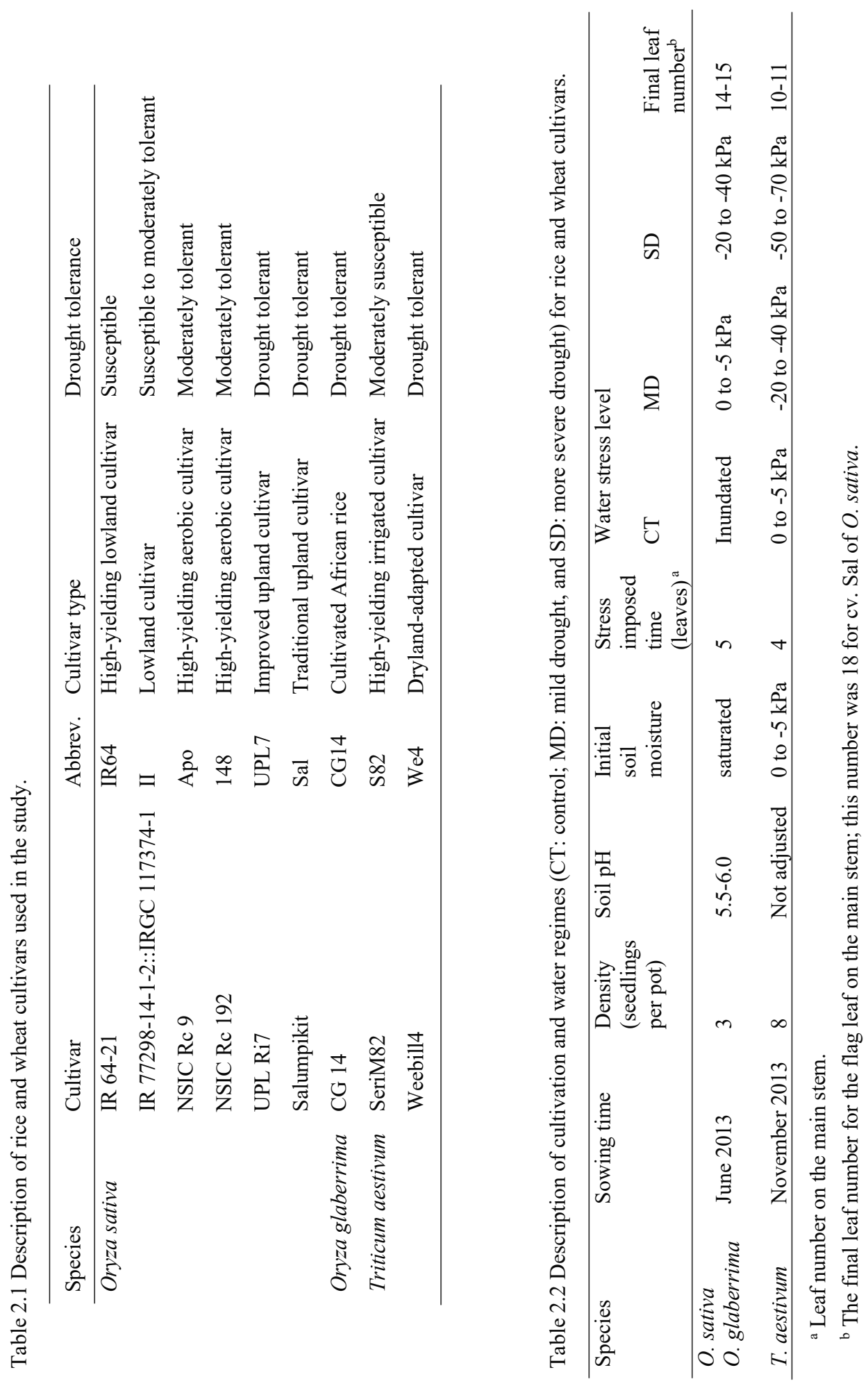
growth duration and are naturally adapted to different moisture environments during domestication histories (Praba et al., 2009), different timings and intensity of stress impositions were applied (Table 2.2). When tension-meter readings reached the lower limit in each stress level, tap water was added until the upper limit of the target stress was reached. Once stress was imposed, the target stress levels were maintained to ensure that leaves for measurements (see below) were initiated and developed under stress, until all the measurements were completed.

\subsubsection{Gas exchange and chlorophyll fluorescence measurements}

An open gas exchange system integrated with a fluorescence chamber head (Li-Cor 6400XT; Li-Cor Inc., Lincoln, NE, USA) was used to simultaneously measure gas exchange (GE) and chlorophyll fluorescence (CF) parameters. During flowering, the penultimate leaf on the main shoot from each replication per treatment was used for measurements. To avoid the effect of fluctuation in outdoor environment on GE measurement, all measurements were taken in a climate chamber with air temperature at $28^{\circ} \mathrm{C}\left(23^{\circ} \mathrm{C}\right.$ for wheat $), 65 \%$ relative humidity and a photosynthetic photon flux density at the leaf surface of $1200 \mu \mathrm{mol} \mathrm{m} \mathrm{m}^{-2}$ (artificial light source). All measurements were made at a leaf temperature of $25^{\circ} \mathrm{C}$ and the leaf-to-air vapour pressure difference (VPD) was kept between 1.0 and $1.6 \mathrm{kPa}$. Light and $\mathrm{CO}_{2}$ response curves were measured under both ambient $(21 \%)$ and low $(2 \%) \mathrm{O}_{2}$ conditions. The low $\mathrm{O}_{2}$ condition was created by using a gas mixture of $2 \% \mathrm{O}_{2}$ and $98 \% \mathrm{~N}_{2}$, and the infrared gas analyser calibration was adjusted for $\mathrm{O}_{2}$ composition of the gas mixture according to the manufacturer's instructions.

For the $\mathrm{CO}_{2}$ response curve, under both $\mathrm{O}_{2}$ conditions, the leaf was consecutively exposed to an incident irradiance $\left(I_{\text {inc }}\right)$ of $1000 \mu \mathrm{mol} \mathrm{m}^{-2} \mathrm{~s}^{-1}$ with different levels of $\mathrm{CO}_{2}: 50,90,150,250$, 400, 700, 1000 and $1500 \mu \mathrm{mol} \mathrm{mol}^{-1}$. For the light response curve, under the $21 \% \mathrm{O}_{2}$ condition, the $\mathrm{CO}_{2}$ was kept constant at $400 \mu \mathrm{mol} \mathrm{mol}^{-1}$ and $I_{\text {inc }}$ was increased in the order of 30, 50, 80, 120, 200, 500, 1000, and $1600 \mu \mathrm{mol} \mathrm{m} \mathrm{m}^{-2} \mathrm{~s}^{-1}$. Under $2 \% \mathrm{O}_{2}$, in order to ensure nonphotorespiratory conditions, the $\mathrm{CO}_{2}$ was kept constant at $1000 \mu \mathrm{mol} \mathrm{mol}^{-1}$ with $I_{\text {inc }}$ levels 30 , $50,80,120$, and $200 \mu \mathrm{mol} \mathrm{m} \mathrm{s}^{-1}$. The measurement flow rate was $400 \mu \mathrm{mol} \mathrm{s}^{-1}$. $\mathrm{CO}_{2}$ exchange rates were corrected for $\mathrm{CO}_{2}$ leakage into and out of the leaf cuvette, based on measurements using the same flow rate on boiled leaves across a range of $\mathrm{CO}_{2}$ levels, and intercellular $\mathrm{CO}_{2}$ levels $\left(C_{\mathrm{i}}\right)$ were then recalculated (Flexas et al., 2007).

The steady-state fluorescence $F_{\mathrm{s}}$ was measured at each light or $\mathrm{CO}_{2}$ step. Then a multiphase 
flash method (Loriaux et al., 2013) was applied to determine $F^{\prime}$ m (the maximum fluorescence during the saturating light pulse). The apparent Photosystem II electron ( $\left.\mathrm{e}^{-}\right)$transport efficiency for each irradiance or $\mathrm{CO}_{2}$ step was calculated as $\Phi_{2}=\left(F^{\prime}{ }_{\mathrm{m}}-F_{\mathrm{s}}\right) / F^{\prime}{ }_{\mathrm{m}}($ Genty et al., 1989).

\subsubsection{Estimation of diffusion components}

Total conductance to $\mathrm{CO}_{2}\left(g_{\text {tot }}\right)$ was calculated based on stomatal and mesophyll conductance according to $1 / g_{\text {tot }}=1 / g_{\mathrm{s}}+1 / g_{\mathrm{m}}$. For the analysis, stomatal conductance for $\mathrm{CO}_{2}\left(g_{\mathrm{s}}\right)$ was obtained as stomatal conductance for water vapour divided by 1.6 , from the data points measured under ambient condition $\left(400 \mu \mathrm{mol} \mathrm{mol}^{-1} \mathrm{CO}_{2}, 1000-1500 \mu \mathrm{mol} \mathrm{m}^{-2} \mathrm{~s}^{-1}\right.$ irradiance, and $25^{\circ} \mathrm{C}$ ) of the light response curve under $21 \% \mathrm{O}_{2}$.

In order to compare $g_{\mathrm{m}}$ across species, genotypes, and treatments, the value of $g_{\mathrm{m}}$ assumed as constant was estimated using the NRH-A variant method (Yin and Struik, 2009):

$$
A_{n}=0.5\left\{J / 4-R_{d}+g_{m}\left(C_{i}+2 \Gamma_{*}\right)-\sqrt{\begin{array}{l}
{\left[J / 4-R_{d}+g_{m}\left(C_{i}+2 \Gamma_{*}\right)\right]^{2}-} \\
4 g_{m}\left[\left(C_{i}-\Gamma_{*}\right) J / 4-R_{d}\left(C_{i}+2 \Gamma_{*}\right)\right]
\end{array}}\right\}
$$

where $\Gamma *$ is the $\mathrm{CO}_{2}$ compensation point in the absence of day respiration $\left(R_{\mathrm{d}}\right)$ and $J$ is the linear electron transport rate used for $\mathrm{CO}_{2}$ fixation and photorespiration. Equation (1) provides a model to estimate $g_{\mathrm{m}}$ by a curve fitting that minimises the difference between measured and estimated $A_{\mathrm{n}}$ (Yin and Struik, 2009). In the model, $\Gamma *$ is calculated from the Rubisco specificity factor $\left(S_{\mathrm{c} / \mathrm{o}}\right)$ as $\Gamma *=0.5 O / S_{\mathrm{c} / \mathrm{o}}$, where $O$ is $\mathrm{O}_{2}$ partial pressure (mbar). $S_{\mathrm{c} / \mathrm{o}}$ at a given temperature is expected to be constant for a specific species; however, the value at $25^{\circ} \mathrm{C}$ did not differ much between rice and wheat (Makino et al., 1988; Yin et al., 2009; Gu et al., 2012), so a single value for $S_{\mathrm{c} / \mathrm{o}}$ at $25^{\circ} \mathrm{C}$ (3.13 $\left.\mathrm{mbar}^{\mathrm{b}} \mathrm{bar}^{-1}\right)$ was adopted from Makino et al. (1988) and Yin et al. (2009). Data obtained from low $I_{\text {inc }}$ levels of the light response curve and high $C_{\text {a }}$ levels of the $\mathrm{CO}_{2}$ response curve measured at $21 \% \mathrm{O}_{2}$ were used for the curve fitting. Model inputs $\left(J\right.$ and $\left.R_{\mathrm{d}}\right)$ were estimated as described by Yin et al. (2009). In brief, using data of light-limited range under non-photorespiratory conditions (i.e. the light response curve under $2 \% \mathrm{O}_{2}$ with 1000 $\mu \mathrm{mol} \mathrm{mol}{ }^{-1} \mathrm{CO}_{2}$ plus points from $>500 \mu \mathrm{mol} \mathrm{mol}^{-1} C_{\mathrm{a}}$ levels of $\mathrm{CO}_{2}$ response curve under $2 \%$ $\mathrm{O}_{2}$ ), a linear regression can be performed for the observed $A_{\mathrm{n}}$ against $I_{\mathrm{inc}} \Phi_{2} / 4$. The day respiration $\left(R_{\mathrm{d}}\right)$ is the intercept of the linear regression, and the slope of the regression yields the estimated lumped parameter $s$ (Yin et al., 2009). Then $J$ at each $C_{\mathrm{i}}$ can be calculated using $J=s I_{\text {inc }} \Phi_{2}$. 


\subsubsection{Light and transmission electron microscopy}

Stomatal density and size were determined using the silicon rubber impression technique (Smith et al., 1989). Stomatal features from this method did not differ from those based on glancing sections cut from fresh leaf sample. The method and impression material are described by Giday et al. (2013). Imprints were taken from both adaxial and abaxial surfaces of the area where GE and CF were measured, and were later on smeared with nail polish in the mid-area between the central vein and the leaf edge, for approximately $20 \mathrm{~min}$. The thin film was carefully peeled off the imprint with no stretching and mounted on a glass slide with a drop of water to improve contrast. Stomatal density $(D)$ was determined by counting the maximum numbers of stomata from ten randomly selected non-overlapping rectangular fields of view per leaf under the light microscope (Axio Imager D2, Carl Zeiss, Germany). Stomatal size $(S)$ was calculated by multiplying guard cell length $(L)$ by width $(W)$. All parameters were determined as the average of both sides of the leaf. Specific stomatal conductance $\left(s g_{\mathrm{s}}\right)$ was determined by dividing $g_{\mathrm{s}}$ by $D$ (Ohsumi et al., 2007). An integrative parameter stomatal area index (SAI) was calculated by multiplying density by size and expressed in $\mathrm{mm}^{2}$ stomata $\mathrm{mm}^{-2}$ leaf. Another integrative parameter, so-called maximum stomatal diffusive conductance $\left(g_{\text {smax }}\right)$, was also calculated, according to Franks and Beerling (2009):

$$
g_{\text {smax }}=\frac{d \cdot D \cdot a_{\text {max }}}{1.6 v\left(l+\frac{\pi}{2} \sqrt{a_{\max } / \pi}\right)}
$$

where $d$ is the diffusivity of water vapour in air, $v$ is the molar volume of air, $a_{\max }$ is the maximum area of the open stomatal pore, and $l$ is the stomatal pore depth for fully open stomata. The values for standard gas constants $d$ and $v$ at $25^{\circ} \mathrm{C}$ are $2.82 \times 10^{-5} \mathrm{~m}^{2} \mathrm{~s}^{-1}$ and $24.5 \mathrm{~m}^{3} \mathrm{~mol}^{-1}$, respectively. $a_{\max }$ was calculated as $\pi(p / 2)^{2}$, where $p$ is the stomatal pore length. $p$ was calculated as $L / 2$ according to Franks and Beerling (2009). $l$ was taken as equal to $W / 2$, assuming guard cells inflate to circular cross section.

For the anatomical measurement of mesophyll cells, leaflet samples were collected from the leaves where GE and CF were measured. Half of the leaves were fixed and further used for anatomical study. Tissue fixation and preparation for light and transmission electron microscopy (TEM) studies followed the method of Scafaro et al. (2011) with small modification. Small leaf samples $\left(4 \times 1.5 \mathrm{~mm}^{2}\right)$ from each cultivar $\times$ water treatment 
combination were cut parallel to the main vein avoiding large veins. The samples were infiltrated in a solution of $3 \%$ glutaraldehyde, $2 \%$ paraformaldehyde, and $0.1 \mathrm{M}$ phosphate buffer ( $\mathrm{pH}$ 7.2) for at least 48 hours. Samples were further post-fixed in 1\% osmium tetroxide for $2 \mathrm{~h}$, followed by dehydration in an ethanol series $(30,50,70,80,90,95$, and $100 \%)$. Ethanol was replaced by 1, 2-epoxypropane, and the samples were further embedded with Spurr's resin (London Resin Company, London, UK) and cured in an oven at $70{ }^{\circ} \mathrm{C}$ for $12 \mathrm{~h}$. Transverse sections for light and TEM studies were cut using an ultra-microtome (Ultra-cut R, Leica, Germany). Leaf cross sections $1 \mu \mathrm{m}$ thick were cut for the light microscopy study, and sections $70 \mathrm{~nm}$ thick were cut for the TEM study. Light sections were stained with safranin (1\%) for $20 \mathrm{~s}$ and followed with methyl purple $(1 \%)$ for $20 \mathrm{~s}$, then viewed and photographed under a light microscope (Axio Imager D2, Carl Zeiss, Germany). Electron sections were doubly stained with uranyl acetate for $30 \mathrm{~min}$ and lead citrate for $15 \mathrm{~min}$, and then photographed under a transmission electron microscope (Tecnai 12, Philips, The Netherlands).

Analyses of images were performed using ImageJ software (National Institutes of Health, Bethesda, MD, USA) (Abràmoff et al., 2004). All mesophyll anatomical characteristics were determined in multiple sections, with 12 to 30 complete mesophyll cells per replication per treatment depending on the image quality. The analysis protocol followed the method of Evans et al. (1994). Mesophyll thickness $\left(T_{\mathrm{m}}\right)$ was measured as the length between the two epidermises of the leaf from light microscopy images. The surface area of mesophyll cells exposed to the intercellular airspace per leaf area $\left(S_{\mathrm{m}}\right)$ was calculated from light microscopy images as:

$$
S_{m}=\frac{L_{m}}{w} F
$$

where $w$ is the width of the section measured, $L_{\mathrm{m}}$ is the length of mesophyll exposed to the intercellular airspace, and $F$ is the curvature correction factor (Thain, 1983; Evans et al., 1994). Although the mesophyll size differed between rice and wheat, mesophyll cells in both species are presented as lobed spheroids with a different orientation of the long axes to the veins (Chonan, 1970, 1972; Sage and Sage, 2009), and thus a difference of curvature correction factors between species was not taken into account in this study, and we adopted the value 1.55 from a previous rice study (Scafaro et al., 2011). Uncertainties were also analysed given that Barbour et al. (2016) recently assumed a value of 1.25 for wheat. 
The chloroplast surface area exposed to the intercellular airspace per leaf area $\left(S_{\mathrm{c}}\right)$ was calculated as:

$$
S_{c}=\frac{L_{c}^{\prime}}{L_{m}^{\prime}} S_{m}
$$

where $L^{\prime} \mathrm{c}$ is the length of chloroplast exposed to the intercellular airspace and $L^{\prime} \mathrm{m}$ is the corresponding length of mesophyll exposed to the intercellular airspace. $L_{\mathrm{c}}^{\prime}$ and $L_{\mathrm{m}}^{\prime}$ were determined from TEM images based on average values measured for 12-30 mesophyll cells (parameters obtained from TEM are marked by a prime (') to distinguish them from $L_{\mathrm{m}}$ measured from light microscopy images). The ratio of the exposed surface area of chloroplast to the exposed surface area of mesophyll cell walls $\left(S_{\mathrm{c}} / S_{\mathrm{m}}\right)$ was set equal to $L^{\prime} \mathrm{c} / L^{\prime} \mathrm{m}$ (Tosens et al., 2012a,b).

In addition, thickness of the mesophyll cell wall $\left(T_{\mathrm{w}}\right)$ was also determined from TEM images. Of the thickness values measured for different sections of each mesophyll cell, only the lower half of the values were averaged as the $T_{\mathrm{w}}$ of that cell to minimise the artefact of inaccurate orientation of ultra-microtome sectioning. The average value of $T_{\mathrm{w}}$ from all mesophyll cells in each cultivar and treatment was used for further analysis.

\subsection{5 $\mathrm{N}$ content measurements}

The other half of the collected leaflets after GE and CF measurements were used to measure the leaf area and then oven dried at $70{ }^{\circ} \mathrm{C}$ to constant weight. Leaflets were weighed to determine leaf mass per unit area (LMA), and then ground to fine powder. Samples were analysed for $\mathrm{N}$ content by using an elementary analyser (Vario Macro cube, Elementar, Germany). Leaf nitrogen per unit area $\left(N_{\mathrm{a}}\right)$ was calculated from these data as a measure of leaf physiological status.

\subsubsection{Statistical analyses}

A one-way analysis of variance (ANOVA) was used to reveal the differences between cultivars in the studied characteristics. A two-way ANOVA was used to study the effect of genotypes, drought treatment, and their interaction on photosynthetic and anatomical parameters. Linear regression analyses were also conducted. These analysis were performed using the $\mathrm{R}$ programming language (http://www.R-project.org/). Non-linear fitting for Eq. (1) was carried out using the GAUSS method in PROC NLIN of SAS (SAS Institute Inc, Cary, NC, USA). 


\subsection{Results}

\subsubsection{Variation in photosynthesis}

The net photosynthesis rate $\left(A_{\mathrm{n}}\right)$ varied almost threefold among species, with $T$. aestivum having a significantly higher $A_{\mathrm{n}}$ than $O$. sativa and $O$. glaberrima (cv. CG14) (Fig. 2.1A). Under the CT condition, $A_{\mathrm{n}}$ varied between $6.9 \mu \mathrm{mol} \mathrm{m}^{-2} \mathrm{~s}^{-1}$ for CG14 and $22.7 \mu \mathrm{mol} \mathrm{m}^{-2} \mathrm{~s}^{-1}$ for $\mathrm{S} 82$. Overall, drought decreased $A_{\mathrm{n}}$ strongly with no significant interaction between cultivars and water treatments (Table S2.1). However, for CG14, drought increased $A_{\mathrm{n}}$ (Fig. 2.1A), and this was probably associated with an increase in $N_{\mathrm{a}}$ by drought in this cultivar (Fig. S2.1A). Across all cultivars and treatments, $A_{\mathrm{n}}$ was positively correlated with $N_{\mathrm{a}}$ among wheat cultivars, but not among cultivars of $O$. sativa (Fig. S2.1B).
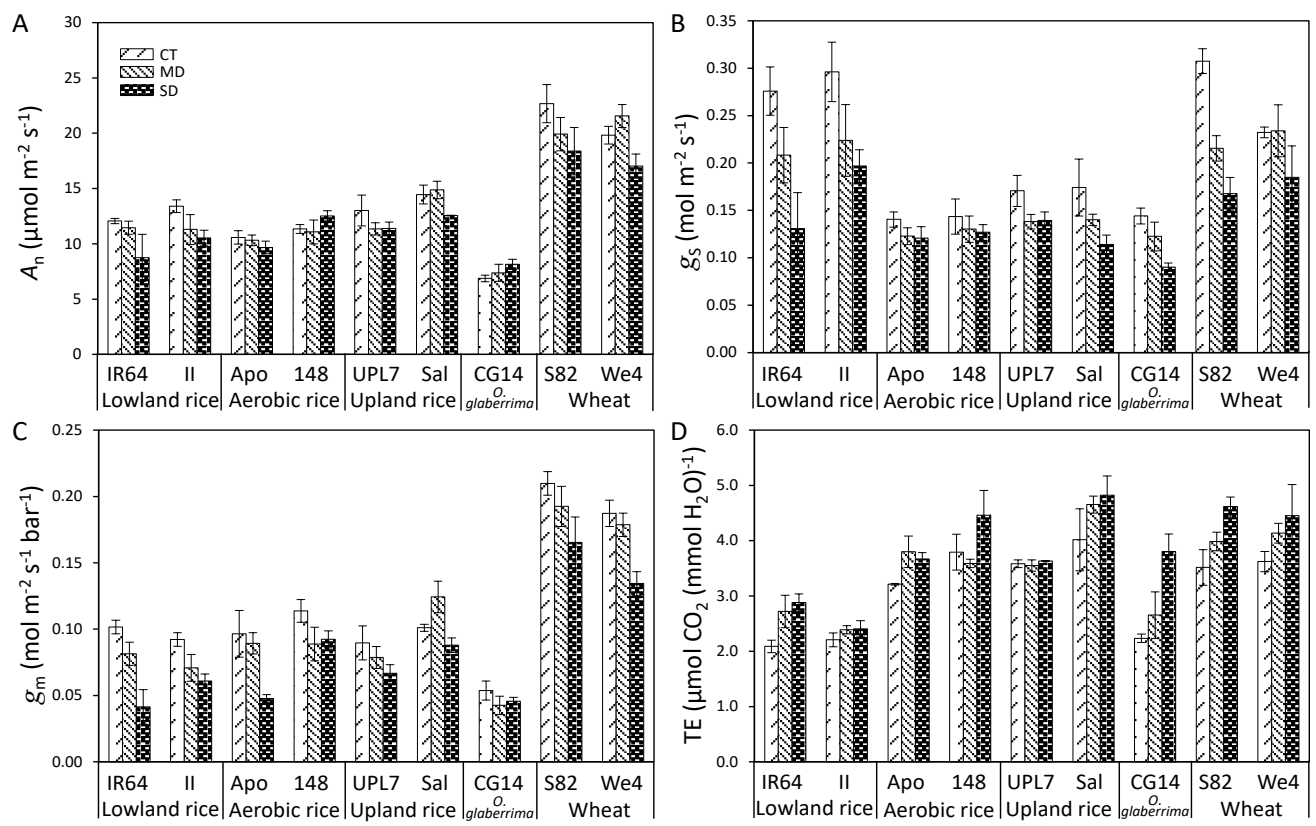

Fig. 2.1 Photosynthetic parameters obtained and estimated from GE and CF data under three treatments: control (CT); mild drought (MD); more severe drought (SD). Values of (A) net photosynthetic rate $\left(A_{\mathrm{n}}\right)$, (B) stomatal conductance $\left(g_{\mathrm{s}}\right)$, and (D) transpiration efficiency (TE) were obtained under the condition of $400 \mu \mathrm{mol} \mathrm{mol}{ }^{-1} \mathrm{CO}_{2}, 1000-1500 \mu \mathrm{mol} \mathrm{m}^{-2} \mathrm{~s}^{-1}$ irradiance, and $25^{\circ} \mathrm{C}$. (C) Mesophyll conductance $\left(g_{\mathrm{m}}\right)$ was calculated based on the NRH-A method (Yin and Struik, 2009). Bars represent standard errors of the mean for $A_{\mathrm{n}}, g_{\mathrm{s}}$, and TE, and standard error of the estimate for $g_{\mathrm{m}}$. 


\subsubsection{Variation in $g_{\mathrm{s}}$ and $g_{\mathrm{m}}$}

Significant variation in stomatal conductance $\left(g_{\mathrm{s}}\right)$ was observed both among species and within $O$. sativa (Table S2.1). Notably, lowland rice and wheat cultivars had a much higher $g_{\mathrm{s}}$ than other cultivars (Fig. 2.1B). $g_{\mathrm{s}}$ decreased under drought in all cultivars, with mild interaction between cultivars and water treatments $(0.05<P<0.1)$. The decrease in $g_{\mathrm{s}}$ was stronger in IR64, Sal, CG14, and S82 than in other cultivars (Fig. 2.1B). Mesophyll conductance $\left(g_{\mathrm{m}}\right)$ varied significantly among species, with wheat having a higher $g_{\mathrm{m}}$ than $O$. sativa, and CG14 having the lowest value (Fig. 2.1C). In wheat, the drought effect on $g_{\mathrm{m}}$ was only significant in We4 under SD condition ( $28 \%$ reduction). The differences in $g_{\mathrm{m}}$ among $O$. sativa cultivars increased with an increase in stress level ( $P>0.05$ under $\mathrm{CT}, P<0.05$ under $\mathrm{MD}$, and $P<0.01$ under SD). Only lowland rice cultivars had significant decreases in $g_{\mathrm{m}}$ under the MD condition. Compared with $g_{\mathrm{m}}$ in CT, a significant decrease in $g_{\mathrm{m}}$ by SD was observed in lowland rice and aerobic rice cv. Apo, but not in other cultivars. The lowest decrease in $g_{\mathrm{m}}$ was observed in Sal and CG14 (ca. 14\%), and the highest decrease was recorded in IR64 (59\%).

\subsubsection{Influences of $g_{\mathrm{s}}$ and $g_{\mathrm{m}}$ on $A_{\mathrm{n}}$ and transpiration efficiency}

Significant positive correlations between $A_{\mathrm{n}}$ and total conductance $\left(g_{\text {tot }}\right)$ were observed among species and within each group (Fig. 2.2A), indicating the presence of major diffusion limitations to $\mathrm{CO}_{2}$ assimilation. Different individual effects of $g_{\mathrm{s}}$ and $g_{\mathrm{m}}$ on $A_{\mathrm{n}}$ were observed (Fig. 2.2B,C). The correlation between $A_{\mathrm{n}}$ and $g_{\mathrm{s}}$ was highly significant in lowland rice, in the wheat group, and for all data combined $(P<0.001)$, and weaker in aerobic and upland rice $(P<0.05)$ and in $O$. glaberrima $(P>0.05)$ (Fig. 2.2B). On the other hand, the correlation between $A_{\mathrm{n}}$ and $g_{\mathrm{m}}$ was highly significant for all data combined as well as in most of the subgroups (Fig. 2.2C). Multiple regression analysis indicated that $g_{\mathrm{s}}$ contributed more to the variation in $A_{\mathrm{n}}$ in lowland rice cultivars, whereas $g_{\mathrm{m}}$ contributed more to the variation in $A_{\mathrm{n}}$ in aerobic rice, upland rice, and wheat cultivars (Table S2.2).

Aerobic rice, upland rice, and wheat cultivars had higher TE than lowland rice cultivars (Fig. 2.1D). Under the CT condition, TE varied between $2.09 \mu \mathrm{mol} \mathrm{CO}_{2}\left(\mathrm{mmol} \mathrm{H}_{2} \mathrm{O}\right)^{-1}$ for IR64 and $4.02 \mu \mathrm{mol} \mathrm{CO} 2\left(\mathrm{mmol} \mathrm{H}_{2} \mathrm{O}\right)^{-1}$ for Sal. TE increased under drought, and the highest increase in TE was recorded for CG14 under the SD condition, with a 70\% increase over the CT condition. A weak negative correlation between TE and $g_{\mathrm{s}}$ was observed within each genotype group (Fig. $\mathrm{S} 2.2 \mathrm{~A}$ ), but the correlation between TE and $g_{\mathrm{m}}$ was not significant in most groups (Fig. S2.2B). 

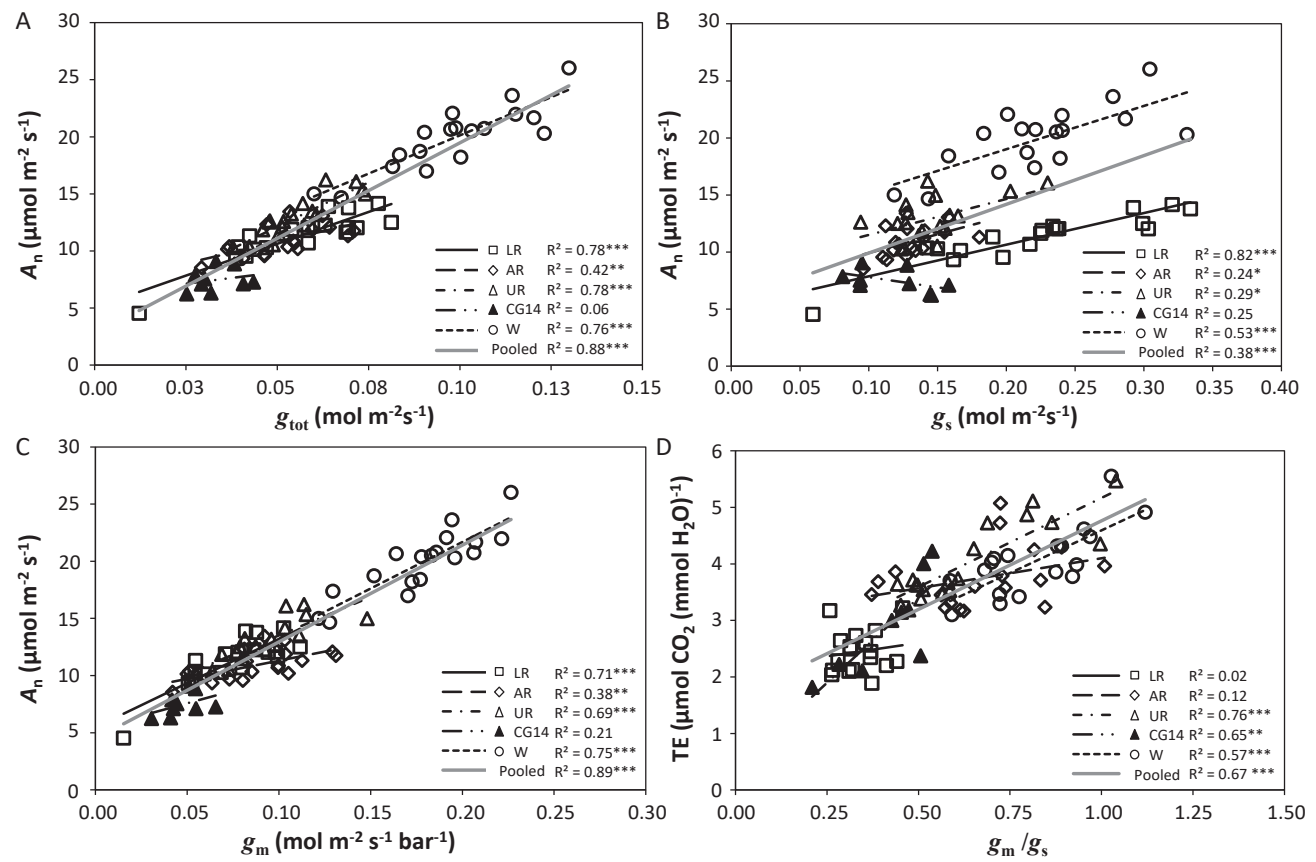

Fig. 2.2 The relationships (A) between photosynthetic rate $\left(A_{\mathrm{n}}\right)$ and total leaf conductance $\left(g_{\text {tot }}\right)$, (B) between $A_{\mathrm{n}}$ and stomatal conductance $\left(g_{\mathrm{s}}\right)$, (C) between $A_{\mathrm{n}}$ and mesophyll conductance $\left(g_{\mathrm{m}}\right)$, and (D) between transpiration efficiency (TE) and the ratio of mesophyll conductance over stomatal conductance $\left(g_{\mathrm{m}} / g_{\mathrm{s}}\right) . A_{\mathrm{n}}, g_{\mathrm{s}}$, and TE were obtained under $400 \mu \mathrm{mol} \mathrm{mol}^{-1} \mathrm{CO}_{2}, 1000-1500 \mu \mathrm{mol} \mathrm{m} \mathrm{m}^{-2} \mathrm{~s}^{-1}$ Iight intensity, and $25^{\circ} \mathrm{C} . g_{\mathrm{m}}$ was calculated based on the NRH-A method (Yin and Struik, 2009). LR: lowland rice; AR: aerobic rice; UR: upland rice; CG14: O. glaberrima; W: wheat. Linear regressions were fitted for overall data and for each genotype group. The significance of each correlation is shown as: *, $P<0.05$; $* *, P<0.01 ; * * *, P<0.001$.

However, TE was well explained by combined $g_{\mathrm{s}}$ and $g_{\mathrm{m}}$ (Table S2.3) and was actually highly correlated to the $g_{\mathrm{m}} / g_{\mathrm{s}}$ ratio (Fig. 2.2D), especially in upland rice, CG14, and wheat cultivars, although this relationship was less clear in lowland and aerobic rice cultivars. Both the $g_{\mathrm{m}} / g_{\mathrm{s}}$ and the TE of aerobic rice, upland rice, and wheat cultivars were higher than those of lowland rice cultivars.

\subsubsection{Anatomical determinants of $g_{\mathrm{s}}$}

Wheat cultivars had significantly lower density and larger stomata than rice cultivars (Fig. 2.3 and Table 2.3). Stomatal density $(D)$ varied significantly among rice cultivars, with lowland rice having higher $D$ than aerobic and upland rice, and CG14 having the lowest value. In rice, $D$ on the adaxial side ( $\left.D_{\text {adaxial }}\right)$ was lower than that on the abaxial side $\left(D_{\text {abaxial }}\right)$, and $D_{\text {adaxial }}$ 
varied significantly among cultivars, whereas less variation was observed for $D_{\text {abaxial }}$ (Table 2.3). Interestingly, the drought effect was significant only for $D_{\text {adaxial }}$ but not for $D_{\text {abaxial }}$ in both rice and wheat (Table S2.1). Drought increased $D_{\text {adaxial }}$ in most cultivars (Fig. S2.3A).

Aerobic rice cultivars had clearly larger stomatal size $(S)$ than other rice cultivars (Table 2.3). This high $S$ resulted more from wider stomatal width $(W)$ than from stomatal length $(L)$ (data not shown). Drought decreased $S$, and the effect was similar on both leaf surfaces in all cultivars (Fig. S2.3C, D). Cultivars CG14 and S82 had the strongest decrease in $S$ in rice and wheat, respectively.
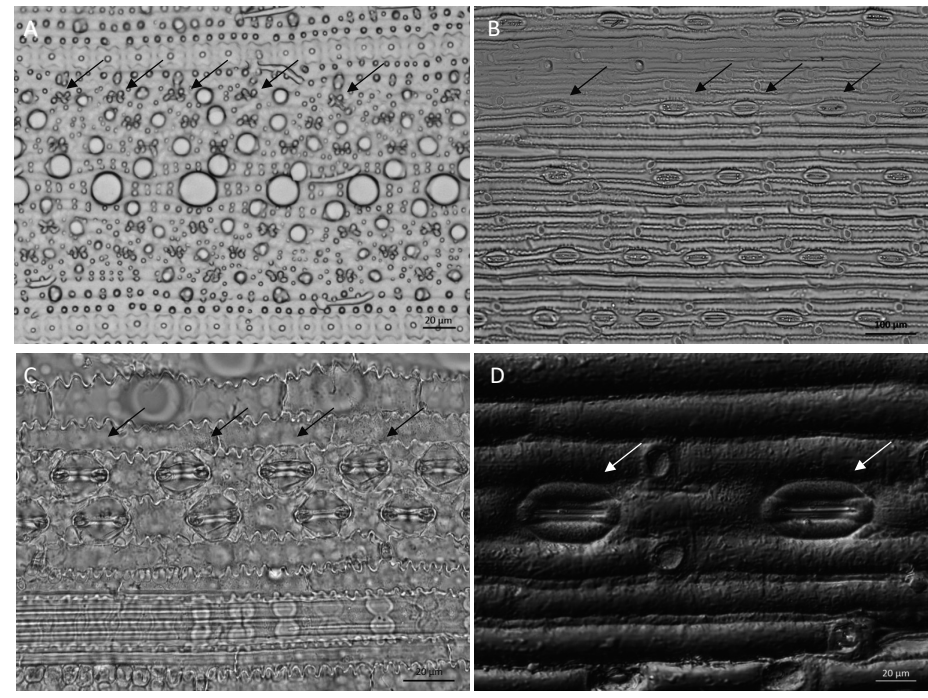

Fig. 2.3 Light micrographs illustrating leaf surfaces of rice (IR64; A, C) and wheat (S82; B, D) used to calculate stomatal density (A, B) and size (C, D). Arrows indicate stomata.
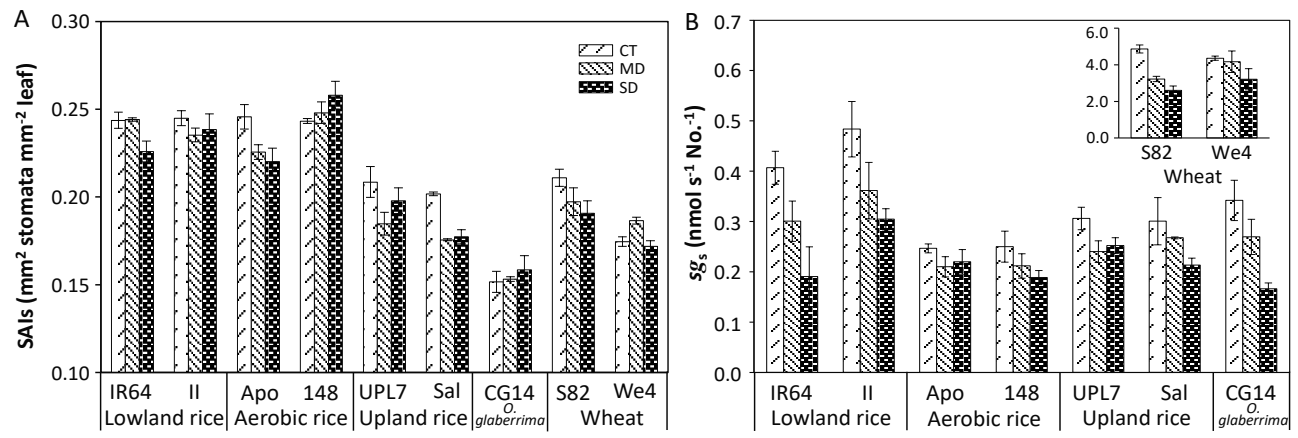

Fig. 2.4 Response of (A) the summed stomatal area index on both sides of the leaf surface (SAIs) and (B) specific stomatal conductance $\left(s g_{s}\right)$ of rice and wheat cultivars to water treatments: control $(\mathrm{CT})$, mild drought (MD), and more severe drought (SD). 
The sum of the stomatal area index on both sides of the leaf (SAIs) differed among the three species, with CG14 having the lowest SAIs and lowland, aerobic rice having higher SAIs than the other cultivars. The variation in SAIs within rice species was more associated with $D$ $\left(\mathrm{R}^{2}=0.58\right)$ than with $S\left(\mathrm{R}^{2}=0.33\right)$. SAIs decreased under drought in most cultivars, except in 148, CG14 and We4 (Fig. 2.4A). Specific stomatal conductance $\left(s g_{\mathrm{s}}\right)$ was much higher in wheat than in rice cultivars, and higher in lowland rice than in other rice cultivars under the CT condition (Fig. 2.4B). Drought decreased $s g_{\mathrm{s}}$ in all cultivars, with IR64, CG14, and S82 showing the highest decrease among rice and wheat cultivars, respectively.

The variation in stomatal properties can partially explain the variation in $g_{\mathrm{s}}$ among species and within species. $g_{\mathrm{s}}$ was partially correlated with $S$ or $D$, depending on genotype groups (Fig. S2.4). A significant positive correlation was found between $g_{\mathrm{s}}$ and SAIs for lowland and upland $O$. sativa as well as for wheat genotypes (Fig. 2.5A). The theoretical maximum stomatal conductance $\left(g_{\text {smax }}\right)$ was higher than the measured $g_{\mathrm{s}}$ in all cultivars and treatments, and was higher in rice than in wheat (Fig. 2.5B). The correlation between $g_{\mathrm{s}}$ and $g_{\text {smax }}$ was significant only for $O$. sativa, and not in wheat and each genotype group (Fig. 2.5B).
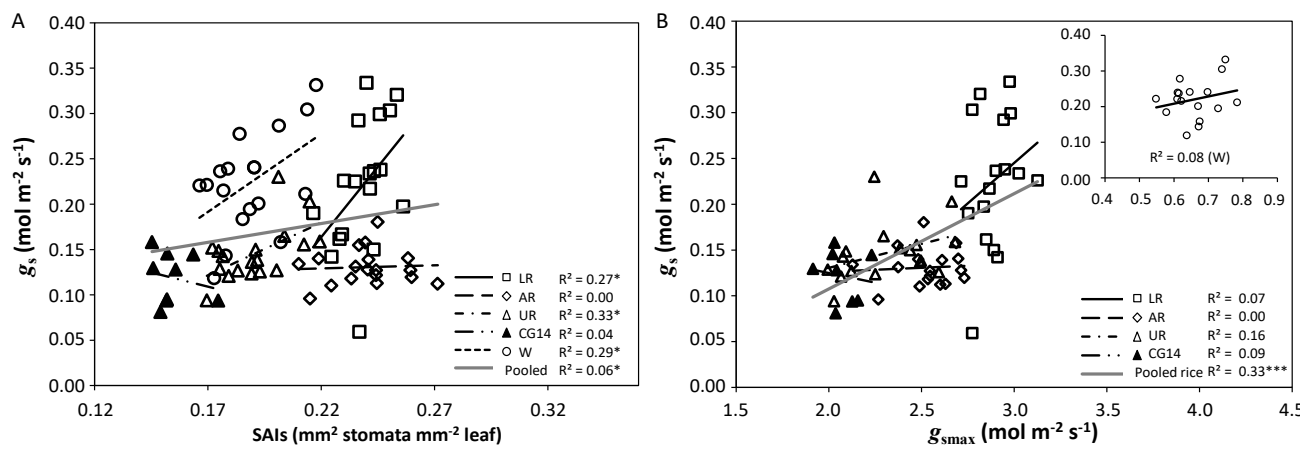

Fig. 2.5 The relationships (A) between stomatal conductance $\left(g_{\mathrm{s}}\right)$ and the summed stomatal area index (SAIs); (B) between $g_{\mathrm{s}}$ and the maximum stomatal diffusive conductance $\left(g_{\text {smax }}\right)$. Values of $g_{\mathrm{s}}$ were obtained and calculated under $400 \mu \mathrm{mol} \mathrm{mol}{ }^{-1} \mathrm{CO}_{2}, 1000-1500 \mu \mathrm{mol} \mathrm{m}^{-2} \mathrm{~s}^{-1}$ Iight intensity, and $25^{\circ} \mathrm{C}$. LR: lowland rice; AR: aerobic rice; UR: upland rice; CG14: O. glaberrima; W: wheat. Linear regressions were fitted for overall data and for each genotype group. The significance of each correlation is shown as: ${ }^{*}, P<0.05 ; * *, P<0.01 ; * * *, P<0.001$.

\subsubsection{Anatomical determinants of $g_{m}$}

Estimation of the transverse sections of leaves by light microscopy revealed a similar general leaf structure among the three species (Fig. 2.6 left panels). Significant variations in some anatomical traits were observed among species and among cultivars within the $O$. sativa species 
(Table 2.3). Wheat mesophyll tissue was about twice as thick as that of $O$. sativa cultivars and almost three times as thick as that of CG14 (Fig. 2.6). No strong drought effect was observed on the mesophyll thickness $\left(T_{\mathrm{m}}\right)$ (Table S2.1). The variation observed in the surface area of mesophyll cells exposed to the intercellular airspace per leaf area $\left(S_{\mathrm{m}}\right)$ was mainly between rice and wheat (Table 2.3), with wheat having a higher $S_{\mathrm{m}}$ than all rice cultivars even when the curvature factor 1.25 was used for wheat (Fig. S2.5B). $S_{\mathrm{m}}$ was significantly increased in wheat cultivars under drought $(P<0.05)$, whereas no clear trend was observed in rice cultivars (Fig. S2.5B).

In both rice and wheat, more than $60 \%$ of the exposed mesophyll cell surface area was covered by chloroplasts $\left(S_{\mathrm{c}}\right)$ (Table 2.3 ). Wheat cultivars and upland rice cultivar Sal had the highest $S_{\mathrm{c}} / S_{\mathrm{m}}$ ratio, and CG14 had the lowest. A significant decrease in $S_{\mathrm{c}} / S_{\mathrm{m}}$ was observed in IR64 and aerobic rice cultivars, whereas an increase was recorded in CG14 under the SD condition (Fig. S2.5C). No strong negative effect on $S_{\mathrm{c}} / S_{\mathrm{m}}$ was observed in upland rice and wheat cultivars under either drought condition (Fig. S2.5C). $S_{\mathrm{c}}$ varied significantly among species and among rice cultivars, with Sal having a higher $S_{\mathrm{c}}$ value than other rice cultivars (Table 2.3). Wheat cultivars showed a clear increase in $S_{\mathrm{c}}$ under drought, whereas no clear $S_{\mathrm{c}}$ response was observed in rice cultivars (Fig. S2.5D). A thinner mesophyll cell wall was observed in wheat cultivars than in all rice cultivars (Fig. 2.6), and drought increased the mesophyll cell wall thickness $\left(T_{\mathrm{w}}\right)$, with the most significant effect observed in IR64, Sal and We4 under the SD condition (Fig. S2.5E). $T_{\mathrm{w}}$ was also observed to be the only anatomical parameter to correlate with $N_{\mathrm{a}}$, a parameter related to leaf physiological maturity (Fig. S2.6).

Contributions of leaf anatomical properties to the variation in $g_{\mathrm{m}}$ were different in wheat and rice. A higher $g_{\mathrm{m}}$ in wheat was associated with a thicker $T_{\mathrm{m}}$, a higher $S_{\mathrm{m}}$, a higher $S_{\mathrm{c}}$ and a thinner $T_{\mathrm{w}}$ compared to rice cultivars, and these associations were little altered by using a different curvature factor for calculating $S_{\mathrm{m}}$ in wheat (Fig. S2.7). However, no clear relationship was observed between $g_{\mathrm{m}}$ and $T_{\mathrm{m}}$ or between $g_{\mathrm{m}}$ and $S_{\mathrm{m}}$ within $O$. sativa or within most genotype groups (Fig. S2.7A, B). $g_{\mathrm{m}}$ was positively correlated with $S_{\mathrm{c}}$ (Fig. S2.7C; $\mathrm{R}^{2}=0.14, P<0.01$ ) and with $S_{\mathrm{c}} / S_{\mathrm{m}}$ (Fig. $2.7 \mathrm{~A} ; \mathrm{R}^{2}=0.33, P<0.001$ ) among rice cultivars. $g_{\mathrm{m}}$ and $T_{\mathrm{w}}$ were negatively correlated among wheat cultivars (Fig. 2.7B), and this correlation only applied among rice cultivars if upland rice was excluded $\left(\mathrm{R}^{2}=0.37, P<0.001\right)$. These correlations were also confirmed by multiple regression analysis, which indicated that $S_{\mathrm{c}} / S_{\mathrm{m}}$ contributed mostly to the variation in $g_{\mathrm{m}}$ within $O$. sativa, whereas $T_{\mathrm{w}}$ was the main determinant of $g_{\mathrm{m}}$ in wheat (Table S2.4). 


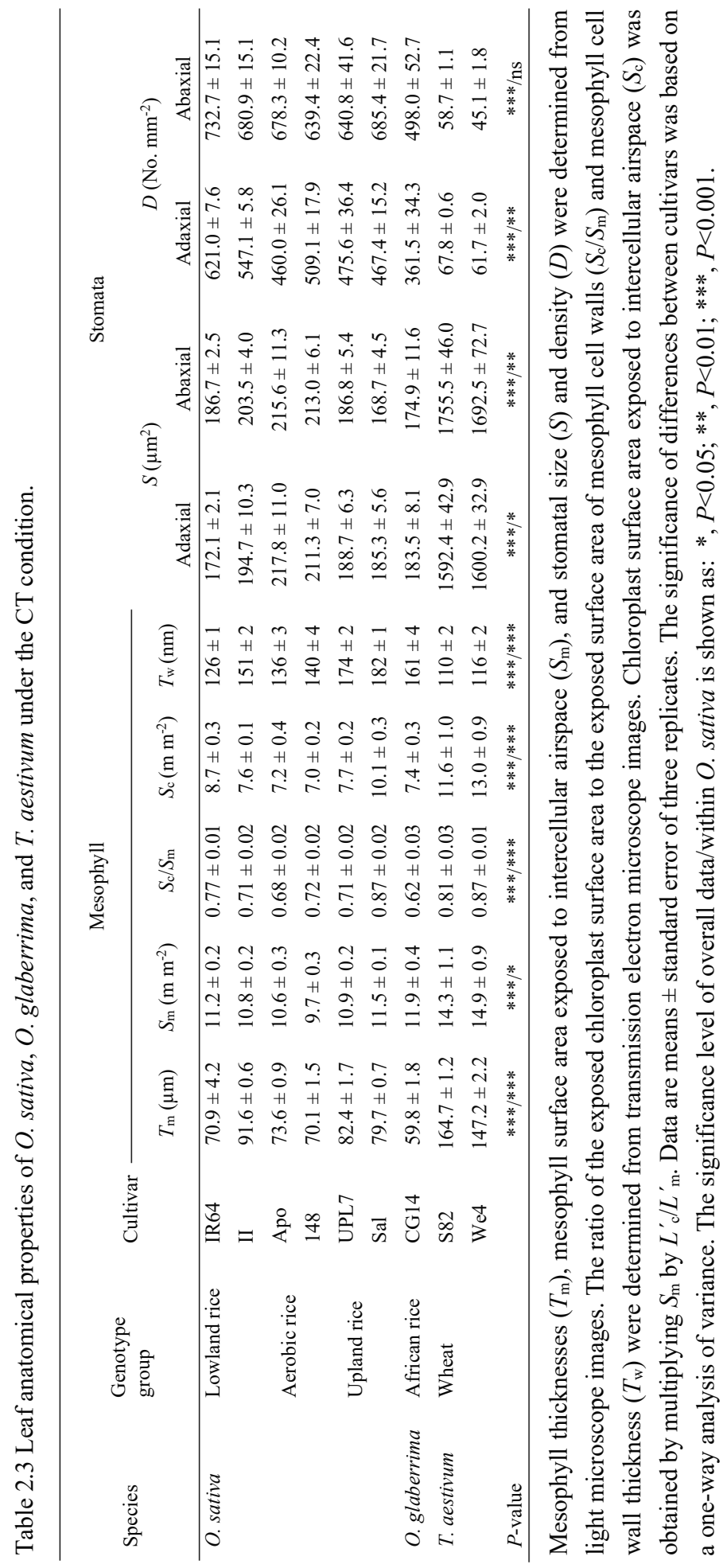



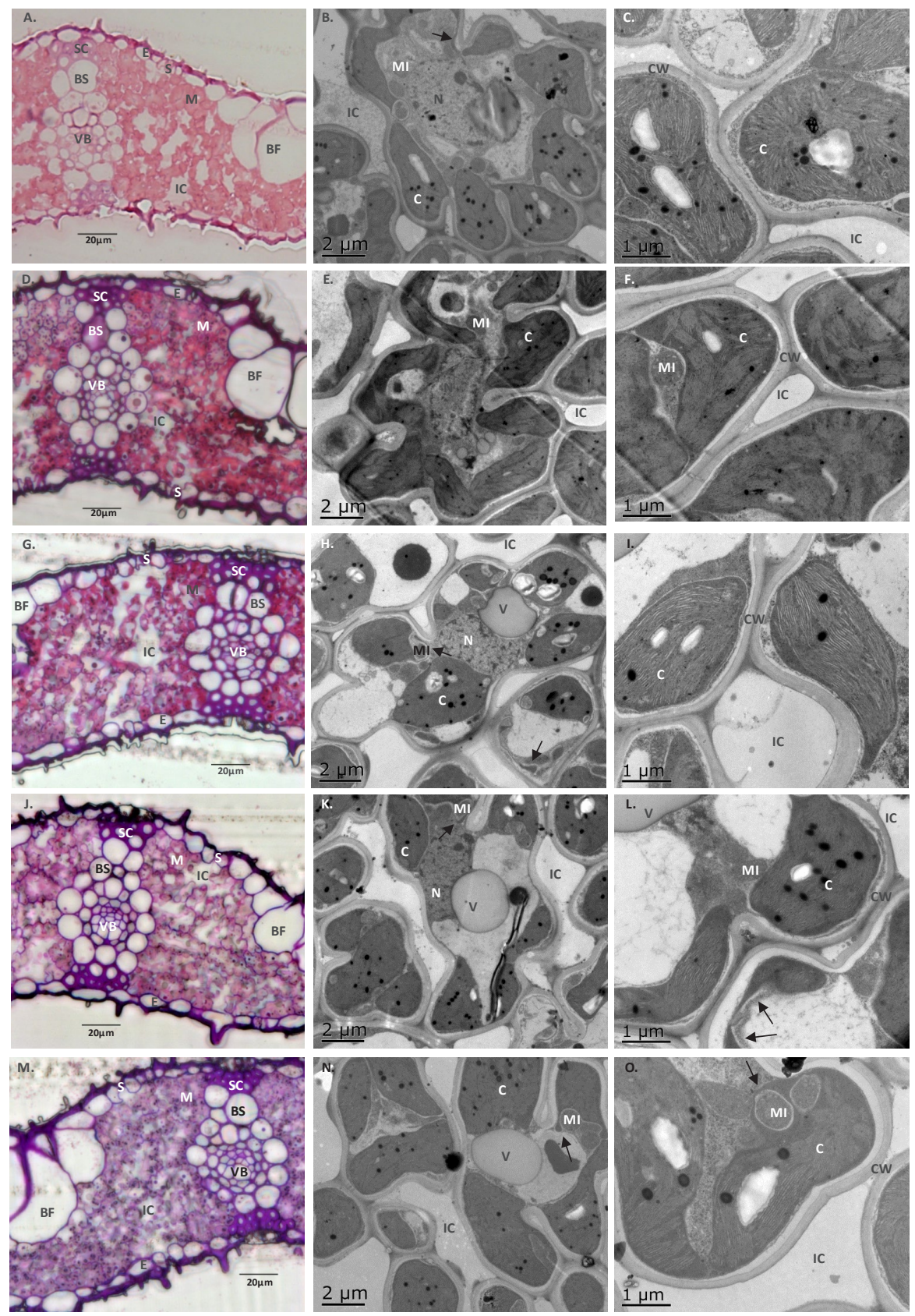

Fig. 2.6 Light (left panels) and electron (middle and right panels) micrographs of leaf structure and anatomy for $O$. sativa cultivars (A-C, IR64; D-F, II; G-I, Apo; J-L, 148; M-O, UPL7; P-R, Sal), O. glaberrima (S-U, CG14), and T. aestivum cultivars (V-X, S82; Y-AA, We4). The left panels show the overall leaf transverse sections; the middle panels show mesophyll cell shape, chloroplast distribution, and lobe development; and the right panels show mesophyll cell walls. Arrows mark stromules. BF: bulliform cell; BS: outer bundle-sheath cell; C: chloroplast; CW: mesophyll cell wall; E: epidermis; IC: intercellular airspace; M: mesophyll cell; MI:, mitochondria; N: nucleus; S: stoma; SC: sclerenchyma strand; VB: vascular bundle; V: vacuole. 

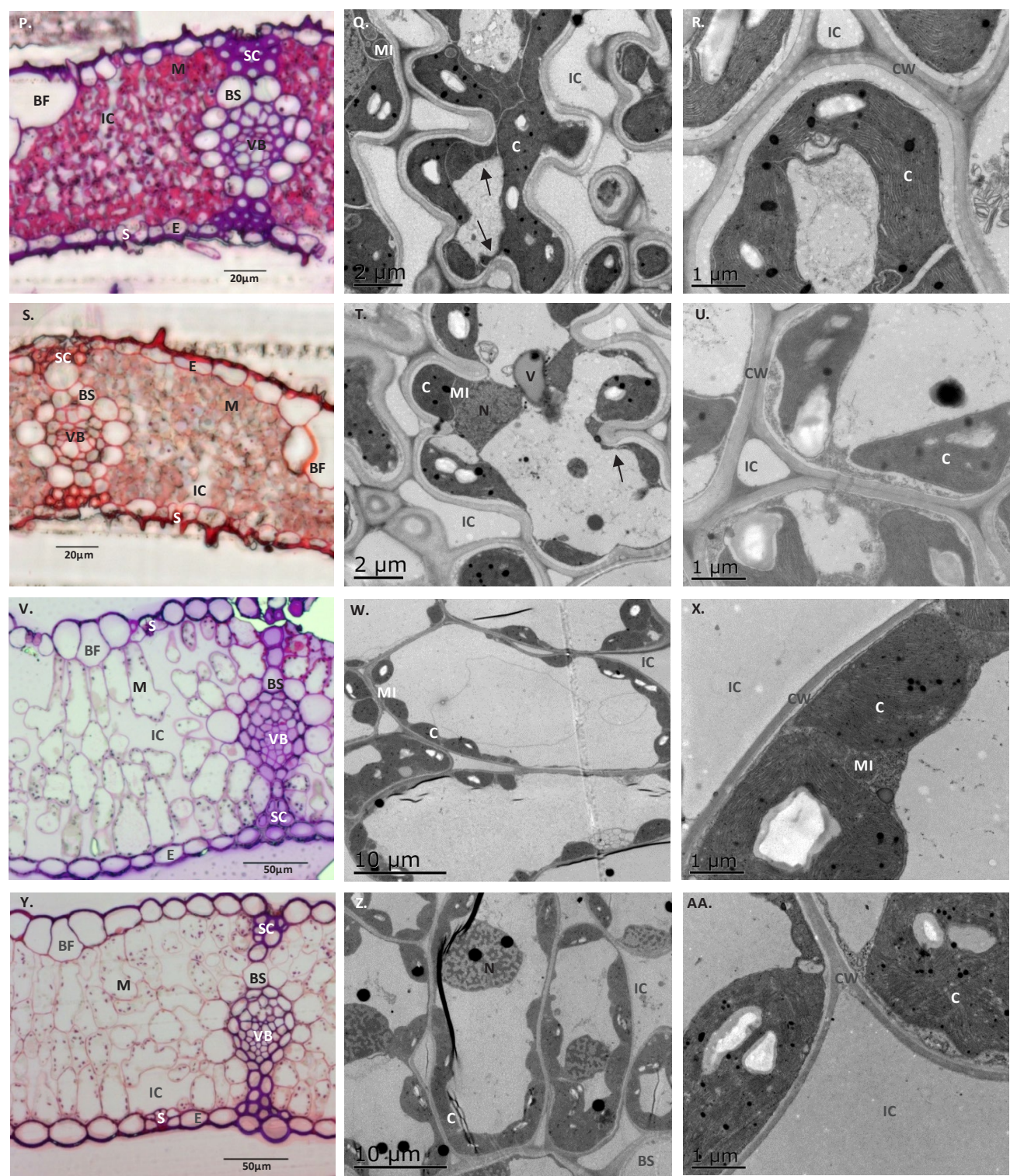

Fig. 2.6 Continued 

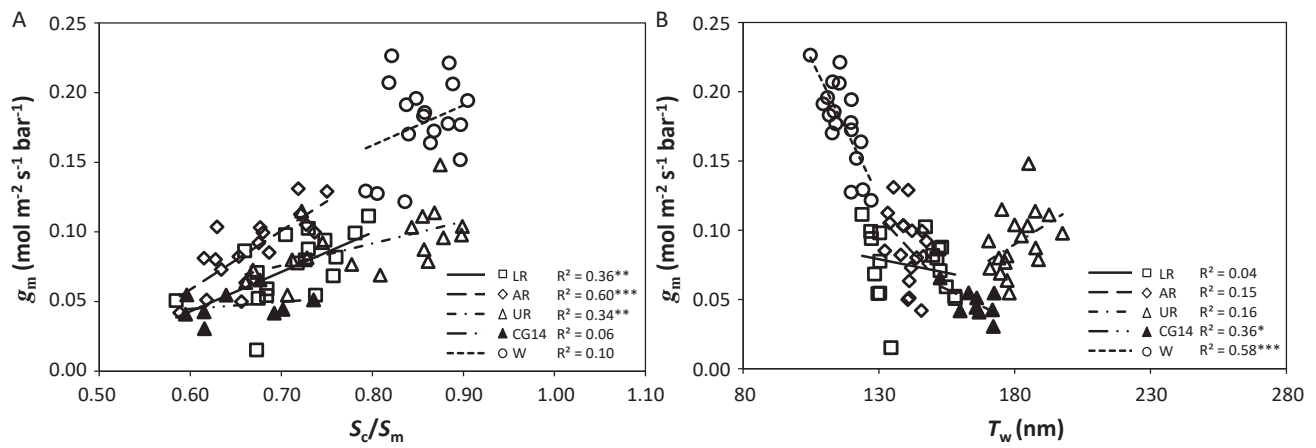

Fig. 2.7 The relationships (A) between mesophyll conductance $\left(g_{\mathrm{m}}\right)$ and the ratio of the exposed chloroplast surface area to the exposed surface area of mesophyll cell walls $\left(S_{\mathrm{c}} / S_{\mathrm{m}}\right)$; and (B) between $g_{\mathrm{m}}$ and the thickness of the mesophyll cell wall $\left(T_{\mathrm{w}}\right)$. LR: lowland rice; AR: aerobic rice; UR: upland rice; CG14: O. glaberrima; W: wheat. Linear regressions were fitted for each genotype group. The significance of each correlation is shown as: *, $P<0.05 ; * *, P<0.01 ; * * *, P<0.001$.

\subsection{Discussion}

\subsubsection{Importance of $g_{\mathrm{s}}$ and $g_{\mathrm{m}}$ in determining $A_{\mathrm{n}}$ and TE}

The photosynthetic capacity of leaves is closely related to their nitrogen content (Evans, 1989). In our study, the large variations in $A_{\mathrm{n}}$ cannot be explained by the small difference in leaf $N_{\mathrm{a}}$ among and within species (Fig. S2.1B). The close correlation between $A_{\mathrm{n}}$ and total leaf conductance $\left(g_{\text {tot }}\right)$ among species as well as within each group (Fig. 2.2A) suggests that the variation in $\mathrm{CO}_{2}$ diffusion limitation could explain the genetic variation in $A_{\mathrm{n}}$. Further, $A_{\mathrm{n}}$ was correlated with $\mathrm{CO}_{2}$ diffusional conductance (Fig. 2.2B, C), especially with $g_{\mathrm{m}}$, in agreement with previous reports (Flexas et al., 2008; Warren, 2008). It is of note that aerobic rice, upland rice, and wheat showed higher dependences of $A_{\mathrm{n}}$ on $g_{\mathrm{m}}$ than lowland rice (Table S2.2).

TE was influenced mostly by $g_{\mathrm{s}}$ within each group (Table S2.3); and this is not surprising given that $g_{\mathrm{s}}$ directly controls the transpirational water flow from leaf to the ambient air. However, $g_{\mathrm{m}}$ can influence $A_{\mathrm{n}}$ with no direct impact on transpiration and therefore can influence TE (Barbour et al., 2010; Jahan et al., 2014). For this reason, it has previously been suggested that the $g_{\mathrm{m}} / g_{\mathrm{s}}$ ratio is a potential target for improving TE under drought in several crops (Flexas et al., 2010; Galmés et al., 2011; Gu et al., 2012; Flexas et al., 2013) and that the ideal plants for arid environment have a high $g_{\mathrm{m}} / g_{\mathrm{s}}$ ratio (Condon et al., 2004; Giuliani et al., 2013). The observed relationship between TE and $g_{\mathrm{m}} / g_{\mathrm{s}}$ supports this (Fig. 2.2D). In the literature, a relationship between an intrinsic TE $\left(A_{\mathrm{n}} / g_{\mathrm{s}}\right)$ and $g_{\mathrm{m}} / g_{\mathrm{s}}$ has often been shown to exclude any 
influence of VPD on the relationship, especially when data are collected from a wide range of sources (Flexas et al., 2013). Mathematically, this is equivalent to the relationship between $A_{\mathrm{n}}$ and $g_{\mathrm{m}}$ (Fig. 2.2C). The somewhat more scattered relation in Fig. 2.2D than in Fig. 2.2C may reflect the influence of VPD, which varied between 1.0 and $1.6 \mathrm{kPa}$ during our measurements. However, we found no systematic effect of such a small range of VPD on transpiration and TE (results not shown), and therefore we preferred to use TE for our illustration instead of intrinsic TE, which has a different biological unit and is more difficult to interpret in agronomic terms. In our case, a higher $g_{\mathrm{m}} / g_{\mathrm{s}}$ ratio in aerobic rice, upland rice, and wheat was found to be associated with higher TE, whereas lowland rice cultivars had a low $g_{\mathrm{m}} / g_{\mathrm{s}}$ ratio and low TE (Fig. 2.2D). Furthermore, there was a higher slope for the linear relationship in TE versus the $g_{\mathrm{m}} / g_{\mathrm{s}}$ ratio in upland rice, O. glaberrima, and wheat (Fig. 2.2D), indicating that the sensitivity of TE in response to the $g_{\mathrm{m}} / g_{\mathrm{s}}$ ratio was higher in drought-tolerant genotypes than in droughtsusceptible genotypes.

Although $g_{\mathrm{m}}$ is expected to have little instantaneous impact on transpiration, our data showed that like $g_{\mathrm{s}}, g_{\mathrm{m}}$ decreased simultaneously under drought in all cultivars (Fig. 2.1B, C). This indicates that long-term drought during growth affected $g_{\mathrm{m}}$ in our experiment, in line with reports for several species (Miyazawa et al., 2008; Flexas et al., 2009), including rice ( Gu et $a l ., 2012)$. When $g_{\mathrm{s}}$ and $g_{\mathrm{m}}$ had a rather parallel decrease, such as in lowland rice and We4 under the MD and the SD condition, or when $g_{\mathrm{m}}$ showed a stronger decrease than $g_{\mathrm{s}}$, such as in aerobic rice and UPL7 under the SD condition, no benefit for TE was observed. Only cultivars with a small decrease in $g_{\mathrm{m}}$ combined with a strong decrease in $g_{\mathrm{s}}$ under drought showed strong increases in TE (e.g. Sal, O. glaberrima, and S82). Therefore, a strong response of $g_{\mathrm{s}}$ combined with a small response of $g_{\mathrm{m}}$ would be beneficial for water conservation and increasing TE under long-term drought.

\subsubsection{Anatomical determinants of $g_{\mathrm{s}}$}

Stomatal conductance $\left(g_{\mathrm{s}}\right)$ is influenced by the structural traits and the opening of stomata (Xu and Zhou, 2008; Franks and Beerling, 2009; Galmés et al., 2013). In our study, $D$ or $S$ alone could not explain the variation in $g_{\mathrm{s}}$ (Fig. S2.4). $S$ and $D$ together determine the total pore area (stomatal area index, SAI) and the maximum stomatal conductance $g_{\text {smax }}$ (Franks and Beerling, 2009; Galmés et al., 2013). Our results confirmed this with marginally significant correlations $(P<0.05)$ when $g_{\text {s }}$ was plotted versus SAIs (Fig. 2.5A) or versus $g_{\text {smax }}$ (Fig. 2.5B). The variation in SAIs or in $g_{\text {smax }}$ within rice species was more associated with $D$ than with $S$. 
Drought-tolerant types of aerobic rice, upland rice, and $O$. glaberrima had lower $D$ than lowland rice (Table 2.3), in line with reports that mutants with reduced leaf stomatal density had enhanced the drought tolerance and WUE of plants (Yu et al., 2008; Franks et al., 2015). Furthermore, the difference in $D$ was larger on the adaxial leaf surface than on the abaxial leaf surface, indicating that rice plants adapted to drier environments have developed fewer stomata on the upper surface to avoid direct water loss.

An increase in $D$ under drought has been reported in several species (Martinez et al., 2007; Hamanishi et al., 2012), but this response has not been widely observed in other species (Xu and Zhou, 2008; Galmés et al., 2013). On the other hand, a decrease in $S$ in response to drought was consistent in those studies. In our study, cultivars with a smaller $S$ under drought were accompanied by a greater reduction in $g_{\mathrm{s}}$ and $s g_{\mathrm{s}}$ (e.g. IR64, Sal, CG14, and S82). This is in line with the idea that smaller stomata are capable of a faster response to drought, compared with larger stomata (Franks and Beerling, 2009).

The stomatal properties examined in our study concerned only the anatomical features. However, biochemical components such as abscisic acid also influence $g_{\mathrm{s}}$, especially under drought (Franks and Farquhar, 2007). Such biochemical components influence the opening of stomata and may be responsible for part of the variability observed in $g_{\mathrm{s}}$.

\subsubsection{Anatomical determinants of $g_{m}$}

Leaf mesophyll thickness $\left(T_{\mathrm{m}}\right)$ and $S_{\mathrm{m}}$ are the critical structural components that impact upon $g_{\mathrm{m}}$ (Evans et al., 1994; Evans et al., 2009; Terashima et al., 2011; Giuliani et al., 2013). In our study, wheat cultivars had a thicker $T_{\mathrm{m}}$, a higher $S_{\mathrm{m}}$, and a higher $g_{\mathrm{m}}$ than rice cultivars. However, the difference in $T_{\mathrm{m}}$ or $S_{\mathrm{m}}$ was not associated with $g_{\mathrm{m}}$ variation within each species (Fig. S2.7A, B). Drought had a stronger effect on $S_{\mathrm{m}}$ in wheat than in rice cultivars. This higher increase in $S_{\mathrm{m}}$ in wheat cultivars might contribute to the smaller decline in $g_{\mathrm{m}}$ under drought conditions (Galmés et al., 2013).

It has been suggested that mesophyll cell walls account for more than $25 \%$ of total mesophyll resistance (Evans et al., 2009; Terashima et al., 2011; Tholen and Zhu, 2011). Han et al. (2016) reported that the decreasing $g_{\mathrm{m}}$ in cotton leaf under drought was associated with increased $T_{\mathrm{w}}$. Variation in $g_{\mathrm{m}}$ between $O$. sativa and wild rice species was suggested to be attributed to the thicker $T_{\mathrm{w}}$ in wild rice species (Scafaro et al., 2011). In our study, wheat cultivars had a thinner $T_{\mathrm{w}}$ than all rice cultivars. However, $T_{\mathrm{w}}$ varied significantly among rice cultivars and the 
difference was not associated with observed differences in $g_{\mathrm{m}}$ (Fig. 2.7B). Increased $T_{\mathrm{w}}$ under drought was observed in our study, but this did not lead to a decreased $g_{\mathrm{m}}$, particularly in cultivars Sal and CG14. This suggests that $T_{\mathrm{w}}$ might not be the most dominant limiting factor for $g_{\mathrm{m}}$ under drought in rice. On the other hand, it has generally been proposed that thick mesophyll cell walls are beneficial for plant drought tolerance (Scafaro et al., 2011; Giuliani et al., 2013). The thicker $T_{\mathrm{w}}$ found in drought-tolerant cultivars (e.g. upland rice and O. glaberrima) than in drought-sensitive cultivars might support this idea.

$S_{\mathrm{c}}$ affects $g_{\mathrm{m}}$ in many species (Tholen et al., 2008; Scafaro et al., 2011; Terashima et al., 2011; Tosens et al., 2012a; Tomás et al., 2013). Barbour et al. (2016) showed that the decrease in $g_{\mathrm{m}}$ in aged wheat and maize leaves was accompanied by a decline in $S_{\mathrm{c}} / S_{\mathrm{m}}$. In our study, the difference in $g_{\mathrm{m}}$ was explained somewhat more by $S_{\mathrm{c}} / S_{\mathrm{m}}$ (Fig. 2.7A) than by $S_{\mathrm{c}}$ (Fig. S2.7D), particularly in rice cultivars. In response to drought, $g_{\mathrm{m}}$ decreased more in cultivars with clear decreased $S_{\mathrm{c}} / S_{\mathrm{m}}$ (e.g. lowland and aerobic rice) and decreased less in cultivars with a relatively constant $S_{\mathrm{c}} / S_{\mathrm{m}}$ ratio (e.g. upland rice and wheat) across water treatments. The increase in $S_{\mathrm{c}} / S_{\mathrm{m}}$ observed in $O$. glaberrima (Fig. S2.5C) might be a compensating strategy for the increase in $T_{\mathrm{w}}$ under drought (Tosens et al., 2012a), which resulted in a small decrease in $g_{\mathrm{m}}$. The high correlation between $g_{\mathrm{m}}$ and $S_{\mathrm{c}} / S_{\mathrm{m}}$ within rice (Fig. 2.7A) indicates that $S_{\mathrm{c}} / S_{\mathrm{m}}$ might be very important in determining $g_{\mathrm{m}}$ in rice.

It has been suggested that certain biochemical components such as aquaporins and carbonic anhydrase are $g_{\mathrm{m}}$-related (Miyazawa et al., 2008; Flexas et al., 2012). These characteristics were not investigated in our study. They might explain the part of the variability observed in $g_{\mathrm{m}}$ that was not explained by anatomical features.

\subsection{Conclusions}

Stomatal conductance and mesophyll conductance explained most of the variability in $A_{\mathrm{n}}$ among species and within the species $O$. sativa. The higher $g_{\mathrm{m}} / g_{\mathrm{s}}$ ratio in aerobic rice, upland rice, and wheat cultivars was associated with higher TE, compared to lowland rice cultivars and O. glaberrima. Our study revealed the genotypic variation in the TE versus $g_{\mathrm{m}} / g_{\mathrm{s}}$ relationship among species and within the species $O$. sativa. There was a higher TE sensitivity in response to $g_{\mathrm{m}} / g_{\mathrm{s}}$ in drought-tolerant groups (O. glaberrima, upland rice, and wheat) than in lowland and aerobic rice. In particular, upland rice, O. glaberrima, and wheat cultivars minimised the decrease in $g_{\mathrm{m}}$; this can simultaneously sustain photosynthesis and increase TE under drought. 
Stomatal development was responsible for the variation in $g_{\mathrm{s}}$ among contrasting rice types and between rice and wheat. SAIs and $g_{\text {smax }}$ were correlated with the genetic variation of $g_{\mathrm{s}}$ among three species. More specifically, stomatal density (one component affecting SAIs and $g_{\text {smax }}$ ) was more related to the genetic variation in $g_{\mathrm{s}}$ among rice cultivars, suggesting that droughttolerant rice cultivars might have developed a mechanism of stomatal acclimation to drier edaphic environments. Moreover, cultivars with smaller stomata had a stronger decrease in $g_{\mathrm{s}}$, and thus a higher increase in TE, under drought stress.

Previous studies indicated that thick $T_{\mathrm{m}}$, high $S_{\mathrm{m}}$, high $S_{\mathrm{c}}$, and thin $T_{\mathrm{w}}$ were associated with high $g_{\mathrm{m}}$. These correlations were observed between wheat and rice but not among rice cultivars in our study. More importantly, for rice cultivars, the adverse impact of thick $T_{\mathrm{w}}$ can be neutralized by other anatomical factors such as a high $S_{\mathrm{c}} / S_{\mathrm{m}}$ ratio. In particular, under drought, the maintained or increased $S_{\mathrm{c}} / S_{\mathrm{m}}$ ratio in upland rice, $O$. glaberrima, and wheat cultivars resulted in a smaller decrease in $g_{\mathrm{m}}$ in them than in lowland and aerobic rice cultivars.

In short, our results suggest that rice TE might be improved by modulating stomatal and mesophyll structural traits via breeding selection and/or genetic engineering.

\section{Acknowledgements}

This work is part of the Growing Rice like Wheat research programme supported by an anonymous private donor who provided the financial support, via Wageningen University Fund, for the first author's PhD fellowship. The experimental work was financed by the College of Agriculture, Yangzhou University, Yangzhou, China. We thank Mrs Zhiqing Wang, Mr Qun Zhou and Mr Zhenxiang Zhou for technical assistance during the experiments, Prof. Zhong Wang, Prof. Fei Xiong, Dr Xurun Yu, and Dr Dongliang Li for guidance with microscopy, Dr Junfei Gu for help with GE and CF measurements, and Dr Herman Berghuijs for helpful discussions. Dr G. van der Linden and Dr P.S. Bindraban are acknowledged for their valuable advice.

\section{References}

Abràmoff MD, Magalhães PJ, Ram SJ. 2004. Image processing with ImageJ. Biophotonics International 11, 36-42.

Atlin G, Lafitte H, Tao D, Laza M, Amante M, Courtois B. 2006. Developing rice cultivars for high-fertility upland systems in the Asian tropics. Field Crops Research 97, 43-52. 
Barbour MM, Evans JR, Simonin KA, von Caemmerer S. 2016. Online $\mathrm{CO}_{2}$ and $\mathrm{H}_{2} \mathrm{O}$ oxygen isotope fractionation allows estimation of mesophyll conductance in $\mathrm{C}_{4}$ plants, and reveals that mesophyll conductance decreases as leaves age in both $\mathrm{C}_{4}$ and $\mathrm{C}_{3}$ plants. New Phytologist 210, 875-889.

Barbour MM, Warren CR, Farquhar GD, Forrester G, Brown H. 2010. Variability in mesophyll conductance between barley genotypes, and effects on transpiration efficiency and carbon isotope discrimination. Plant, Cell \& Environment 33, 1176-1185.

Bouman B, Peng S, Castaneda A, Visperas R. 2005. Yield and water use of irrigated tropical aerobic rice systems. Agricultural Water Management 74, 87-105.

Bouman B, Tuong TP. 2001. Field water management to save water and increase its productivity in irrigated lowland rice. Agricultural Water Management 49, 11-30.

Chaves MM, Pereira JS, Maroco J, Rodrigues ML, Ricardo CPP, Osório ML, Carvalho I, Faria T, Pinheiro C. 2002. How plants cope with water stress in the field? Photosynthesis and growth. Annals of Botany 89, 907-916.

Chonan N. 1970. Studies on the photosynthetic tissues in the leaves of cereal crops. V. Comparison of the mesophyll structure among seedling leaves of cereal crops. Crop Science Society of Japan 39, 418-425.

Chonan N. 1972. Differences in mesophyll structures between temperate and tropical grasses. Crop Science Society of Japan 41, 414-419.

Condon AG, Richards RA, Rebetzke GJ, Farquhar GD. 2004. Breeding for high water-use efficiency. Journal of Experimental Botany 55, 2447-2460.

Evans JR. 1989. Photosynthesis and nitrogen relationships in leaves of $\mathrm{C}_{3}$ plants. Oecologia 78, 9-19.

Evans JR, Kaldenhoff R, Genty B, Terashima I. 2009. Resistances along the $\mathrm{CO}_{2}$ diffusion pathway inside leaves. Journal of Experimental Botany 60, 2235-2248.

Evans JR, Vellen L. 1996 Wheat cultivars differ in transpiration efficiency and $\mathrm{CO}_{2}$ diffusion inside their leaves. In: Ishii R, Horie T, eds. Crop research in Asia: achievements and perspective. Fukui, Japan: Asian Crop Science Association, 326-329.

Evans JR, von Caemmerer S, Setchell BA, Hudson GS. 1994. The relationship between $\mathrm{CO}_{2}$ transfer conductance and leaf anatomy in transgenic tobacco with a reduced content of Rubisco. Functional Plant Biology 21, 475-495.

Flexas J, Barbour MM, Brendel O, Cabrera HM, Carriquí M, Díaz-Espejo A, Douthe C, Dreyer E, Ferrio JP, Gago J. 2012. Mesophyll diffusion conductance to $\mathrm{CO}_{2}$ : an unappreciated central 
player in photosynthesis. Plant Science 193, 70-84.

Flexas J, Barón M, Bota J, Ducruet J-M, Gallé A, Galmés J, Jiménez M, Pou A, Ribas-Carbó M, Sajnani C. 2009. Photosynthesis limitations during water stress acclimation and recovery in the drought-adapted Vitis hybrid Richter-110 (V. berlandieri $\times$ V. rupestris). Journal of Experimental Botany 60, 2361-2377.

Flexas J, Díaz-Espejo A, Berry J, Cifre J, Galmés J, Kaldenhoff R, Medrano H, Ribas-Carbó M. 2007. Analysis of leakage in IRGA's leaf chambers of open gas exchange systems: quantification and its effects in photosynthesis parameterization. Journal of Experimental Botany 58, 1533-1543.

Flexas J, Galmés J, Gallé A, Gulías J, Pou A, Ribas-Carbó M, Tomàs M, Medrano H. 2010. Improving water use efficiency in grapevines: potential physiological targets for biotechnological improvement. Australian Journal of Grape and Wine Research 16, 106-121.

Flexas J, Niinemets Ü, Gallé A, Barbour MM, Centritto M, Diaz-Espejo A, Douthe C, Galmés J, Ribas-Carbo M, Rodriguez PL, Rosselló F, Soolanayakanahally R, Tomas M, Wright IJ, Farquhar GD, Medrano H. 2013. Diffusional conductances to $\mathrm{CO}_{2}$ as a target for increasing photosynthesis and photosynthetic water-use efficiency. Photosynthesis Research 117, 45-59.

Flexas J, Ribas-Carbó M, Díaz-Espejo A, Galmés J, Medrano H. 2008. Mesophyll conductance to $\mathrm{CO}_{2}$ : current knowledge and future prospects. Plant, Cell \& Environment 31, 602-621.

Franks PJ, Farquhar GD. 2007. The mechanical diversity of stomata and its significance in gasexchange control. Plant Physiology 143, 78-87.

Franks PJ, Beerling DJ. 2009. Maximum leaf conductance driven by $\mathrm{CO}_{2}$ effects on stomatal size and density over geologic time. Proceedings of the National Academy of Sciences 106, 10343-10347.

Franks PJ, W Doheny-Adams TW, Britton-Harper ZJ, Gray JE. 2015. Increasing water-use efficiency directly through genetic manipulation of stomatal density. New Phytologist 207, 188195.

Galmés J, Conesa MÀ, Ochogavía J, Perdomo JA, Francis DM, Ribas-Carbó M, Savé R, Flexas J, Medrano H, Cifre J. 2011. Physiological and morphological adaptations in relation to water use efficiency in Mediterranean accessions of Solanum lycopersicum. Plant, Cell \& Environment 34, 245-260.

Galmés J, Ochogavía J, Gago J, Roldán EJ, Cifre J, Conesa MÀ. 2013. Leaf responses to drought stress in Mediterranean accessions of Solanum lycopersicum: anatomical adaptations in relation to gas exchange parameters. Plant, Cell \& Environment 36, 920-935. 
Genty B, Briantais J-M, Baker NR. 1989. The relationship between the quantum yield of photosynthetic electron transport and quenching of chlorophyll fluorescence. Biochimica et Biophysica Acta (BBA)-General Subjects 990, 87-92.

George T, Magbanua R, Garrity DP, Tubana BS, Quiton J. 2002. Rapid yield loss of rice cropped successively in aerobic soil. Agronomy Journal 94, 981-989.

Giday H, Kjaer KH, Fanourakis D, Ottosen CO. 2013. Smaller stomata require less severe leaf drying to close: a case study in Rosa hydrida. Journal of Plant Physiology 170, 1309-1316.

Giuliani R, Koteyeva N, Voznesenskaya E, Evans MA, Cousins AB, Edwards GE. 2013. Coordination of leaf photosynthesis, transpiration, and structural traits in rice and wild relatives (genus Oryza). Plant Physiology 162, 1632-1651.

Gorton HL, Herbert SK, Vogelmann TC. 2003. Photoacoustic analysis indicates that chloroplast movement does not alter liquid-phase $\mathrm{CO}_{2}$ diffusion in leaves of Alocasia brisbanensis. Plant Physiology 132, 1529-1539.

Gu J, Yin X, Stomph TJ, Wang H, Struik PC. 2012. Physiological basis of genetic variation in leaf photosynthesis among rice (Oryza sativa L.) introgression lines under drought and wellwatered conditions. Journal of Experimental Botany 63, 5137-5153.

Haefele S, Siopongco J, Boling A, Bouman B, Tuong T. 2009. Transpiration efficiency of rice (Oryza sativa L.). Field Crops Research 111, 1-10.

Hamanishi ET, Thomas BR, Campbell MM. 2012. Drought induces alterations in the stomatal development program in Populus. Journal of Experimental Botany 63, 4959-4971.

Han JM, Meng HF, Wang SY, Jiang CD, Liu F, Zhang WF, Zhang YL. 2016. Variability of mesophyll conductance and its relationship with water use efficiency in cotton leaves under drought pretreatment. Journal of Plant Physiology 194, 61-71.

Jahan E, Amthor JS, Farquhar GD, Trethowan R, Barbour MM. 2014. Variation in mesophyll conductance among Australian wheat genotypes. Functional Plant Biology 41, 568-580.

Kadam NN, Yin X, Bindraban PS, Struik PC, Jagadish KS. 2015. Does morphological and anatomical plasticity during the vegetative stage make wheat more tolerant of water-deficit stress than rice? Plant Physiology 167, 1389-1401.

Kemanian AR, Stöckle CO, Huggins DR. 2005. Transpiration-use efficiency of barley. Agricultural and Forest Meteorology 130, 1-11.

Lawlor DW, Tezara W. 2009. Causes of decreased photosynthetic rate and metabolic capacity in water-deficient leaf cells: a critical evaluation of mechanisms and integration of processes. Annals of Botany 103, 561-579. 
Liu J, Liao D, Oane R, Estenor L, Yang X, Li Z, Bennett J. 2006. Genetic variation in the sensitivity of anther dehiscence to drought stress in rice. Field Crops Research 97, 87-100.

Loriaux SD, Avenson TJ, Welles JM, McDermitt DK, Eckles RD, Riensche B, Genty B. 2013. Closing in on maximum yield of chlorophyll fluorescence using a single multiphase flash of sub-saturating intensity. Plant, Cell \& Environment 36, 1755-1770.

Makino A, Mae T, Ohira K. 1988. Differences between wheat and rice in the enzymic properties of ribulose-1,5-bisphosphate carboxylase/oxygenase and the relationship to photosynthetic gas exchange. Planta 174, 30-38.

Martinez J, Silva H, Ledent J, Pinto M. 2007. Effect of drought stress on the osmotic adjustment, cell wall elasticity and cell volume of six cultivars of common beans (Phaseolus vulgaris L.). European Journal of Agronomy 26, 30-38.

Miyazawa S-I, Yoshimura S, Shinzaki Y, Maeshima M, Miyake C. 2008. Deactivation of aquaporins decreases internal conductance to $\mathrm{CO}_{2}$ diffusion in tobacco leaves grown under long-term drought. Functional Plant Biology 35, 553-564.

Nuijten E, van Treuren R, Struik PC, Mokuwa A, Okry F, Teeken B, Richards P. 2009. Evidence for the emergence of new rice types of interspecific hybrid origin in West African farmers' fields. PLoS One 4, e7335.

Ohsumi A, Kanemura T, Homma K, Horie T, Shiraiwa T. 2007. Genotypic variation of stomatal conductance in relation to stomatal density and length in rice (Oryza sativa L.). Plant Production Science 10, 322-328.

Pinheiro C, Chaves M. 2011. Photosynthesis and drought: can we make metabolic connections from available data? Journal of Experimental Botany 62, 869-882.

Praba ML, Cairns J, Babu R, Lafitte H. 2009. Identification of physiological traits underlying cultivar differences in drought tolerance in rice and wheat. Journal of Agronomy and Crop Science 195, 30-46.

Sage TL, Sage RF. 2009. The functional anatomy of rice leaves: implications for refixation of photorespiratory $\mathrm{CO}_{2}$ and efforts to engineer $\mathrm{C}_{4}$ photosynthesis into rice. Plant and Cell Physiology 50, 756-772.

Sarla N, Swamy BM. 2005. Oryza glaberrima: a source for the improvement of Oryza sativa. Current Science Bangalore 89, 955-963.

Scafaro AP, von Caemmerer S, Evans JR, Atwell BJ. 2011. Temperature response of mesophyll conductance in cultivated and wild Oryza species with contrasting mesophyll cell wall thickness. Plant, Cell \& Environment 34, 1999-2008. 
Scartazza A, Lauteri M, Guido M, Brugnoli E. 1998. Carbon isotope discrimination in leaf and stem sugars, water-use efficiency and mesophyll conductance during different developmental stages in rice subjected to drought. Functional Plant Biology 25, 489-498.

Singh S, Ladha J, Gupta R, Bhushan L, Rao A. 2008. Weed management in aerobic rice systems under varying establishment methods. Crop Protection 27, 660-671.

Smith S, Weyers J, Berry W. 1989. Variation in stomatal characteristics over the lower surface of Commelina communis leaves. Plant, Cell \& Environment 12, 653-659.

Terashima I, Hanba YT, Tholen D, Niinemets Ü. 2011. Leaf functional anatomy in relation to photosynthesis. Plant Physiology 155, 108-116.

Thain J. 1983. Curvature correction factors in the measurement of cell surface areas in plant tissues. Journal of Experimental Botany 34, 87-94.

Thanh N, Thanh N, Zheng H, Dong N, Trinh L, Ali M, Nguyen H. 1999. Genetic variation in root morphology and microsatellite DNA loci in upland rice (Oryza sativa L.) from Vietnam. Euphytica 105, 53-62.

Tholen D, Boom C, Noguchi K, Ueda S, Katase T, Terashima I. 2008. The chloroplast avoidance response decreases internal conductance to $\mathrm{CO}_{2}$ diffusion in Arabidopsis thaliana leaves. Plant, Cell \& Environment 31, 1688-1700.

Tholen D, Zhu XG. 2011. The mechanistic basis of internal conductance: a theoretical analysis of mesophyll cell photosynthesis and $\mathrm{CO}_{2}$ diffusion. Plant Physiology 156, 90-105.

Tomás M, Flexas J, Copolovici L, Galmés J, Hallik L, Medrano H, Ribas-Carbó M, Tosens T, Vislap V, Niinemets Ü. 2013. Importance of leaf anatomy in determining mesophyll diffusion conductance to $\mathrm{CO}_{2}$ across species: quantitative limitations and scaling up by models. Journal of Experimental Botany 64, 2269-2281.

Tosens T, Niinemets U, Vislap V, Eichelmann H, Castro Diez P. 2012a. Developmental changes in mesophyll diffusion conductance and photosynthetic capacity under different light and water availabilities in Populus tremula: how structure constrains function. Plant, Cell \& Environment 35, 839-856.

Tosens T, Niinemets Ü, Westoby M, Wright IJ. 2012b. Anatomical basis of variation in mesophyll resistance in eastern Australian sclerophylls: news of a long and winding path. Journal of Experimental Botany 63, 5105-5119.

Warren CR. 2008. Stand aside stomata, another actor deserves centre stage: the forgotten role of the internal conductance to $\mathrm{CO}_{2}$ transfer. Journal of Experimental Botany 59, 1475-1487.

Xu Z, Zhou G. 2008. Responses of leaf stomatal density to water status and its relationship with 
photosynthesis in a grass. Journal of Experimental Botany 59, 3317-3325.

Yang J, Zhang J, Wang Z, Liu L, Zhu Q. 2003. Postanthesis water deficits enhance grain filling in two-line hybrid rice. Crop Science 43, 2099-2108.

Yang J, Zhang J. 2006. Grain filling of cereals under soil drying. New Phytologist 169, 223236.

Yin X, Struik PC. 2009. Theoretical reconsiderations when estimating the mesophyll conductance to $\mathrm{CO}_{2}$ diffusion in leaves of $\mathrm{C}_{3}$ plants by analysis of combined gas exchange and chlorophyll fluorescence measurements. Plant, Cell \& Environment 32, 1513-1524 (with corrigendum in 33,1595$)$.

Yin X, Struik PC, Romero P, Harbinson J, Evers JB, Van Der Putten PE, Vos J. 2009. Using combined measurements of gas exchange and chlorophyll fluorescence to estimate parameters of a biochemical $\mathrm{C}_{3}$ photosynthesis model: a critical appraisal and a new integrated approach applied to leaves in a wheat (Triticum aestivum) canopy. Plant, Cell \& Environment 32, 448464.

Yu H, Chen X, Hong YY, Wang Y, Xu P, Ke SD, Liu HY, Zhu JK, Oliver DJ, Xiang CB. 2008. Activated expression of an Arabidopsis HD-START protein confers drought tolerance with improved root system and reduced stomatal density. The Plant Cell 20, 1134-1151.

Zhang H, Zhang S, Yang J, Zhang J, Wang Z. 2008. Postanthesis moderate wetting drying improves both quality and quantity of rice yield. Agronomy Journal 100, 726-734. 


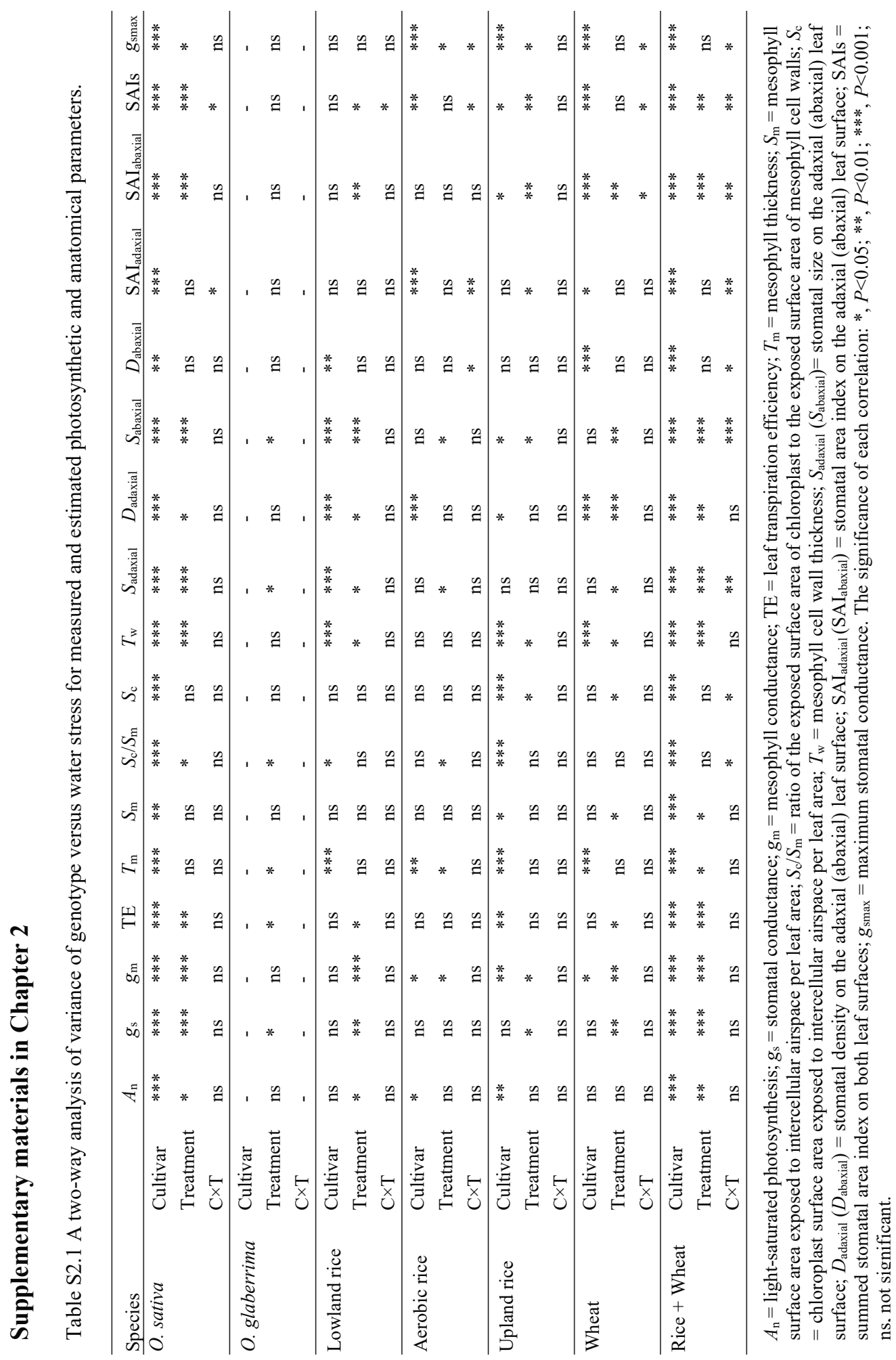


Table S2.2 Multiple regression analysis of light-saturated photosynthesis $\left(A_{\mathrm{n}}\right)$ as a function of $g_{\mathrm{s}}$ and $g_{\mathrm{m}}$ $\left(A_{\mathrm{n}}=b_{0}+b_{1} g_{\mathrm{s}}+b_{2} g_{\mathrm{m}}\right)$, based on data of three treatments.

\begin{tabular}{|c|c|c|c|c|c|}
\hline \multirow{2}{*}{ Genotype } & \multirow{2}{*}{$\begin{array}{l}\text { Intercept } \\
b_{0}\end{array}$} & \multicolumn{4}{|c|}{ Regression coefficient } \\
\hline & & $b_{1}$ & $b_{2}$ & $\mathrm{R}^{2}$ & No. of data points \\
\hline Lowland rice & 4.79 & $20.91 * *$ & 23.83 & 0.85 & 18 \\
\hline Aerobic rice & 6.58 & 16.13 & $25.30 *$ & 0.42 & 18 \\
\hline Upland rice & 4.67 & $19.26^{*}$ & $59.76 * * *$ & 0.79 & 18 \\
\hline O. glaberrima & 7.40 & -19.69 & 50.02 & 0.52 & 9 \\
\hline O. sativa & 5.55 & $9.10 * *$ & $52.80 * * *$ & 0.59 & 54 \\
\hline Wheat & 5.31 & 13.41 & $65.13 * * *$ & 0.79 & 18 \\
\hline Rice + Wheat & 3.43 & $9.58 * *$ & $77.76 * * *$ & 0.90 & 81 \\
\hline
\end{tabular}

$*, * * * * *$ significant at the $0.05,0.01$ and 0.001 probability levels, respectively.

Table S2.3 Multiple regression analysis of TE as a function of $g_{\mathrm{s}}$ and $g_{\mathrm{m}}\left(\mathrm{TE}=b_{0}+b_{1} g_{\mathrm{s}}+b_{2} g_{\mathrm{m}}\right)$, based on data of three treatments.

\begin{tabular}{llllll}
\hline \multirow{2}{*}{ Genotype } & Intercept & \multicolumn{4}{l}{ Regression coefficient } \\
\cline { 2 - 6 } & $b_{0}$ & $b_{1}$ & $b_{2}$ & $\mathrm{R}^{2}$ & No. of data points \\
\hline Lowland rice & 3.41 & $-4.19^{*}$ & -0.48 & 0.69 & 18 \\
Aerobic rice & 5.46 & $-18.45^{*}$ & 8.03 & 0.34 & 18 \\
Upland rice & 4.78 & $-16.95^{* * *}$ & $19.01^{* * *}$ & 0.74 & 18 \\
O. glaberrima & 5.47 & $-27.06^{* *}$ & 13.60 & 0.82 & 9 \\
O. sativa & 4.13 & $-12.11^{* * *}$ & $15.33^{* * *}$ & 0.72 & 54 \\
Wheat & 5.46 & $-10.38^{* * *}$ & 5.12 & 0.63 & 18 \\
Rice + Wheat & 4.07 & $-12.21^{* * *}$ & $15.33^{* * *}$ & 0.69 & 81 \\
\hline
\end{tabular}

$*, * *, * * *$ significant at the $0.05,0.01$ and 0.001 probability levels, respectively. 
Chapter 2

Table S2.4 Multiple regression analysis of mesophyll conductance $\left(g_{\mathrm{m}}\right)$ as a function of $T_{\mathrm{w}}, S_{\mathrm{c}} / S_{\mathrm{m}}$ and $N_{\mathrm{a}}\left(g_{\mathrm{m}}=b_{0}+b_{1} T_{\mathrm{w}}+b_{2} S_{\mathrm{c}} / S_{\mathrm{m}}+b_{3} N_{\mathrm{a}}\right)$, based on combined data of all three water treatments.

\begin{tabular}{lllllll}
\hline \multirow{2}{*}{ Genotype } & Intercept & \multicolumn{2}{l}{ Regression coefficient } \\
\cline { 2 - 7 } & $b_{0}$ & $b_{1}$ & $b_{2}$ & $b_{3}$ & $\mathrm{R}^{2}$ & No. of data points \\
\hline Lowland rice & -0.11 & -0.03 & $0.33^{*}$ & -0.04 & 0.43 & 18 \\
Aerobic rice & -0.15 & -0.18 & $0.42^{* *}$ & -0.02 & 0.60 & 18 \\
Upland rice & -0.15 & 0.13 & 0.15 & 0.11 & 0.44 & 18 \\
O. glaberrima & -0.06 & 0.37 & $0.24^{*}$ & $-0.17^{* *}$ & 0.86 & 9 \\
O. sativa & 0.08 & $-0.67^{* *}$ & $0.24^{* * *}$ & $-0.06^{* *}$ & 0.40 & 54 \\
Wheat & 0.36 & $-4.04^{* * *}$ & 0.29 & 0.04 & 0.74 & 18 \\
Rice + Wheat & 0.04 & $-1.15^{* * *}$ & $0.36^{* * *}$ & $-0.05^{* *}$ & 0.78 & 81 \\
\hline
\end{tabular}

$*, * *, * * *$ significant at the $0.05,0.01$ and 0.001 probability levels, respectively. 

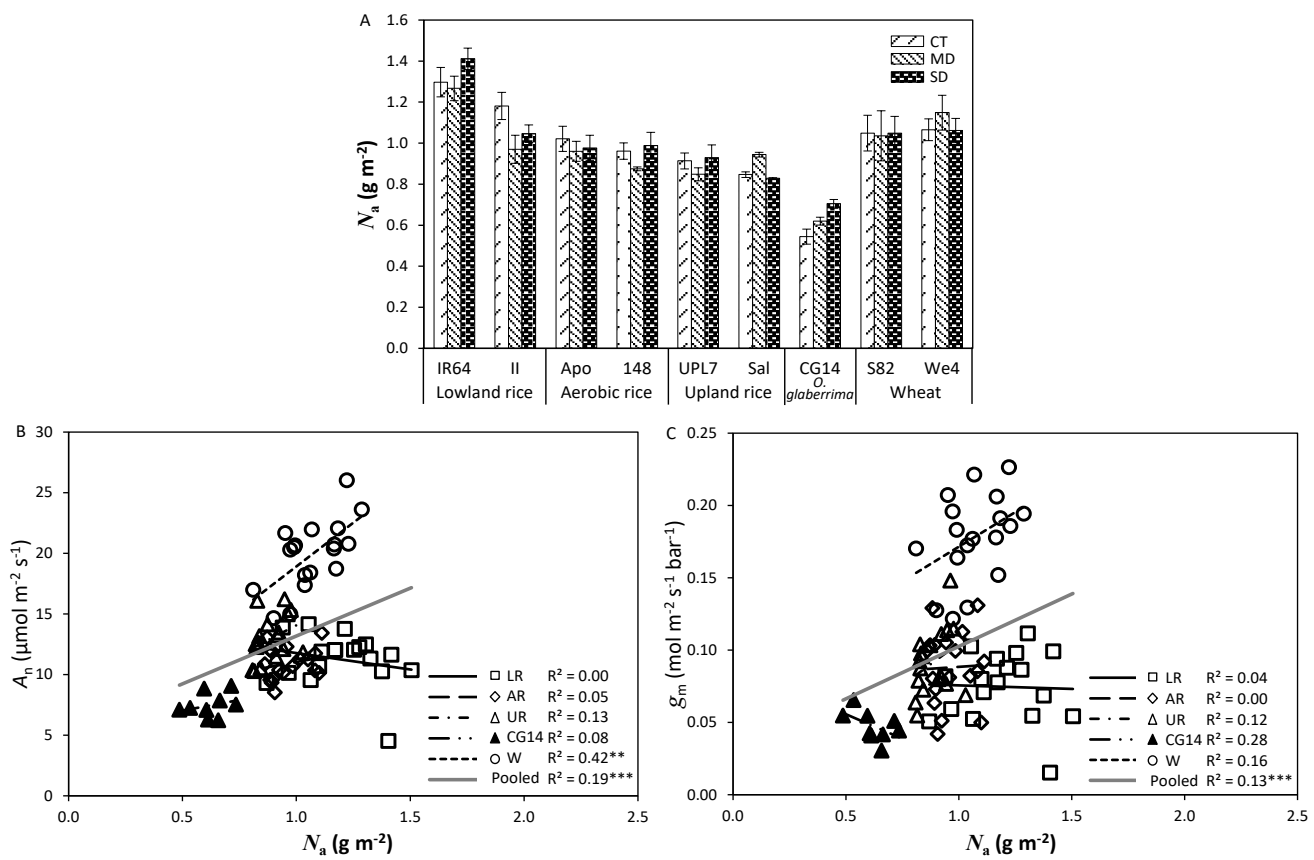

Fig. S2.1 (A) Response of leaf nitrogen per unit area $\left(N_{\mathrm{a}}\right)$ of rice and wheat cultivars to water stress treatments: control (CT); mild drought (MD); more severe drought (SD). (B) Relationship between photosynthetic rate $\left(A_{\mathrm{n}}\right)\left(400 \mu \mathrm{mol} \mathrm{mol}^{-1} \mathrm{CO}_{2}, 1000-1500 \mu \mathrm{mol} \mathrm{m}^{-2} \mathrm{~s}^{-1}\right.$ irradiance, and $\left.25^{\circ} \mathrm{C}\right)$ and $N_{\mathrm{a}}$; (C) Relationship between mesophyll conductance $\left(g_{\mathrm{m}}\right)$ and $N_{\mathrm{a}}$. LR: lowland rice; AR: aerobic rice; UR: upland rice; CG14: O. glaberrima; W: wheat. Linear regressions were fitted for overall data and for each genotype group. The significance of each correlation is shown as: **, $P<0.01 ; * * *, P<0.001$.
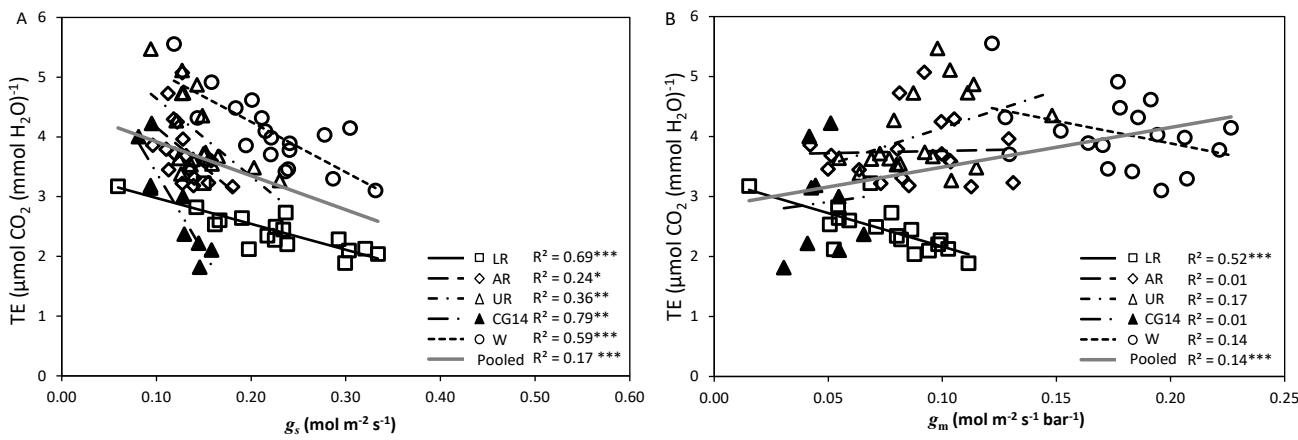

Fig. S2.2 Relationship between transpiration efficiency (TE) and stomatal conductance $\left(g_{\mathrm{s}}\right)$, and between TE and mesophyll conductance $\left(g_{\mathrm{m}}\right)$. Values of TE and $g_{\mathrm{s}}$ were obtained and calculated under $400 \mu \mathrm{mol} \mathrm{mol}{ }^{-1} \mathrm{CO}_{2}, 1000-1500 \mu \mathrm{mol} \mathrm{m}{ }^{-2} \mathrm{~s}^{-1}$ irradiance, and $25^{\circ} \mathrm{C} . \mathrm{g}_{\mathrm{m}}$ was calculated based on the nonrectangular hyperbolic method (Yin and Struik, 2009). LR: lowland rice; AR: aerobic rice; UR: upland rice; CG14: O. glaberrima; W: wheat. Linear regressions were fitted for overall data and for each genotype group. The significance of each correlation is shown as: ${ }^{*}, P<0.05 ;{ }^{* *}, P<0.01 ; * * *, P<0.001$. 

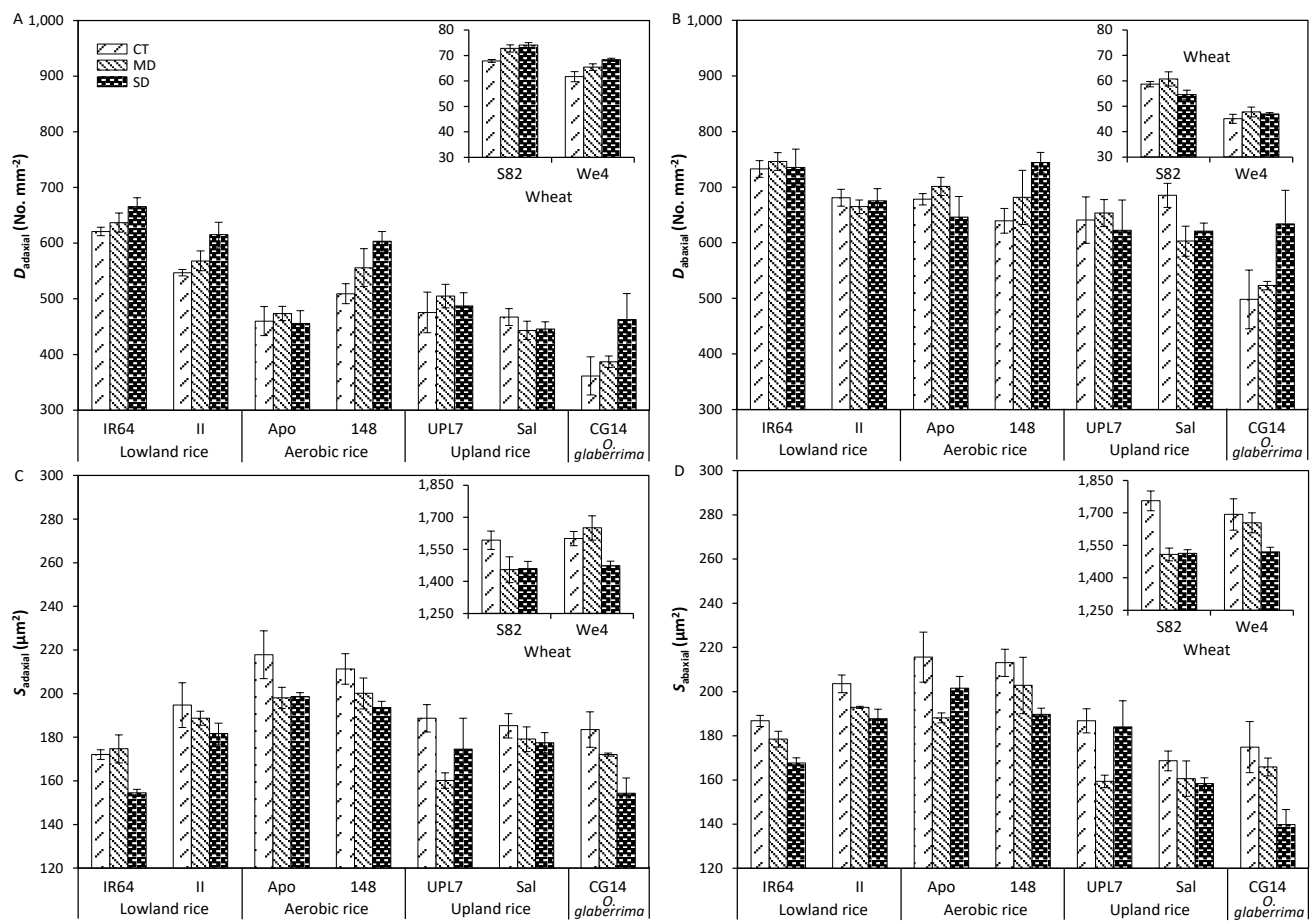

Fig. S2.3 Stomatal density $(D)$ and size $(S)$ from adaxial side (A, C) and abaxial side (B, D) of rice and wheat cultivars under three treatments: control (CT); mild drought (MD); and more severe drought (SD).
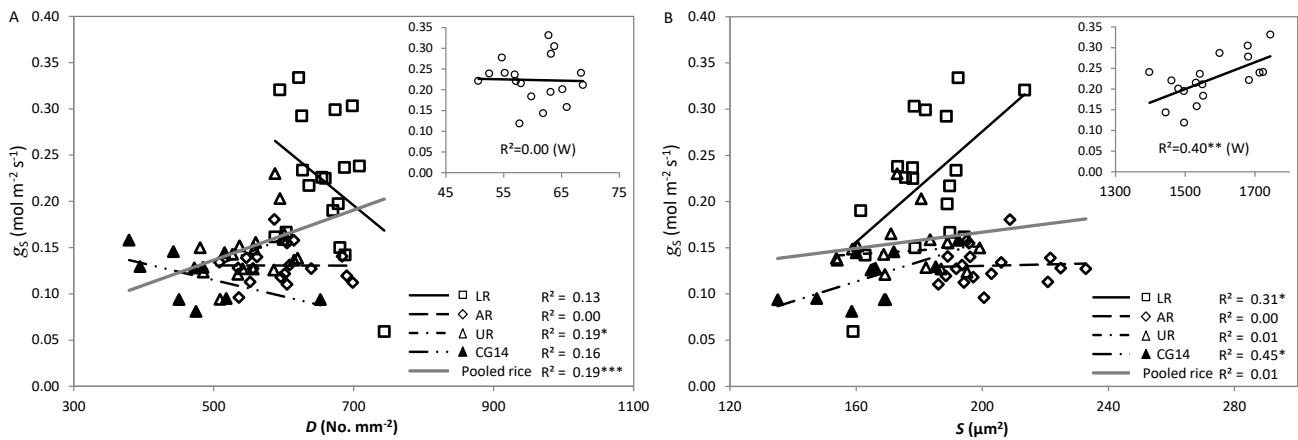

Fig. S2.4 The relationship between stomatal conductance $\left(g_{\mathrm{s}}\right)$ and stomatal density $(D)$, and between $g_{\mathrm{s}}$ and stomatal size $(S)$; Values of $g_{\mathrm{s}}$ were obtained and calculated under $400 \mu \mathrm{mol} \mathrm{mol}^{-1} \mathrm{CO}_{2}, 1000-1500$ $\mu \mathrm{mol} \mathrm{m} \mathrm{m}^{-2} \mathrm{~s}^{-1}$ irradiance, and $25^{\circ} \mathrm{C} . S$ and $D$ have been calculated as the average between both sides of the leaf. LR: lowland rice; AR: aerobic rice; UR: upland rice; CG14: O. glaberrima; W: wheat. Linear regressions were fitted for overall data and for each genotype group. The significance of each correlation is shown as: *, $P<0.05 ; * * *, P<0.001$. 

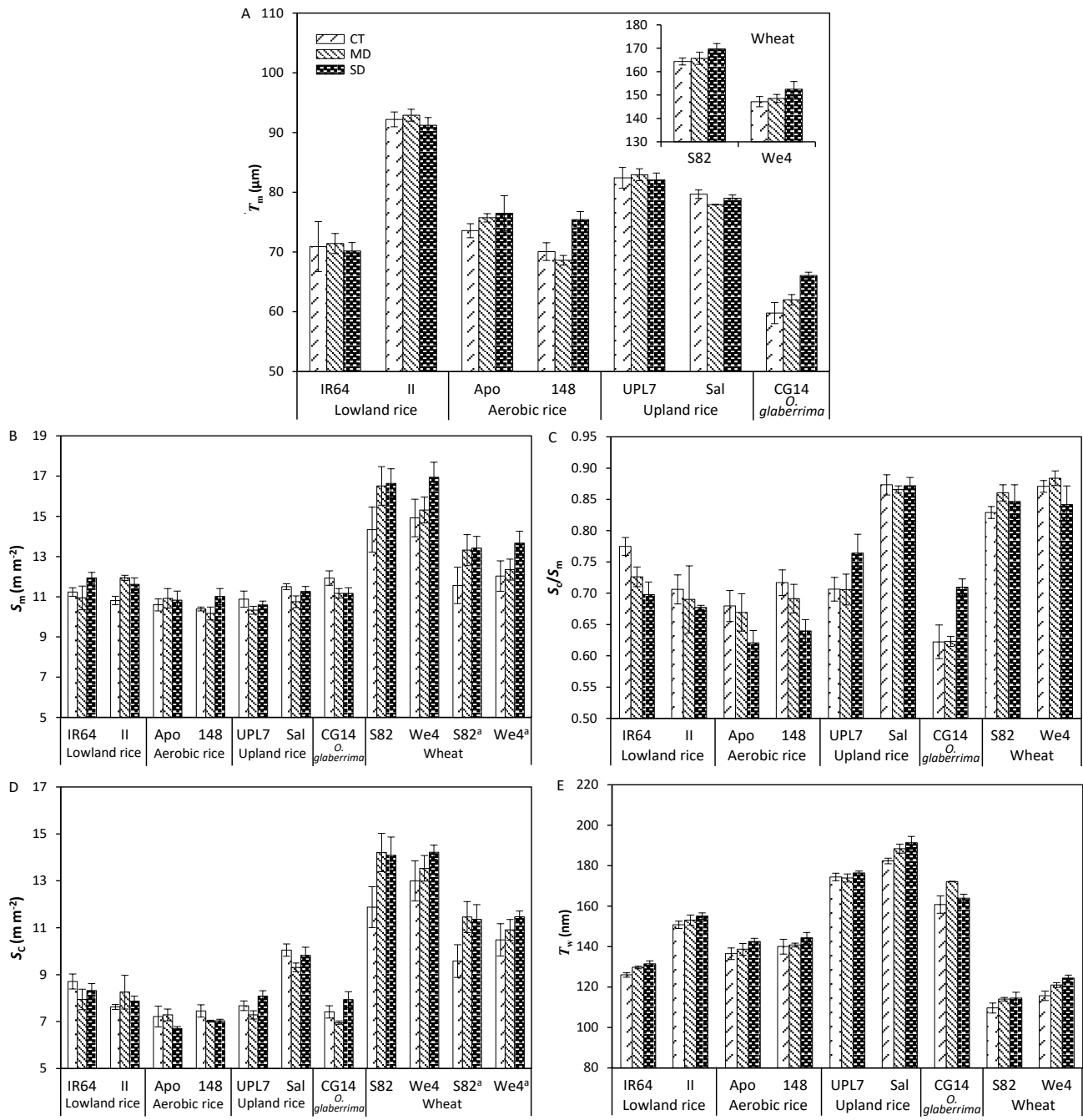

Fig. S2.5 Mesophyll cell properties of wheat and rice leaves obtained from light and electron microscope images under three treatments: control (CT); mild drought (MD); and more severe drought (SD). (A) mesophyll thickness $\left(T_{\mathrm{m}}\right)$; (B) the surface area of mesophyll cells exposed to the intercellular airspaces per leaf area $\left(S_{\mathrm{m}}\right)$; (C) ratio of the exposed surface area of chloroplast to the exposed surface area of mesophyll cell walls $\left(S_{\mathrm{c}} / S_{\mathrm{m}}\right)$; (D) the surface area of chloroplasts exposed to intercellular airspace per leaf area $\left(S_{\mathrm{c}}\right)$; and $(\mathrm{E})$ thickness of the mesophyll cell wall $\left(T_{\mathrm{w}}\right)$. For wheat cultivars marked by superscript ${ }^{\mathrm{a}}$ in $\mathrm{B}$ and $\mathrm{D}$, we used the alternative value 1.25 as the curvature correction factor $(F)$ for calculating $S_{\mathrm{m}}$ and $S_{\mathrm{c}}$. 

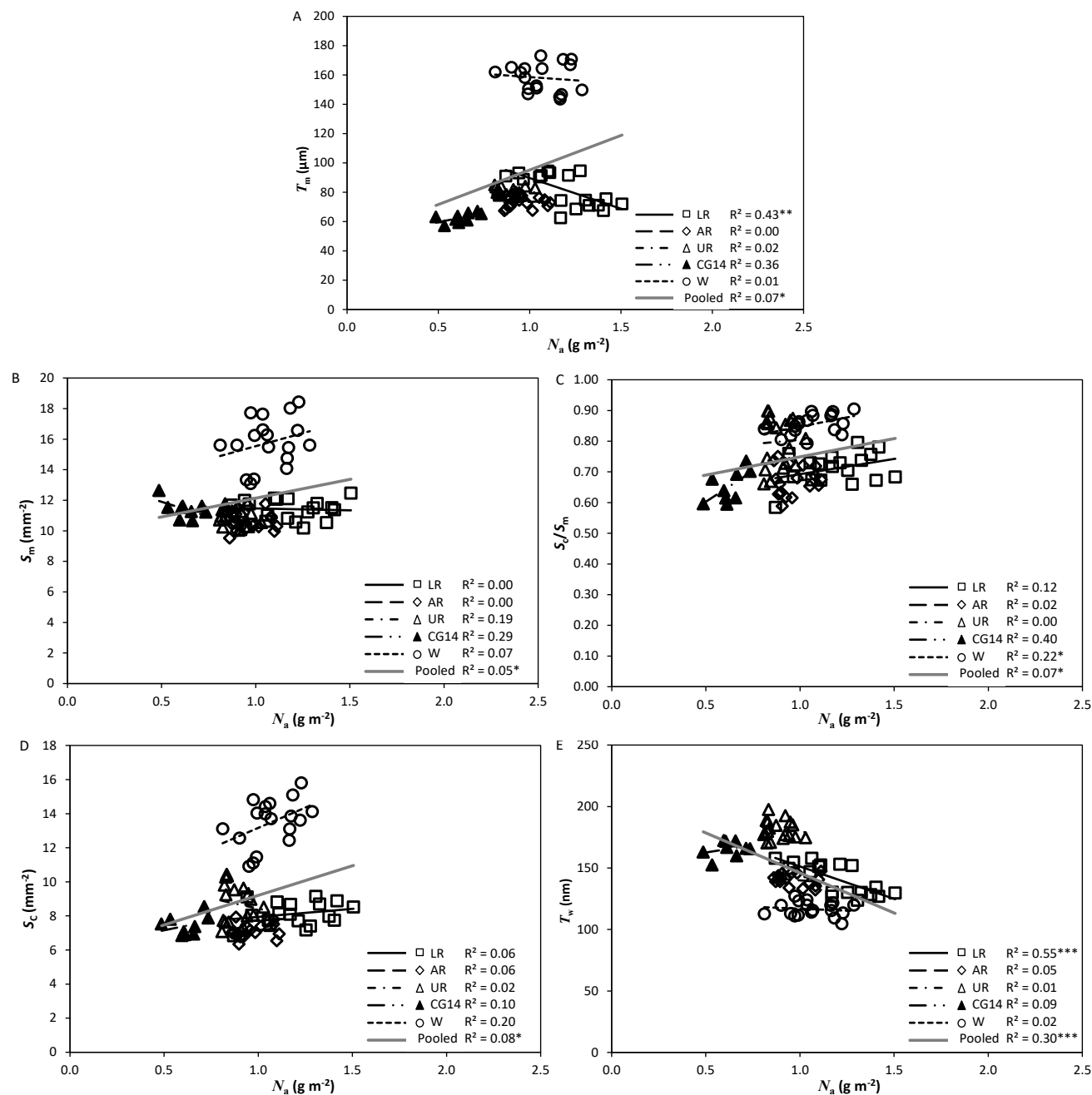

Fig. S2.6 Relationship between (A) mesophyll thickness ( $\left.T_{\mathrm{m}}\right)$ and $N_{\mathrm{a}}$; (B) the surface area of mesophyll cells exposed to the intercellular airspaces per leaf area $\left(S_{\mathrm{m}}\right)$ and $N_{\mathrm{a}} ;(\mathrm{C})$ ratio of the exposed surface area of chloroplast to the exposed surface area of mesophyll cell walls $\left(S_{\mathrm{c}} / S_{\mathrm{m}}\right)$ and $N_{\mathrm{a}}$; (D) the surface area of chloroplasts exposed to intercellular airspace per leaf area $\left(S_{\mathrm{c}}\right)$ and $N_{\mathrm{a}}$; (E) thickness of the mesophyll cell wall $\left(T_{\mathrm{w}}\right)$ and $N_{\mathrm{a}}$. LR: lowland rice; AR: aerobic rice; UR: upland rice; CG14: O. glaberrima; W: wheat. Linear regressions were fitted for each genotype group. The significance of each correlation is shown as: *, $P<0.05$; **, $P<0.01$; ***, $P<0.001$. 

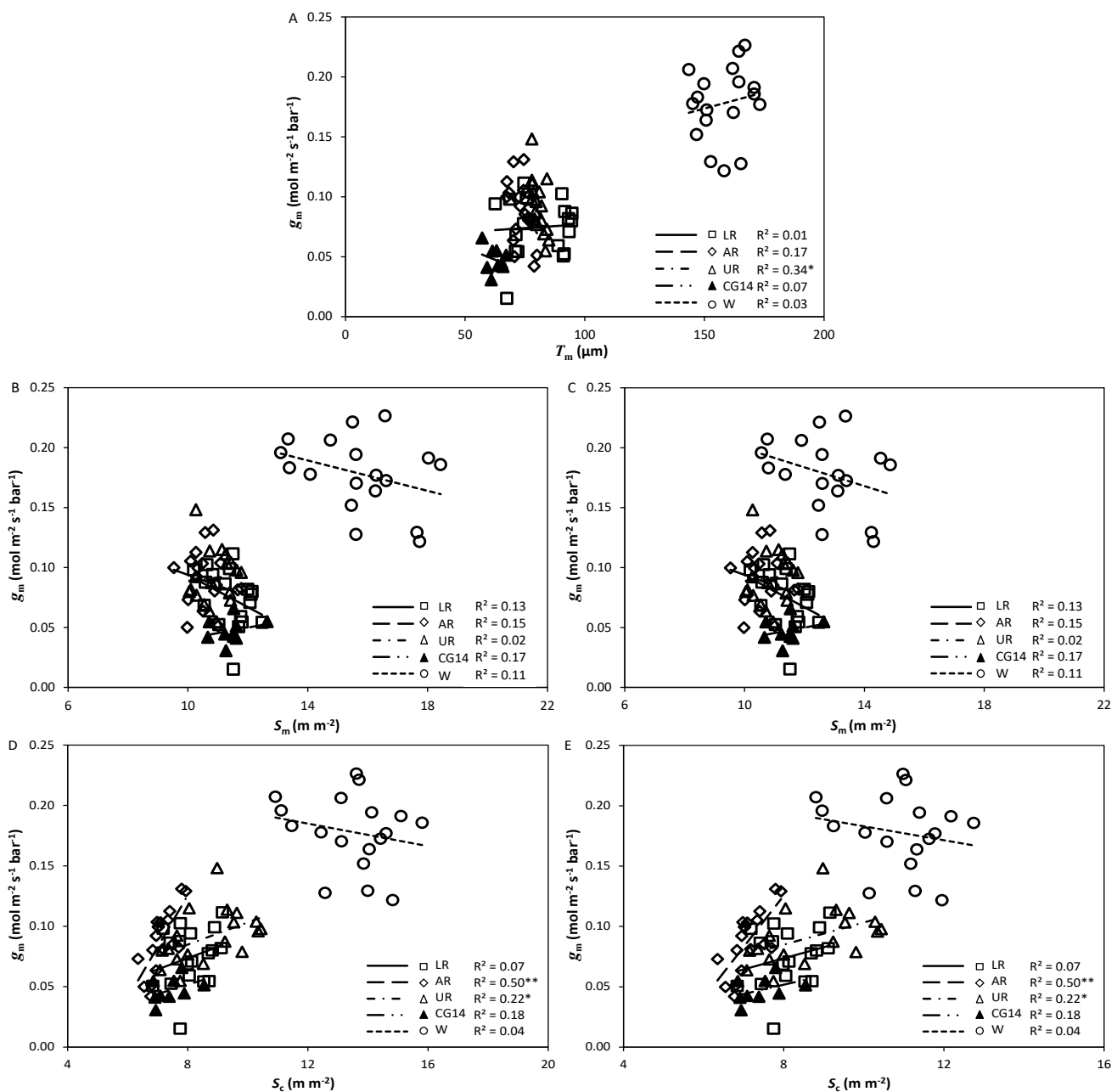

Fig. S2.7 The relationship between mesophyll conductance $\left(g_{\mathrm{m}}\right)$ (NRH-A method) and (A) mesophyll thickness $\left(T_{\mathrm{m}}\right) ;(\mathrm{B}, \mathrm{C})$ the surface area of mesophyll cells exposed to the intercellular airspaces per leaf area $\left(S_{\mathrm{m}}\right)$; and $(\mathrm{D}, \mathrm{E})$ the surface area of chloroplasts exposed to intercellular airspace per leaf area $\left(S_{\mathrm{c}}\right)$. In B and D we used the value 1.55 as curvature correction factor $(F)$ for calculating $S_{\mathrm{m}}$ and $S_{\mathrm{c}}$ in both rice and wheat cultivars; in $\mathrm{C}$ and $\mathrm{E}$ we used the value 1.55 as $F$ for calculating $S_{\mathrm{m}}$ and $S_{\mathrm{c}}$ in rice and 1.25 for wheat cultivars. LR: lowland rice; AR: aerobic rice; UR: upland rice; CG14: O. glaberrima; $\mathrm{W}$ : wheat. Linear regressions were fitted for each genotype group. The significance of each correlation is shown as: *, $P<0.05 ; * *, P<0.01$. 



\section{Chapter 3}

\section{Comparisons with wheat reveal root anatomical and histochemical constraints of rice}

\section{under water-deficit stress}

Wenjing Ouyang ${ }^{1}$, Xinyou Yin ${ }^{1}$, Jianchang Yang ${ }^{2}$ and Paul C. Struik ${ }^{1}$

${ }^{1}$ Centre for Crop Systems Analysis, Wageningen University \& Research, 6700 AK Wageningen, The Netherlands

${ }^{2}$ College of Agriculture, Yangzhou University, 225009 Yangzhou, Jiangsu, China 


\begin{abstract}
To face the challenge of decreasing freshwater availability for agriculture, it is important to explore avenues for developing rice genotypes that can be grown like dryland cereals. Roots play a key role in plant adaptation to dry environments. We examined anatomical and histochemical root traits that affect water acquisition in rice (Oryza sativa) and wheat (Triticum aestivum). These traits and root growth were measured at two developmental stages for three rice and two wheat cultivars that were grown in pots under three water regimes. Wheat roots had larger xylem sizes than rice roots, which potentially led to a higher axial conductance, especially under water-deficit conditions. Suberization, lignification and thickening of the endodermis in rice roots increased with increasing water deficit, resulting in stronger radial barriers for water flow in rice than in wheat, especially near the root apex. In addition, water deficit strongly impeded root growth and lateral root proliferation in rice, but only slightly in wheat, and cultivars within a species differed little in these responses. The stress sensitivity of rice attributes was slightly more prominent at vegetative than at flowering stages. Rice root characteristics, which are essential for growth under inundated conditions, are not conducive to growth under water deficit. Although rice roots show considerable plasticity under different watering regimes, improving root xylem size and reducing the radial barriers would be required if rice is to grow like dryland cereals.
\end{abstract}

Keywords: Lignin; rice; root anatomy; root morphology; suberin; water deficit; wheat 


\subsection{Introduction}

Climate change as well as the decreasing availability of freshwater resources for agriculture will increase the frequency and severity of water limitation for crop production (Madadgar et al., 2017). Rice (Oryza sativa L.), one of the major staple food crops, is very sensitive to even mild water-deficit (Pantuwan et al., 2002; Centritto et al., 2009), because of its (semi-)aquatic growth nature. Developing rice genotypes that maintain high productivity under water-deficit conditions is a major challenge for breeders and synthetic biologists.

Rice is mostly grown under irrigated lowland conditions (i.e. in inundated paddy fields). However, natural diversity in water-deficit adaptation has allowed to develop rice cultivars for other types of production systems: aerobic (moderately dry soil without flooding) and dry upland (dry soils without irrigation) environments (Bouman et al., 2005; Peng et al., 2006). Irrigated lowland rice is high yielding, but its production requires large amounts of water and will be particularly constrained by the increasing freshwater scarcity (Peng et al., 2009). Aerobic and upland rice grow under drier conditions but at the cost of different levels of yield penalties (Bouman et al., 2005). Nevertheless, the adaptation of rice ecotypes to these ranges of edaphic conditions indicates that rice has the potential to grow like dryland cereals, such as wheat (Triticum aestivum L.). Roots are the first organs to sense the dehydration of soil and thus play an important role in plant adaptation to water-deficit conditions (Zingaretti et al., 2013). Comparative studies on differences of root traits in response to water deficit among rice ecotypes and between different species will possibly identify the mechanisms required for developing water-deficit tolerant, yet high-yielding, rice varieties.

Rice and wheat root systems are mainly composed of nodal roots and extensively branched lateral roots (O'Brien, 1979; O'Toole and Bland, 1987). Nodal roots are important for anchoring plants in the soil (Krauss et al., 2003), acquiring water and nutrients, as well as transporting water and nutrients to the aerial parts (Steffens and Rasmussen, 2016), while lateral roots contribute to the adhesion of the nodal root to the rhizosphere and regulate nutrients (Ma et al., 2001) and water (Zhan et al., 2015) acquisition from the soil. Genetic variation in root biomass and root morphology under the exposure to water deficit across diverse rice germplasms is well documented (Kato et al., 2006; Henry et al., 2011; Kadam et al., 2015). But the key root traits that are involved in plant adaptation to soil water deficit for different species are not fully understood. 
The water uptake by roots involves first radial water transport from soil solution into root stele, and then axial water flow up into the shoot by through xylem vessels (Steudle and Peterson, 1998). Apoplastic transport and symplastic transport are the two main radial pathways for water movement into the root (Steudle and Peterson, 1998). Plasmodesmata facilitate symplastic paths and permit solutes to move between cells nonspecifically (Rutschow et al., 2011). Evidence suggests that the relative contribution of the apoplastic path to the overall hydraulic conductivity is higher than that of symplastic path in rice roots (Ranathunge et al., 2004). The hydraulic conductance of the apoplastic path is strongly affected by root anatomy (Steudle and Peterson, 1998; Zimmermann et al., 2000). Like those of many other wetland species, rice nodal roots are characterized by an extensive intercellular space (i.e. aerenchyma) in the root cortex (McDonald et al., 2002). Such anatomical features are considered to provide a low internal resistance for gas movement within the roots, thereby enhancing rice root aeration (Drew et al., 2000; Colmer, 2002; Suralta and Yamauchi, 2008). However, this system may be developed at the cost of reducing the space for the vascular transport system.

Xylem vessels act as a duct which collects and transports water and minerals within the root and from the root to the shoot, thus directly affecting root axial hydraulic conductance (Steudle and Peterson, 1998; Kim et al., 2014). The root axial conductance differences between species were related to differences in cross-sectional area of matured xylem (Bramley et al., 2009). Genetic variation for xylem vessel diameter and number has also been shown in rice (Henry et al., 2012; Uga et al., 2013; Hazman and Brown, 2018) and in wheat (Richards and Passioura, 1981; Wasson et al., 2012). Xylem vessel diameter and number can be affected by water deficit (Henry et al., 2012). It should be noted that while mature late metaxylem vessels in the basal parts transfer water and nutrients to the shoot, protoxylem and early metaxylem vessels function in the apical part of the roots, in land plants (Baluska et al., 1995). However, the existing literature on root responses to water-deficit stresses mostly focuses on late metaxylem, whereas the contribution of protoxylem and early metaxylem vessels has largely been overlooked (Henry et al., 2011; Kadam et al., 2015).

The exodermis and endodermis are the outermost and innermost layers of the root cortex (Peterson and Cholewa, 1998; Steudle and Peterson, 1998). Previous studies have documented that structural features on root exodermis and endodermis, i.e. Casparian bands, suberin lamellae, lignin deposition and tertiary walls, are finely tuned in response to water deficit (Enstone et al., 2002; Henry et al., 2012; Geldner, 2013; Tylová et al., 2017). A clear response is increased amounts of suberin and lignin, which form important components of endodermal 
cell walls (Henry et al., 2012; Lee et al., 2016; Ranathunge et al., 2017; Tylová et al., 2017; Kreszies et al., 2018). Suberization and lignification of root cell layers can restrict the movement of water into and within the root, mainly by reducing apoplastic transport (Ma and Peterson, 2003; Lynch et al., 2014). However, differences in cell wall modifications between rice and wheat and the genetic variation within those species when exposed to different levels of water deficit are still not known.

Like our previous study (Kadam et al., 2015), studies focusing on root traits in response to water deficit were commonly carried out for one single growth stage and/or a specific position of the root (Kashiwagi et al., 2006; Kano et al., 2011; Zhan et al., 2015; Prince et al., 2017). However, the sensitivity of rice plants to water-deficit might differ among developmental stages (Pantuwan et al., 2002; Centritto et al., 2009). Furthermore, root anatomical and histochemical properties are variable along spatially different root zones (Bramley et al., 2009; Kreszies et $a l ., 2018)$. An extended understanding of the functional role of root plasticity for rice and wheat plant adapting to water deficit stress would require a detailed study.

Our main hypothesis was that the requirement extensive aerenchyma in rice as a (semi-)aquatic plant may have pushed for a reduced vascular transport system, thereby impeding the axial water flow transport in the root cylinder. We further hypothesized that suberization and lignification of root cell layers and other anatomical features that influence the ability of radial water transport differ between rice and dryland cereals in response to water deficit. Both axial and radial transport capability, if reduced, would contribute to the reduced tolerance of rice when grown under water-deficit conditions. Hence, in this study, we evaluated differences in root growth, aerenchyma, xylem vessel development, and histochemical features (i.e. lignin and suberin), between three rice genotypes and two wheat genotypes grown under water-deficit treatments, at both vegetative and flowering stages.

\subsection{Materials and methods}

\subsubsection{Plant materials and treatments}

Three rice ( $O$. sativa L., subsp. indica) cultivars and two wheat (T. aestivum L.) cultivars were selected based on their tolerance to water deficit. Among the three rice cultivars, the highyielding lowland cv. IR 64-21 (IR64) is highly sensitive to water deficit (Venuprasad et al., 2008), the improved aerobic cv. NSIC Rc9 (Apo) is moderately tolerant to water deficit (Venuprasad et al., 2007), and the improved upland cv. UPL Ri7 (UPL7) is tolerant to drought 
(Atlin et al., 2006). Wheat cultivar SeriM82 (S82) is moderately susceptible (Pfeiffer 1988) to tolerant (Villareal et al., 1995), while wheat cv. Weebill4 (We4) is highly tolerant (Praba et al., 2009), to water deficit. Seeds of rice and wheat were obtained from the International Rice Research Institute (IRRI) and from the International Maize and Wheat Improvement Center (CIMMYT), respectively.

Pot experiments were carried out in an open field, which was sheltered from rain by a mobile transparent polyethylene shelter, at Yangzhou University, China $\left(32^{\circ} 30^{\prime} \mathrm{N}, 119^{\circ} 25^{\prime} \mathrm{E}\right)$. Each pot (30 cm in height and $25 \mathrm{~cm}$ in diameter) was filled with sandy loam soil from a local rice/wheat rotated field. Rice and wheat seeds were sown in their natural growth season (Table 3.1). Plants were managed as described by Ouyang et al. (2017). Three levels of soil moisture were imposed after seedling establishment, i.e. control (CT), mild drought (MD), and more severe drought (SD). Across species and treatments, three replications were maintained and placed in a completely randomized design. Because rice and wheat are naturally adapted to different moisture environments (Praba et al., 2009), different intensities of stress were imposed (Table 3.1). Soil water potential was monitored with a tensiometer (Institute of Soil Sciences, Chinese Academy of Sciences, Nanjing, China) installed in each pot at a depth of $15 \mathrm{~cm}$. We checked the tensiometer twice a day, and water was added to bring soil moisture back to the upper limit of the target stress when tensiometer readings reached the lower limit. Once stress was imposed, the target levels were maintained until all measurements were completed. Leaf water potential at midday (13:00-15:00 h) was measured at vegetative and flowering stages to monitor the stress level the plants were actually experiencing (Table S3.1). Three topmost fully expanded leaves of the main stems were chosen, and three to four discs (about $6 \mathrm{~mm}$ in diameter) from the middle part of the leaves were cut and sealed in the C-52 thermocouple psychrometer (Wescor PSYPRO, Inc., Logan, UT, USA). The readings were recorded by a water potential data logger in the psychrometric mode, and the average value from the same plant was considered to represent leaf water potential.

\subsubsection{Root sample preparation}

Roots were sampled at vegetative and flowering stages. Because rice and wheat have different growth durations, rice samples for the vegetative stage were taken after 30 days, while wheat roots were taken after 20 days, of stress imposition. The root systems were washed from soil over a 1-mm sieve to minimise the loss of fine roots. Except for a few nodal roots used for cross-section samples (see below), all whole-plant root samples were stored in $70 \%$ alcohol at 
Rice and wheat root anatomy and histochemistry

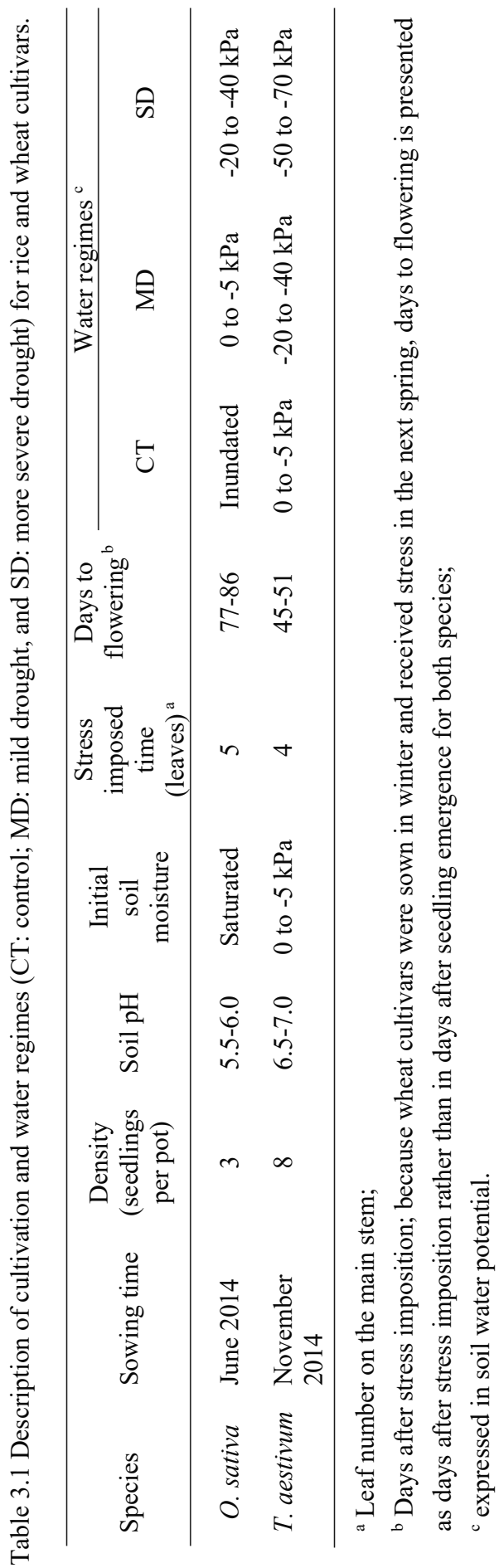


$4{ }^{\circ} \mathrm{C}$ to analyze root morphology by scanning image analyses.

To make a meaningful comparison between rice and wheat, nodal roots were used for anatomical and histochemical measurements. Three to five healthy nodal roots $(30-35 \mathrm{~cm}$ long for wheat, and 35-40 cm long for rice) per replicate per treatment were selected and excised at the root-shoot junction and stored in $25 \%(\mathrm{v} / \mathrm{v})$ alcohol. Three segments (each $\sim 10 \mathrm{~mm}$ long) were obtained from three different positions along the excised nodal root: (1) 10-20 mm below the root-shoot junction; (2) three-quarters (3/4) of the root between the root-shoot junction and root apex; and (3) 30-40 mm above the root apex (Fig. 3.1A). Excised segments were embedded in 5\% low melting point agarose. Cross-sections were prepared by cutting those agarose blocks using a vibrating microtome (ZQP-86, Zhisun, Shanghai, China). Multiple transverse sections per segment were stored in 50\% (v/v) alcohol and washed several times with deionized water before being used for anatomical and histochemical analysis.

Samples for scanning were cut to fit the scanner tray and meticulously separated in water to avoid overlapping. An 8-bit grayscale image acquired at a resolution of 600 dots per inch with a flat image scanner (Epson Expression 1680 Scanner, Seiko Epson Corp., Tokyo, Japan) was analyzed for root length by using the WinRHIZO Root Analyzer System (Regent Instruments Inc., Quebec, Canada). Roots were classified by WinRHIZO according to their diameters. A diameter of $0.2 \mathrm{~mm}$ was designated as the threshold used to distinguish between thick and fine roots (Henry et al., 2011; Kato and Okami, 2011). The fine to thick root length ratio then could be determined. Scanned root samples were oven-dried at $70^{\circ} \mathrm{C}$ to constant weight and root dry mass was determined.

\subsubsection{Root anatomy}

Cross-sectional images were analyzed by using ImageJ software (Bethesda, Maryland, USA) (Abràmoff et al., 2004). All anatomical properties such as cross sectional area, stele area, aerenchyma area, thickness of the inner tangential wall of endodermal cell, number and total cross sectional area of early metaxylem, and number and total cross sectional area of late metaxylem were determined in three to five sections per root segment. Note that water and minerals are absorbed into protoxylem vessels and then are transported upwards through early and late metaxylem (Kim et al., 2014). It was difficult to identify the protoxylem in our light microscopy images, and thus we investigated the properties of early metaxylem and late metaxylem. Stele area and aerenchyma area in proportion to cross sectional area, as well as 
A.

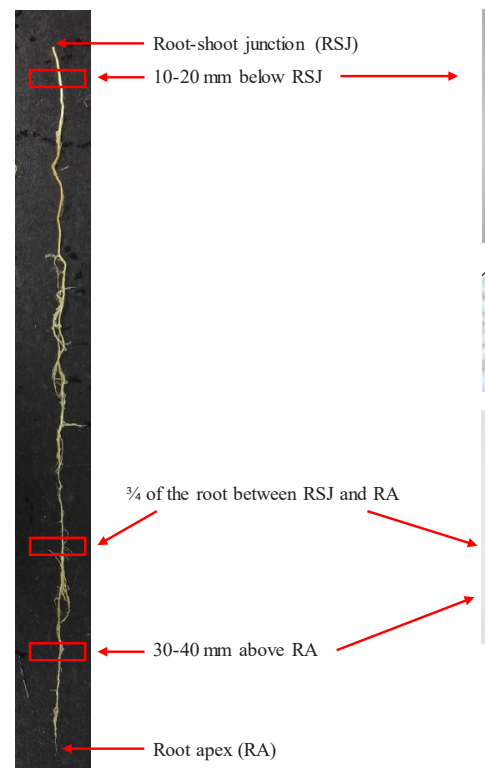

B.
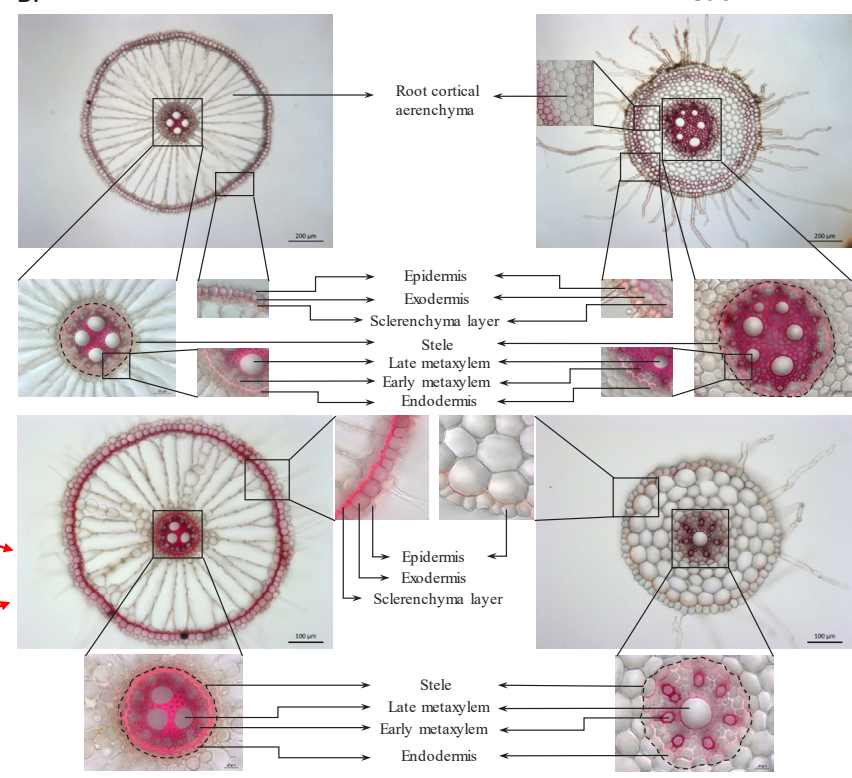

Fig. 3.1 Illustrations of (A) three sectioning positions along the root, and (B) root anatomical properties of rice and wheat with different cross-section structures. Sections stained with phloroglucinol- $\mathrm{HCl}$ and viewed under white light.

averaged area of early metaxylem and late metaxylem were calculated from these data. A schematic sketch of measured anatomical properties is provided in Fig. 3.1B.

\subsubsection{Histochemical detection of suberin and lignin}

Suberin lamellae in root tissues were detected by staining cross-sections at $70{ }^{\circ} \mathrm{C}$ for 10 minutes with a saturated solution of Sudan III (Merck, Darmstadt, Germany) dissolved in ethanol/water $(1: 1 ; \mathrm{v} / \mathrm{v})$, according to Gerlach (1984). Suberin lamellae were recognized by orange colour under bright-field illumination (Axio Imager D2, Carl Zeiss, Germany). Lignin deposition in cross-sections was detected by staining for several minutes with phloroglucinol/ $\mathrm{HCl}$ at room temperature (Jensen, 1962). Transverse sections were mounted in a mixture with $10 \%(\mathrm{v} / \mathrm{v})$ $\mathrm{H}_{2} \mathrm{SO}_{4}$ in $75 \%$ (v/v) glycerol to prevent colour fading. Lignified tissues were viewed as bright red/pink under bright-field illumination (Axio Imager D2, Carl Zeiss, Germany). Suberization and lignification of exodermis and endodermis were assessed for 3-5 roots per replicate. A scoring system similar to the one described by Enstone and Peterson (2005) was used to characterize suberin and lignin deposition in exodermis and endodermis: " 0 " represented no suberin or lignin staining (no detectable suberin lamella and lignin deposition); "1" to " 3 " 
represented slight to moderate suberin or lignin staining; and " 4 " to " 5 " represented strong to very strong suberin or lignin staining.

\subsubsection{Theoretically calculated axial conductance}

Theoretical axial conductance $\left(k_{\mathrm{h}} ; \mathrm{mg} \mathrm{m} \mathrm{MPa} \mathrm{m}^{-1} \mathrm{~s}^{-1}\right)$ was calculated with the modified HagenPoisseuille's law described by Tyree and Ewers (1991):

$$
k_{\mathrm{h}}=\left(\frac{\pi \rho}{128 \eta}\right) \sum_{i=1}^{n}\left(d_{i}^{4}\right)
$$

where $d_{\mathrm{i}}$ is the diameter of the $i$ th xylem vessel in meters, $\rho$ is the fluid density (assumed to be $1 \times 10^{9} \mathrm{mg} \mathrm{m}^{-3}$ ) and $\eta$ is the viscosity (assumed to be $1 \times 10^{-9} \mathrm{MPa} \cdot \mathrm{s}$ ).

\subsubsection{Statistical analyses}

To test the significance for the effects of cultivar, treatment, stage and their interactions on each parameter, data was statistically analyzed using a general linear model (GLM) with the R programming language (http://www.R-project.org/). Root position was included as an additional factor in the analysis of root anatomical and histochemical parameters. For these parameters, values of 3-5 nodal roots per replicate were averaged for the GLM analysis.

\subsection{Results}

Midday leaf water potential ( $\left.\Psi_{\text {leaf }}\right)$ varied largely between rice and wheat, with wheat having a significantly higher $\Psi_{\text {leaf }}$ than rice (Table S3.1). Across stages, both species had a lower $\Psi_{\text {leaf }}$ under water deficit treatments, although the MD treatment imposed to wheat was comparable to the SD treatment imposed to rice (Table S3.1). These data indicated the actual level of stress experienced by plants, with which we investigated root anatomical, histochemical and morphological traits.

\subsubsection{Root cross-section structures}

Root transversal structures were similar among cultivars within each species but differed between species (Fig. 3.2 and Fig. S3.1). In rice, the outer cell layers of all root cross-sections contained exodermis and a tightly packed sclerenchyma layer cells between the exodermal and cortex cells (Figs. 3.1 and 3.2; Figs. S3.1, S3.2 and S3.3). In wheat, exodermis and sclerenchymatous cells (two or three layers) were only detected in the cross-sections near the root-shoot junction but not at the two lower positions (Figs. 3.1 and 3.2; Figs. S3.1, S3.2 and 


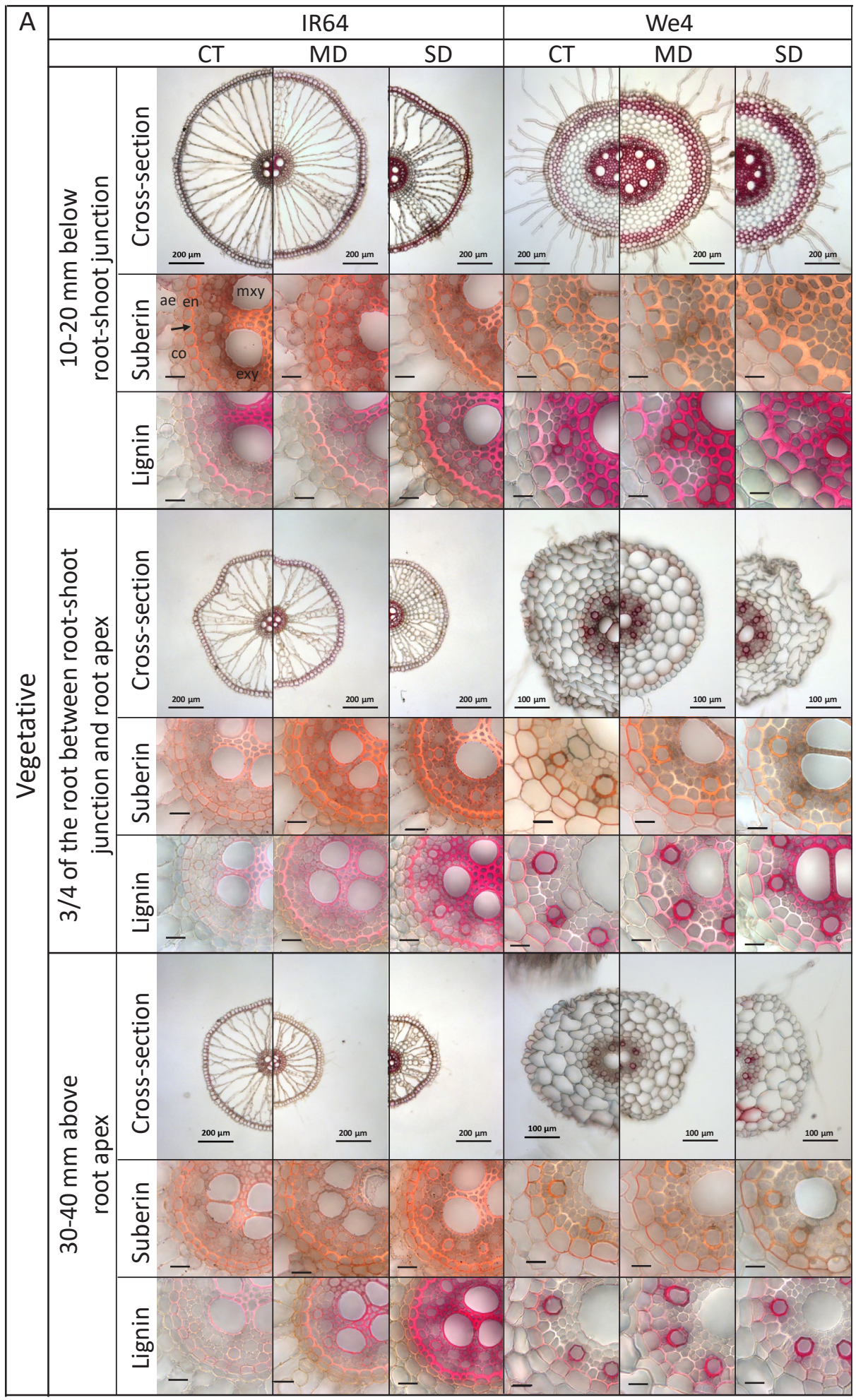




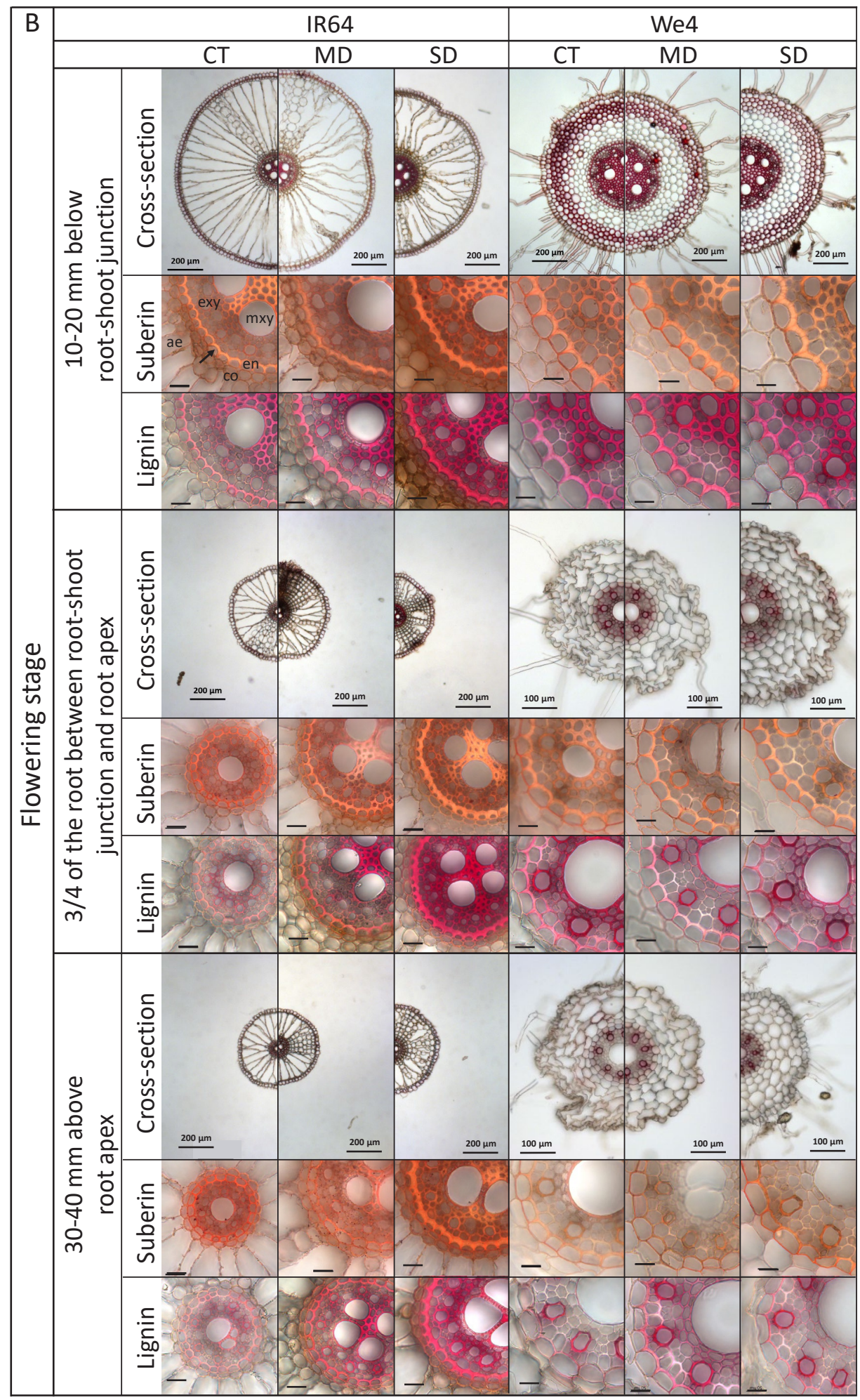


Fig. 3.2 Light microscopy images of nodal roots for the representative genotypes, cv. IR 64 for rice and cv. We4 for wheat, grown under control (CT), mild drought (MD), and more severe drought (SD) conditions. Root segments were sampled at 10 to $20 \mathrm{~mm}$ below root-shoot junction, 3/4 of the root between root-shoot junction and root apex, and 30 to $40 \mathrm{~mm}$ above root apex, at (A) vegetative and (B) flowering stages. Cross-section, suberin and lignin deposition pattern in the inner part of the root were presented. ae, aerenchyma; co, cortical cells; en, endodermis; mxy, late metaxylem; exy, early metaxylem. Each scale bar represents $100 \mu \mathrm{m}$ for wheat cross-section images at 3/4 of the root between root-shoot junction and root apex and 30 to $40 \mathrm{~mm}$ above root apex, and $200 \mu \mathrm{m}$ for other cross-section images. Each scale bar represents $20 \mu \mathrm{m}$ for suberin and lignin deposition images. Images for all genotypes are shown in Supplementary Fig. S3.1.

Fig. 3.3 Response of aerenchyma percentage of root cortex area along nodal roots of rice and wheat to water treatments: control (CT), mild drought (MD), and more severe drought (SD). Root cross-sections were taken at (A) 10 to $20 \mathrm{~mm}$ below root-shoot junction, (B) $3 / 4$ of the root between root-shoot junction and root apex, (C) 30 to $40 \mathrm{~mm}$ above root apex, at vegetative and flowering stages. Bars represent standard errors of the mean for three replicates. Due to the large differences of the aerenchyma area and in proportion to the root cortex area between rice and wheat cultivars, data for wheat are shown in insets.
Aerenchyma (\%)
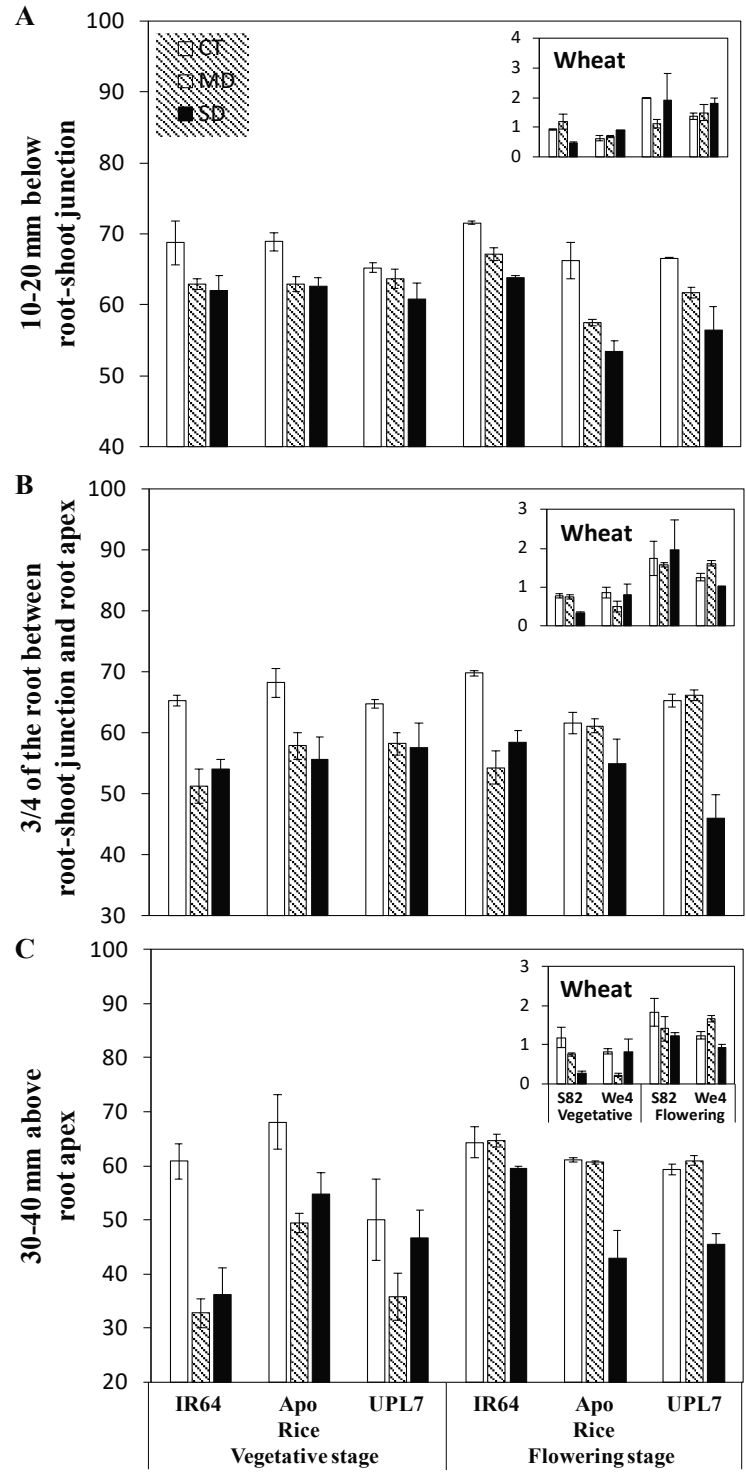
S3.3). The cortex of rice root contained a large proportion of intercellular spaces (aerenchyma), even under water-deficit treatments (Fig. 3.3 and Fig. S3.1). However, there was virtually no aerenchyma area in any root sections of wheat. At the vegetative stage, a negative effect of water-deficit stress on the formation of aerenchyma was detected in rice cultivars across all three positions (Fig. 3.3 and Fig. S3.4). At the flowering stage, the formation of aerenchyma at the position near the root-shoot junction in all rice cultivars was significantly reduced under both water-deficit treatments $(P<0.001$ for MD and SD; Fig. 3.3A). However, the formation of aerenchyma at the two lower sectioning positions was affected by $\operatorname{SD}(P<0.001)$ but not by MD $(P>0.05)$ (Fig. 3.3B, C).

Rice had significantly larger $(P<0.001)$ root cross sectional area than wheat, regardless of cultivar, position and stage (Fig. 3.4A-C and Fig. S3.1). Compared with the vegetative stage, the cross sectional area at the flowering stage was lower in all rice cultivars at all three positions but was relatively consistent (S82) or increased (We4) in wheat (Fig. 3.4A-C). The cross sectional area in rice was reduced by water-deficit treatments $(P<0.001)$, and the reduction was less at 10-20 mm below root-shoot junction (up to $18 \%$ decrease under the SD condition) than at the other two positions (up to $55 \%$ decrease under the SD condition) (Fig. 3.4A-C). Furthermore, the treatment effect on cross sectional area in rice was stronger at the vegetative than at the flowering stage (Fig. 3.4A-C). Conversely, water-deficit treatments significantly increased the cross sectional area at $10-20 \mathrm{~mm}$ below the root-shoot junction in both wheat cultivars at the vegetative stage, as well as in S82 at the flowering stage (Fig. 3.4A). Waterdeficit treatments did not significantly affect cross sectional area at the other positions in wheat at both stages (Fig. 3.4B, C).

Wheat had a much higher stele area than rice, especially at 10-20 mm below root- shoot junction (Fig. 3.4D-F). In each species, cultivars with larger root cross sectional area under control and water-deficit conditions also showed larger stele areas. This trend was confirmed by the significant positive correlation between root cross sectional area and stele area under each treatment at all positions (data not shown). Furthermore, an increasing trend in stele area under water-deficit conditions across positions and stages was observed in both species, although the trend was more clear in wheat roots (Fig. 3.4D-F ).

Across positions, stages and treatments, the stele area to root cross sectional area ratio was significantly higher in wheat than in rice (Fig. 3.4G-I). In both species, water-deficit treatments had a significant, positive effect on the ratio across all three positions, with a higher increase of 

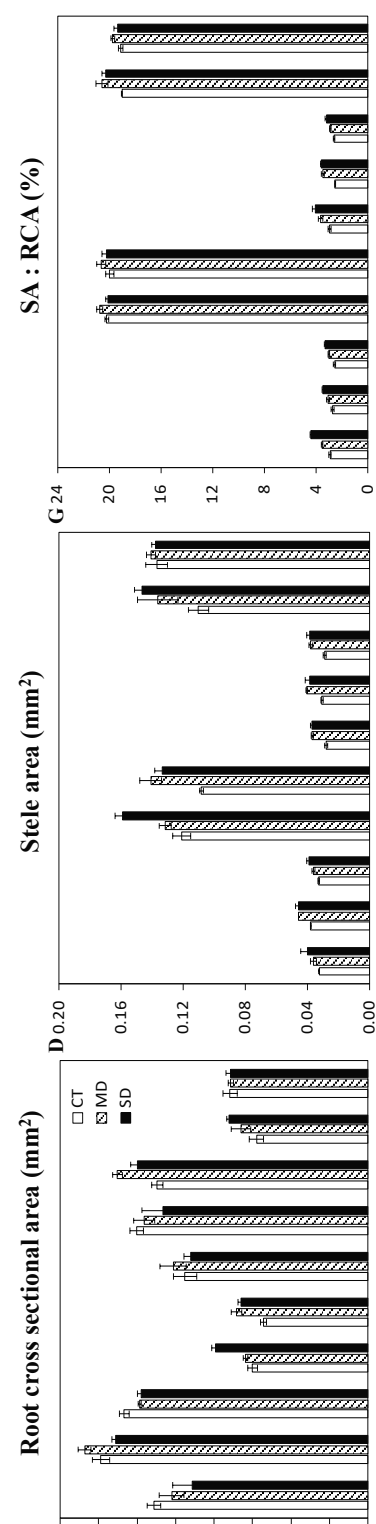

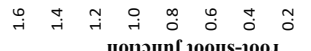
uo!̣oun! 1004s-100. морәq шu 0z-0 I
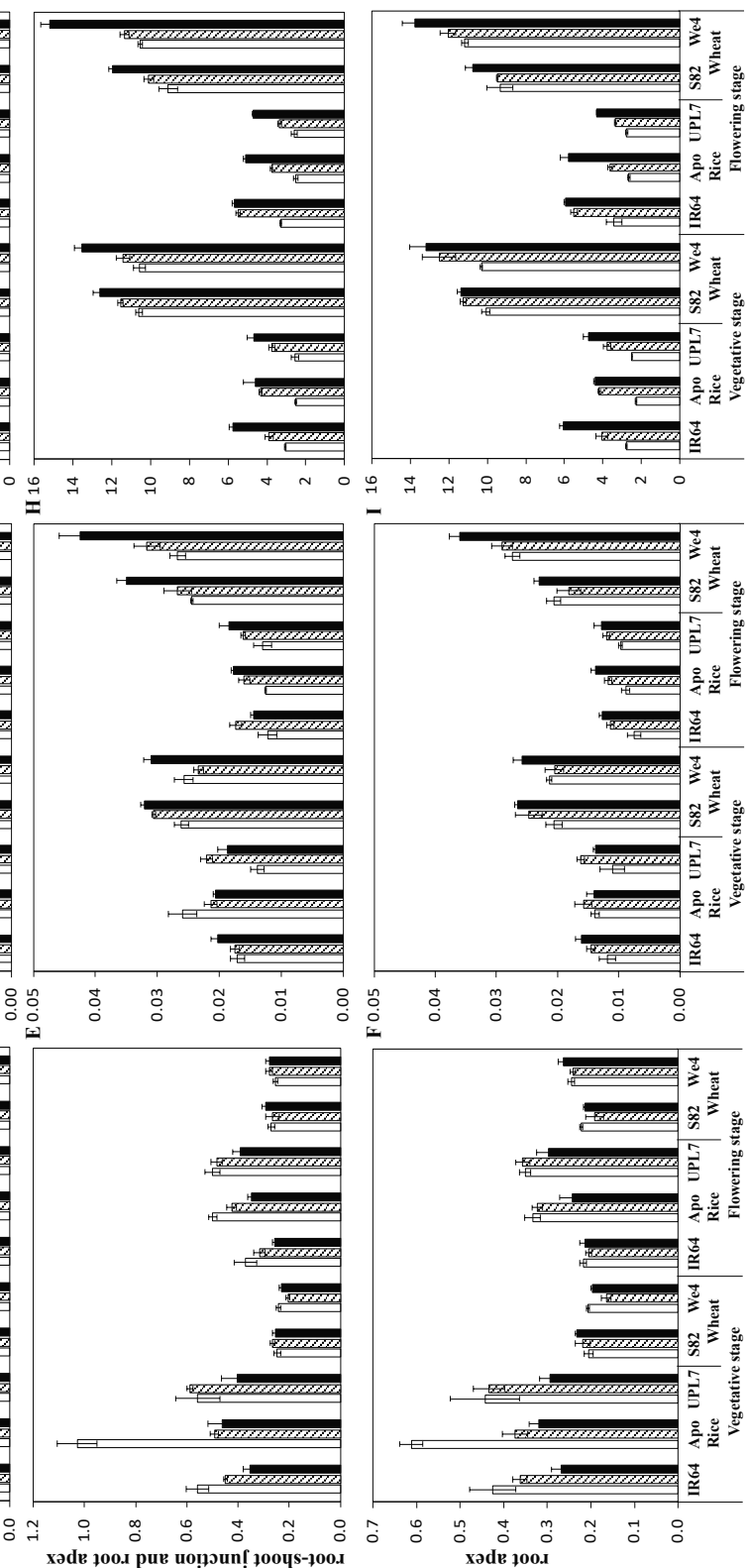

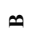

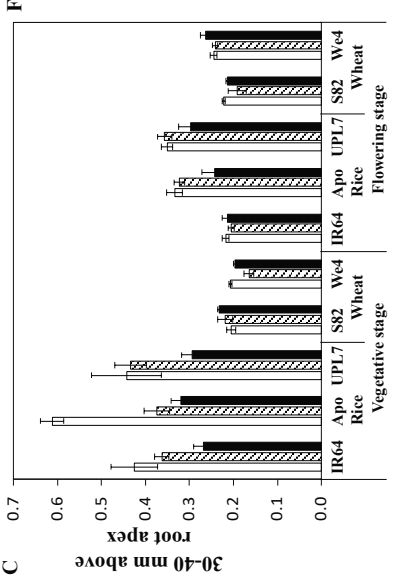

$4 \div$

늉으

00

त्वृ

\& $<$

of

त

娄

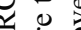

$\ddot{\vec{\Delta}}$

零

을

컨 苟导

ॠ

t)

当

$\vec{\circ}$

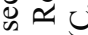

岂唡㐫

0 产

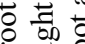

$\vec{\partial}$

은

एँ

$\div$ 远

के

휳

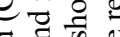

चै का

ชิ

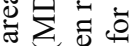

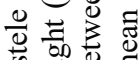

Iิ

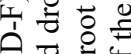

글

ฮే छี

崖范

可元

m

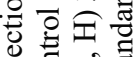

क 다 뙤

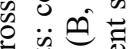

ठ웜

응 छี

(ิ)

政

渮的

ษ

牙

월

व 3

$\checkmark \tau 0$

ণ $\Xi$ छ

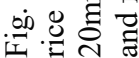


the ratio under water-deficit treatments in rice (up to 119\%) than in wheat (up to $31 \%$ ) (Fig. 3.4G-I). Additionally, the increase in the ratio at the two lower positions was stronger than that near the root-shoot junction in all cultivars of both species at both stages (Fig. 3.4G-I).

\subsubsection{Modifications of the endodermis}

Endodermis is the connection between root cortical cells and stele (Fig. 3.1B). Three consecutive developmental stages of endodermis can be distinguished: (i) primary stage during which endodermal cell walls are impregnated with Casparian bands; (ii) secondary stage characterized by the uniform deposition of a thin suberin lamella to the inner surface of radial and tangential walls of the endodermal cells; and (iii) the tertiary stage with heavy U-shaped cell wall deposition on the inner tangential cell walls of the endodermal cells (Schreiber et al., 1999). Under the CT condition, the endodermis at 10-20 mm below the root-shoot junction in both species was in the tertiary stage whereas the endodermis at the two lower positions was in the secondary stage (Fig. 3.2, Figs. S3.2 and S3.3). Wheat showed a significantly thicker inner tangential wall of the endodermis than rice $(P<0.001)$ under the CT condition, especially at the root-shoot junction (Fig. 3.5, Figs. S3.2 and S3.3). Under water-deficit conditions, a transformation of the endodermis from secondary to tertiary stage at the two lower positions was observed in rice but not in wheat (Fig. 3.2 and Fig. S3.2). Water deficit significantly thickened the inner tangential wall of the endodermis in all root positions in all rice cultivars, but the thickening was less marked in UPL7 (Fig. 3.5). Higher degree of thickening at the two lower positions (up to $183 \%$ increase under the SD condition) than at the root-shoot junction (up to $80 \%$ increase under the SD condition) was observed in rice. Furthermore, a greater treatment-induced thickening of the inner tangential wall in rice was observed at flowering (up to $183 \%$ increase under the SD condition) than that at the vegetative stage (up to $139 \%$ increase under the SD condition) (Fig. 3.5). On the other hand, water-deficit treatments did not induce remarkable changes on the thickness of the inner tangential wall at any position of wheat root $(P>0.05$; Fig. 3.5, Figs. S3.2 and S3.3). It is noteworthy that, wheat maintained a thinner inner tangential wall than rice at the two lower root positions under both water-deficit treatments (Fig. 3.5, Figs. S3.2 and S3.3).

\subsubsection{Early metaxylem and late metaxylem}

The early and late metaxylem vessels were well lignified in rice at all positions and both stages, even under the CT condition (Fig. S3.3). At 30-40 mm above the apex of wheat roots, the early 
Fig. 3.5 Response of the thickness of the inner tangential wall of the endodermis along nodal roots of rice and wheat to water treatments: control (CT), mild drought (MD), and more severe drought (SD). Root cross-sections were taken at (A) 10 to $20 \mathrm{~mm}$ below root-shoot junction, (B) 3/4 of the root between root-shoot junction and root apex, (C) 30 to $40 \mathrm{~mm}$ above root apex, at vegetative and flowering stages. Bars represent standard errors of the mean for three replicates.

metaxylem was well lignified but the central late metaxylem was not, indicating the immaturity of the late metaxylem vessels (Fig. S3.3).

The early metaxylem number was not strongly variable among species (Fig. S3.5AC). Across positions and stages, water-deficit treatments did not induce a clear effect on the early metaxylem number in both species (Fig. S3.5A-C). The total early metaxylem area was two to four times larger in wheat than in rice, regardless of sectioning positions, stages and treatments (Fig. 3.6A-
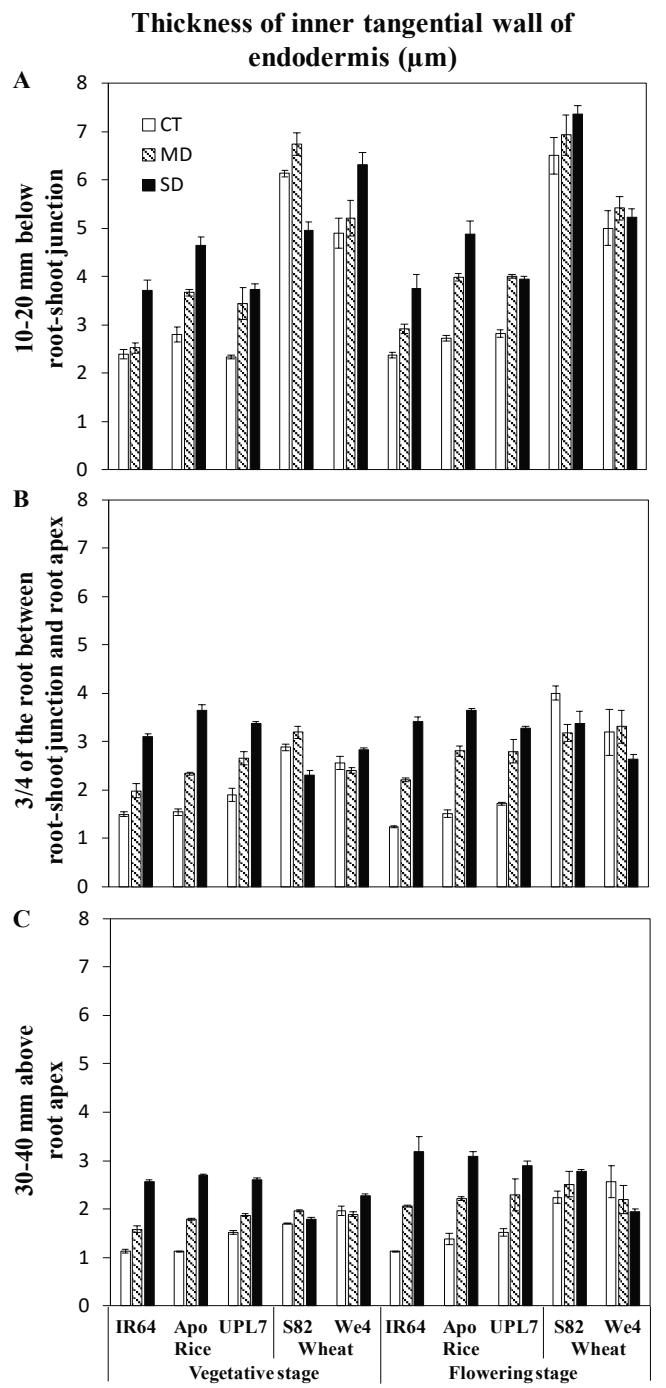
C). Water deficit increased the total early metaxylem area in both species (Fig. 3.6A-C). Averaged area per early metaxylem, an indicator of the size of individual early metaxylem, was calculated as the total area by the number of early metaxylem vessels. Under all growing conditions, wheat had a significantly higher averaged area per early metaxylem than rice, and the difference was larger at the two lower positions (Fig. S3.5D-F). In both species, water deficit increased the averaged area per early metaxylem across positions and stages (Fig. S3.5D-F). As expected, the calculated axial conductance of early metaxylem (Fig. S3.6A-C) followed a similar pattern as the total early metaxylem area (Fig. 3.6A-C). Water deficit treatments increased the axial conductance of early metaxylem in both species, with a higher increase at the two lower positions (up to $177 \%$ under 
the SD condition) than that at $10-20 \mathrm{~mm}$ below the root-shoot junction in wheat (up to $87 \%$ under the SD condition) but not in rice (Fig. S3.6A-C).

The late metaxylem number was significantly higher at the $10-20 \mathrm{~mm}$ below root-shoot junction in wheat, but much lower at the two lower positions than in rice (Fig. S3.5G-I). Water-deficit
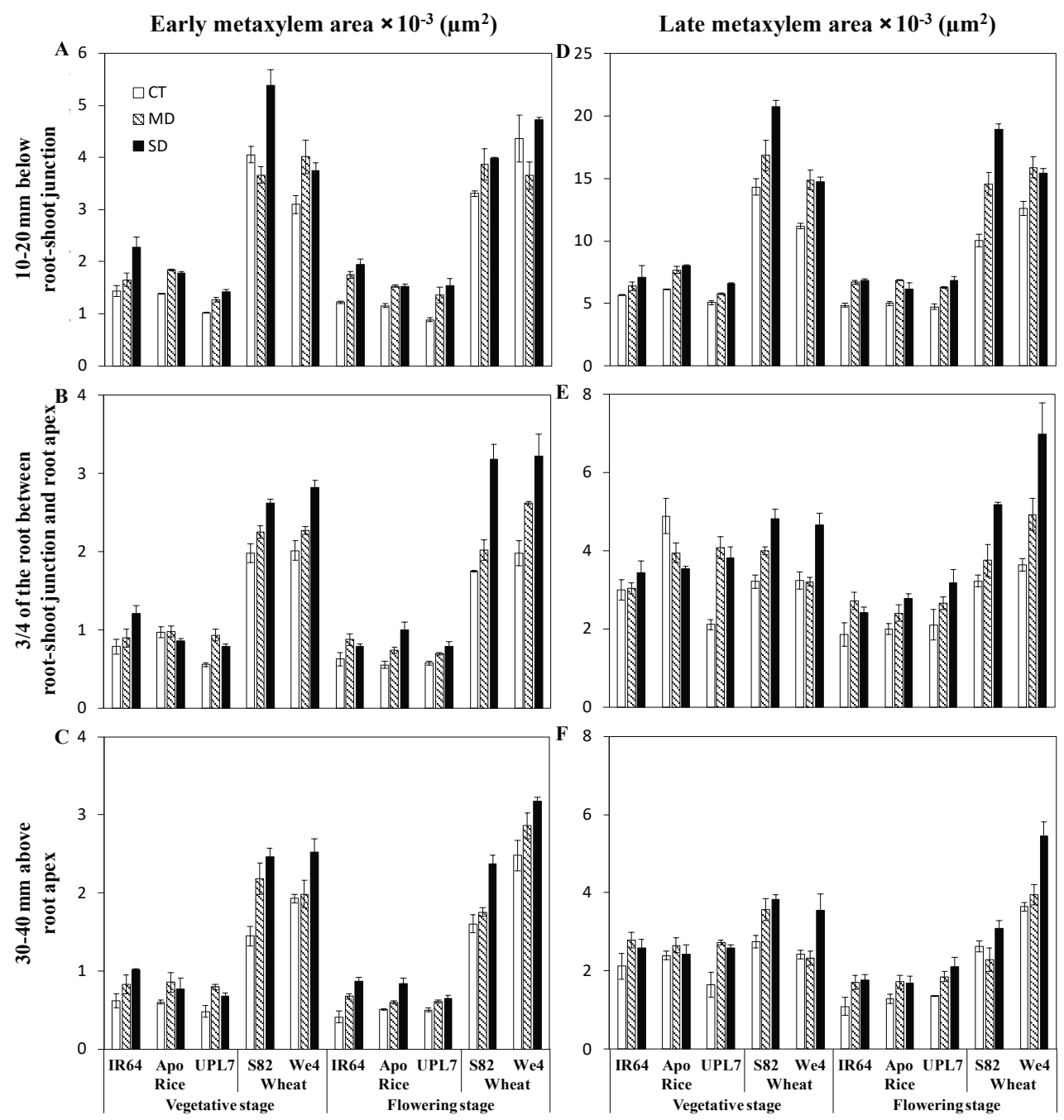

Fig. 3.6 Response of (A-C) early metaxylem area, and (D-F) late metaxylem area along nodal roots of rice and wheat to water treatments: control (CT), mild drought (MD), and more severe drought (SD). Root cross-sections were taken at (A, D) 10 to $20 \mathrm{~mm}$ below root-shoot junction, (B, E) 3/4 of the root between root-shoot junction and root apex, and (C, F) 30 to $40 \mathrm{~mm}$ above root apex, at vegetative and flowering stages. Bars represent standard errors of the mean for three replicates. 
treatments did not induce a clear pattern of late metaxylem number across positions in both species, except for an increase in the late metaxylem number at the 10-20 mm below root-shoot junction in wheat (Fig. S3.5G-I). In general, the total late metaxylem area was higher in wheat than in rice at all three positions, and the difference was much larger at the 10-20 mm below root-shoot junction (Fig. 3.6D-F). Across stages, water-deficit treatments induced a clear increase in the total late metaxylem area at the 10-20 mm below root-shoot junction in rice and at all three positions in wheat (Fig. 3.6D-F). The averaged area per late metaxylem, as a measure of the individual late metaxylem size, was obtained from total late metaxylem area and number. Compared to rice, wheat had a significantly higher averaged area per late metaxylem $(P<0.001)$ at all positions (Fig. S3.5J-L). No clear pattern of the averaged area per late metaxylem was observed with water-deficit exposure in both species (Fig. S3.5J-L). Across positions and stages, wheat had a significantly higher calculated axial conductance of late metaxylem than rice (Fig. S3.6D-F). Water-deficit treatments increased the axial conductance of late metaxylem at the two upper positions in most cultivars (Fig. S3.6D, E). However, a clear pattern was not observed at 30 to $40 \mathrm{~mm}$ above root apex (Fig. S3.6F).

\subsubsection{Suberin and lignin deposition}

In the outer cell layers, suberin and lignin deposition was mainly observed in the sclerenchyma layer in all rice cross sections, and in the sclerenchyma layers and exodermal cells in wheat at 10-20 mm below the root-shoot junction (Figs. S3.2 and S3.3). In both species, the suberin and lignin deposition in endodermal cells varied significantly with cultivar and position along the root (Table S3.2, Figs. S3.2 and S3.3). Under the CT condition, the degree of suberization and lignification in the endodermis at 10-20 mm below the root-shoot junction was higher than that at the two lower positions in both species (Figs. 3.2 and 3.7, Figs. S3.2 and S3.3), with wheat showing a greater difference. A significant species $\times$ treatment effect $(P<0.001)$ was observed for the degree of suberization. In rice, water-deficit stress significantly increased the suberization of endodermis $(P<0.001)$, with significant interaction between treatment and position $(P<0.001)$, between cultivar and treatment $(P<0.001)$, but no significant interaction between treatment and stage $(P>0.05)$ (Fig. S3.2 and Table S3.2). Particularly, the increase in the suberization under water-deficit treatments was much larger at the two lower positions than at the root-shoot junction (Figs. 3.2 and 3.7A-C, Fig. S3.2). Furthermore, water-deficit induced changes on the degree of lignification of endodermal cells in rice was similar as that on the degree of suberization of endodermal cells (Figs. 3.2 and 3.7D-F, Fig. S3.3). Also, a 
significantly lower increase of suberization and lignification was observed in UPL7, compared to other rice cultivars (Fig. 3.7, Figs. S3.2 and S3.3). However, the water-deficit treatment effect on suberization and lignification of endodermis was not prominent in wheat at both stages (Figs. 3.2 and 3.7, Figs. S3.2 and S3.3).

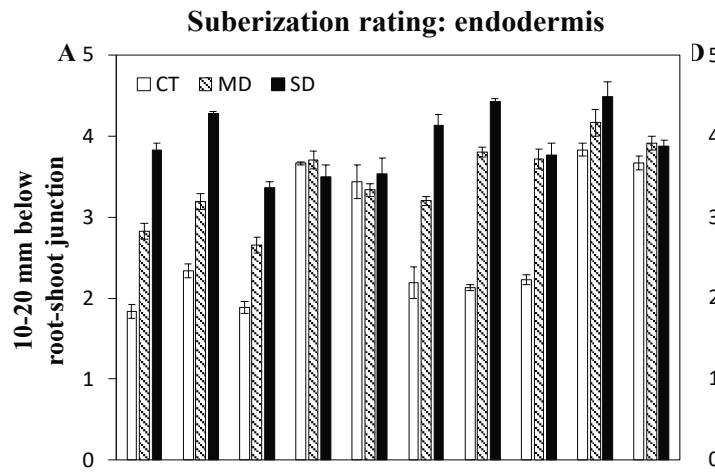

Lignification rating: endodermis
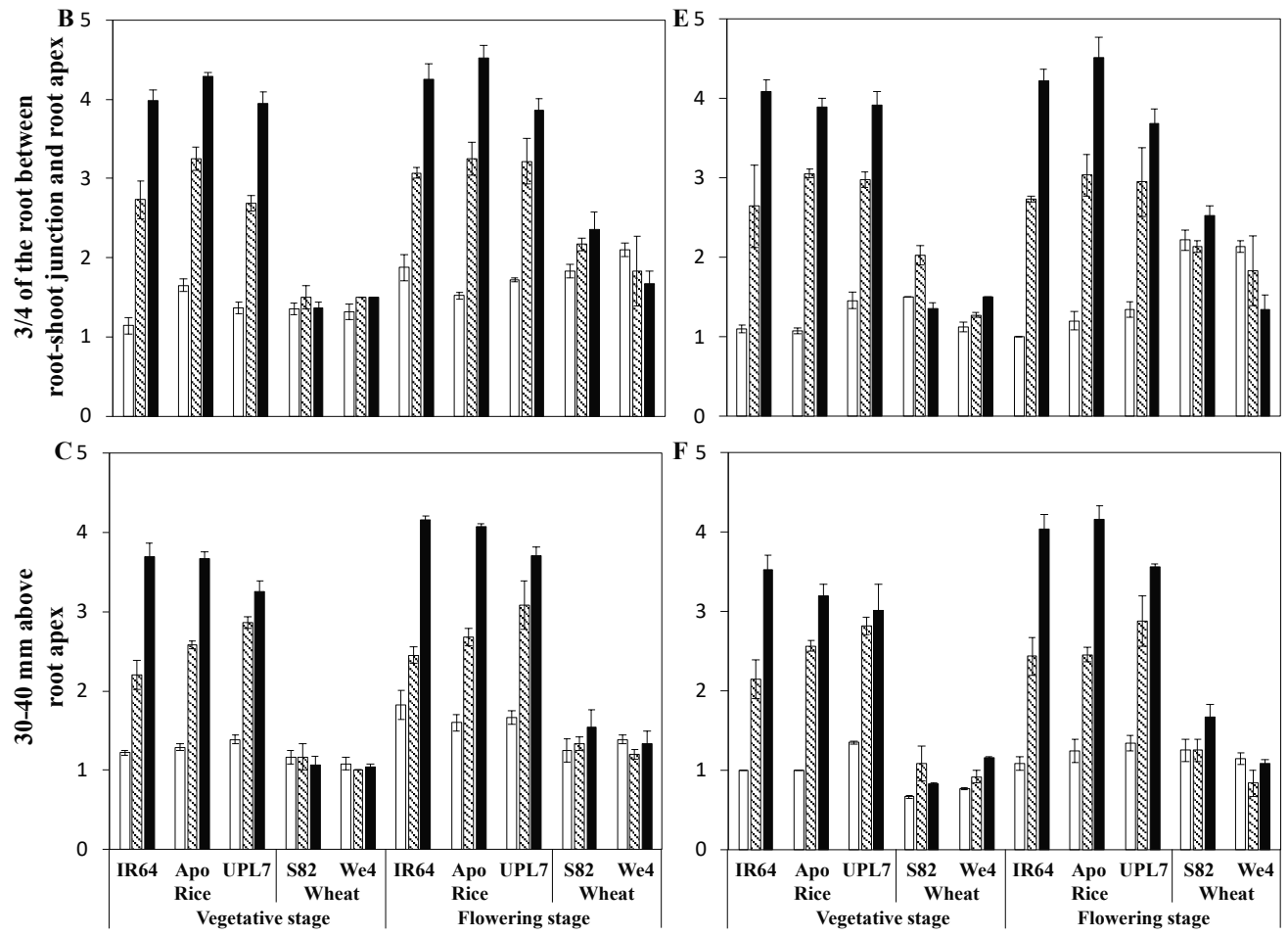

Fig. 3.7 Response of (A-C) suberin and (D-F) lignin deposition rating value of root endodermis along nodal roots of rice and wheat to water treatments: control (CT), mild drought (MD), and more severe drought (SD). Root cross-sections were taken at (A, D) 10 to $20 \mathrm{~mm}$ below root-shoot junction, (B, E) $3 / 4$ of the root between root-shoot junction and root apex, and (C, F) 30 to $40 \mathrm{~mm}$ above root apex, at vegetative and flowering stages. Bars represent standard errors of the mean for three replicates. 


\subsubsection{Root morphology}

Significant variation in root biomass and in total root length per plant was observed among species $(P<0.001)$, and rice had much higher root biomass and root length than wheat at both stages (Fig. 3.8A, B). A significant species $\times$ treatment effect $(P<0.001)$ was observed for root biomass and root length (Table S3.3). Water deficit significantly decreased root biomass and length in all rice cultivars, with a reduction of up to $60 \% / 48 \%$ (vegetative/flowering) of root biomass and up to $78 \% / 68 \%$ (vegetative/flowering) of root length by the SD condition (Fig. 3.8A, B). Lower biomass and shorter length were observed under water-deficit conditions in lowland rice cultivar IR64, compared with the other two cultivars. The highest reduction of root biomass in wheat was $34 \%$, recorded in We4 under the SD condition at the flowering stage. Furthermore, water deficit only had a small effect $(0.05<P<0.1)$ on root length for wheat cultivars, except for We4 under the SD condition (32\% reduction) at the flowering stage.

Fine-to-thick root length ratio is a proxy for the lateral to nodal root length ratio. The fine-to-thick root length ratio varied significantly among species, with rice having a significantly higher ratio than wheat (Fig. 3.8C). A significant species $\times$ treatment $\times$ stage effect $(P<0.01)$ on this ratio was observed. Across all rice

Fig. 3.8 Response of root morphological parameters of rice and wheat cultivars to water treatments: control (CT), mild drought (MD), and more severe drought (SD). (A) Root biomass, (B) root length, and (C) fineto-thick root length ratio, at vegetative stage and flowering stage. Bars represent standard errors of the mean for three replicates.
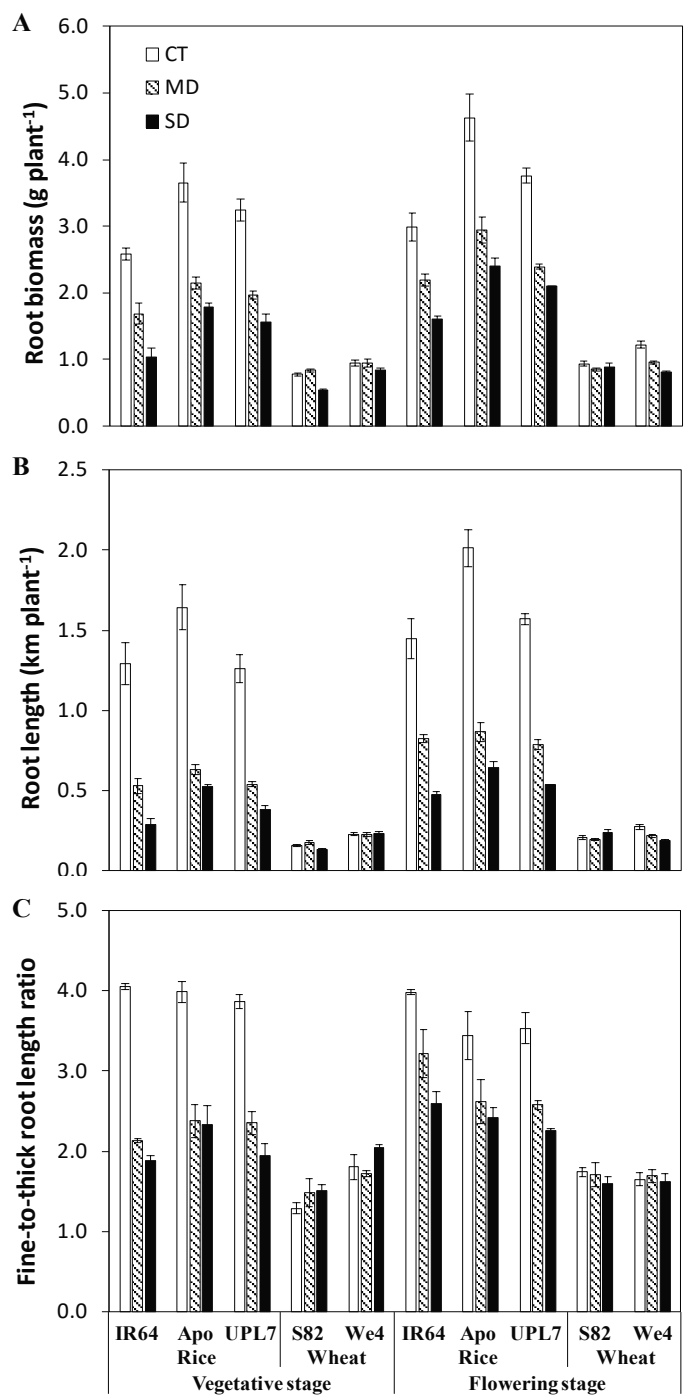
cultivars, water-deficit stress significantly decreased this ratio $(P<0.001)$, with a larger reduction at the vegetative stage (up to 54\%) than that at the flowering stage (up to 36\%) (Fig. 3.8C). However, the ratio in wheat was not significantly affected by water-deficit treatments $(P>0.05$; Table S3.3).

\subsection{Discussion}

\subsubsection{The attributes of rice root may have pushed for a reduced axial transport capacity}

Root aerenchyma is commonly formed in wetland species (Drew et al., 2000; Vysotskaya et al., 2004; Abiko et al., 2012; Argus et al., 2015), to enable an efficient supply of oxygen to roots when plants grow under hypoxic conditions (Suralta and Yamauchi, 2008). This was confirmed by our data for the large cortex area with a high proportion of aerenchyma in rice root (Figs. 3.2 and 3.3; Figs. S3.1 and S3.4). A reduced but yet high proportion of aerenchyma has been observed in water-limited rice roots (Fig. 3.3), confirming the result of Suralta and Yamauchi (2008).

The root cross sectional area depends on the area of its cortex as well as the size of the stele. However, compared to wheat roots, the larger root cross sectional area in rice was only linked to the larger cortex area which was composed of a high proportion of aerenchyma, since rice roots had a much lower stele area at all positions than wheat roots (Figs. 3.3 and 3.4; Fig. S3.1). Such differences between rice and wheat support our first hypothesis that rice as a (semi-)aquatic plant requiring extensive aerenchyma may have pushed for a reduced vascular transport system.

Individual and total areas of early as well as late metaxylem were much smaller in rice than in wheat, regardless of position and stage (Fig. 3.6 and Fig. S3.5). Smaller xylem vessels have lower potential for water flow (Bramley et al., 2009), since the hydraulic conductance varies with the fourth power of the vessel radius (Calkin et al., 1986; Eq. 1). Hence, rice cultivars would have a much lower axial water transport than wheat cultivars because of the lower xylem areas. This was confirmed with the calculated axial conductance, which indicated the maximum overall axial hydraulic conductance (Fig. S3.6). Furthermore, under water-deficit conditions, the early and late xylem area in wheat roots showed a more prominent response to water-deficit than rice roots (Fig. 3.6), which would result in a higher axial water transport in wheat than in rice under water-limited conditions (Fig. S3.6).

We also observed more specific differences in xylem development between rice and wheat. 
Lignification of xylem vessels indicates the maturity of xylem (Brundrett et al., 1988). A previous study using fluorescence images revealed that the early metaxylem was lignified far closer to the root tip than the central late metaxylem vessel in wheat roots (Bramley et al., 2009). Our histochemical staining of lignin in the xylem vessel confirmed this (Fig. S3.3). The immaturity of the late metaxylem at the lowest sectioning position in wheat (Fig. S3.3) indicated that the central vessel in wheat may become functional at greater distances from the root tip (Bramley et al., 2009). Furthermore, our result revealed that the axial conductance of early metaxylem near root tips in wheat responded more prominently than that of late metaxylem when exposed to water-deficit treatments (Fig. S3.6). However, such phenomena were not observed in rice. We therefore surmise that the water axial transport close to the root tip in wheat roots mainly depends on the early metaxylem, regardless whether they grow in wellwatered or drought-stressed conditions. On the other hand, matured early and late metaxylem were observed in all rice cross-sections (Fig. S3.3). If all mature metaxylem vessels function for water transport, this might be beneficial for plants with a high demand of transpiration under inundation but might cause a risk of xylem embolism when water uptake is limited in stressed plants (Cochard, 2002).

\subsubsection{Anatomical and histochemical changes suggest a lower radial transport capacity in rice than wheat under water-deficit conditions}

Water needs to pass through several layers of cortical cells to reach the endodermis. Rice had greater root cross sectional area, smaller stele area, and the resultant smaller stele to root cross sectional area ratio than wheat (Fig. 3.4), similar to commonly observed differences between wetland species and dryland species (McDonald et al., 2002). This suggests a longer radial distance for water transport in rice roots than in wheat. An increase in the stele to cross sectional area ratio along the root axis in response to water deficit was observed in both species (Fig. 3.4G-I), which would shorten the radial path across the cortical cells, thus helping improve the radial conductance for water flow (Chimungu et al., 2014; Lynch et al., 2014). The increase of the stele to cross sectional area ratio under water-deficit treatments in rice (Fig. 3.4G-I) was mainly due to the reduction of the cross sectional area (Fig. 3.4A-C). On the other hand, in wheat, the stress-induced increase in stele to cross sectional area ratio (especially at the two lower positions) was only due to the increase in stele area (Fig. 3.4D-F), since the root cross sectional area in wheat was not influenced by the treatments (Fig. 3.4A-C). Although both strategies helped reduce the radial path for water flow, it was at the expense of reducing the 
absorptive surface root area in rice, which would impede water acquisition under water-deficit conditions (Comas et al., 2013).

The suberized exodermis and lignified sclerenchyma layer in the outer part of the rice root was suggested to act as apoplastic barrier to prevent oxygen loss from aerenchyma to soil under oxygen-deficient conditions (Colmer, 2002; Kotula et al., 2009), but may impede water and nutrient uptake of wetland species (Končalová, 1990). However, we did not observe any regular suberin or lignin staining in the outer part of the roots (i.e. exodermal cells and sclerenchyma layers) in both species (data not shown). This was not caused by the staining procedure, as the endodermal cells were well stained in the same sections (Figs. S3.2 and S3.3). This led us to speculate that the outer part of rice root might act as an additional apoplastic barrier and not be responsive to water-deficit. On the other hand, the presence of exodermis and highly suberized/lignified sclerenchymatous cells in wheat roots was only observed near the root-shoot junction (Figs. S3.2 and S3.3). The absence of exodermis at the two lower positions in wheat root was similar to what has been reported for some dryland cereals such as maize (Abiko et al., 2012) and barley (Ranathunge et al., 2017).

The endodermis is regarded as the main apoplastic transport barrier for passive uptake of water from dry soil (Schreiber et al., 1999; Geldner, 2013; Miyamoto et al., 2001; Enstone et al., 2002; Ranathunge et al., 2017). Water-deficit stress generally leads to larger parts of the root developing secondary and tertiary developmental stage of the endodermis (North and Nobel, 1995; Schreiber et al. 1999). Thickened tertiary endodermal cell walls contained significantly higher amounts of lignin and suberin, compared to endodermal cell walls in their primary state of development (Zeier and Schreiber, 1998). Our anatomical and histochemical observations in rice roots confirmed this by showing an increased suberization, lignification and thickening of the inner wall of the endodermis under water-deficit conditions (Figs. 3.5 and 3.7, Figs. S3.2 and S3.3). Yet, we did not observe such modification in wheat root sections.

Because of the hydrophobic nature of suberin, suberized cell walls in the root endodermis form transport barriers to water and solutes (Peterson et al., 1993; Peterson and Cholewa, 1998; Steudle and Peterson, 1998). In our study, across positions, the suberization in endodermis increased with water-deficit intensity in all rice cultivars (Fig. 3.7A-C and Fig. S3.2), which would restrict the apoplastic water flow in water-deficit roots, and eventually lead to the reduction of overall root hydraulic conductance under water deficit (Schreiber et al., 1999; Vandeleur et al., 2009; Kreszies et al., 2018). In wheat, the endodermis appeared heavily 
suberized at the sections near the root-shoot-junction but weakly suberized at the sections closer to the root apex, and the suberization responded little to water-deficit treatments (Fig. 3.7A-C and Fig. S3.2). Such developmental differences along a root were accompanied by differences in hydraulic conductance in a highly and successfully drought-adapted plant, Agave deserti (North and Nobel, 2000). It is an advantage for plants to increase suberization in the older basal part of the roots under water deficit to minimise the backflow of water to the drying soil (Steudle and Peterson, 1998; Steudle, 2000). At the same time, the apical part of the roots continuously grows into deeper wet soil layers acquiring water. Kreszies et al. (2018) observed an increased suberization at different root zones but not in the youngest zone near the root apex in barley plants under water-deficit conditions. This suggests that, at least from the histochemical point of view, roots of dryland cereals are better programmed to adapt to water-deficit conditions than rice roots. It is possible that rice roots adapt to drying soil by preventing water from leaking out of the stele (Henry et al., 2012), thereby also impeding the radial water transport into the stele. Wheat roots minimise water loss in the root zone near the root-shoot junction while maintaining water absorption in the apical portions where water availability is higher than the upper soil. All these support our second hypothesis that suberization of root endodermal cell layers and other anatomical features allowed dryland cereals having a better radial water transport ability than rice under water deficit. Our observation that the suberization under water deficit was increased to a lower extent in upland than in lowland and aerobic rice genotypes but still more than in wheat (Fig. 3.7A-C), suggests that rice adaptation to upland environments for a higher radial transport capability was only a small adjustment.

\subsubsection{Consequences of anatomical and histochemical changes on root growth}

Perhaps as consequences of different stress responses in water transport capabilities, wheat had higher abilities than rice in maintaining root growth (root biomass, total root length) and fineto-thick root ratio under water-deficit treatments, at both stages (Fig. 3.8). Although some genetic variation within a species was observed, morphological differences were most apparent between species and between treatments.

Although our plants were grown in relatively restricted pots, the observed root morphological changes in rice and wheat are consistent with those previously reported (Reynolds et al., 2006; Henry et al., 2012). Even without any sign of water stress (leaf rolling and drying), rice and wheat plants experienced water shortage - having decreased leaf water potential at both stages (Table S3.1). More specifically, the root growth of rice plants was impeded by both treatments 
with varying degrees (Fig. 3.8). The highest water deficit treatment we imposed to rice in this study (SD condition with soil potential between $-20 \mathrm{kPa}$ to $-40 \mathrm{kPa}$ ) was similar to the aerobic culture used by Kato and Okami (2011). It appears that rice roots respond to aerobic conditions as they were under water-deficit stress (Kato and Okami, 2011; Henry et al., 2012). On the other hand, increase in absolute root mass in response to water deficit has been shown previously in wheat (Reynolds et al., 2006). In our study, the root growth of wheat cultivars was not very sensitive to water deficit treatments (Fig. 3.8).

In our study, the severe reduction of biomass and total root length under water deficit in rice (Fig. 3.8) was associated with the strong lignification along the root (Fig. 3.7D-F and Fig. S3.3). In contrast, root growth and lignification were least affected by water deficit treatments in wheat roots (Figs. 3.7D-F and 3.8; Fig. S3.3). Lignification is an energy-consuming process. The increase in lignin deposition in roots was accompanied by decreased root growth in several water-deficit-stressed plants (Steudle, 2000; Fan et al., 2006; Yang et al., 2006; Kováč et al., 2018). In maize, the inhibition of root growth under water deficit was shown to be associated with the increased expression of genes involved in the biosynthesis of lignin and with the deposition of lignin in the elongating zone of the root (Fan et al., 2006). Similar results were obtained in rice roots, when plant encountered water deficit after 48 to 72 hours (Yang et al., 2006). Moreover, the advanced lignification in rice root under water deficit conditions might be a trade-off mechanism for preventing xylem embolism, as the stem xylem embolism resistance in herbaceous requires up-regulation of the lignin pathway (Lens et al., 2016; Dória et al., 2018).

Rice plants promote the emergence of nodal root in inundated environments to alleviate hypoxia stress (Mergemann and Sauter, 2000; Steffens and Rasmussen, 2016). The severe decline of rice root biomass and total root length under water deficit (Fig. 3.8A, B) might be associated with the down-regulated nodal root number as previously shown in rice plants grown in dry soil (Suralta and Yamauchi, 2008; Kato and Okami, 2011; Hazman and Brown, 2018). Furthermore, the significantly decreased lateral root length per nodal root length (fine-to-thick root length ratio) under water deficit in rice (Fig. 3.8C) should also be responsible for the severe reduction of root biomass and total root length, as lateral roots account for a large proportion of the total root system in terms of root length and number (Henry et al., 2012).

Lateral root plasticity is a variable trait in plant adaptation to water-deficit conditions (Niones et al., 2012; Zhan et al., 2015). Water deficit decreased lateral root formation in shallow soil 
layers and increased lateral root branching density and length in at deeper soil layers when rice plants grown in mesocosms (Hazman and Brown, 2018). However, this might differ in field conditions. Unlike dryland cereals, rice plants are generally having a shallow rooting system with decreased lateral root branching when grown in aerobic and dry fields (Kato and Okami, 2011; Uga et al., 2013). We observed a large reduction of lateral root formation in rice genotypes under water-deficit conditions (Fig. 3.8C). On the contrary, wheat maintained or even increased lateral root branching under stress treatments (Fig. 3.8C). This would in turn allow for a better water acquisition from water-limited soil, as lateral roots provide the greatest surface area with the least investments in biomass (Waisel and Eshel, 2002; Wasson et al., 2012; Postma et al., 2014; Tylová et al., 2017).

In our study, we only examined the root anatomical and histochemical properties, which might influence the water transport under water-deficit conditions. We observed large differences on the anatomical barrier between rice and wheat root. Although there is lack of physiological measurements on the axial and radial conductivities in our study, the barrier formation in rice root under water deficit is evident. However, although it is not covered by this study, the modification of other cell wall structures such as Casparian bands should not be neglected. The presence and number of Casparian bands would also affect the apoplastic water transport between root cells (Tylová et al., 2017). In addition, the symplastic connections with plasmodesmata across endodermis create intercellular passages for passive movement of nutrients and water (Rutschow et al., 2011), and thus, could be important for water transport under water-limited condition. Furthermore, the role of certain biochemical components such as aquaporins cannot be excluded. Research on barley roots indicated that osmotic stress impeded the hydraulic conductance of the apoplastic pathway by altering histochemical and anatomical features, but had little influence on aquaporin expression, thus did not alter the hydraulic conductance of the cell-to-cell pathway (Kreszies et al., 2018). Further studies would be needed to obtain insights into possible roles of aquaporins and plasmodesmata for rice adaptation in drier soil conditions. Moreover, it is also necessary to examine how shoot morphology and anatomy respond to water-deficit stress in various rice and wheat genotypes.

\subsection{Conclusions}

Rice and wheat cultivars showed distinct root morphological, anatomical and histochemical responses at both developmental stages to long-term water-deficit treatments. The larger proportion of aerenchyma, smaller stele and xylem in rice, compared to wheat, would lead to a 
lower axial conductance. The highly suberized, lignified and thickened endodermal cell walls at the region close to the root apex in rice roots formed strong barriers for radial water transport into the stele. As a result, water-deficit stress limited root growth and lateral root proliferation, resulting in a significant decrease in root biomass and total root length in rice, at both vegetative and flowering stages. Our comprehensive comparison of two species demonstrated the difference of the root structures in adaptation to water-deficit stress. Our results suggest that rice could grow like dryland cereals after a genetic modification of its root anatomical and histochemical traits in a way that increases radial and axial water transport.

\section{Acknowledgements}

This work was supported by an anonymous private donor who financed, via Wageningen University Fund, the first author's PhD fellowship. The experimental work was financed by the College of Agriculture, Yangzhou University. We thank IRRI and CIMMYT for providing rice and wheat seeds, Mrs Zhiqin Wang and Mr Zhenxiang Zhou for assistance during experimentation, and Dr C.G. van der Linden, Dr P.S. Bindraban and Dr Krishna S.V. Jagadish for valuable support.

\section{References}

Abiko T, Kotula L, Shiono K, Malik AI, Colmer TD, Nakazono M. 2012. Enhanced formation of aerenchyma and induction of a barrier to radial oxygen loss in adventitious roots of Zea nicaraguensis contribute to its waterlogging tolerance as compared with maize (Zea mays ssp. mays). Plant, Cell \& Environment 35, 1618-1630.

Abràmoff MD, Magelhães PJ, Ram SJ. 2004. Image processing with ImageJ. Biophotonics International 11, 36-42.

Argus RE, Colmer TD, Grierson PF. 2015. Early physiological flood tolerance is followed by slow post-flooding root recovery in the dryland riparian tree Eucalyptus camaldulensis subsp. refulgens. Plant, Cell \& Environment 38, 1189-1199.

Atlin GN, Lafitte HR, Tao D, Laza M, Amante M, Courtois B. 2006. Developing rice cultivars for high-fertility upland systems in the Asian tropics. Field Crops Research 97, 43-52.

Baluska F, Ciamporová M, Gasparíková O, Barlow PW. 1995. Structure and Function of Roots: Proceedings of the Fourth International Symposium on Structure and Function of Roots, June 20-26, 1993, Stará Lesná, Slovakia. Springer Science \& Business Media.

Bouman BAM, Peng S, Castaneda AR, Visperas RM. 2005. Yield and water use of irrigated 
tropical aerobic rice, systems. Agricultural Water Management 74, 87-105.

Bramley H, Turner NC, Turner DW, Tyerman SD. 2009. Roles of morphology, anatomy, and aquaporins in determining contrasting hydraulic behavior of roots. Plant Physiology 150, 348364.

Brundrett MC, Enstone DE, Peterson CA. 1988. A berberine-aniline blue fluorescent staining procedure for suberin, lignin, and callose in plant tissue. Protoplasma 146, 133-142.

Calkin HW, Gibson AC, Nobel PS. 1986. Biophysical model of xylem conductance in tracheids of the fern Pteris vittata. Journal of Experimental Botany 37, 1054-1064.

Centritto M, Lauteri M, Monteverdi MC, Serraj R. 2009. Leaf gas exchange, carbon isotope discrimination, and grain yield in contrasting rice genotypes subjected to water deficits during the reproductive stage. Journal of Experimental Botany 60, 2325-2339.

Chimungu JG, Brown KM, Lynch JP. 2014. Reduced root cortical cell file number improves drought tolerance in maize. Plant Physiology 166, 1943-1955.

Cochard H. 2002. Xylem embolism and drought-induced stomatal closure in maize. Planta 215, 466-471.

Colmer TD. 2002. Aerenchyma and an inducible barrier to radial oxygen loss facilitate root aeration in upland, paddy and deep-water rice (Oryza sativa L.). Annals of Botany 91, 301-309.

Comas L, Becker S, Cruz VMV, Byrne PF, Dierig DA. 2013. Root traits contributing to plant productivity under drought. Frontiers in Plant Science 4, 442.

Dória LC, Podadera DS, del Arco M, Chauvin T, Smets E, Delzon S, Lens F. 2018. Insular woody daisies (Argyranthemum, Asteraceae) are more resistant to drought-induced hydraulic failure than their herbaceous relatives. Functional Ecology 32, 1467-1478.

Drew MC, He C-J, Morgan PW. 2000. Programmed cell death and aerenchyma formation in roots. Trends in Plant Science 5, 123-127.

Enstone DE, Peterson CA, Ma F. 2002. Root endodermis and exodermis: structure, function, and responses to the environment. Journal of Plant Growth Regulation 21, 335-351.

Enstone DE, Peterson CA. 2005. Suberin lamella development in maize seedling roots grown in aerated and stagnant conditions. Plant, Cell \& Environment 28, 444-455.

Fan L, Linker R, Gepstein S, Tanimoto E, Yamamoto R, Neumann PM. 2006. Progressive inhibition by water deficit of cell wall extensibility and growth along the elongation zone of maize roots is related to increased lignin metabolism and progressive stelar accumulation of wall phenolics. Plant Physiology 140, 603-612. 
Geldner N. 2013. The endodermis. Annual Review of Plant Biology 64, 531-558.

Gerlach ZBD. 1984. Botanische Mikrotechnik. $3^{\text {rd }}$ ed. Georg Thieme Verlag, Stuttgart.

Hazman M, Brown KM. 2018. Progressive drought alters architectural and anatomical traits of rice roots. Rice 11,62 .

Henry A, Gowda VR, Torres RO, McNally KL, Serraj R. 2011. Variation in root system architecture and drought response in rice (Oryza sativa): phenotyping of the OryzaSNP panel in rainfed lowland fields. Field Crops Research 120, 205-214.

Henry A, Cal AJ, Batoto TC, Torres RO, Serraj R. 2012. Root attributes affecting water uptake of rice (Oryza sativa) under drought. Journal of Experimental Botany 63, 4751-4763.

Jensen WA. 1962. Botanical histochemistry: principles and practice. (No. QK 861. J46).

Kadam NN, Yin X, Bindraban PS, Struik PC, Jagadish KVS. 2015. Does morphological and anatomical plasticity during the vegetative stage make wheat more tolerant of water-deficit stress than rice? Plant Physiology 167, 1389-1401.

Kano M, Inukai Y, Kitano H, Yamauchi A. 2011. Root plasticity as the key root trait for adaptation to various intensities of drought stress in rice. Plant and Soil, 342, 117-128.

Kashiwagi J, Krishnamurthy L, Crouch JH, Serraj R. 2006. Variability of root length density and its contributions to seed yield in chickpea (Cicer arietinum L.) under terminal drought stress. Field Crops Research 95, 171-181.

Kato Y, Abe J, Kamoshita A, Yamagishi J. 2006. Genotypic variation in root growth angle in rice (Oryza sativa L.) and its association with deep root development in upland fields with different water regimes. Plant and Soil 287, 117-129.

Kato Y, Okami M. 2011. Root morphology, hydraulic conductivity and plant water relations of high-yielding rice grown under aerobic conditions. Annals of Botany 108, 575-583.

Kim HK, Park J, Hwang I. 2014. Investigating water transport through the xylem network in vascular plants. Journal of Experimental Botany 65, 1895-1904.

Končalová H. 1990. Anatomical adaptations to waterlogging in roots of wetland graminoids: limitations and drawbacks. Aquatic Botany 38, 127-134.

Kotula L, Ranathunge K, Schreiber L, Steudle E. 2009. Functional and chemical comparison of apoplastic barriers to radial oxygen loss in roots of rice (Oryza sativa L.) grown in aerated or deoxygenated solution. Journal of Experimental Botany 60, 2155-2167.

Kováč J, Lux A, Vaculík M. 2018. Formation of a subero-lignified apical deposit in root tip of radish (Raphanus sativus) as a response to copper stress. Annals of Botany 221, 180-194. 
Krauss KW, Allen JA, Cahoon DR. 2003. Differential rates of vertical accretion and elevation change among aerial root types in Micronesian mangrove forests. Estuarine, Coastal and Shelf Science 56, 251-259.

Kreszies T, Shellakkutti N, Osthoff A, Yu P, Baldauf JA, Zeisler-Diehl VV, Ranathunge K, Hochholdinger F, Schreiber L. 2018. Osmotic stress enhances suberization of apoplastic barriers in barley seminal roots: analysis of chemical, transcriptomic and physiological responses. New Phytologist 221, 180-194.

Lee D-K, Jung H, Jang G, Jeong JS, Kim YS, Ha S-H, Do Choi Y, Kim J-K. 2016. Overexpression of the OsERF71 transcription factor alters rice root structure and drought resistance. Plant Physiology 172, 575-588.

Lens F, Picon-Cochard C, Delmas CE, Signarbieux C, Buttler A, Cochard H, Jansen S, Chauvin T, Dória LC, Del Arco M, Delzon S. 2016. Herbaceous angiosperms are not more vulnerable to drought-induced embolism than angiosperm trees. Plant Physiology 172, 661-667.

Lynch JP, Chimungu JG, Brown KM. 2014. Root anatomical phenes associated with water acquisition from drying soil: targets for crop improvement. Journal of Experimental Botany 65, 6155-6166.

Ma F, Peterson CA. 2003. Current insights into the development, structure, and chemistry of the endodermis and exodermis of roots. Canadian Journal of Botany 81, 405-421.

Ma JF, Goto S, Tamai K, Ichii M. 2001. Role of root hairs and lateral roots in silicon uptake by rice. Plant Physiology 127, 1773-1780.

Madadgar S, AghaKouchak A, Farahmand A, Davis SJ. 2017. Probabilistic estimates of drought impacts on agricultural production. Geophysical Research Letters 44, 7799-7807.

McDonald MP, Galwey NW, Colmer TD. 2002. Similarity and diversity in adventitious root anatomy as related to root aeration among a range of wetland and dryland grass species. Plant, Cell \& Environment 25, 441-451.

Mergemann H, Sauter M. 2000. Ethylene induces epidermal cell death at the site of adventitious root emergence in rice. Plant Physiology 124, 609-614.

Miyamoto N, Steudle E, Hirasawa T, Lafitte R. 2001. Hydraulic conductivity of rice roots. Journal of Experimental Botany 52, 1835-1846.

Niones JM, Suralta RR, Inukai Y, Yamauchi A. 2012. Field evaluation on functional roles of root plastic responses on dry matter production and grain yield of rice under cycles of transient soil moisture stresses using chromosome segment substitution lines. Plant and Soil 359, $107-$ 120. 
North GB, Nobel PS. 1995. Hydraulic conductivity of concentric root tissues of Agave deserti Engelm. under wet and drying conditions. New Phytologist 130, 47-57.

North GB, Nobel PS. 2000. Heterogeneity in water availability alters cellular development and hydraulic conductivity along roots of a desert succulent. Annals of Botany 85, 247-255.

O'Brien L. 1979. Genetic variability of root growth in wheat (Triticum aestivum L.). Australian Journal of Agricultural Research 30 587-595.

O'Toole JC, Bland WL. 1987. Genotypic variation in crop plant root systems. Advances in agronomy 41, 91-145.

Ouyang W, Struik PC, Yin X, Yang J. 2017. Stomatal conductance, mesophyll conductance, and transpiration efficiency in relation to leaf anatomy in rice and wheat genotypes under drought. Journal of Experimental Botany 68, 5191-5205.

Pantuwan G, Fukai S, Cooper M, Rajatasereekul S, O'Toole JC. 2002. Yield response of rice (Oryza sativa L.) genotypes to different types of drought under rainfed lowlands - Part 1. Grain yield and yield components. Field Crops Research 73, 153-168.

Peng S, Bouman B, Visperas RM, Castañeda A, Nie L, Park H-K. 2006. Comparison between aerobic and flooded rice in the tropics: agronomic performance in an eight-season experiment. Field Crops Research 96, 252-259.

Peng S, Tang Q, Zou Y. 2009. Current status and challenges of rice production in China. Plant Production Science 12, 3-8.

Peterson CA, Murrmann M, Steudle E. 1993. Location of the major barriers to water and ion movement in young roots of Zea mays L. Planta 190, 127-136.

Peterson CA, Cholewa E. 1998. Structural modifications of the apoplast and their potential impact on ion uptake. Zeitschrift für Pflanzenernährung und Bodenkunde 161, 521-531.

Pfeiffer WH. 1988. Drought tolerance in bread wheat: analysis of yield improvement over the years in CIMMYT germplasm. Wheat Production Constraints in Tropical Environments. Chiang Mai, Thailand.

Postma JA, Dathe A, Lynch J. 2014. The optimal lateral root branching density for maize depends on nitrogen and phosphorus availability. Plant Physiology 166, 590-602.

Praba ML, Cairns JE, Babu RC, Lafitte HR. 2009. Identification of physiological traits underlying cultivar differences in drought tolerance in rice and wheat. Journal of Agronomy and Crop Science 195, 30-46.

Prince SJ, Murphy M, Mutava RN, Durnell LA, Valliyodan B, Shannon JG, Nguyen HT. 2017. 
Root xylem plasticity to improve water use and yield in water-stressed soybean. Journal of Experimental Botany 68, 2027-2036.

Ranathunge K, Kim YX, Wassmann F, Kreszies T, Zeisler V, Schreiber L. 2017. The composite water and solute transport of barley (Hordeum vulgare) roots: effect of suberized barriers. Annals of Botany 119, 629-643.

Ranathunge K, Kotula L, Steudle E, Lafitte R. 2004. Water permeability and reflection coefficient of the outer part of young rice roots are differently affected by closure of water channels (aquaporins) or blockage of apoplastic pores. Journal of Experimental Botany 55, 433447.

Reynolds M, Dreccer F, Trethowan R. 2006. Drought-adaptive traits derived from wheat wild relatives and landraces. Journal of Experimental Botany 58, 177-186.

Richards RA, Passioura JB. 1981. Seminal Root Morphology and Water Use of Wheat II. Genetic Variation 1. Crop Science 21, 253-255.

Rutschow HL, Baskin TI, Kramer EM. 2011. Regulation of solute flux through plasmodesmata in the root meristem. Plant Physiology 155, 1817-1826.

Schreiber L, Hartmann K, Skrabs M, Zeier J. 1999. Apoplastic barriers in roots: chemical composition of endodermal and hypodermal cell walls. Journal of Experimental Botany 50, 1267-1280.

Steffens B, Rasmussen A. 2016. The physiology of adventitious roots. Plant Physiology 170, 603-617.

Steudle E, Peterson CA. 1998. How does water get through roots? Journal of Experimental Botany 49, 775-788.

Steudle E. 2000. Water uptake by roots: effects of water deficit. Journal of Experimental Botany $51,1531-1542$.

Suralta RR, Yamauchi A. 2008. Root growth, aerenchyma development, and oxygen transport in rice genotypes subjected to drought and waterlogging. Environmental and Experimental Botany 64, 75-82.

Tyree MT, Ewers FW. 1991. The hydraulic architecture of trees and other woody plants. New Phytologist 119, 345-360.

Tylová E, Pecková E, Blascheová Z, Soukup A. 2017. Casparian bands and suberin lamellae in exodermis of lateral roots: an important trait of roots system response to abiotic stress factors. Annals of Botany 120: 71-85. 
Uga Y, Sugimoto K, Ogawa S, et al. 2013. Control of root system architecture by DEEPER ROOTING 1 increases rice yield under drought conditions. Nature Genetics 45, 1097.

Vandeleur RK, Mayo G, Shelden MC, Gilliham M, Kaiser BN, Tyerman SD. 2009. The role of plasma membrane intrinsic protein aquaporins in water transport through roots: diurnal and drought stress responses reveal different strategies between isohydric and anisohydric cultivars of grapevine. Plant Physiology 149, 445-460.

Venuprasad R, Lafitte HR, Atlin GN. 2007. Response to direct selection for grain yield under drought stress in rice. Crop Science 47, 285-293.

Venuprasad R, Cruz MS, Amante M, Magbanua R, Kumar A, Atlin GN. 2008. Response to two cycles of divergent selection for grain yield under drought stress in four rice breeding populations. Field Crops Research 107, 232-244.

Villareal RL, del Toro E, Mujeeb-Kazi A, Rajaram S. 1995. The 1BL/1RS chromosome translocation effect on yield characteristics in a Triticum aestivum L. cross. Plant Breeding 114, 497-500.

Vysotskaya LB, Arkhipova TN, Timergalina LN, Dedov AV, Veselov SY, Kudoyarova GR. 2004. Effect of partial root excision on transpiration, root hydraulic conductance and leaf growth in wheat seedlings. Plant Physiology and Biochemistry 42, 251-255.

Waisel Y, Eshel A. 2002. Functional diversity of various constituents of a single root system. In Plant Roots: the hidden half 271-296. CRC Press.

Wasson AP, Richards R, Chatrath R, Misra S, Prasad SS, Rebetzke G, Kirkegaard J, Christopher J, Watt M. 2012. Traits and selection strategies to improve root systems and water uptake in water-limited wheat crops. Journal of Experimental Botany 63, 3485-3498.

Yang L, Wang CC, Guo WD, Li XB, Lu M, Yu CL. 2006. Differential expression of cell wall related genes in the elongation zone of rice roots under water deficit. Russian Journal of Plant Physiology 53, 390-395.

Zeier J, Schreiber L. 1998. Comparative investigation of primary and tertiary endodermal cell walls isolated from the roots of five monocotyledonous species: chemical composition in relation to fine structure. Planta 206, 349-361.

Zhan A, Schneider H, Lynch J. 2015. Reduced lateral root branching density improves drought tolerance in maize. Plant Physiology 168, 1603-1615.

Zimmermann HM, Hartmann K, Schreiber L, Steudle E. 2000. Chemical composition of apoplastic transport barriers in relation to radial hydraulic conductivity of corn roots (Zea mays L.). Planta 210, 302-311. 
Zingaretti SM, Inácio MC, de Matos Pereira L, Paz TA, de Castro França S. 2013. Water stress and agriculture. Responses of Organisms to Water Stress, 1. 


\section{Supplementary materials in Chapter 3}

Table S3.1 Midday leaf water potential (mean \pm standard error of the mean of three replicated plants) of rice and wheat cultivars under different water treatments.

\begin{tabular}{|c|c|c|c|c|c|c|c|}
\hline \multirow{3}{*}{ Species } & \multirow{3}{*}{ Cultivar } & \multicolumn{6}{|c|}{ Leaf water potential (MPa) } \\
\hline & & \multicolumn{3}{|c|}{ Vegetative stage } & \multicolumn{3}{|c|}{ Flowering stage } \\
\hline & & $\mathrm{CT}$ & MD & SD & $\mathrm{CT}$ & MD & SD \\
\hline \multirow[t]{3}{*}{ O. sativa } & IR64 & $-1.37 \pm 0.05$ & $-1.86 \pm 0.07$ & $-1.91 \pm 0.03$ & $-1.21 \pm 0.02$ & $-1.34 \pm 0.02$ & $-1.89 \pm 0.03$ \\
\hline & Apo & $-1.37 \pm 0.02$ & $-2.00 \pm 0.03$ & $-2.06 \pm 0.03$ & $-1.54 \pm 0.07$ & $-1.63 \pm 0.05$ & $-1.90 \pm 0.02$ \\
\hline & UPL7 & $-1.29 \pm 0.06$ & $-1.45 \pm 0.06$ & $-1.59 \pm 0.12$ & $-1.26 \pm 0.07$ & $-1.58 \pm 0.07$ & $-1.69 \pm 0.03$ \\
\hline \multirow[t]{2}{*}{ T. aestivum } & S82 & $-0.43 \pm 0.01$ & $-0.44 \pm 0.01$ & $-0.52 \pm 0.02$ & $-0.40 \pm 0.01$ & $-0.44 \pm 0.01$ & $-0.53 \pm 0.02$ \\
\hline & We4 & $-0.31 \pm 0.01$ & $-0.37 \pm 0.01$ & $-0.44 \pm 0.02$ & $-0.32 \pm 0.01$ & $-0.34 \pm 0.01$ & $-0.39 \pm 0.01$ \\
\hline
\end{tabular}


Table S3.2 Analysis of variance results for nodal root anatomical traits in rice and wheat.

\begin{tabular}{|c|c|c|c|c|c|c|c|c|c|c|c|}
\hline Species & & RCA & SA & SA:RCA & CWT & EXA & EXN & MXA & MXN & ENS & ENL \\
\hline \multirow{15}{*}{ Rice } & Cultivar (C) & $* * *$ & $* * *$ & $* * *$ & $* * *$ & $* * *$ & $* * *$ & $* * *$ & $* * *$ & $* * *$ & $* * *$ \\
\hline & Treatment $(\mathrm{T})$ & $* * *$ & $* * *$ & $* * *$ & $* * *$ & $* * *$ & $* * *$ & $* * *$ & $* * *$ & $* * *$ & $* * *$ \\
\hline & Position $(\mathrm{P})$ & $* * *$ & $* * *$ & $* * *$ & $* * *$ & $* * *$ & $* * *$ & $* * *$ & $* * *$ & $* * *$ & $* * *$ \\
\hline & Stage (S) & $* * *$ & $* * *$ & $* *$ & $* * *$ & $* * *$ & $* * *$ & $* * *$ & $* * *$ & $* * *$ & $* * *$ \\
\hline & Cultivar $\times$ Treatment & $* * *$ & ns & $* * *$ & $* * *$ & $* *$ & ns & $* *$ & $* *$ & $* * *$ & $* * *$ \\
\hline & Cultivar $\times$ Position & $* * *$ & $* *$ & $*$ & $* * *$ & $* * *$ & $* *$ & $* * *$ & $\mathrm{~ns}$ & $* *$ & $* * *$ \\
\hline & Treatment $\times$ Position & $* * *$ & $* * *$ & $* * *$ & $* *$ & $* * *$ & $* *$ & $* * *$ & $*$ & $* * *$ & $* *$ \\
\hline & Cultivar $\times$ Stage & $* * *$ & $* * *$ & $* * *$ & $\mathrm{~ns}$ & $* *$ & $\mathrm{~ns}$ & $* * *$ & $\mathrm{~ns}$ & $* *$ & $*$ \\
\hline & Treatment $\times$ Stage & $* * *$ & $* *$ & ns & $* * *$ & $\mathrm{~ns}$ & ns & $\mathrm{ns}$ & $*$ & $\mathrm{~ns}$ & $\mathrm{~ns}$ \\
\hline & Position $\times$ Stage & ns & ns & $*$ & $* *$ & ns & $* *$ & $* *$ & $* * *$ & ns & $*$ \\
\hline & $\mathrm{C} \times \mathrm{T} \times \mathrm{P}$ & $*$ & $\mathrm{~ns}$ & ns & $*$ & ns & $*$ & $*$ & $*$ & $\mathrm{~ns}$ & ns \\
\hline & $\mathrm{C} \times \mathrm{T} \times \mathrm{S}$ & ns & $*$ & $* * *$ & ns & $* * *$ & $* * *$ & ns & ns & $*$ & ns \\
\hline & $\mathrm{C} \times \mathrm{P} \times \mathrm{S}$ & $\mathrm{ns}$ & $\mathrm{ns}$ & $* *$ & ns & $\mathrm{ns}$ & ns & $*$ & $*$ & ns & ns \\
\hline & $\mathrm{T} \times \mathrm{P} \times \mathrm{S}$ & $\mathrm{ns}$ & $\mathrm{ns}$ & ns & ns & ns & $\mathrm{ns}$ & $\mathrm{ns}$ & ns & $* * *$ & $* *$ \\
\hline & $\mathrm{C} \times \mathrm{T} \times \mathrm{P} \times \mathrm{S}$ & $* * *$ & $*$ & $* * *$ & ns & $\mathrm{ns}$ & $* *$ & $* *$ & $*$ & ns & ns \\
\hline \multirow{15}{*}{ Wheat } & Cultivar (C) & ns & $\mathrm{ns}$ & $* * *$ & $* * *$ & $* *$ & $* * *$ & ns & $*$ & $* * *$ & $* * *$ \\
\hline & Treatment $(\mathrm{T})$ & $* * *$ & $* * *$ & $* * *$ & ns & $* * *$ & $* * *$ & $* * *$ & $* * *$ & $* *$ & $* *$ \\
\hline & Position (P) & $* * *$ & $* * *$ & $* * *$ & $* * *$ & $* * *$ & $* * *$ & $* * *$ & $* * *$ & $* * *$ & $* * *$ \\
\hline & Stage (S) & $* * *$ & $*$ & $* * *$ & $* * *$ & $*$ & $*$ & ns & $* * *$ & $* * *$ & $* * *$ \\
\hline & Cultivar $\times$ Treatment & $* *$ & ns & $*$ & ns & ns & ns & $* *$ & ns & $* *$ & ns \\
\hline & Cultivar $\times$ Position & ns & ns & $* * *$ & $* * *$ & $* * *$ & $* * *$ & $* * *$ & $* * *$ & $\mathrm{~ns}$ & $*$ \\
\hline & Treatment $\times$ Position & $* * *$ & $* * *$ & $* * *$ & $*$ & ns & $* * *$ & $* * *$ & $* * *$ & $*$ & $* *$ \\
\hline & Cultivar $\times$ Stage & $* * *$ & $* * *$ & $* * *$ & $* * *$ & $* * *$ & $* * *$ & $* * *$ & $* * *$ & $*$ & $* * *$ \\
\hline & Treatment $\times$ Stage & ns & ns & $*$ & ns & ns & ns & ns & $* * *$ & $\mathrm{~ns}$ & $* *$ \\
\hline & Position $\times$ Stage & ns & ns & ns & ns & ns & ns & $* * *$ & $* *$ & $* *$ & $*$ \\
\hline & $\mathrm{C} \times \mathrm{T} \times \mathrm{P}$ & $* *$ & $* * *$ & ns & ns & ns & ns & $* * *$ & $* * *$ & ns & ns \\
\hline & $\mathrm{C} \times \mathrm{T} \times \mathrm{S}$ & ns & ns & ns & $* * *$ & ns & ns & ns & ns & $* * *$ & $* * *$ \\
\hline & $\mathrm{C} \times \mathrm{P} \times \mathrm{S}$ & $*$ & ns & $* * *$ & $*$ & $* *$ & $*$ & $* *$ & $*$ & ns & ns \\
\hline & $\mathrm{T} \times \mathrm{P} \times \mathrm{S}$ & $*$ & ns & ns & ns & ns & ns & $\mathrm{ns}$ & $* * *$ & $*$ & ns \\
\hline & $\mathrm{C} \times \mathrm{T} \times \mathrm{P} \times \mathrm{S}$ & $* *$ & $* *$ & ns & $* *$ & $* * *$ & $* * *$ & $*$ & ns & ns & ns \\
\hline \multirow{15}{*}{$\begin{array}{l}\text { Rice + } \\
\text { Wheat }\end{array}$} & Species & $* * *$ & $* * *$ & $* * *$ & $* * *$ & $* * *$ & $* * *$ & $* * *$ & $* * *$ & $* * *$ & $* * *$ \\
\hline & Treatment $(\mathrm{T})$ & $* * *$ & $* * *$ & $* * *$ & $* * *$ & $* * *$ & $* * *$ & $* * *$ & $* * *$ & $* * *$ & $* * *$ \\
\hline & Position (P) & $* * *$ & $* * *$ & $* * *$ & $* * *$ & $* * *$ & $* * *$ & $* * *$ & $* * *$ & $* * *$ & $* * *$ \\
\hline & Stage (S) & $* * *$ & ns & ns & $* * *$ & ns & ns & $* * *$ & $* * *$ & $* * *$ & $* * *$ \\
\hline & Species $\times$ Treatment & $* * *$ & $* * *$ & $* * *$ & $* * *$ & $* * *$ & $*$ & $* * *$ & $* * *$ & $* * *$ & $* * *$ \\
\hline & Species $\times$ Position & $* * *$ & $* * *$ & $* * *$ & $* * *$ & $* * *$ & $* * *$ & $* * *$ & $* * *$ & $* * *$ & $* * *$ \\
\hline & Treatment $\times$ Position & $* *$ & $* * *$ & $* *$ & $\mathrm{~ns}$ & ns & $* *$ & $* * *$ & $*$ & $*$ & ns \\
\hline & Species $\times$ Stage & $* * *$ & $* * *$ & ns & $*$ & $* *$ & $* *$ & $* * *$ & $* * *$ & ns & $*$ \\
\hline & Treatment $\times$ Stage & $*$ & ns & ns & ns & ns & ns & ns & $* *$ & ns & ns \\
\hline & Position $\times$ Stage & $\mathrm{ns}$ & ns & $* *$ & ns & $\mathrm{ns}$ & $\mathrm{ns}$ & ns & $* * *$ & ns & ns \\
\hline & Species $\times \mathrm{T} \times \mathrm{P}$ & ns & $* *$ & ns & ns & ns & ns & $* * *$ & $* * *$ & $* * *$ & $* *$ \\
\hline & Species $\times \mathrm{T} \times \mathrm{S}$ & $*$ & ns & $\mathrm{ns}$ & ns & ns & ns & ns & ns & ns & ns \\
\hline & Species $\times \mathrm{P} \times \mathrm{S}$ & ns & ns & ns & ns & ns & ns & $* * *$ & $*$ & $*$ & ns \\
\hline & $\mathrm{T} \times \mathrm{P} \times \mathrm{S}$ & ns & ns & ns & ns & ns & ns & ns & ns & $* *$ & ns \\
\hline & Species $\times \mathrm{T} \times \mathrm{P} \times \mathrm{S}$ & ns & ns & ns & ns & ns & $\mathrm{ns}$ & $\mathrm{ns}$ & $* *$ & $\mathrm{~ns}$ & ns \\
\hline
\end{tabular}

$\mathrm{RCA}=$ root cross sectional area, $\mathrm{SA}=$ stele area, $\mathrm{SA}: \mathrm{RCA}=$ stele area in proportion to root cross sectional area, CWT $=$ thickness of the inner wall of endodermis, EXA = total early metaxylem area, $\mathrm{EXN}=$ early metaxylem number, $\mathrm{MXA}=$ total late metaxylem area, $\mathrm{MXN}=$ late metaxylem number, $\mathrm{ENS}=$ suberization rating on endodermis, $\mathrm{ENL}=$ lignification rating on endodermis. The significance of each factor or interaction was shown as: ns, not significant; *, $P<0.05$; **, $P<0.01$; ***,$P<0.001$. 
Table S3.3 Analysis of variance to assess the significance of the effects of cultivar, water treatment, stage and of their interactions on measured and calculated morphological features of rice and wheat.

\begin{tabular}{|c|c|c|c|c|}
\hline Species & & $\mathrm{RB}$ & RL & FRL:TRL \\
\hline \multirow{7}{*}{ Rice } & Cultivar & $* * *$ & $* * *$ & ns \\
\hline & Treatment $(\mathrm{T})$ & $* * *$ & $* * *$ & $* * *$ \\
\hline & Stage & $* * *$ & $* * *$ & $*$ \\
\hline & Cultivar $\times$ Treatment & $*$ & $* *$ & ns \\
\hline & Cultivar $\times$ Stage & ns & ns & $* *$ \\
\hline & Treatment $\times$ Stage & ns & ns & $* * *$ \\
\hline & Cultivar $\times \mathrm{T} \times$ Stage & ns & $\mathrm{ns}$ & ns \\
\hline \multirow{7}{*}{ Wheat } & Cultivar & $* * *$ & *** & $* *$ \\
\hline & Treatment $(\mathrm{T})$ & $* * *$ & $\mathrm{~ns}$ & ns \\
\hline & Stage & $* * *$ & $* * *$ & $\mathrm{~ns}$ \\
\hline & Cultivar $\times$ Treatment & ns & $*$ & $\mathrm{~ns}$ \\
\hline & Cultivar $\times$ Stage & ns & $* * *$ & $* * *$ \\
\hline & Treatment $\times$ Stage & $* *$ & $*$ & $\mathrm{~ns}$ \\
\hline & Cultivar $\times \mathrm{T} \times$ Stage & $* * *$ & $* * *$ & $\mathrm{~ns}$ \\
\hline \multirow{7}{*}{ Rice + Wheat } & Species & $* * *$ & $* * *$ & $* * *$ \\
\hline & Treatment $(\mathrm{T})$ & $* * *$ & $* * *$ & $* * *$ \\
\hline & Stage & $* * *$ & $* * *$ & $*$ \\
\hline & Species $\times$ Treatment & $* * *$ & $* * *$ & $* * *$ \\
\hline & Species $\times$ Stage & $* *$ & $* * *$ & $\mathrm{~ns}$ \\
\hline & Treatment $\times$ Stage & ns & $\mathrm{ns}$ & $* *$ \\
\hline & Species $\times \mathrm{T} \times$ Stage & ns & ns & $* *$ \\
\hline
\end{tabular}

$\mathrm{RB}=$ root biomass $\left(\mathrm{g}\right.$ plant $\left.{ }^{-1}\right), \mathrm{RL}=$ root length $\left(\mathrm{km} \mathrm{plant}^{-1}\right), \mathrm{FRL}: \mathrm{TRL}=$ fine root length to thick root length ratio. The significance of each factor or interaction was shown as: ns, not significant; *, $P<0.05$; $* *, P<0.01 ; * * *, P<0.001$. 


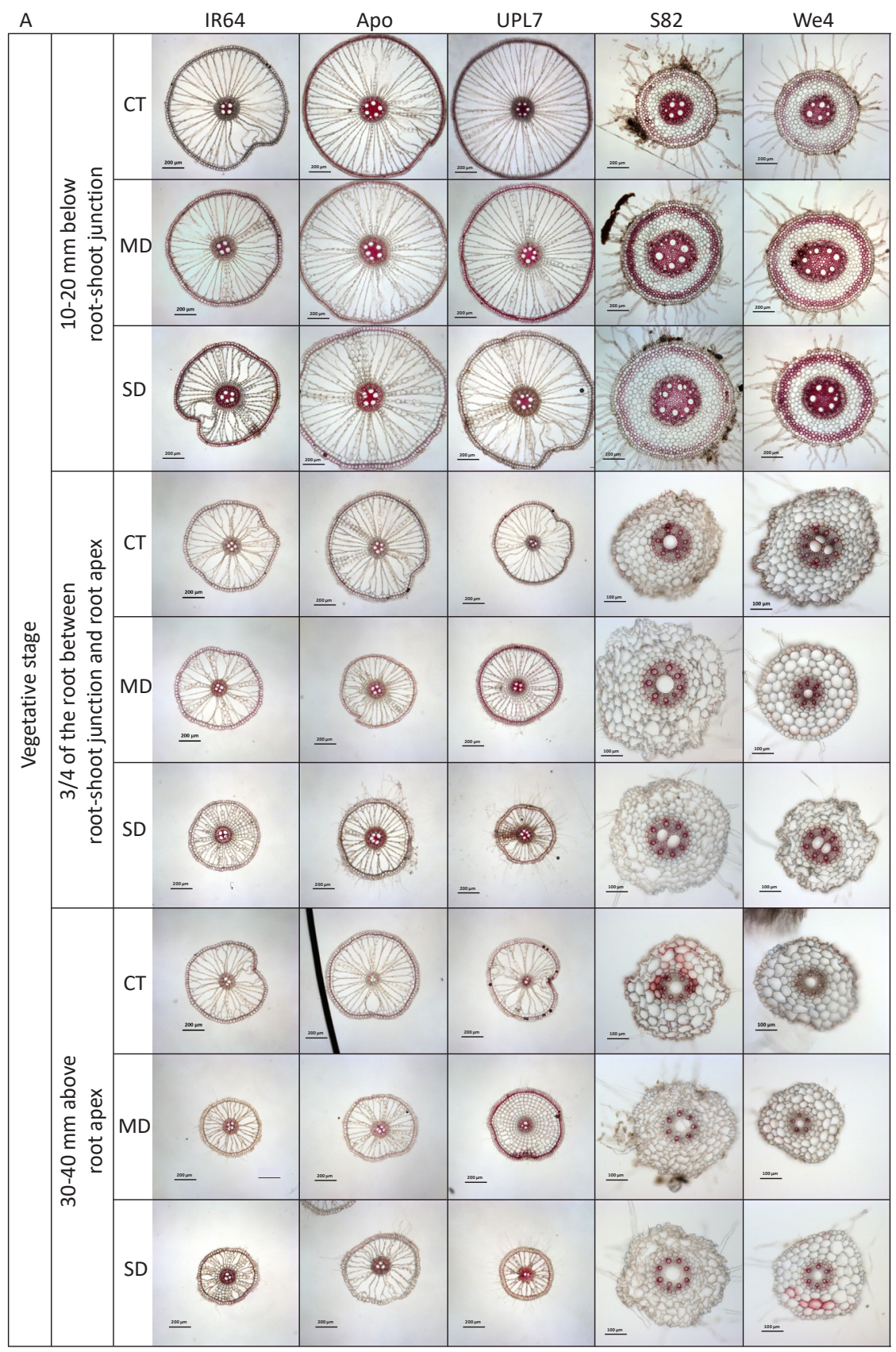

Fig. S3.1 Cross-sections of rice and wheat nodal roots grown under control (CT), mild drought (MD), and more severe drought (SD) conditions. Root segments were sampled at 10 to $20 \mathrm{~mm}$ below rootshoot junction, $3 / 4$ of the root between root-shoot junction and root apex, and 30 to $40 \mathrm{~mm}$ above root apex, at (A) vegetative and (B) flowering stages. Sectioning positions are displayed on the left side of the figures. Sections stained with phloroglucinol- $\mathrm{HCl}$ and viewed under white light. Each scale bar represents $100 \mu \mathrm{m}$ for wheat cross-section images at 3/4 of the root between root-shoot junction and root apex and 30 to $40 \mathrm{~mm}$ above root apex, and $200 \mu \mathrm{m}$ for other cross-section images. 
Chapter 3

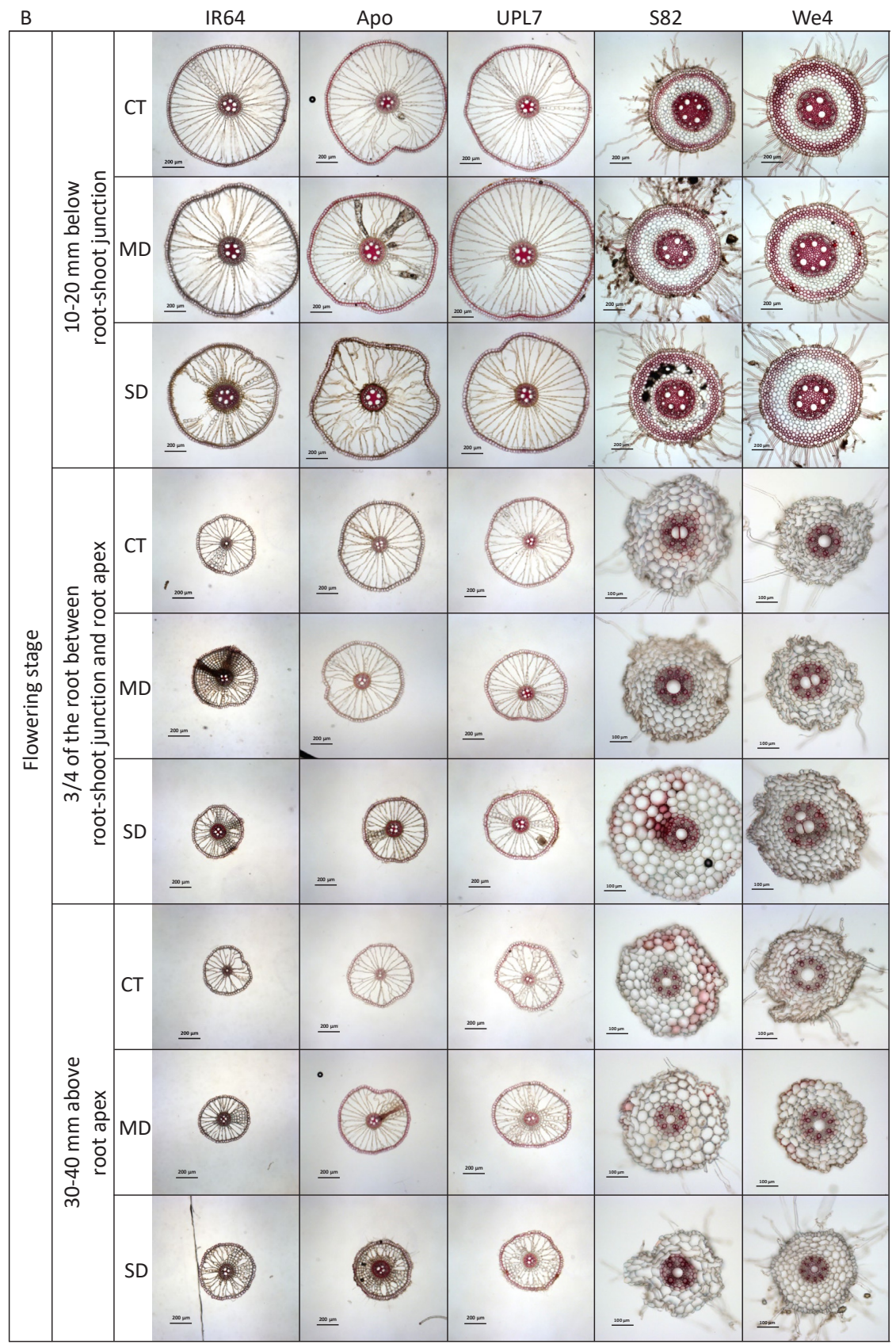

Fig. S3.1 Continued 


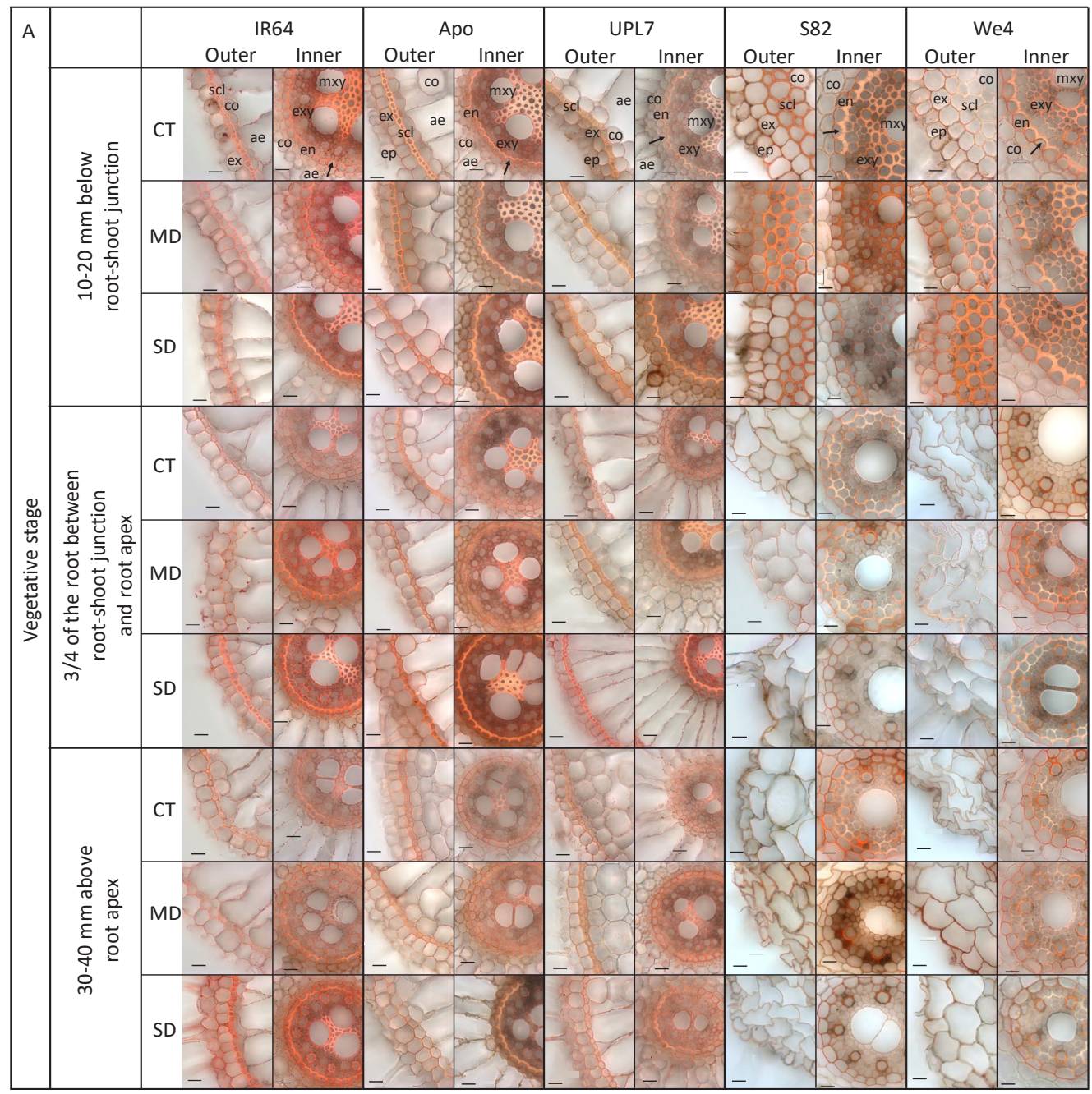

Fig. S3.2 Comparison of suberin deposition in the outer parts and inner parts of rice and wheat nodal roots grown under control (CT), mild drought (MD), and more severe drought (SD) conditions. Root segments sampled at 10 to $20 \mathrm{~mm}$ below root-shoot junction, $3 / 4$ of the root between root-shoot junction and root apex, and 30 to $40 \mathrm{~mm}$ above root apex, at vegetative (A) and flowering (B) stages. Sectioning positions are displayed on the left side of the figures. Suberin in cell walls was detected by an orange color staining with Sudan III. ae, aerenchyma; co, cortical cells; ep, epidermis; ex, exodermis; en, endodermis; scl, sclerenchyma cells; mxy, late metaxylem; exy, early metaxylem. Arrows indicate the inner walls of endodermis. Each scale bar represents $20 \mu \mathrm{m}$. 
Chapter 3

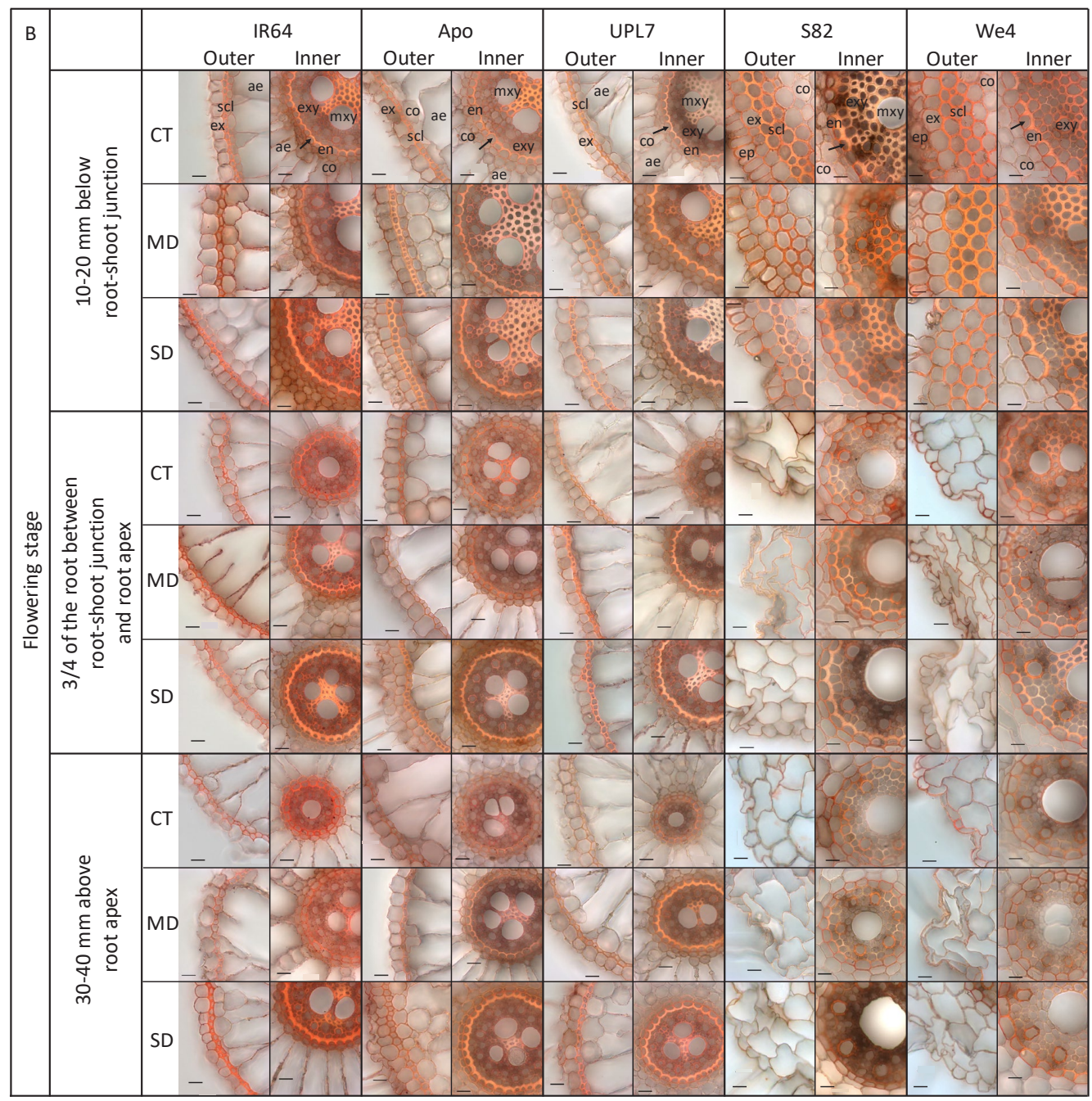

Fig. S3.2 Continued 


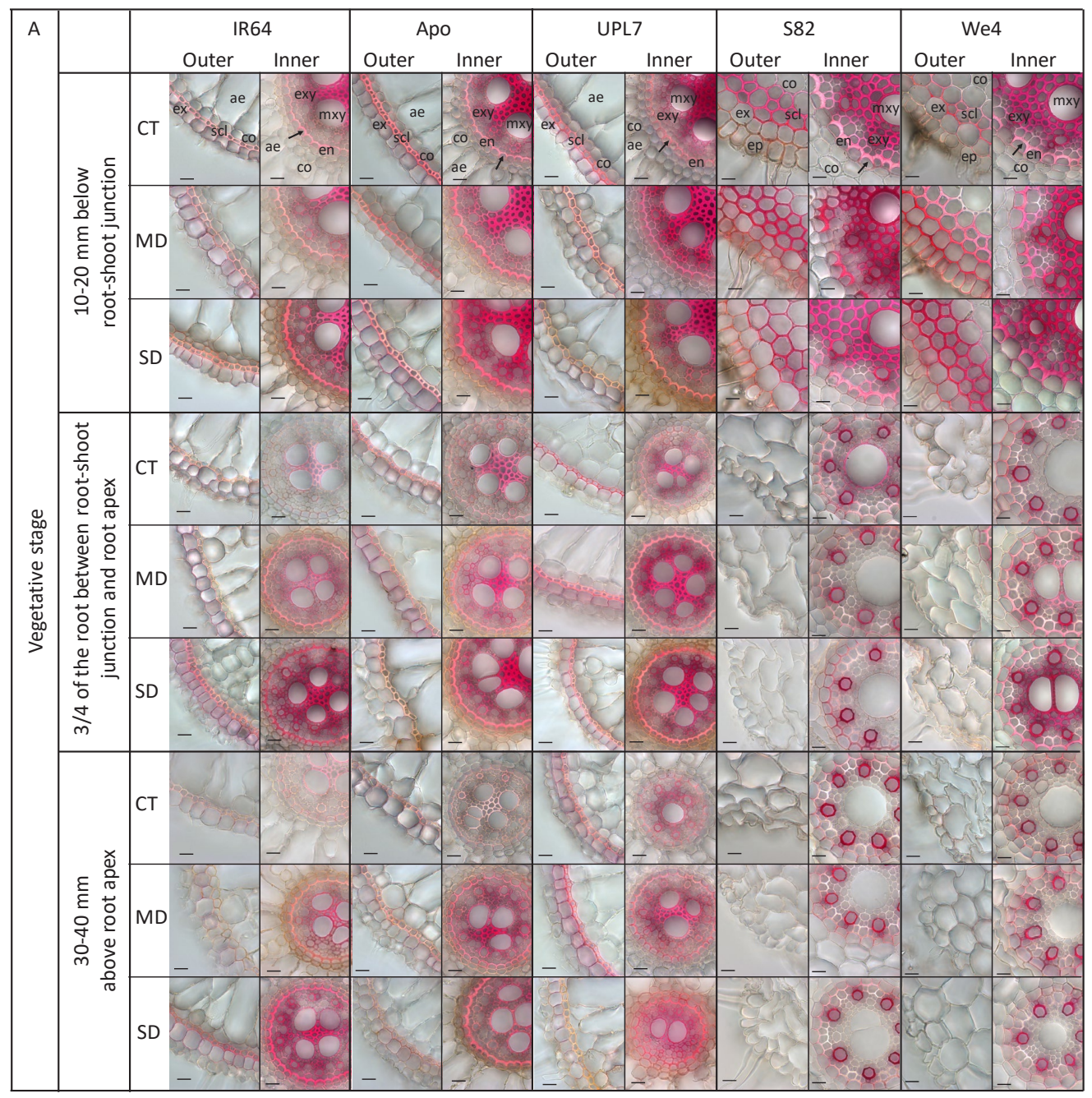

Fig. S3.3 Comparison of lignin deposition in the outer parts and inner parts of rice and wheat nodal roots grown under control (CT), mild drought (MD), and more severe drought (SD) conditions. Root segments sampled at 10 to $20 \mathrm{~mm}$ below root-shoot junction, $3 / 4$ of the root between root-shoot junction and root apex, and 30 to $40 \mathrm{~mm}$ above root apex, at vegetative (A) and flowering (B) stages. Sectioning positions are displayed on the left side of the figures. Lignin in cell walls was detected by a red pink staining with phloroglucinol-HCl. ae, aerenchyma; co, cortical cells; ep, epidermis; ex, exodermis; en, endodermis; scl, sclerenchyma cells; mxy, late metaxylem; exy, early metaxylem. Arrows indicate the inner walls of endodermis. Each scale bar represents $20 \mu \mathrm{m}$. 


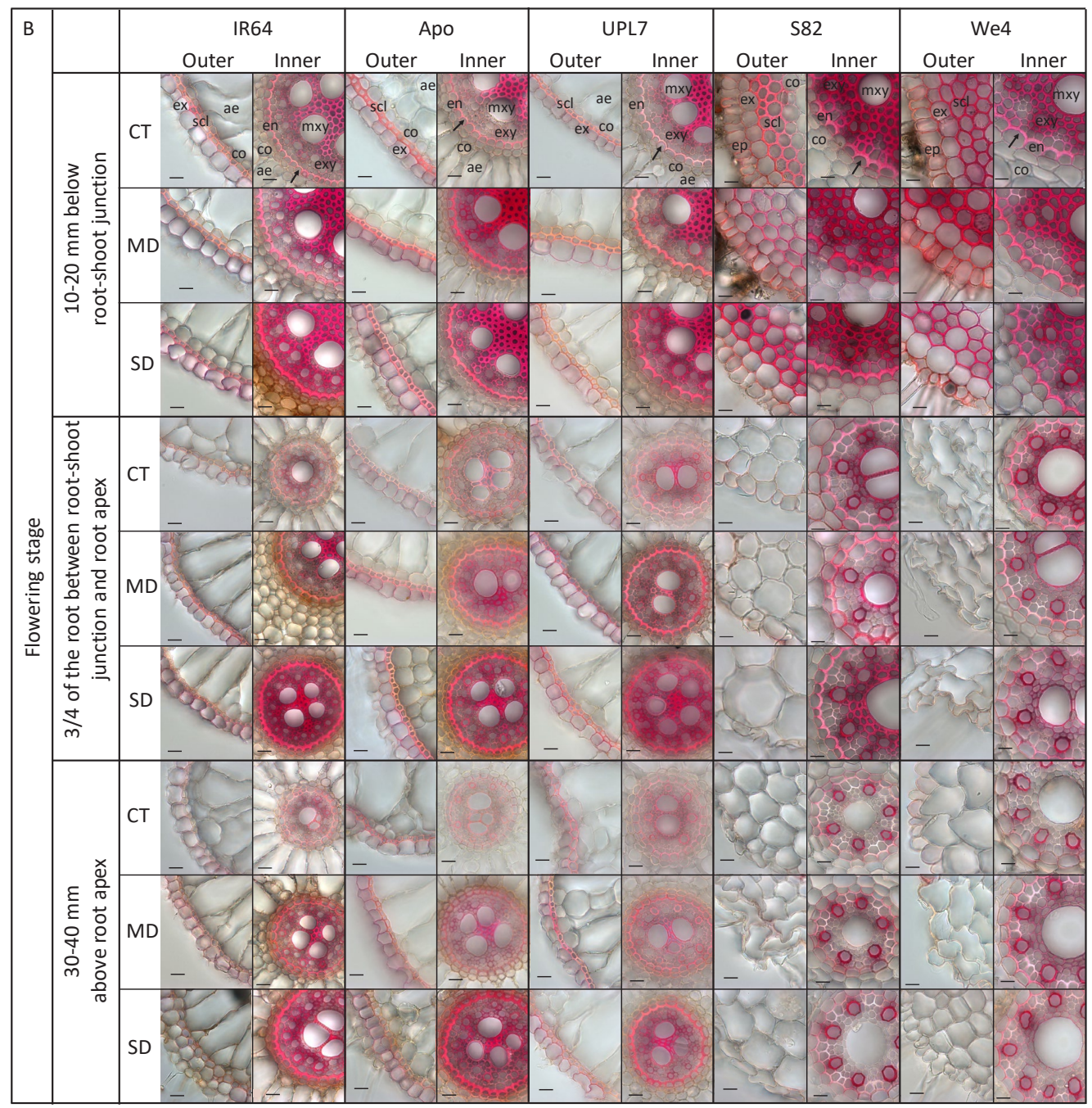

Fig. S3.3 Continued 

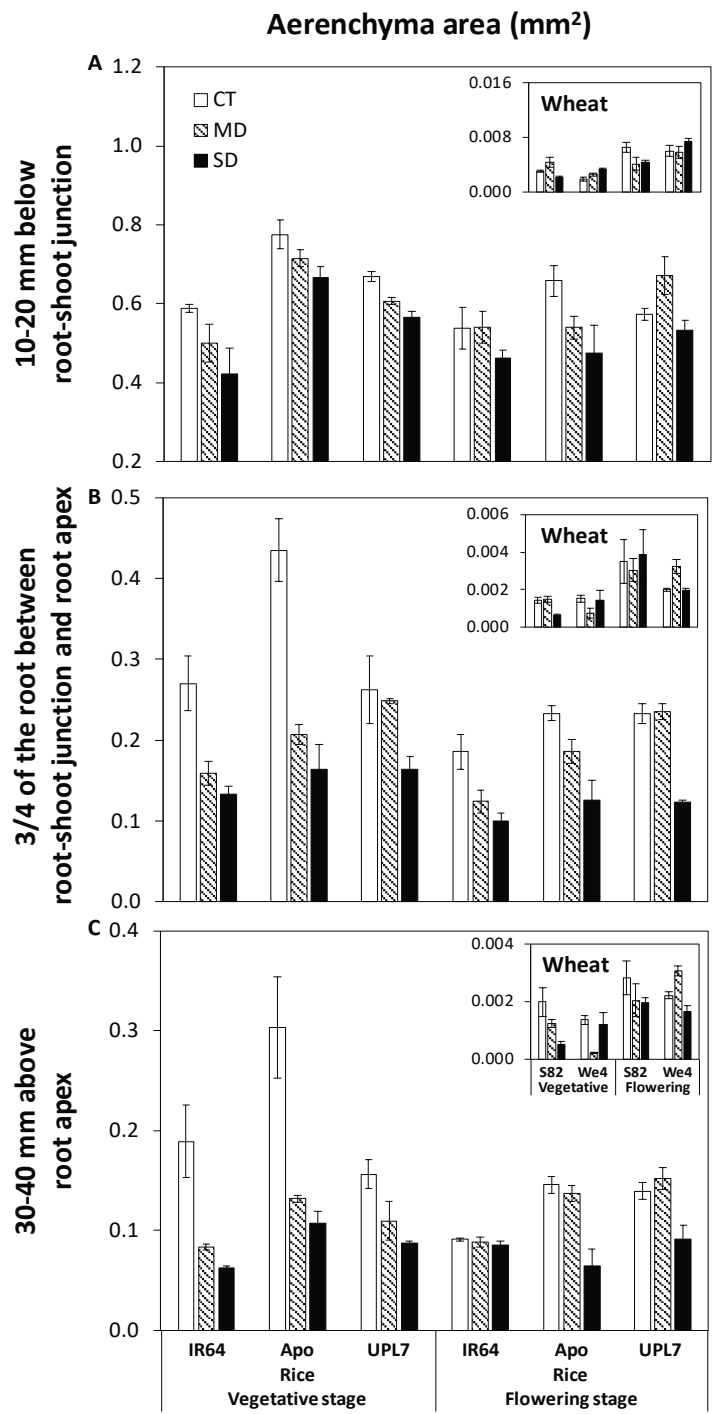

Fig. S3.4 Response of aerenchyma area along nodal roots of rice and wheat to water treatments: control (CT), mild drought (MD), and more severe drought (SD). Root cross-sections were taken at (A) 10 to $20 \mathrm{~mm}$ below root-shoot junction, (B) 3/4 of the root between root-shoot junction and root apex, (C) 30 to $40 \mathrm{~mm}$ above root apex, at vegetative and flowering stages. Bars represent standard errors of the mean for three replicates. Due to the large differences of the aerenchyma area and in proportion to the root cortex area between rice and wheat cultivars, data for wheat are shown in insets. 

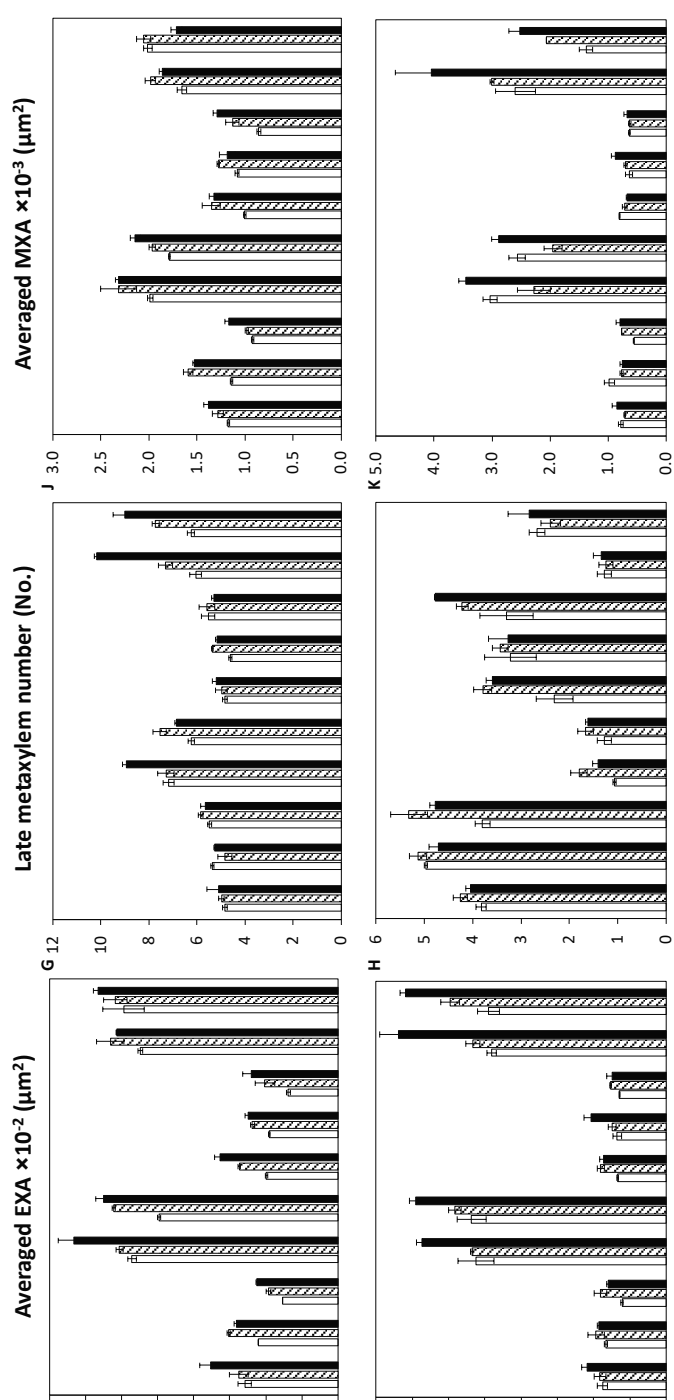

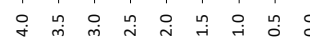

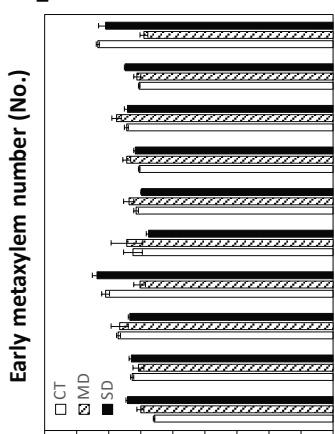

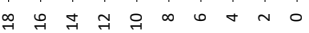

uo!̣oun! 7004s-700. морәq uس 0z-0т
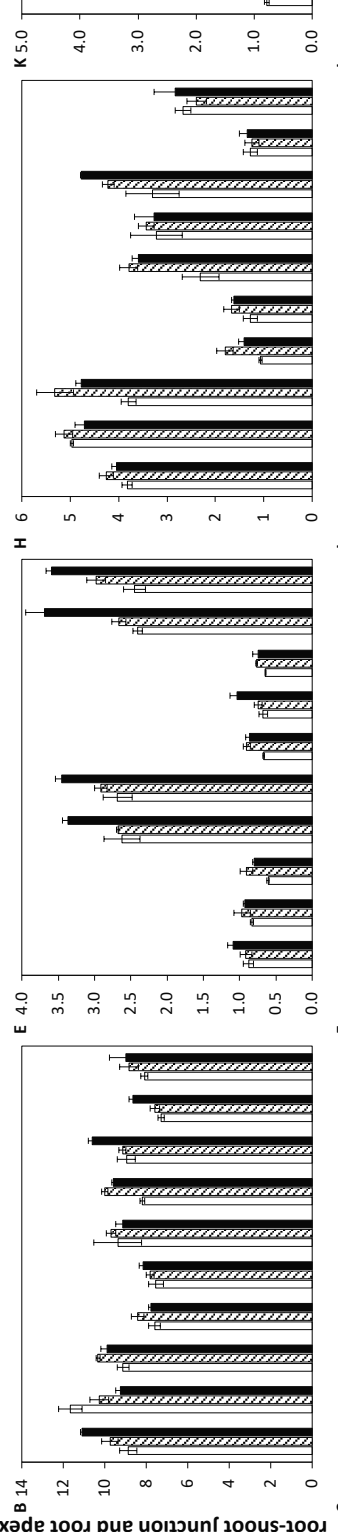

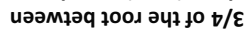
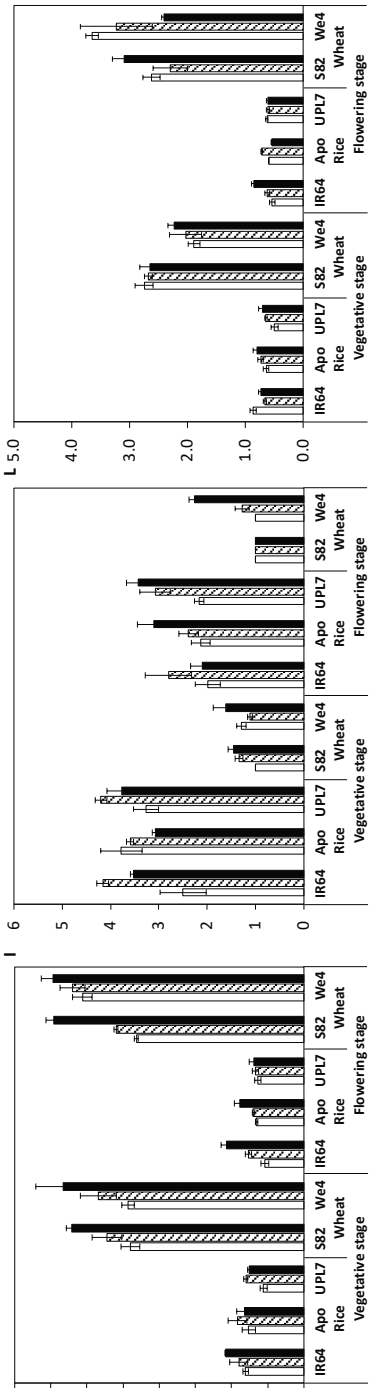

엉

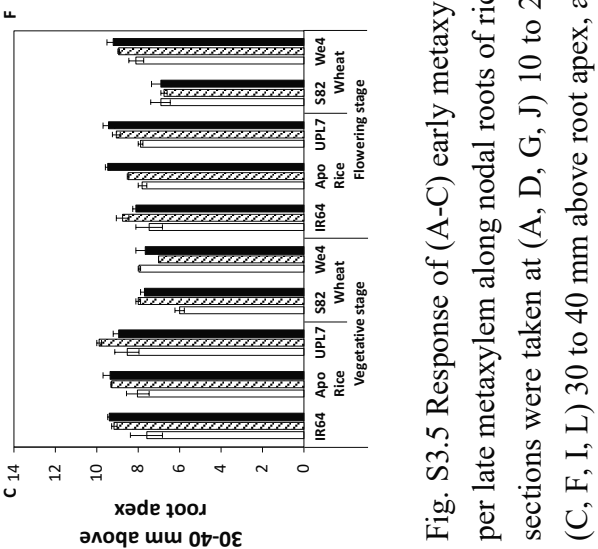



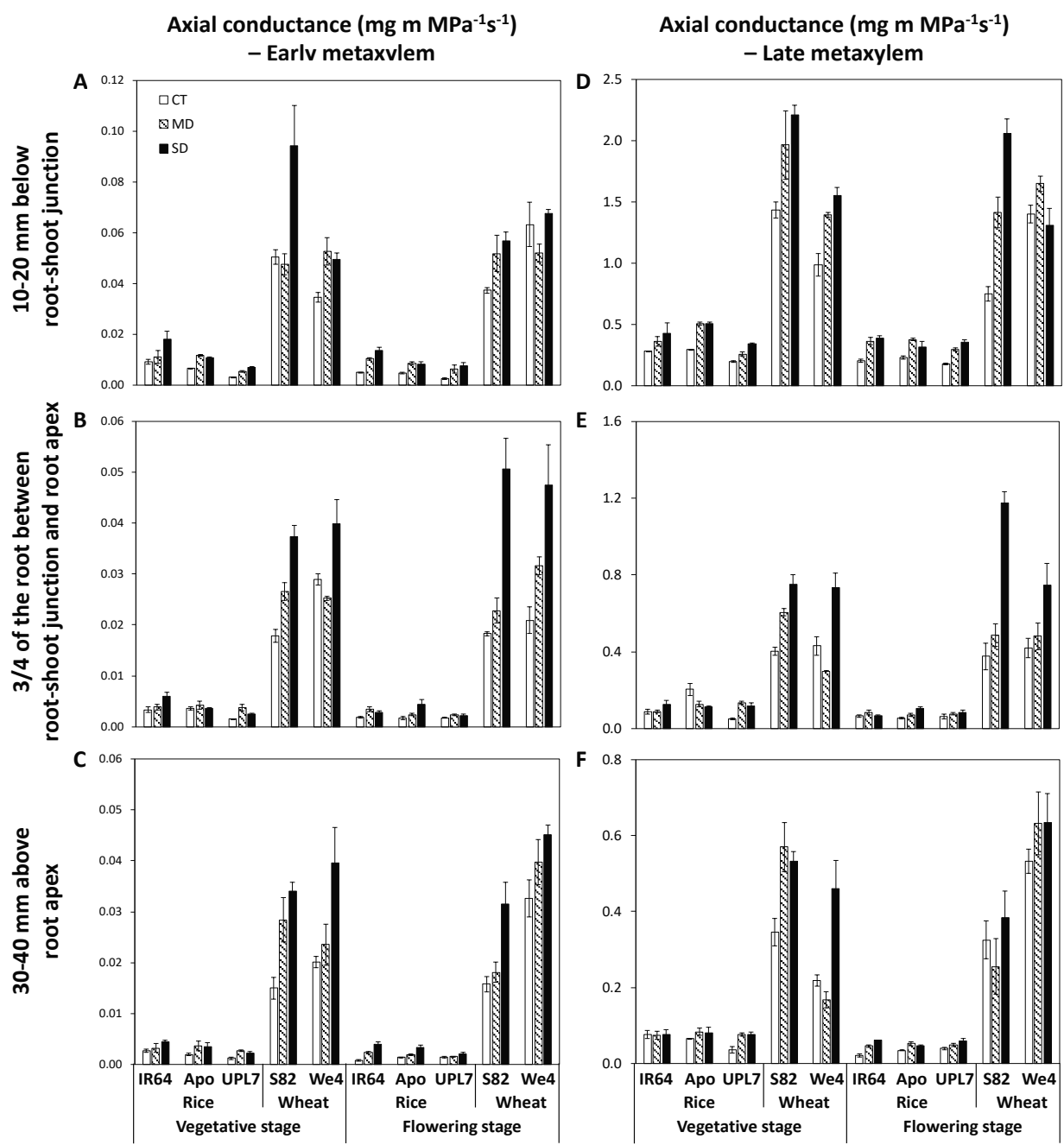

Fig. S3.6 Response of theoretically calculated axial hydraulic conductance of (A-C) early and (D-F) late metaxylem along nodal root of rice and wheat to water treatments: control (CT), mild drought (MD), and more severe drought (SD). Root cross-sections were taken at (A, D) 10 to $20 \mathrm{~mm}$ below root-shoot junction, (B, E) 3/4 of the root between root-shoot junction and root apex, and (C, F) 30 to $40 \mathrm{~mm}$ above root apex, at vegetative and flowering stages. Bars represent standard errors of the mean for three replicates. 



\title{
Chapter 4
}

\section{Do shoot anatomical characteristics allow \\ rice to grow well under water deficit?}

\author{
Wenjing Ouyang ${ }^{1}$, Xinyou Yin ${ }^{1}$, Jianchang Yang ${ }^{2}$ and Paul C. Struik ${ }^{1}$ \\ ${ }^{1}$ Centre for Crop Systems Analysis, Wageningen University \& Research, \\ 6700 AK Wageningen, The Netherlands \\ ${ }^{2}$ College of Agriculture, Yangzhou University, \\ 225009 Yangzhou, Jiangsu, China
}




\begin{abstract}
Increasing fresh water scarcity is a major constraint for rice (Oryza sativa) productivity under future climatic conditions. It is important to understand why rice cannot perform like other dryland cereals, when grown under drier soil conditions. The responses of plant growth, plant water status, leaf and stem anatomical attributes to soil water deficit were examined at two developmental stages of three rice and two wheat (Triticum aestivum) cultivars grown under three water regimes in a pot experiment. Yield and yield components were determined at plant maturity. The stress sensitivity of plant growth was slightly more prominent at vegetative than at flowering stages. Water deficit limited root growth but had little impact on above-ground growth in rice plants. The xylem system of the leaves was more developed in rice than in wheat, but the opposite was true for the root xylem system. Compared with stem xylem attributes, leaf xylem attributes played a larger role in modulating leaf water potential under water deficit. In addition, the variation in yield response to water deficit between various types of rice, and between rice and wheat was closely associated with the response of leaf water potential to water deficit. To grow rice in drier conditions, its xylem system should be balanced by increasing root growth and modifying leaf anatomy.
\end{abstract}

Keywords: Leaf anatomy; leaf water potential; rice; stem anatomy; water deficit; wheat 


\subsection{Introduction}

Water deficit stress is considered to be one of the most important abiotic factors limiting plant growth and yield in many areas (Kramer and Boyer, 1997). Climate change as well as the decreasing fresh water availability for agriculture will increase the frequency and severity of water limitation to crop production (Madadgar et al., 2017). Rice (Oryza sativa L.), an essential crop for global food security, requires massive amounts of fresh water for irrigation. Various water-saving practices have been designed, such as alternate wetting and drying (Bouman and Tuong, 2001; Mishra and Salokhe, 2010; Carrijo et al., 2017; Menge et al., 2020), and controlled soil drying during grain filling (Yang et al., 2003; Yang and Zhang, 2006). However, yield penalties appear unavoidable. To face the challenge of increasing fresh water scarcity for agriculture, it is important to further explore avenues for developing rice genotypes that can be grown in drier conditions.

A large ecological diversity of rice germplasm has allowed to cultivate rice in various cropping systems: lowland (inundated paddy fields), aerobic (moderately dry soil, irrigated, but without standing water), and dry upland (dry soils without irrigation) systems (Bouman et al., 2005; Peng et al., 2006; Venuprasad et al., 2008). Rice genotypes adapted to lowland systems are very sensitive to even mild water deficit (Pantuwan et al., 2002; Centritto et al., 2009), while genotypes adapted to aerobic and upland systems can be grown under drier conditions but at the cost of different levels of yield penalties (Garrity and O'Toole, 1994; Bouman et al., 2005; Venuprasad et al., 2007; Bernier et al., 2008). In order to develop rice genotypes with relatively small yield declines under water-deficit conditions, it is important to understand why rice cannot perform like other dryland cereals, such as wheat (Triticum aestivum L.), when grown under relatively dry conditions. A comparison of rice with wheat would allow to decipher the physiological basis of rice susceptibility to water deficit and to suggest avenues for improved performance under water deficit.

Biomass accumulation and partitioning among different organs (i.e. green leaves, stems, panicles and roots) vary at different growth stages, and could be influenced by different nutrient and water supplies (Somaweera et al., 2016). Plants exposed to long-term water-limited conditions tend to slow down their growth. Under water deficit, a decrease in dry matter accumulation was reported in all plant organs (Wu et al., 2008; Kato and Okami, 2010; Farooq et al., 2010; Liu et al., 2011), but different organs might manifest varying degrees of such a decrease (Rodrigues et al., 1995; Wu et al., 2008; Farooq et al., 2012). Roots, being the first 
organs to sense the dehydration of soil, have been suggested as the main organ in maintaining plant water status under prolonged water-deficit conditions (Nguyen et al., 1997; Kato et al., 2006; Kano et al., 2011). The response of the root system of rice to water deficit shows large genetic variation (Kato et al., 2006; Praba et al., 2009; Henry et al., 2011). Many studies investigated root growth, root hydraulic conductivity and structural changes in the rice root system under water deficit (Kato et al., 2006; Kano et al., 2011; Kadam et al., 2015; Grondin et al., 2016; Ouyang et al., 2020). As rice plants are highly adapted to inundated conditions, their internal vascular network differs from that of dryland cereals. Rice has smaller stele and xylem vessels in the roots and is less plastic in root anatomical adaptation to water deficit, compared with wheat (Kadam et al., 2015; Ouyang et al., 2020). Comparatively little attention has been paid to the shoot (i.e. stem and leaf) structural adaptation to water deficit.

Leaf water potential, as a reliable parameter for quantifying the plant water stress response (Matin et al., 1989; Gutierrez et al., 2010), is one of the traits that are mostly investigated when plants are subject to water deficit. Genotypic variation in leaf water potential was observed in rice (Boonjung and Fukai, 1996; Jongdee et al., 2002) and in wheat (Gutierrez et al., 2010). The variation in grain yield of rice cultivars grown under water deficit conditions is associated with the variation in leaf water potential at flowering and grain filling stages (Jongdee et al., 2002; Pantuwan et al., 2002). In vascular plants, water is taken up from the soil by roots and transported through the xylem network to the leaves (Kim et al., 2014). Therefore, the genotypic variation in leaf water potential may be related to the differences in vascular anatomy in both leaf and stem. Sibounheuang et al. (2006) reported that the genetic variation in leaf water potential under short-term water-deficit conditions in rice cultivars could be linked to the anatomical features of the stem. Yet, the leaf and stem structural characters could vary in response to the variation in water availability (Deblonde and Ledent, 2001; Quero et al., 2006), thereby strongly influencing the changes in whole-plant water transport.

Efforts to understand water-deficit responsive mechanisms in rice plants were commonly carried out for a single growth stage, with a short-term stress imposition lasting from hours to several days (Sibounheuang et al., 2006; Kumar et al., 2008; Parent et al., 2010; Kadam et al., 2015). However, growth and structural responses at different growth stages of rice to water deficit have received less attention. Yield, as the end product of a crop, is the ultimate measure of crop performance responding to various environmental stresses (Tardieu et al., 2018). The sensitivity of yield varies with the timing of stress periods (Vijayaraghavareddy et al., 2020). 
Most crop species show high sensitivity to short-term water deficit around flowering time (Parent et al., 2017; Praba et al., 2009). However, long-term water deficit could affect a larger spectrum of plant functions such as shoot and root growth, and reproductive development (Chaves et al., 2003; Tardieu et al., 2018). In order to understand why rice is highly sensitive to water deficit, a study on the long-term consequences of water deficit on rice plant growth and yield is needed.

Hence, we aim to investigate the responses of leaf water status, structural features of leaf and stem, as well as shoot growth and grain yield in rice plants grown under prolonged water-deficit conditions and compare those responses with the responses in wheat. Our main hypotheses were that (i) the genetic variation in water-deficit sensitivity between various types of rice, and between rice and wheat is associated with variation in leaf water status; and (ii) variation in leaf water potential is caused by variation in structural parameters in leaf and stem. Therefore, we analyzed the variation in leaf water potential, vascular and xylem development in leaf and stem, plant growth and biomass partitioning, yield, and yield components among contrasting rice and wheat genotypes in response to a long-term water deficit, at both vegetative and flowering stages.

\subsection{Materials and methods}

\subsubsection{Plant materials and treatments}

Three cultivars of rice (O. sativa L., subsp. indica) and two cultivars of wheat (T. aestivum L.) were chosen based on their sensitivity to water deficit. These were: (1) the lowland rice cultivar IR 64-21 (IR64), considered as highly sensitive (Venuprasad et al., 2008); (2) the aerobic rice cultivar NSIC Rc9 (Apo), generally considered as moderately tolerant (Venuprasad et al., 2007); (3) the upland rice cultivar UPL Ri7 (UPL7), considered as tolerant (Atlin et al., 2006); (4) the wheat cultivar SeriM82 (S82), considered as moderately susceptible (Pfeiffer, 1988) to tolerant (Villareal et al., 1995); and (5) the wheat cultivar Weebill4 (We4), highly tolerant (Praba et al., 2009). Seeds of rice and wheat were obtained from the International Rice Research Institute (IRRI) and from the International Maize and Wheat Improvement Center (CIMMYT), respectively.

Pot experiments were conducted in an open field, which was sheltered from rain by a mobile transparent polyethylene shelter, at Yangzhou University, China $\left(32^{\circ} 30^{\prime} \mathrm{N}, 119^{\circ} 25^{\prime} \mathrm{E}\right)$ in 2013 and 2014. Across two years, rice seeds were sown in saturated soil after pre-germination, and 
wheat seeds were sown directly in moist soil. Each pot $(30 \mathrm{~cm}$ in height and $25 \mathrm{~cm}$ in diameter) was filled with sandy loam soil from a local rice/wheat rotated field. Rice and wheat plants were grown in their respective natural growing season (Table 4.1). In both years, plants were managed as described by Ouyang et al. (2017). Three levels of soil moisture were imposed after seedling establishment, i.e. control (CT), mild drought (MD), and more severe drought (SD). Because rice and wheat are naturally adapted to different moisture environments (Praba et al., 2009), different intensities of stress were imposed (Table 4.1). Soil water potential was monitored with a tensiometer (Institute of Soil Sciences, Chinese Academy of Sciences, Nanjing, China) installed in each pot at a depth of $15 \mathrm{~cm}$. We checked the tensiometer twice a day, and water was added to bring soil moisture back to the upper limit of the target stress when tensiometer readings reached the lower limit. Once stress was imposed, the target levels were maintained until physiological maturity of the grains. Pots were arranged in a completely randomized design. All measurements were done in three replicates (one pot as one replicate), except for the measurement of grain yield and yield components.

\subsubsection{Plant growth measurements}

Whole rice plants were sampled at flowering stage in 2013, and at vegetative stage and flowering stage in 2014. In 2013, plant shoots (including leaves, stems and panicles) were cut and above-ground dry biomass was determined after oven drying at $70{ }^{\circ} \mathrm{C}$ for 3 days. The root biomass was reported in our previous study (Ouyang et al., 2020). In 2014, plant water status, stem and leaf anatomy were measured before the plant was used for destructive sampling. Several plant growth traits were determined additionally in 2014. The number of tillers was counted after shoots were cut off. Leaf area per pot was measured with an area meter (LI-3100; LI-COR, Lincoln, Nebraska, USA). Leaf, stem and panicle (or spike) (flowering stage sampling) were separately oven dried at $70{ }^{\circ} \mathrm{C}$ for 3 days prior to weighing. Biomass partitioning was presented as root, stem, leaf and panicle to total weight ratios.

\subsubsection{Yield and yield components}

For both species and in both years, yield (weight of all filled grains) per pot was determined as average from five pots per replicate. Yield components (number of panicles/spikes per pot, number of spikelets per panicle or grains per spike, filled-grain percentage, and 1000 filledgrain weight) were measured according to Praba et al. (2009), and were determined from plants of three randomly chosen pots per replicate of each treatment. Filled and unfilled spikelets were 
counted for rice, and only filled grains were measured for wheat. The filled-grain percentage was defined as the number of filled grains in proportion to total number of spikelets. The number of spikelets per panicle or grains per spike was calculated as the total number of spikelets/grains per pot by the number of panicles/spikes per pot.

\subsubsection{Plant water status}

In 2014, transpiration and leaf water potential ( $\left.\Psi_{\text {leaf }}\right)$ were measured at vegetative and flowering stages. Because rice and wheat have different growth durations, rice samples for vegetative stage were taken after 30 days, while wheat samples were taken after 20 days, of stress imposition. Sampling time for flowering stage is listed in Table 4.1. To prevent evaporation, soil surfaces were covered tightly with aluminum foil and plastic wrap, after the plants were watered to reach the upper-stress level. In order to avoid the effect of fluctuation in outdoor environment, sealed pots were immediately moved into a growth chamber with setpoint air temperature at $28{ }^{\circ} \mathrm{C}$ for rice and $23{ }^{\circ} \mathrm{C}$ for wheat, $65 \%$ relative humidity, and a photosynthetic photon flux density at the leaf surface of $1200 \mu \mathrm{mol} \mathrm{m}^{-2} \mathrm{~s}^{-1}$ (artificial light source). The initial pot weight was determined once pots were moved into the growth chamber. Total transpiration rate was calculated based on differences in pot weight measured after two hours. Average transpiration rate per unit of leaf area was determined by dividing total transpiration rate by whole plant leaf area. All transpiration measurements were conducted between

Table 4.1 Description of cultivation and water regimes for rice and wheat cultivars

\begin{tabular}{|c|c|c|c|}
\hline \multicolumn{2}{|l|}{ Species } & Oryza sativa & Triticum aestivum \\
\hline \multicolumn{2}{|l|}{ Cultivars } & IR64, Apo, UPL7 & S82, We4 \\
\hline \multicolumn{2}{|l|}{ Sowing time } & June 2013, 2014 & November 2013, 2014 \\
\hline \multicolumn{2}{|c|}{ Density (seedlings per pot) } & 3 & 8 \\
\hline \multicolumn{2}{|c|}{ Soil $\mathrm{pH}$} & $5.5-6.0$ & $6.5-7.0$ \\
\hline \multicolumn{2}{|c|}{ Initial soil moisture } & Saturated & 0 to $-5 \mathrm{kPa}$ \\
\hline \multicolumn{2}{|c|}{ Stress imposed time (leaves) ${ }^{a}$} & 5 & 4 \\
\hline \multirow{2}{*}{ Sampling time ${ }^{\mathrm{b}}$} & Vegetative stage & 30 & 20 \\
\hline & Flowering stage & $77-86$ & $45-51$ \\
\hline \multirow{3}{*}{ Water regimes $^{c}$} & Control (CT) & $\begin{array}{l}2 \text { to } 5 \mathrm{~cm} \text { water } \\
\text { above soil surface }\end{array}$ & 0 to $-5 \mathrm{kPa}$ \\
\hline & Mild drought (MD) & 0 to $-5 \mathrm{kPa}$ & -20 to $-40 \mathrm{kPa}$ \\
\hline & More severe drought (SD) & -20 to $-40 \mathrm{kPa}$ & -50 to $-70 \mathrm{kPa}$ \\
\hline
\end{tabular}

\footnotetext{
a Leaf number on the main stem;

${ }^{\mathrm{b}}$ Presented as days after stress imposition for both species;

${ }^{\mathrm{c}}$ Expressed in soil water potential.
} 
11:00 to 14:00 h. After that, $\Psi_{\text {leaf }}$ was measured on the topmost fully expanded leaf (vegetative stage) or penultimate leaf (flowering stage) of the main stem by using a thermocouple psychrometer (Wescor PSYPRO, Inc., Logan, UT, USA). Three to four discs (about $6 \mathrm{~mm}$ in diameter) from the middle part of the leaves were cut and sealed in the C-52 psychrometer chamber. The readings were recorded by a water potential data logger in the psychrometric mode, and the averaged value from the same leaf was considered to represent $\Psi_{\text {leaf. }}$

\subsubsection{Stem and leaf anatomy}

Leaflets close to the portion where leaf water potential was measured were collected to study the leaf anatomy. The stems (internodes), to which the sampled leaves were attached, were collected to study the stem anatomy. Cross sections of the leaf and stem were taken using sharp blades and photographed using a light microscope (Axio Imager D2, Carl Zeiss, Germany). Analyses of leaf and stem cross-sectional images were performed using ImageJ software (Bethesda, Maryland, USA) (Abràmoff et al., 2004). Leaf width was defined as leaf blade width without midrib. Leaf cross-sectional tissue area (without epidermis, bulliform cells and midrib), number and area of leaf vascular bundles (VBs), and area of leaf xylem vessels were determined. Leaf xylem area to leaf tissue area ratio were calculated from these data. Similarly for stems, the inner and outer cross-sectional areas of the stem, number and area of stem VBs, and area of stem xylem vessels were measured. Stem tissue area and stem xylem area to stem tissue area ratio were calculated from these data. A schematic sketch of measured anatomical properties is provided in Fig. 4.1. Root xylem number and area were determined in a previous study (Ouyang et al., 2020).
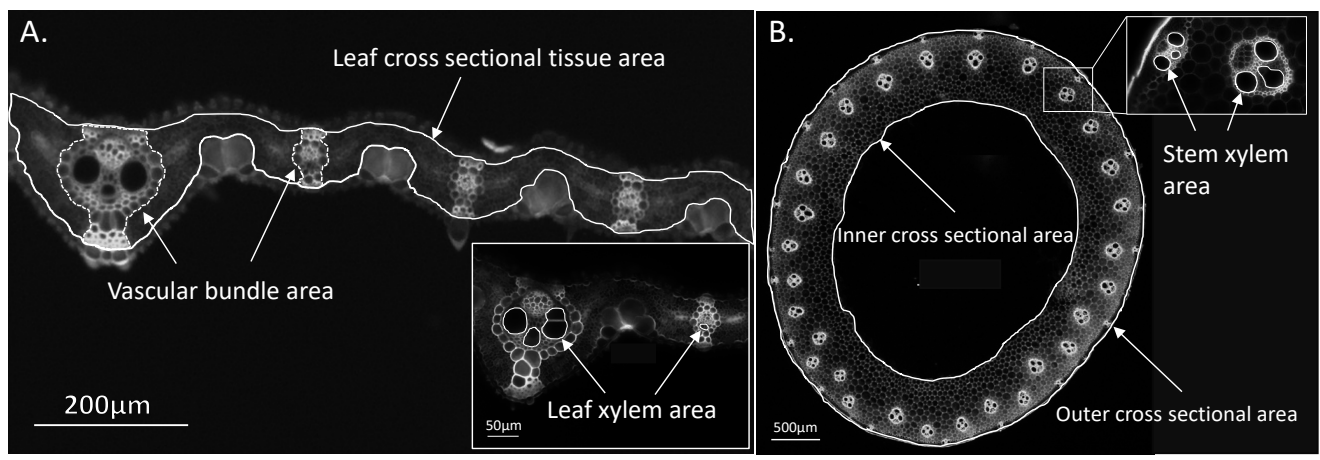

Fig. 4.1 Light micrographs illustrating (A) leaf and (B) stem structures (Apo) used to calculate anatomical parameters. Cross sections were taken from fresh leaves and stems and viewed under fluorescent light with black and white colour. 


\subsubsection{Statistical analyses}

Data were analysed using a general linear model (GLM) to test the significance for the effects of cultivar, treatment, stage and their interactions on each parameter, with the $\mathrm{R}$ programme (http://www.R-project.org/). Linear regression analyses were also conducted to assess the relationship between anatomical parameters and leaf water potential, and the relationship between leaf water potential and yield.

\subsection{Results}

\subsubsection{Plant growth and biomass partitions among each organ}

Above-ground (shoot) and below-ground (root) dry biomass of three rice cultivars and two wheat cultivars in response to water deficit treatments were first tested at flowering stage in year 2013. Water deficit decreased the above-ground dry biomass in both species, with no significant interaction between species and treatments (Fig. 4.2A; Table S4.1). However, a significant species $\times$ treatment effect $(P<0.05)$ was observed for root biomass: rice (up to $46 \%$ reduction) had higher reduction of root biomass than wheat (up to $13 \%$ reduction) (Fig. 4.2B).
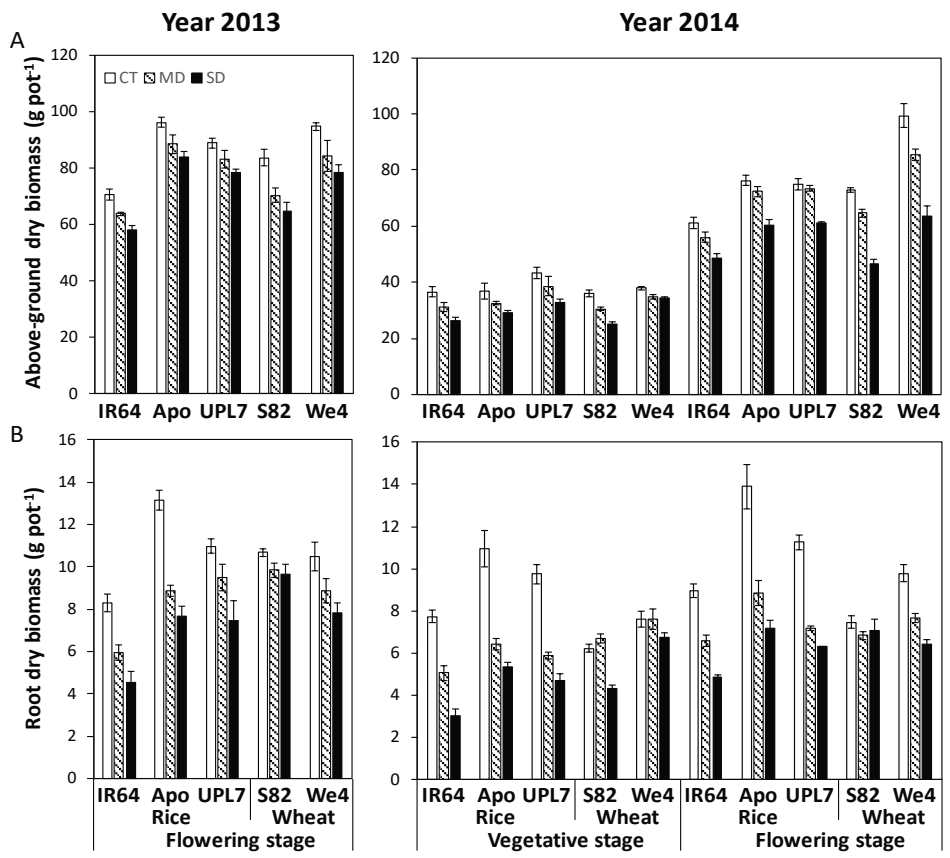

Fig. 4.2 Response of (A) above-ground (shoot) dry biomass, and (B) below-ground (root) dry biomass of rice and wheat cultivars to water treatments: control (CT), mild drought (MD), and more severe drought (SD). Data collected at flowering stage in 2013 (left panels) and at vegetative and flowering stages in 2014 (right panels). Bars represent standard errors of the mean for three replicates. 
The effects on above-ground and root dry biomass of water deficit treatments in year 2014 generally followed those in year 2013 (Fig. 4.2). Across years, stages and treatments, lowland rice cultivar IR64 had the lowest root biomass, compared with the other two rice cultivars (Fig. 4.2B). To further confirm the observed variation in plant growth, we examined shoot and root morphological variables in year 2014. Overall, water deficit treatments reduced the tested growth traits in 2014 (Table S4.2). Stem (tiller) number per pot was lower under water deficit treatments than in the control in rice for cultivar Apo and UPL7 at flowering stage, and in wheat at both stages. Leaf area, leaf biomass and panicle/spike number per pot were lower under water deficit than in the control in all cultivars, and those effects were not significantly different between species or between stages (Table S4.1). The productive tiller percentage was significantly decreased only in IR64, but not in other cultivars.

In general, both species had a lower biomass partitioning to roots than to stems, leaves and panicles (at flowering stage) (Fig. 4.3). Root weight ratio varied only among rice cultivars $(P<0.001)$, with IR64 having the lowest root weight ratio across treatments and stages. Across stages, root weight ratio was decreased by water deficit treatments only in rice cultivars $(P<0.001)$. Stem weight ratio increased under water-deficit treatments only in rice cultivars $(P<0.001)$, while the leaf weight ratio decreased only in wheat $(P<0.01)$. These changes were not significantly different between cultivars within each species or between stages (Table S4.1). The panicle weight ratio at flowering stage was decreased by water deficit in all rice cultivars $(P<0.001)$, with UPL7 having a lower reduction of panicle weight ratio than the other two rice cultivars (Fig. 4.3B). On the other hand, water deficit did not induce a significant change in panicle weight ratio in wheat $(P>0.05)$.

\subsubsection{Yield and yield components}

Grain yield of rice in 2013 was 11-20\% higher than that in 2014, while grain yield of wheat in 2013 was 12-17\% lower than that in 2014 (Table 4.2). Nevertheless, the yield in both experimental years showed similar tendencies in response to water deficit, except wheat cultivars had stronger yield decrease under SD conditions in 2014 compared with that in 2013. A significant cultivar $\times$ treatment effect $(P<0.01)$ was observed for yield per pot in rice. Across years, the highest and lowest reduction recorded in lowland rice cultivar IR64 (by 27\%/52\% under MD/SD conditions) and in upland rice cultivar UPL7 (by 7\%/34\% under MD/SD conditions), respectively (Table 4.2). On the other hand, wheat cultivars recorded on average $95 \%$ and $70 \%$ of control yield under MD and SD conditions, respectively (Table 4.2). Overall, 
Fig. 4.3 Biomass partitioning to various organs of rice and wheat cultivars in different water treatments: control (CT), mild drought (MD), and more severe drought (SD). (A) root, stem (tiller), and leaf weight ratio at vegetative stage, and (B) root, stem (tiller), leaf, and panicle weight ratio at flowering stage. Bars represent standard errors of the mean for three replicates.

the number of panicles per pot decreased under water deficit treatments in both species, with rice recording a lower decrease $(7 \%$ $19 \%$ ) than wheat (19\%-21\%) under SD conditions. In both years, water deficit significantly influenced the number of spikelets per panicle in

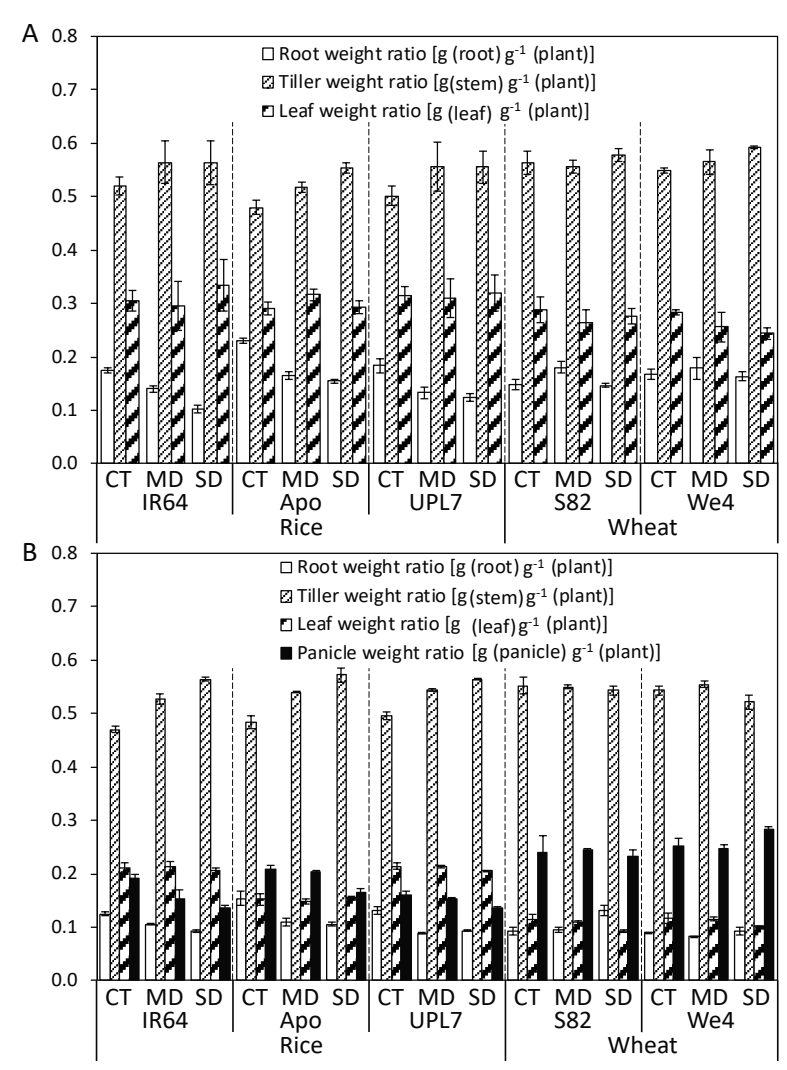
rice $(P<0.001)$ but not the number of grains per spike in wheat $(P>0.05)$. The number of spikelets per panicle was clearly decreased by SD in all rice cultivars $(P<0.001)$, but decreased by MD only in IR64 (Table 4.2). A decreased filled grain\% was observed in IR64 and Apo under SD conditions (Table 4.2). In general, water deficit decreased 1000-grain weight in all cultivars. The water deficit effect on 1000-grain weight in rice was stronger $(P<0.001)$ in 2014 (up to $4 \%$ reduction) than in 2013 (up to $7 \%$ reduction).

\subsubsection{Transpiration rate and leaf water potential}

Water deficit decreased the average transpiration rate per unit of leaf area, with no significant difference between species and treatments (Fig. 4.4A; Table S4.3). Across stages, the decrease in average transpiration rate in rice was mild under $\mathrm{MD}$ conditions $(P<0.05$; up to $13 \%$ decrease) and strong under SD conditions ( $P<0.001$; up to $36 \%$ decrease) (Fig. 4.4A). Furthermore, the decrease in average transpiration rate in wheat was higher $(P<0.001)$ at vegetative stage (up to $34 \%$ decrease under SD conditions) than at flowering stage (up to $11 \%$ decrease under SD conditions). 
Table 4.2 Yield and yield components of rice and wheat under different water regimes.

\begin{tabular}{|c|c|c|c|c|c|c|c|c|}
\hline Species & Year & Cultivar & Treatment & $\mathrm{Y}\left(\mathrm{g} \mathrm{pot}^{-1}\right)$ & PN (No. pot $^{-1}$ ) & SPP (No.) & $\mathrm{FG} \%{ }^{\mathrm{a}}$ & GW (g) \\
\hline \multirow{18}{*}{ Rice } & \multirow{9}{*}{2013} & \multirow{3}{*}{ IR64 } & CT & $52.0 \pm 1.0$ & $30 \pm 0.3$ & $77 \pm 1$ & $87.4 \pm 0.9$ & $25.3 \pm 0.2$ \\
\hline & & & MD & $37.3 \pm 1.2$ & $27 \pm 0.7$ & $68 \pm 5$ & $85.4 \pm 1.1$ & $23.7 \pm 0.4$ \\
\hline & & & SD & $24.8 \pm 1.8$ & $25 \pm 2.0$ & $55 \pm 2$ & $77.9 \pm 1.1$ & $23.6 \pm 0.5$ \\
\hline & & \multirow{3}{*}{ Apo } & $\mathrm{CT}$ & $64.5 \pm 1.7$ & $21 \pm 0.3$ & $149 \pm 6$ & $91.3 \pm 1.2$ & $22.3 \pm 0.1$ \\
\hline & & & MD & $53.7 \pm 1.5$ & $20 \pm 0.3$ & $136 \pm 7$ & $87.1 \pm 0.9$ & $22.0 \pm 0.1$ \\
\hline & & & SD & $45.0 \pm 1.8$ & $20 \pm 0.3$ & $126 \pm 4$ & $82.4 \pm 1.2$ & $21.4 \pm 0.3$ \\
\hline & & \multirow{3}{*}{ UPL7 } & $\mathrm{CT}$ & $68.3 \pm 3.2$ & $23 \pm 0.9$ & $143 \pm 11$ & $86.3 \pm 0.4$ & $23.8 \pm 0.1$ \\
\hline & & & MD & $63.4 \pm 1.9$ & $23 \pm 0.3$ & $139 \pm 7$ & $85.5 \pm 0.9$ & $23.5 \pm 0.1$ \\
\hline & & & SD & $49.5 \pm 1.5$ & $22 \pm 0.7$ & $113 \pm 2$ & $87.3 \pm 1.3$ & $23.2 \pm 0.6$ \\
\hline & \multirow{9}{*}{2014} & \multirow{3}{*}{ IR64 } & $\mathrm{CT}$ & $46.3 \pm 1.1$ & $25 \pm 0.6$ & $77 \pm 2$ & $89.9 \pm 0.7$ & $26.8 \pm 0.3$ \\
\hline & & & MD & $34.4 \pm 1.3$ & $23 \pm 0.6$ & $66 \pm 2$ & $90.5 \pm 0.6$ & $25.7 \pm 0.1$ \\
\hline & & & SD & $22.3 \pm 0.7$ & $20 \pm 0.7$ & $56 \pm 4$ & $78.6 \pm 4.0$ & $24.7 \pm 0.3$ \\
\hline & & \multirow{3}{*}{ Apo } & CT & $51.6 \pm 0.4$ & $15 \pm 0.3$ & $160 \pm 4$ & $91.1 \pm 0.8$ & $23.2 \pm 0.1$ \\
\hline & & & MD & $45.7 \pm 1.1$ & $14 \pm 0.7$ & $163 \pm 6$ & $92.0 \pm 1.3$ & $22.3 \pm 0.2$ \\
\hline & & & SD & $26.9 \pm 3.1$ & $14 \pm 0.3$ & $115 \pm 13$ & $79.8 \pm 4.6$ & $20.0 \pm 0.1$ \\
\hline & & \multirow{3}{*}{ UPL7 } & $\mathrm{CT}$ & $50.2 \pm 1.1$ & $17 \pm 0.3$ & $131 \pm 2$ & $84.1 \pm 0.7$ & $27.0 \pm 0.1$ \\
\hline & & & MD & $46.4 \pm 0.6$ & $15 \pm 0.9$ & $127 \pm 7$ & $91.7 \pm 0.7$ & $25.8 \pm 0.1$ \\
\hline & & & SD & $29.0 \pm 0.9$ & $13 \pm 0.6$ & $104 \pm 10$ & $88.8 \pm 1.9$ & $23.8 \pm 0.3$ \\
\hline \multirow{12}{*}{ Wheat } & \multirow{6}{*}{2013} & \multirow{3}{*}{ S82 } & $\mathrm{CT}$ & $59.8 \pm 2.0$ & $36 \pm 1.0$ & $42 \pm 1$ & - & $40.0 \pm 0.7$ \\
\hline & & & MD & $56.7 \pm 1.6$ & $35 \pm 1.5$ & $42 \pm 4$ & - & $39.1 \pm 1.1$ \\
\hline & & & SD & $45.5 \pm 2.0$ & $32 \pm 1.0$ & $38 \pm 1$ & - & $37.7 \pm 0.4$ \\
\hline & & \multirow{3}{*}{ We4 } & $\overline{\mathrm{CT}}$ & $66.0 \pm 1.4$ & $41 \pm 0.7$ & $36 \pm 1$ & - & $45.6 \pm 0.8$ \\
\hline & & & MD & $62.8 \pm 0.3$ & $39 \pm 0.7$ & $36 \pm 1$ & - & $44.6 \pm 1.3$ \\
\hline & & & SD & $55.2 \pm 2.6$ & $36 \pm 2.0$ & $37 \pm 1$ & - & $42.2 \pm 0.5$ \\
\hline & \multirow{6}{*}{2014} & \multirow{3}{*}{ S82 } & $\mathrm{CT}$ & $66.8 \pm 0.8$ & $33 \pm 0.9$ & $43 \pm 2$ & - & $42.1 \pm 0.3$ \\
\hline & & & MD & $63.3 \pm 1.3$ & $32 \pm 0.3$ & $44 \pm 1$ & - & $42.2 \pm 1.0$ \\
\hline & & & SD & $40.8 \pm 1.6$ & $24 \pm 0.6$ & $41 \pm 4$ & - & $41.8 \pm 0.5$ \\
\hline & & \multirow{3}{*}{ We4 } & $\mathrm{CT}$ & $77.4 \pm 1.0$ & $40 \pm 0.3$ & $38 \pm 2$ & - & $48.7 \pm 0.2$ \\
\hline & & & MD & $74.5 \pm 1.8$ & $36 \pm 1.5$ & $40 \pm 2$ & - & $48.6 \pm 0.2$ \\
\hline & & & SD & $53.6 \pm 2.4$ & $28 \pm 0.7$ & $38 \pm 3$ & - & $46.8 \pm 0.3$ \\
\hline \multirow{7}{*}{\multicolumn{2}{|c|}{ Rice }} & \multicolumn{2}{|c|}{ Cultivar (C) } & $* * *$ & $* * *$ & **** & $*$ & $* * *$ \\
\hline & & \multicolumn{2}{|c|}{ Treatment $(\mathrm{T})$} & $* * *$ & $* * *$ & $* * *$ & $* * *$ & $* * *$ \\
\hline & & Year $(\mathrm{Y})$ & & $* * *$ & $* * *$ & ns & $*$ & $* * *$ \\
\hline & & Cultivar $x$ & Treatment & $* *$ & $*$ & $*$ & $* * *$ & $*$ \\
\hline & & Cultivar $\times$ & Year & $* * *$ & $* *$ & $* * *$ & $\mathrm{~ns}$ & $* * *$ \\
\hline & & Treatmen & $x$ Year & ns & ns & $\mathrm{ns}$ & $*$ & $* * *$ \\
\hline & & $\mathrm{C} \times \mathrm{T} \times \mathrm{Y}$ & & ns & ns & $* *$ & ns & $*$ \\
\hline & & Cultivar ( & & $* * *$ & $* * *$ & $* * *$ & - & $* * *$ \\
\hline & & Treatmen & & $* * *$ & $* * *$ & $\mathrm{~ns}$ & - & $* *$ \\
\hline & & Year $(\mathrm{Y})$ & & $* * *$ & $* * *$ & $* *$ & - & $* * *$ \\
\hline Wh & & Cultivar $x$ & Treatment & ns & $\mathrm{ns}$ & ns & - & ns \\
\hline & & Cultivar $\times$ & Year & $*$ & ns & ns & - & ns \\
\hline & & Treatmen & $x$ Year & $* * *$ & $* * *$ & ns & - & ns \\
\hline & & $\mathrm{C} \times \mathrm{T} \times \mathrm{Y}$ & & ns & ns & ns & - & ns \\
\hline & & Species (S & & $* * *$ & $* * *$ & $* * *$ & - & $* * *$ \\
\hline & & Treatmen & & $* * *$ & $* * *$ & $*$ & - & $* *$ \\
\hline & & Year $(Y)$ & & $* *$ & $* * *$ & ns & - & $* * *$ \\
\hline Rice + & Wheat & Species $\times$ & reatment & ns & $*$ & ns & - & ns \\
\hline & & Species $\times$ & Year & $* * *$ & ns & ns & - & $*$ \\
\hline & & Treatmen & $\times$ Year & ns & ns & ns & - & ns \\
\hline & & $\mathrm{S} \times \mathrm{T} \times \mathrm{Y}$ & & $*$ & ns & $* * *$ & - & $*$ \\
\hline
\end{tabular}

$\overline{\mathrm{Y}}=$ yield per pot $(\mathrm{g}) ; \mathrm{PN}=$ number of panicles or spikes per pot $\left(\mathrm{No} \cdot \operatorname{pot}^{-1}\right) ; \mathrm{SPP}=$ number of spikelets per panicle in rice or number of grains per spike in wheat (No.); $\mathrm{FG} \%=$ filled-grain $\%$; $\mathrm{GW}=1000$-grain weight $(\mathrm{g})$. Significance level: ${ }^{*}, P<0.05 ; * *, P<0.01 ; * * *, P<0.001$; ns $=$ non-significant. 
Midday leaf water potential $\left(\Psi_{\text {leaf }}\right)$ varied largely between species, with rice having a significantly lower $\Psi_{\text {leaf }}$ than wheat (Fig. 4.4B). A significant species $\times$ treatment effect $(P<0.001)$ was observed for $\Psi_{\text {leaf. }}$ Rice cultivars experienced a significantly more negative $\Psi_{\text {leaf }}$ under water deficit, with up to $33 \% / 18 \%$ (vegetative/flowering) reduction by $\mathrm{MD}$, and $41 \% / 56 \%$ (vegetative/flowering) reduction by SD (Fig. 4.4B). Upland variety UPL7 and lowland variety IR64 showed the lowest and highest reduction of $\Psi_{\text {leaf }}$ under water-deficit treatments, respectively. For wheat, MD decreased $\Psi_{\text {leaf }}$ by on average $6 \%$ (at both stages), while SD decreased it by up to $26 \% / 33 \%$ (vegetative/flowering) (Fig. 4.4B).

\subsubsection{Leaf anatomical parameters}

Light microscopy of the leaf transverse sections revealed a similar general leaf structure in rice and wheat (Fig. S4.1 left panels). Variations in some anatomical traits were observed between species and among cultivars within each species (Table S4.3). Leaf blade width (midrib excluded) significantly varied only within rice, with IR64 having the narrowest and UPL7 having the widest leaf blades (Fig. S4.2A). In each species, cultivars with wider leaf blades had larger leaf tissue area, higher vascular bundle (VB) number and larger VB area (Fig. S4.2). This trend was confirmed by the significant positive correlations of leaf blade width with leaf tissue area $\left(P<0.001, \mathrm{R}^{2}=0.87\right.$ in rice; $P<0.001, \mathrm{R}^{2}=0.58$ in wheat), with leaf $\mathrm{VB}$ number $(P<0.001$, $\mathrm{R}^{2}=0.85$ in rice; $P<0.001, \mathrm{R}^{2}=0.58$ in wheat $)$, and with total leaf $\mathrm{VB}$ area $\left(P<0.001, \mathrm{R}^{2}=0.80\right.$ in rice; $P<0.001, \mathrm{R}^{2}=0.67$ in wheat).
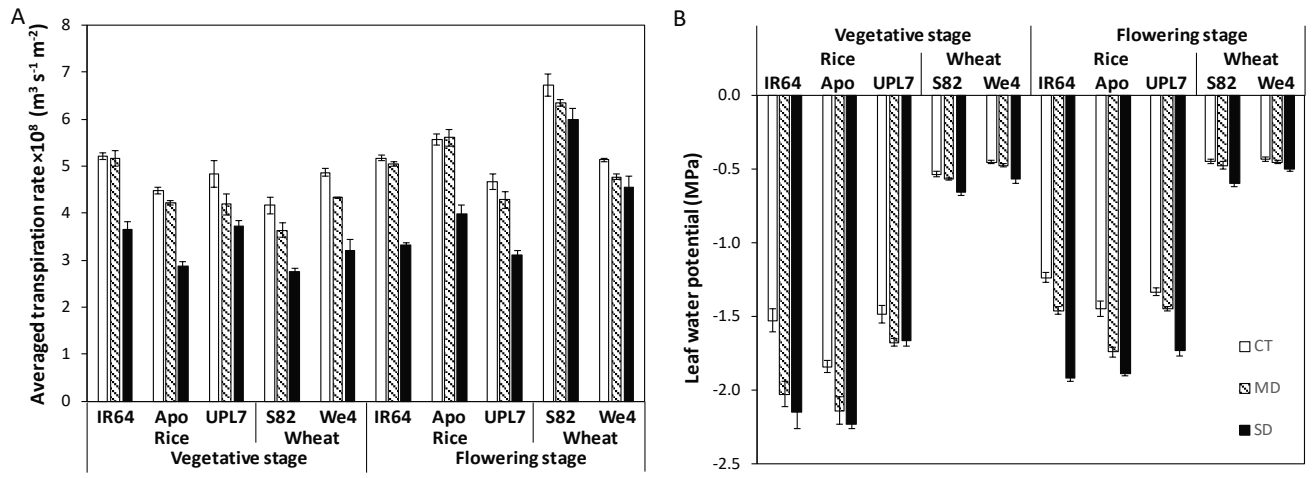

Fig. 4.4 Response of (A) averaged transpiration rate per unit leaf area and (B) midday leaf water potential $\left(\Psi_{\text {leaf }}\right)$ of rice and wheat cultivars to water treatments: control (CT), mild drought (MD) and more severe drought (SD), at vegetative and flowering stage. Bars represent standard errors of the mean for three replicates. 
In each species, a cultivar with larger total leaf VB area under control and water deficit conditions also showed larger total leaf xylem area (Fig. 4.5A and Fig. S4.2D). Across stages and treatments, the total leaf xylem area was one and a half times higher (Fig. 4.5A), and the leaf xylem area to leaf tissue area ratio was three times higher (Fig. 4.5B), in rice than in wheat. Water deficit decreased the total leaf xylem area and the leaf xylem area to leaf tissue area ratio in both species at both stages, with no significant interaction between species and treatments (Table S4.3).

\subsubsection{Stem anatomical parameters}

Rice and wheat cultivars had a similar general stem structure (Fig. S4.1 right panels). Across treatments, cultivars with larger stem cross-sectional area had larger stem tissue area, higher stem VB number, larger stem total VB area and larger stem total xylem area (Fig. 4.5C and Fig. S4.3). The total xylem area in rice stem was not significantly influenced by the MD treatment $(P>0.05)$ but decreased by SD $(P<0.05)$, without significant interaction between cultivar and treatment (Fig. 4.5C). Nonetheless, upland cultivar UPL7 had the highest value of total xylem
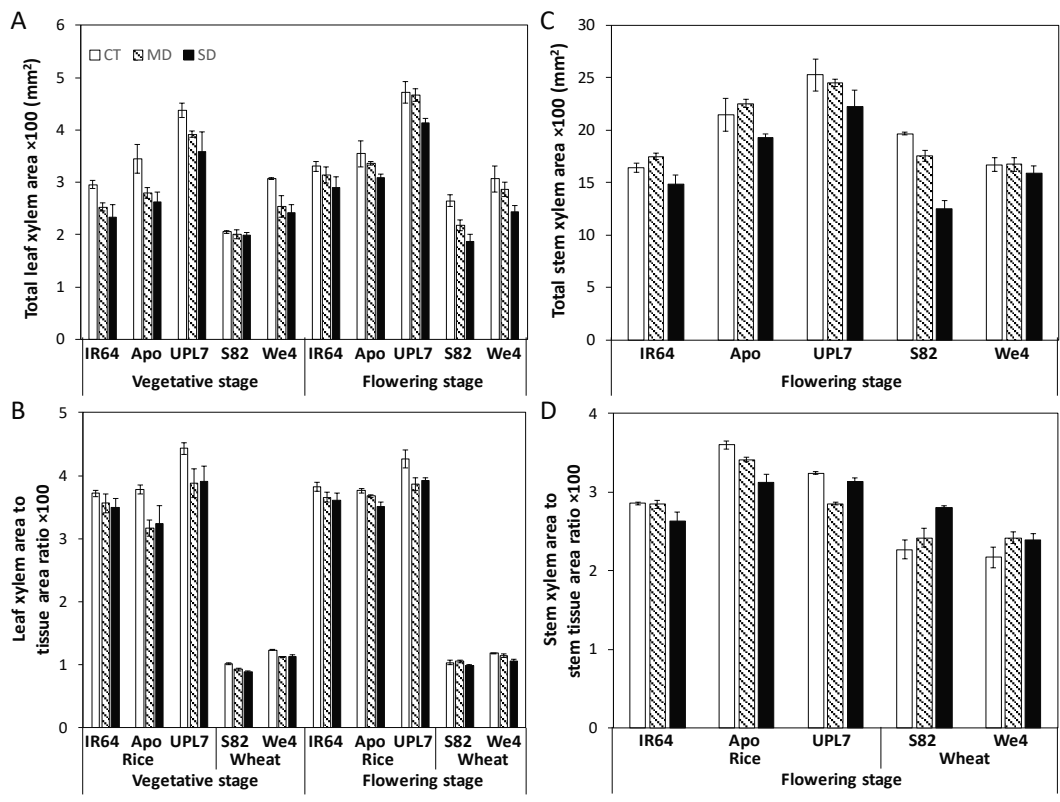

Fig. 4.5 Response of xylem characteristics of leaf and stem anatomical parameters of rice and wheat cultivars to water treatments: control (CT), mild drought (MD), and more severe drought (SD). (A) total leaf xylem area, (B) leaf xylem area to leaf tissue area ratio, (C) total stem xylem area, and (D) stem xylem area to stem tissue area ratio. Leaf sections were collected at vegetative and flowering stages. Stem sections were collected at flowering stage. Bars represent standard errors of the mean for three replicates. 
area across treatments, while lowland cultivar IR64 had the lowest. In wheat stems, S82 had a higher total xylem area than We4 under CT conditions. Water deficit treatments decreased the total xylem area in S82 $(P<0.001$ and $P<0.001)$ but did not significantly affect it in We4 $(P>0.05$ and $P>0.05)$, resulting in larger total xylem area in We4 than in S82 under SD conditions. Stem xylem area to tissue area ratio significantly varied within each species (Fig. 4.5D; Table S4.4). Under water deficit treatments, the ratio decreased in rice cultivars IR64 and Apo, but increased in wheat.

\subsubsection{Relations between anatomical traits, leaf water potential and yield}

Significant correlations were observed between $\Psi_{\text {leaf }}$ and most of the leaf anatomical parameters, but $\Psi_{\text {leaf }}$ correlated more with leaf xylem characteristics than with the other leaf parameters (Table S4.5). Positive correlations were observed between $\Psi_{\text {leaf }}$ and leaf xylem area to leaf tissue area ratio in each species (Fig. 4.6). Furthermore, the association between $\Psi_{\text {leaf }}$ and leaf xylem area to leaf tissue area ratio was strengthened by water deficit, from non-significant under CT conditions to significant under MD and SD conditions. Noteworthily, upland rice cultivar UPL7 had the highest value in leaf xylem area to leaf tissue area ratio but the lowest reduction rate in $\Psi_{\text {leaf }}$ under water deficit treatments. $\Psi_{\text {leaf }}$ was positively correlated with the total stem xylem area under SD conditions in rice $\left(P<0.05, \mathrm{R}^{2}=0.36\right)$. However, no direct relationships between $\Psi_{\text {leaf }}$ and stem anatomical parameters were observed in rice when data from all treatments were combined (Table S4.5). On the other hand, positive correlations between $\Psi_{\text {leaf }}$ and several stem parameters were observed in wheat, when data from all treatments were combined.

Fig. 4.6 Relationship of the leaf water potential with leaf xylem area to tissue area ratio in rice and wheat grown under three water treatments. Data obtained from vegetative and flowering stage was marked with open and closed symbols, respectively. Linear regressions were fitted for each cultivar, for pooled rice and wheat. Due to the differences of the leaf water potential between rice and wheat cultivars, data for wheat are shown in an inset. The significance of each correlation is shown by asterisks: *, $P<0.05$; **, $P<0.01$; ***, $P<0.001$.

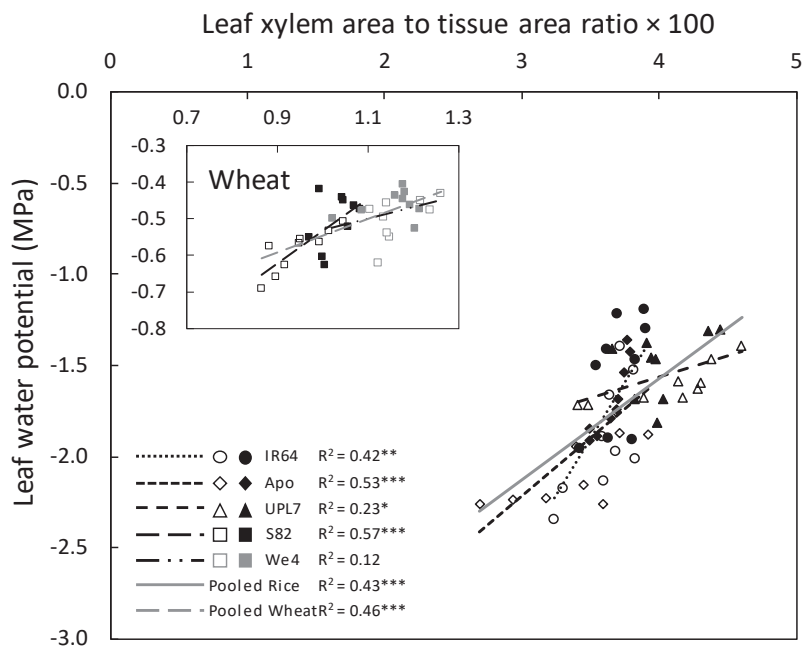


Fig. 4.7 Relationship between leaf water potential decrease (at flowering stage) and yield decrease in rice and wheat grown under MD and SD conditions. Data obtained from the decreased percentage under $\mathrm{MD}$ and $\mathrm{SD}$ conditions was marked with open and closed symbols, respectively. Linear regressions were fitted for overall data and for each species.

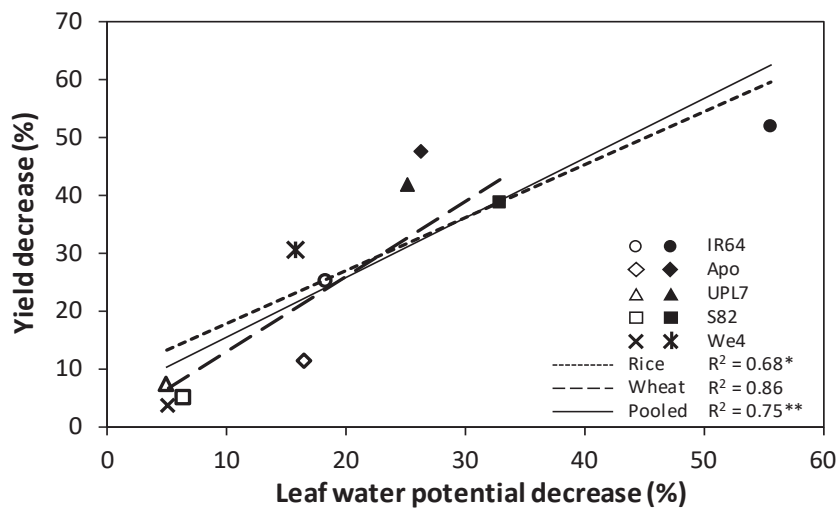

The significance of each correlation is shown by asterisks: $*, P<0.05$; **, $P<0.01$.

There was a positive correlation between the decrease in $\Psi_{\text {leaf }}$ at flowering stage and the decrease in yield by stress treatments when data from rice and wheat were combined $(P<0.01$, $\mathrm{R}^{2}=0.75$; Fig. 4.7). A positive association between the decrease of $\Psi_{\text {leaf }}$ at flowering stage and the yield decrease was also observed in each species, but the relationship was only significant in rice $\left(P<0.05 ; \mathrm{R}^{2}=0.68\right)$, but was marginally significant in wheat $(0.05<P<0.10)$.

\subsection{Discussion}

\subsubsection{Effects of water deficit on plant growth and biomass partitioning}

Our study aimed at understanding why rice plants cannot perform well like other dryland cereals, such as wheat, when grown under relatively dry conditions. We did not intend to impose severe drought to rice plants. The highest water deficit treatment imposed to rice in this study was similar to, or slightly lower than, the deficit in aerobic culture (SD conditions with soil potential between -20 to $-40 \mathrm{kPa}$ ) (Kato and Okami, 2011). In order to produce stress symptoms in wheat, a higher level of water deficit stress was applied to plants under the more severe treatment (SD soil potential between -50 to $-70 \mathrm{kPa}$ ). Even without any sign of drought stress like leaf rolling and drying, the growth of rice and wheat plants was impeded by both treatments in varying degrees (Fig. 4.2). Shoot growth, as indicated by traits including number of tillers, leaf biomass, leaf area, stem biomass and panicle (or spike) biomass, was inhibited under waterlimited conditions (Table S4.2). The decreases in shoot growth reflect plant adaptation to water deficit, aimed at ensuring plant survival by limiting water loss (Claeys and Inzé, 2013). Although plants were grown in relatively restricted pots in our experiments, the observed 
morphological changes are consistent with those previously reported for rice and wheat under field conditions (Reynolds et al., 2007; Henry et al., 2012).

By comparing plant growth under water deficit treatments with the control conditions in rice and wheat, we revealed several features that are characteristic of rice plants. First, at both stages, all rice plants developed roots poorly even under the MD conditions with a soil potential at 0 to $-5 \mathrm{kPa}$ (Fig. 4.2B). In addition, analysis of biomass partitioning suggested a restricted root growth (decreased root weight ratio) in rice but not in wheat (Fig. 4.3). Promotion of biomass partitioning to roots was suggested to be an adaptive response to water limitation (Price et al., 2002; Yin and Schapendonk, 2004; Kato et al., 2006). However, an opposite effect would occur if water stress was very severe (Asch et al., 2005) or stress was imposed at the seedling stage (Kato and Okami, 2010). The restricted root growth (in terms of biomass amount and biomass partitioning) in MD and SD conditions indicates that rice roots were very sensitive to relatively dry conditions as if they were under severe drought stress (Kato and Okami, 2010; Kato and Okami, 2011). Furthermore, at both stages, changes in assimilate partitioning under waterlimited conditions tend to favour leaf and stem growth in rice (Fig. 4.3), in contrast to the classical functional equilibrium paradigm (Brouwer, 1983; Yin and Schapendonk, 2004). On the contrary, wheat plants slightly decreased the leaf weight partitioning but maintained the level of panicle weight partitioning across treatments (Fig. 4.3). In addition, water limitation suppressed panicle growth in rice while it maintained the level of spike weight partitioning in wheat. Panicle weight under water deficit stress was suggested to be linked to the rooting ability in rice plants (Kato et al., 2007). Limiting the water availability during early vegetative stage (as imposed in this study) would highly impede root growth, thus be detrimental to panicle growth in rice.

\subsubsection{Yield traits responded differently to water deficit in rice and wheat}

Stress occurring during the vegetative stage restricts plant growth and canopy establishment, thus affects grain yield and yield components (Pantuwan et al., 2002; Vijayaraghavareddy et $a l ., 2020)$. In our study, water-deficit treatments were imposed at the early tillering stage until plant maturity (Table 4.1), and influence of water deficit on yield and yield components was investigated. Compared with other dryland cereals, rice yield is highly susceptible to soil water deficit (Praba et al., 2009). In the present study, the MD treatment imposed to wheat was comparable with the SD treatment imposed to rice (Table 4.1). If we compare the treatment effects on the grain yield in rice and wheat at the same stress level, rice lost at least $42 \%$ of the 
control yield while wheat lost less than $10 \%$ of the control yield (Table 4.2 ).

Villegas et al. (2007) reported that the number of spikes per plant and the number of grains per spike were the yield components that are mostly affected by water deficit in wheat. However, only the number of spikes was significantly affected by water-deficit treatments in our tested wheat cultivars (Table 4.2). The largely reduced spikes in wheat at maturity under water-deficit conditions could be linked to the reduction of tillers at vegetative and flowering stages (Table S4.2). In contrast, the tiller number in rice was least affected by water treatments (Table S4.2). Instead, fewer panicles were produced, leading to a lower productive tiller percentage in all rice cultivars under water deficit treatments (Table S4.2). Filled grain\% was highly correlated with grain yield under water-limitation conditions in rice, when short-term water-deficit stress was imposed during the reproductive stage (Garrity and O'Toole, 1994). In our study, the decrease in rice yield under mild water deficit was mainly related to fewer panicles and lower 1000-grain weight. The SD treatment decreased nearly all yield components in the rice cultivars (Table 4.2). Those results suggest that prolonged water deficit influenced rice yield mainly by controlling yield components while water deficit directly affected the yield of wheat by reducing the number of tillers.

\subsubsection{Variations in plant water relations and anatomical variables}

Rice roots have a substantially lower hydraulic conductivity than other herbaceous roots, even when grown in hydroponics (Miyamoto et al., 2001). However, rice transpires more, compared to other cereals (Tanguilig et al., 1987). The low root conductivity, combined with the high transpiration demand, carries the inherent danger of xylem cavitation (Stiller et al., 2003), which could explain the relatively low $\Psi_{\text {leaf }}$ found in the rice cultivars (Fig. 4.4B). Our studies support this by comparing anatomical features between rice and wheat. Earlier, we observed a much lower xylem area (both early and late metaxylem) in rice roots than in wheat roots, which would lead to a potentially lower axial root conductance (Ouyang et al., 2020). On the other hand, rice leaves had a higher xylem area and xylem area to leaf tissue area ratio than wheat leaves (Fig. 4.5A, B), indicating that rice leaves is equipped with a more advanced xylem system to meet the demand of high transpiration. Perhaps compensating for this imbalanced design of xylem structure, rice plant develop extensively branched rooting systems under flooded culture (Ouyang et al., 2020). However, the root growth (root biomass and biomass partitioning) was highly impeded in rice by water deficit while the growth of vegetative tissues (stem and leaves) was less affected (Figs. 4.2 and 4.3), and these different effects on root and 
shoot growth must disturb the water balance in the rice plant. In contrast, wheat plants reduced leaf growth (Fig. 4.3 and Table S4.2) but maintained root growth (Figs. 4.2B and 4.3), which would favour the maintenance of the plant water status under water deficit conditions.

As leaf water potential ( $\left.\Psi_{\text {leaf }}\right)$ indicates the plant water status under different levels of water stress, the maintenance of a high leaf water potential under water deficit has long been considered to be associated with water deficit tolerance (Tanguilig et al., 1987). Rice cultivars showed differences in water-deficit tolerance under three levels of water treatments measured as midday $\Psi_{\text {leaf }}$ across stages (Fig. 4.4B). The differences of $\Psi_{\text {leaf }}$ in response to water deficit partly explained the differences in yield response to water deficit among all cultivars, as the yield decrease was positively correlated with the decrease of $\Psi_{\text {leaf }}$ at flowering stage (Fig. 4.7).

A prompt response of plants to water deficit is stomata closure, and thus transpiration declines soon after soil moisture declines (Tanguilig et al., 1987; Stiller et al., 2003). It was demonstrated that a range of -15 to $-20 \mathrm{kPa}$ at $20-\mathrm{cm}$ depth is a threshold for maintaining transpiration in aerobic soils (Kato and Okami, 2011). Similarly, across stages, we observed a severe decrease in average transpiration rate per unit of leaf area under the SD conditions in all rice cultivars, although this rate was only slightly decreased under the MD conditions (Fig. 4.4A). However, a clear decrease in $\Psi_{\text {leaf }}$ under MD conditions was observed in all rice cultivars at both stages (Fig. 4.4B). Thus, maintaining high transpiration rate per unit of leaf area of the rice plant may have caused the rapid decline in $\Psi_{\text {leaf }}$ under the MD conditions. To further confirm the observed variation in $\Psi_{\text {leaf, }}$ we investigated the relationship between $\Psi_{\text {leaf }}$ and the anatomical variables in the leaf and in the stem of the plants where $\Psi_{\text {leaf }}$ was measured.

Leaf xylem characters were strongly correlated with $\Psi_{\text {leaf }}$ under water deficit treatments in both species (Fig. 4.6), suggesting significant effects of leaf anatomy on $\Psi_{\text {leaf. }}$ In rice, the tolerant cultivar (i.e. UPL7) had broader leaf blades, which linked to a higher proportion of leaf xylem area, and maintained higher $\Psi_{\text {leaf }}$ under water deficit conditions, compared to the other two rice cultivars (Figs. 4.4 and 4.5). The reduced leaf xylem development that we observed in both species (Fig. 4.5A, B) could be an adaptive response to water deficit to reduce the water demand, which in turn prevents higher degree of xylem cavitation in the whole plant. This might explain the much less reduced value of $\Psi_{\text {leaf }}$ in the present study than previous observations where short-term water deficit treatments were mostly imposed (Bajji et al., 2001; Jongdee et al., 2002; Stiller et al., 2003). Nevertheless, a large difference in $\Psi_{\text {leaf }}$ in response to water deficit was observed between rice and wheat, when plants were growing under comparable 
treatments (i.e. MD for wheat vs SD for rice) (Table 4.1; Fig. 4.4B). The contribution of root ability to maintaining plant hydration status cannot be neglected. Recently, we found that water deficit induced strong anatomical and histochemical barriers for water flow in rice roots but not in wheat roots (Ouyang et al., 2020). Traits related to deep root growth were also suggested to be correlated with maintenance of plant water status under water deficit (Lopes and Reynolds, 2010).

In general, the stem anatomical characteristics were less responsive to water deficit than the leaf anatomical parameters, except for wheat cultivar S82 (Fig. 4.5 and Fig. S4.3). Sibounheuang et al. (2006) reported that maintenance of high leaf water potential under water deficit was associated with greater stem area and larger stem xylem diameter in rice cultivars. We did not find an association between $\Psi_{\text {leaf }}$ and stem anatomical parameters in rice (Table S4.5). Nevertheless, the stem xylem area was positively correlated with leaf xylem (data not shown), and the $\Psi_{\text {leaf }}$ was positively correlated with the total stem xylem area under the SD conditions in both species. Those results suggest that genotypic variation in leaf water potential under prolonged water deficit could be strongly associated with leaf xylem area in rice, but only indirectly associated with the stem xylem area.

\subsection{Concluding remarks}

In our study, the observed variation in leaf water potential under water-deficit conditions between various types of rice, and between rice and wheat was associated with differences in leaf vascular and xylem properties. Stiller et al. (2003) and Kato and Okami (2011) showed the importance of soil-leaf hydraulic conductance on maintaining plant water status under waterdeficit conditions, which was not covered in our study. Moreover, we only examined structural properties of single leaves and stems. How canopy structure responds to water-deficit stress in various types of rice needs further investigation. Nevertheless, our study demonstrated that compared with wheat, rice had a more severe loss of yield and reduction of yield components under water deficit. We revealed several features that were specific to the response of rice plants to water deficit. Rice plants tended to limit root growth but to maintain above-ground growth under relatively drier conditions. We showed that a sophisticated VB system was developed in rice leaves, presumably to support the high demand of transpiration in rice plants. However, root growth (i.e. root biomass and root biomass ratio) in rice was strongly restricted by water-deficit treatments, while the transpiration requirement was still relatively high. Such a situation in a rice plant could disturb the water balance of the plant. Nevertheless, the 
genotypic variation in yield response to water deficit among various types of rice, and between rice and wheat was associated with the genotypic variation in leaf water potential. Our results suggest that leaf structure, rather than stem structure, was directly responsible for the variation in leaf water potential under water deficit. Therefore, to grow rice in a drier condition, it is necessary not only to increase root growth (as proven in our previous study, Ouyang et al., 2020), but also to modify leaf anatomy in rice as shown here.

\section{Acknowledgements}

This work was supported by an anonymous private donor who financed, via Wageningen University Fund, the first author's PhD fellowship. The experimental work was financed by the College of Agriculture, Yangzhou University. We thank IRRI and CIMMYT for providing rice and wheat seeds, Mrs Zhiqin Wang and Mr Zhenxiang Zhou for assistance during experimentation, and Dr C.G. van der Linden, Dr P.S. Bindraban and Dr Krishna S.V. Jagadish for valuable support.

\section{References}

Abràmoff MD, Magelhães P, and Ram S. 2004. Image processing with ImageJ. Biophotonics International 11, 36-42.

Atlin GN, Lafitte HR, Tao D, Laza M, Amante M, Courtois B. 2006. Developing rice cultivars for high-fertility upland systems in the Asian tropics. Field Crops Research 97, 43-52.

Asch F, Dingkuhn M, Sow A, Audebert A. 2005. Drought-induced changes in rooting patterns and assimilate partitioning between root and shoot in upland rice. Field Crops Research 93, 223-236.

Bajji M, Lutts S, Kinet JM. 2001. Water deficit effects on solute contribution to osmotic adjustment as a function of leaf ageing in three durum wheat (Triticum durum Desf.) cultivars performing differently in arid conditions. Plant Science 160, 669-681.

Bernier J, Atlin GN, Serraj R, Kumar A, Spaner D. 2008. Breeding upland rice for drought resistance. Journal of the Science of Food and Agriculture 88, 927-939.

Bouman BAM, Tuong TP. 2001. Field water management to save water and increase its productivity in irrigated lowland rice. Agricultural Water Management 49, 11-30.

Bouman BAM, Peng S, Castaneda AR, Visperas RM. 2005. Yield and water use of irrigated tropical aerobic rice systems. Agricultural Water Management 74, 87-105. 
Boonjung H, Fukai S. 1996. Effects of soil water deficit at different growth stages on rice growth and yield under upland conditions. 1. Growth during drought. Field Crops Research 48, $37-45$.

Brouwer R. 1983. Functional equilibrium: sense or nonsense? Netherlands Journal of Agricultural Science 31: 335-348.

Carrijo DR, Lundy ME, Linquist BA. 2017. Rice yields and water use under alternate wetting and drying irrigation: A meta-analysis. Field Crops Research 203, 173-180.

Centritto M, Lauteri M, Monteverdi MC, Serraj R. 2009. Leaf gas exchange, carbon isotope discrimination, and grain yield in contrasting rice genotypes subjected to water deficits during the reproductive stage. Journal of Experimental Botany 60, 2325-2339.

Chaves MM, Maroco JP, Pereira JS. 2003. Understanding plant responses to drought - from genes to the whole plant. Functional Plant Biology 30, 239-264.

Claeys H, Inzé D. 2013. The agony of choice: how plants balance growth and survival under water-limiting conditions. Plant Physiology 162, 1768-1779.

Deblonde PMK, Ledent JF. 2001. Effects of moderate drought conditions on green leaf number, stem height, leaf length and tuber yield of potato cultivars. European Journal of Agronomy 14, $31-41$.

Farooq M, Hussain M, Wahid A, Siddique KHM. 2012. Drought stress in plants: an overview. In Plant responses to drought stress (pp. 1-33). Springer, Berlin, Heidelberg.

Farooq M, Kobayashi N, Ito O, Wahid A, Serraj R. 2010. Broader leaves result in better performance of indica rice under drought stress. Journal of Plant Physiology 167, 1066-1075.

Garrity DP, O'Toole JC. 1994. Screening rice for drought resistance at the reproductive phase. Field Crops Research 39, 99-110.

Grondin A, Mauleon R, Vadez V, Henry A. 2016. Root aquaporins contribute to whole plant water fluxes under drought stress in rice (Oryza sativa L.). Plant, Cell \& Environment 39, 347365.

Gutierrez M, Reynolds MP, Klatt AR. 2010. Association of water spectral indices with plant and soil water relations in contrasting wheat genotypes. Journal of Experimental Botany 61, 3291-3303.

Henry A, Gowda VR, Torres RO, McNally KL, Serraj R. 2011. Variation in root system architecture and drought response in rice (Oryza sativa): phenotyping of the OryzaSNP panel in rainfed lowland fields. Field Crops Research 120, 205-214. 
Henry A, Cal AJ, Batoto TC, Torres RO, Serraj R. 2012. Root attributes affecting water uptake of rice (Oryza sativa) under drought. Journal of Experimental Botany 63, 4751-4763.

Jongdee B, Fukai S, Cooper M. 2002. Leaf water potential and osmotic adjustment as physiological traits to improve drought tolerance in rice. Field Crops Research 76, 153-163.

Kadam NN, Yin X, Bindraban PS, Struik PC, Jagadish KVS. 2015. Does morphological and anatomical plasticity during the vegetative stage make wheat more tolerant of water-deficit stress than rice? Plant Physiology 167, 1389-1401.

Kano M, Inukai Y, Kitano H, Yamauchi A. 2011. Root plasticity as the key root trait for adaptation to various intensities of drought stress in rice. Plant and Soil 342, 117-128.

Kato Y, Abe J, Kamoshita A, Yamagishi J. 2006. Genotypic variation in root growth angle in rice (Oryza sativa L.) and its association with deep root development in upland fields with different water regimes. Plant and Soil 287, 117-129.

Kato Y, Kamoshita A, Yamagishi J. 2007. Evaluating the resistance of six rice cultivars to drought: restriction of deep rooting and the use of raised beds. Plant and Soil 300, 149.

Kato Y, Okami M. 2010. Root growth dynamics and stomatal behaviour of rice (Oryza sativa L.) grown under aerobic and flooded conditions. Field Crops Research 117, 9-17.

Kato Y, Okami M. 2011. Root morphology, hydraulic conductivity and plant water relations of high-yielding rice grown under aerobic conditions. Annals of Botany 108, 575-583.

Kim HK, Park J, Hwang I. 2014. Investigating water transport through the xylem network in vascular plants. Journal of Experimental Botany 65, 1895-1904.

Kramer PJ, Boyer JS. 1997. Water relations of plants and soils. San Diego: Academic Press.

Kumar A, Bernier J, Verulkar S, Lafitte HR, Atlin GN. 2008. Breeding for drought tolerance: direct selection for yield, response to selection and use of drought-tolerant donors in upland and lowland-adapted populations. Field Crops Research 107, 221-231.

Liu H, Wang X, Wang D, Zou Z, Liang Z. 2011. Effect of drought stress on growth and accumulation of active constituents in Salvia miltiorrhiza Bunge. Industrial Crops and Products 33, 84-88.

Lopes, M.S. \& Reynolds, M.P. (2010). Partitioning of assimilates to deeper roots is associated with cooler canopies and increased yield under drought in wheat. Functional Plant Biology, 37 , 147-156.

Matin MA, Brown JH, Ferguson H. 1989. Leaf water potential, relative water content, and diffusive resistance as screening techniques for drought resistance in barley. Agronomy Journal 
$81,100-105$

Madadgar, S., AghaKouchak, A., Farahmand, A. \& Davis, S.J. (2017). Probabilistic estimates of drought impacts on agricultural production. Geophysical Research Letters, 44, 7799-7807.

Menge DM, Kano-Nakata M, Yamauchi A, Suralta RR, Makihara D. 2020. Root and shoot responses of upland New Rice for Africa varieties to fluctuating soil moisture conditions as affected by different levels of nitrogen fertilization. Journal of Agronomy and Crop Science 206, 322-337.

Miyamoto N, Steudle E, Hirasawa T, Lafitte R. 2001. Hydraulic conductivity of rice roots. Journal of Experimental Botany 52, 1835-1846.

Mishra A, Salokhe VM. 2010. Flooding stress: The effects of planting pattern and water regime on root morphology, physiology and grain yield of rice. Journal of Agronomy and Crop Science 196, 368-378.

Nguyen HT, Babu RC, Blum A. 1997. Breeding for drought resistance in rice: physiology and molecular genetics considerations. Crop Science 37, 1426-1434.

Ouyang W, Struik PC, Yin X, Yang J. 2017. Stomatal conductance, mesophyll conductance, and transpiration efficiency in relation to leaf anatomy in rice and wheat genotypes under drought. Journal of Experimental Botany 68, 5191-5205.

Ouyang W, Yin X, Yang J, Struik PC. 2020. Comparisons with wheat reveal root anatomical and histochemical constraints of rice under water-deficit stress. Plant and Soil 452, 547-568.

Pantuwan G, Fukai S, Cooper M, Rajatasereekul S, O'Toole JC. 2002. Yield response of rice (Oryza sativa L.) genotypes to different types of drought under rainfed lowlands. Part 1. Grain yield and yield components. Field Crops Research 73, 153-168.

Parent B, Suard B, Serraj R, Tardieu F. 2010. Rice leaf growth and water potential are resilient to evaporative demand and soil water deficit once the effects of root system are neutralized. Plant, Cell \& Environment 33, 1256-1267.

Parent B, Bonneau J, Maphosa L, Kovalchuk A, Langridge P, Fleury D. 2017. Quantifying wheat sensitivities to environmental constraints to dissect Genotype $\times$ Environment interactions in the field. Plant Physiology 174, 1669-1682.

Peng S, Bouman B, Visperas RM, Castañeda A, Nie L, Park H-K. 2006. Comparison between aerobic and flooded rice in the tropics: agronomic performance in an eight-season experiment. Field Crops Research 96, 252-259.

Praba ML, Cairns JE, Babu RC, Lafitte HR. 2009. Identification of physiological traits underlying cultivar differences in drought tolerance in rice and wheat. Journal of Agronomy 
and Crop Science 195, 30-46.

Price AH, Steele KA, Gorham J, Bridges JM, Moore BJ, Evans JL, Richardson P, Jones RGW. 2002. Upland rice grown in soil-filled chambers and exposed to contrasting water-deficit regimes: I. Root distribution, water use and plant water status. Field Crops Research 76, 11-24.

Pfeiffer WH. 1988. Drought tolerance in bread wheat: analysis of yield improvement over the years in CIMMYT germplasm. In Wheat Production Constraints in Tropical Environments. Chiang Mai, Thailand. 19-23 Jan 1987.

Quero JL, Villar R, Marañón T, Zamora R. 2006. Interactions of drought and shade effects on seedlings of four Quercus species: physiological and structural leaf responses. New Phytologist $170,819-834$.

Reynolds M, Dreccer F, Trethowan R. 2007. Drought-adaptive traits derived from wheat wild relatives and landraces. Journal of Experimental Botany 58, 177-186.

Rodrigues ML, Pacheco CMA, Chaves MM. 1995. Soil-plant water relations, root distribution and biomass partitioning in Lupinus albus L. under drought conditions. Journal of Experimental Botany 46, 947-956.

Sibounheuang V, Basnayake J, Fukai S. 2006. Genotypic consistency in the expression of leaf water potential in rice (Oryza sativa L.). Field Crops Research 97, 142-154.

Somaweera KATN, Suriyagoda LDB, Sirisena DN, De Costa WAJM. 2016. Accumulation and partitioning of biomass, nitrogen, phosphorus and potassium among different tissues during the life cycle of rice grown under different water management regimes. Plant and Soil 401, 169183.

Stiller V, Lafitte HR, Sperry JS. 2003. Hydraulic properties of rice and the response of gas exchange to water stress. Plant Physiology 132, 1698-1706.

Tanguilig VC, Yambao EB, O’toole JC, De Datta SK. 1987. Water stress effects on leaf elongation, leaf water potential, transpiration, and nutrient uptake of rice, maize, and soybean. Plant and Soil 103, 155-168.

Tardieu F, Simonneau T, Muller B. 2018. The physiological basis of drought tolerance in crop plants: a scenario-dependent probabilistic approach. Annual Review of Plant Biology 69, 733759.

Venuprasad R, Lafitte HR, Atlin GN. 2007. Response to direct selection for grain yield under drought stress in rice. Crop Science 47, 285-293.

Venuprasad R, Cruz MS, Amante, M, Magbanua R, Kumar A, Atlin GN. 2008. Response to two cycles of divergent selection for grain yield under drought stress in four rice breeding 
populations. Field Crops Research 107, 232-244.

Villareal RL, del Toro E, Mujeeb-Kazi A, Rajaram S. 1995. The 1BL/1RS chromosome translocation effect on yield characteristics in a Triticum aestivum L. cross. Plant Breeding 114, 497-500.

Villegas D, Garcia del Moral LF, Rharrabti Y, Martos V, Royo C. 2007. Morphological traits above the flag leaf node as indicators of drought susceptibility index in durum wheat. Journal of Agronomy and Crop Science 193, 103-116.

Vijayaraghavareddy P, Yin X, Struik PC, Makarla U, Sreeman S. 2020. Responses of lowland, upland and aerobic rice genotypes to water limitation during different phases. Rice Science 27 , 345-354.

Wu F, Bao W, Li F, Wu N. 2008. Effects of drought stress and N supply on the growth, biomass partitioning and water-use efficiency of Sophora davidii seedlings. Environmental and Experimental Botany 63, 248-255.

Yang J, Zhang J, Wang Z, Liu L, Zhu Q. 2003. Postanthesis water deficits enhance grain filling in two-line hybrid rice. Crop Science 43, 2099-2108.

Yang J, Zhang J. 2006. Grain filling of cereals under soil drying. New Phytologist 169, 223 236.

Yin X, Schapendonk AHCM. 2004. Simulating the partitioning of biomass and nitrogen between root and shoot in crop and grass plants. NJAS-Wageningen Journal of Life Sciences $51,407-426$. 


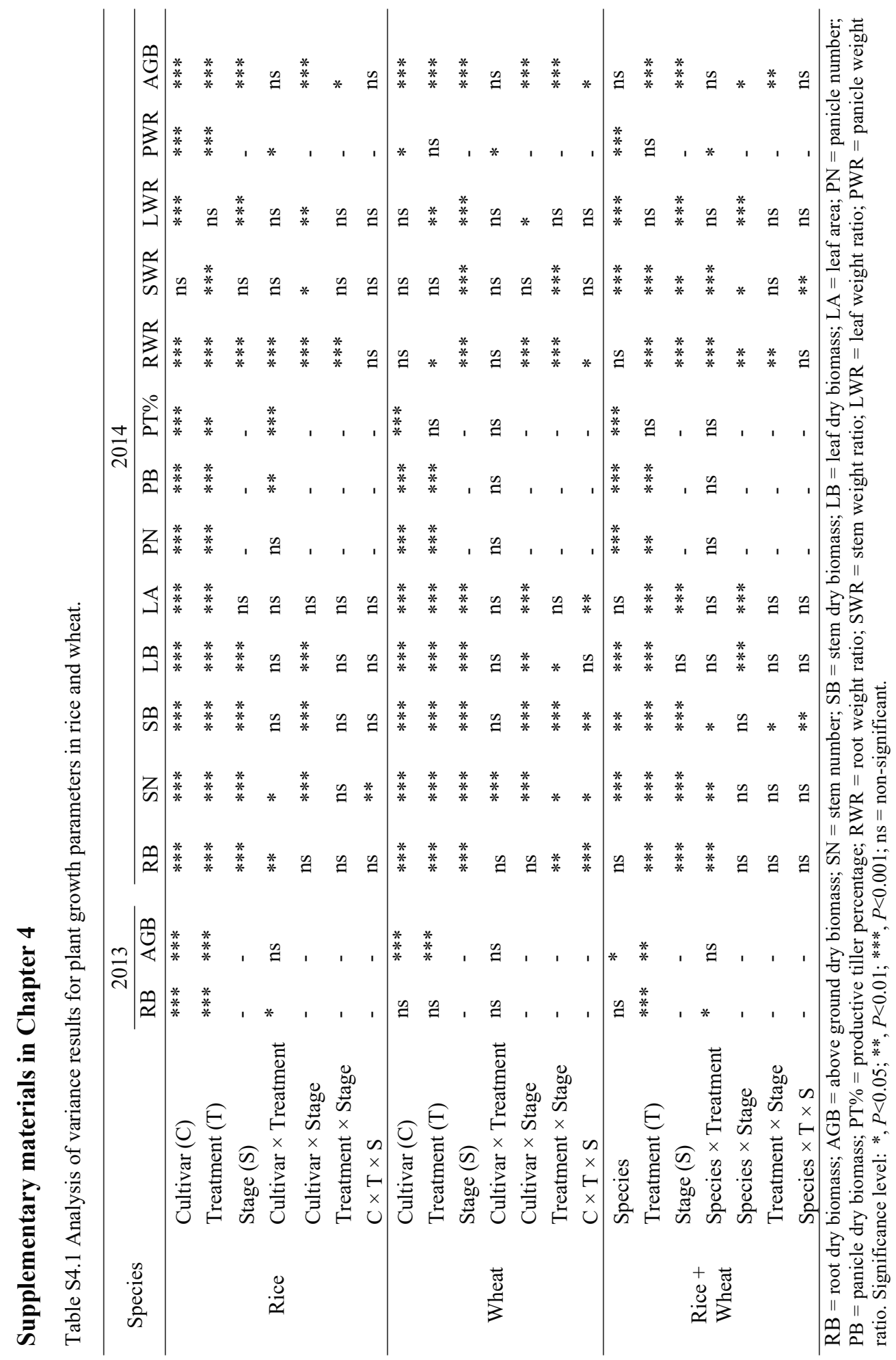




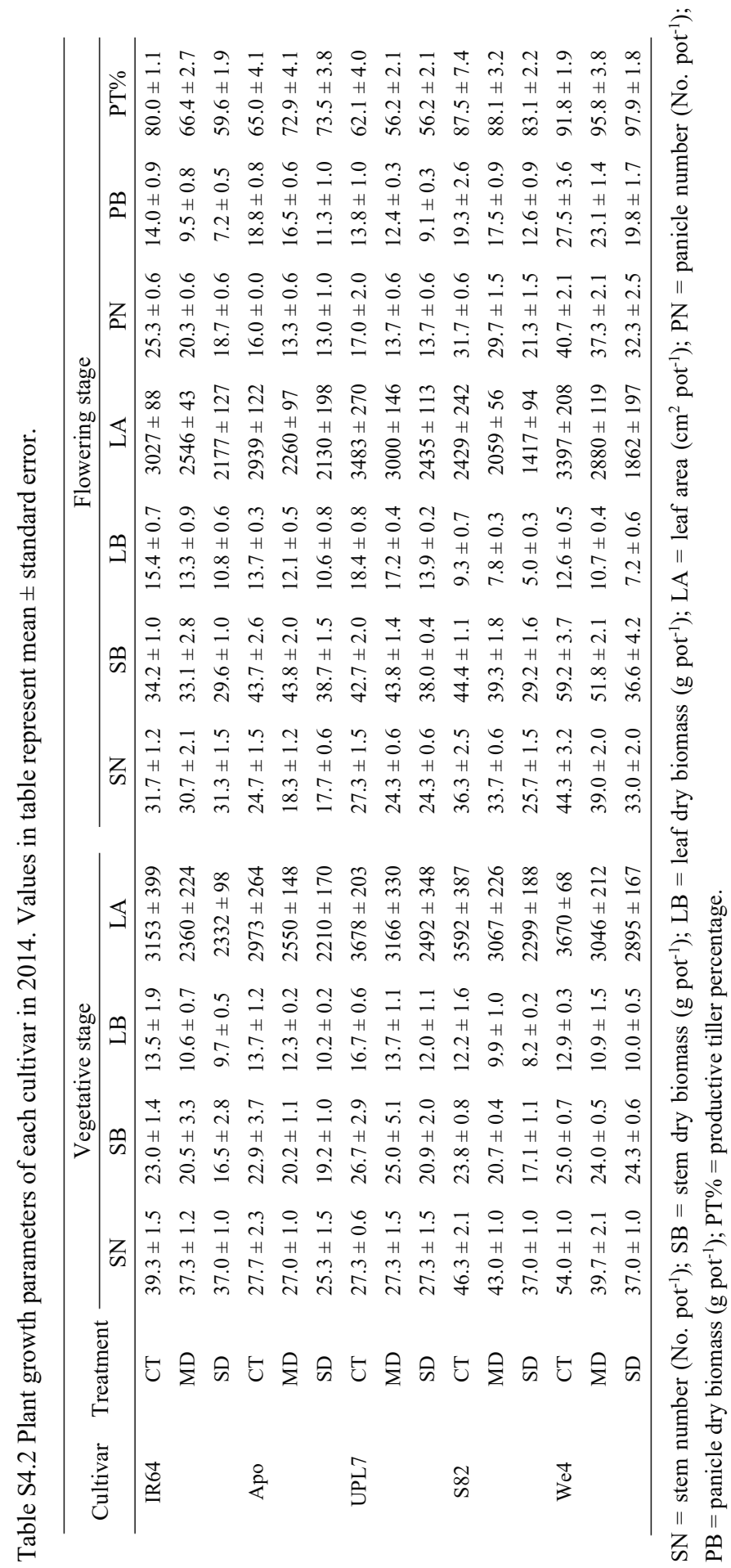


Table S4.3 Analysis of variance results for plant water status and leaf anatomical traits in rice and wheat.

\begin{tabular}{|c|c|c|c|c|c|c|c|c|c|}
\hline Species & & TR.LA & $\Psi_{\text {leaf }}$ & LW & LTA & VBN & VBA & $\mathrm{XA}$ & $\mathrm{XA} / \mathrm{LTA}$ \\
\hline \multirow{7}{*}{ Rice } & Cultivar (C) & $* * *$ & $* * *$ & $* * *$ & $* * *$ & $* * *$ & $* * *$ & $* * *$ & $* * *$ \\
\hline & Treatment $(\mathrm{T})$ & $* * *$ & $* * *$ & $* *$ & $* *$ & ns & $* * *$ & $* * *$ & $* * *$ \\
\hline & Stage (S) & $* * *$ & $* * *$ & $* * *$ & $* * *$ & $* * *$ & $* * *$ & $* * *$ & $* *$ \\
\hline & Cultivar $\times$ Treatment & $* *$ & $* * *$ & ns & ns & ns & ns & ns & ns \\
\hline & Cultivar $\times$ Stage & $* * *$ & $* * *$ & ns & $*$ & ns & ns & ns & $*$ \\
\hline & Treatment $\times$ Stage & ns & $* *$ & ns & ns & ns & ns & ns & ns \\
\hline & $\mathrm{C} \times \mathrm{T} \times \mathrm{S}$ & ns & ns & $\mathrm{ns}$ & ns & ns & $\mathrm{ns}$ & ns & ns \\
\hline \multirow{7}{*}{ Wheat } & Cultivar (C) & $* * *$ & $* * *$ & ns & $* * *$ & ns & $* * *$ & $* * *$ & $* * *$ \\
\hline & Treatment $(\mathrm{T})$ & $* * *$ & $* * *$ & $* *$ & $*$ & ns & $* *$ & $* * *$ & $* *$ \\
\hline & Stage (S) & $* * *$ & $* * *$ & ns & ns & ns & $*$ & $*$ & $*$ \\
\hline & Cultivar $\times$ Treatment & ns & $\mathrm{ns}$ & ns & ns & ns & ns & ns & ns \\
\hline & Cultivar $\times$ Stage & $* * *$ & $*$ & ns & ns & ns & ns & ns & $* * *$ \\
\hline & Treatment $\times$ Stage & $* *$ & ns & ns & ns & ns & ns & ns & $*$ \\
\hline & $\mathrm{C} \times \mathrm{T} \times \mathrm{S}$ & ns & ns & ns & $*$ & ns & ns & ns & ns \\
\hline \multirow{7}{*}{ Rice + Wheat } & Species & $*$ & $* * *$ & ns & $* * *$ & $* * *$ & $* * *$ & $* * *$ & $* * *$ \\
\hline & Treatment $(\mathrm{T})$ & $* * *$ & $* * *$ & $*$ & $*$ & ns & $* *$ & $* *$ & $* *$ \\
\hline & Stage (S) & $* * *$ & $* * *$ & $* * *$ & $* *$ & $* * *$ & $* * *$ & $* *$ & $*$ \\
\hline & Species $\times$ Treatment & ns & $* * *$ & ns & ns & ns & ns & ns & ns \\
\hline & Species $\times$ Stage & $* * *$ & $* *$ & $*$ & ns & $*$ & ns & ns & ns \\
\hline & Treatment $\times$ Stage & $\mathrm{ns}$ & $\mathrm{ns}$ & ns & ns & ns & ns & ns & ns \\
\hline & Species $\times \mathrm{T} \times \mathrm{S}$ & ns & ns & ns & ns & ns & ns & ns & ns \\
\hline
\end{tabular}

TR.LA $=$ averaged transpiration rate per unit leaf area; $\Psi_{\text {leaf }}=$ leaf water potential; $\mathrm{LW}=$ leaf blade width; $\mathrm{LTA}=$ leaf tissue area; VBN= leaf vascular bundle number; VBA = total leaf vascular bundle area; $\mathrm{XA}=$ total leaf xylem area; $\mathrm{XA} / \mathrm{LTA}=$ leaf xylem area to leaf tissue area ratio. Significance level: ${ }^{*}, P<0.05$; ${ }^{* *}, P<0.01$; $* * *, P<0.001 ; \mathrm{ns}=$ non-significant. 
Table S4.4 Analysis of variance results for stem anatomical traits in rice and wheat.

\begin{tabular}{llllllll}
\hline Species & & SA & STA & SVBN & SVBA & SXA & SXA/STA \\
\hline Rice & Cultivar & $* * *$ & $* * *$ & $* * *$ & $* * *$ & $* * *$ & $* * *$ \\
& Treatment & $* * *$ & $*$ & $* *$ & $*$ & $* *$ & $* * *$ \\
& Cultivar $\times$ Treatment & $\mathrm{ns}$ & $\mathrm{ns}$ & $\mathrm{ns}$ & $\mathrm{ns}$ & $\mathrm{ns}$ & $* * *$ \\
\hline Wheat & Cultivar & $\mathrm{ns}$ & $\mathrm{ns}$ & $\mathrm{ns}$ & $\mathrm{ns}$ & $\mathrm{ns}$ & $\mathrm{ns}$ \\
& Treatment & $* *$ & $* * *$ & $\mathrm{~ns}$ & $* * *$ & $* * *$ & $*$ \\
& Cultivar $\times$ Treatment & $\mathrm{ns}$ & $* *$ & $\mathrm{~ns}$ & $* * *$ & $* * *$ & $\mathrm{~ns}$ \\
\hline Rice + Wheat & Species & $\mathrm{ns}$ & $\mathrm{ns}$ & $* * *$ & $\mathrm{~ns}$ & $* * *$ & $* * *$ \\
& Treatment & $* *$ & $* *$ & $\mathrm{~ns}$ & $\mathrm{~ns}$ & $*$ & $\mathrm{~ns}$ \\
& Species $\times$ Treatment & $\mathrm{ns}$ & $* *$ & $\mathrm{~ns}$ & $\mathrm{~ns}$ & $\mathrm{~ns}$ & $* *$ \\
\hline
\end{tabular}

$\mathrm{SA}=$ stem cross sectional area; $\mathrm{STA}=$ stem tissue area; $\mathrm{SVBN}=$ stem vascular bundle number; $\mathrm{SVBA}=$ total stem vascular bundle area; SXA = total stem xylem area; SXA/STA = Stem xylem area to tissue area ratio. Significance level: *, $P<0.05 ; * *, P<0.01 ; * * *, P<0.001 ;$ ns $=$ non-significant.

Table S4.5 Regression analysis of leaf water potential as a function of each leaf and stem anatomical parameters, based on data of three treatments.

\begin{tabular}{lllll}
\hline \multirow{2}{*}{ Anatomical parameters } & Rice & \multicolumn{3}{l}{ Wheat } \\
\cline { 2 - 5 } & Significance $^{\mathrm{a}}$ & $\mathrm{R}^{2}$ & Significance & $\mathrm{R}^{2}$ \\
\hline Leaf width & $* * *$ & 0.23 & $* * *$ & 0.35 \\
Leaf tissue area & $* * *$ & 0.28 & $* * *$ & 0.36 \\
Leaf vascular bundle number & $* * *$ & 0.20 & $\mathrm{~ns}$ & 0.10 \\
Leaf total vascular bundle area & $* * *$ & 0.40 & $* * *$ & 0.52 \\
Leaf total xylem area & $* * *$ & 0.45 & $* * *$ & 0.57 \\
Leaf xylem area to tissue area ratio & $* * *$ & 0.43 & $* * *$ & 0.46 \\
\hline Stem cross sectional area & $\mathrm{ns}$ & 0.08 & $* * *$ & 0.75 \\
Stem tissue area & $\mathrm{ns}$ & 0.05 & $* * *$ & 0.76 \\
Stem vascular bundle number & $\mathrm{ns}$ & 0.04 & $\mathrm{~ns}$ & 0.05 \\
Stem total vascular bundle area & $\mathrm{ns}$ & 0.04 & $* *$ & 0.48 \\
Stem total xylem area & $\mathrm{ns}$ & 0.04 & $* * *$ & 0.58 \\
\hline
\end{tabular}

${ }^{\text {a }}$ Significance level: ${ }^{* *}, P<0.01 ; * * *, P<0.001 ;$ ns $=$ non-significant. 


\section{Leaf}
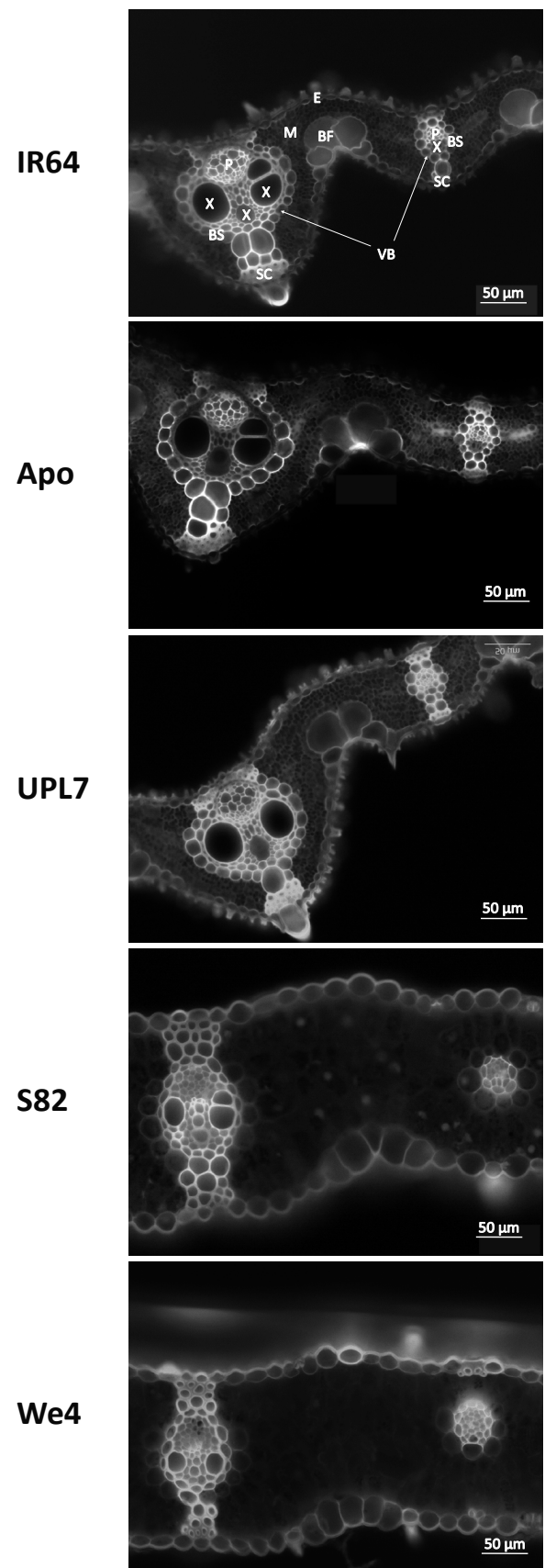

Stem
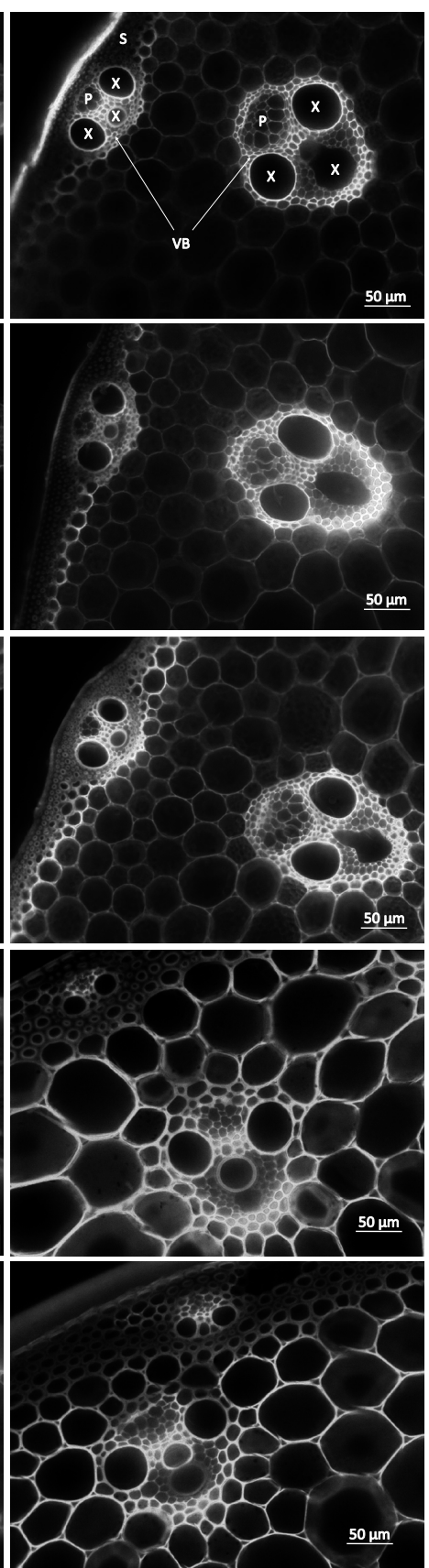

Fig. S4.1 Light micrographs of leaf (left panels) and stem (right panels) structure for rice and wheat cultivars. The left panels show the overall leaf transverse sections with vascular bundles; and the right panels show stem transverse sections with vascular bundle on the tissue area and on the sclerenchyma near stem epidermis. Arrows mark vascular bundles in leaf and stem. BF, bulliform cell; BS, outer bundle-sheath cell; E, epidermis on leaf; $\mathrm{M}$, mesophyll cell; P, phloem; SC, sclerenchyma strand in leaf; S, sclerenchyma in stem; VB, vascular bundle; $\mathrm{X}$, xylem. Each scale bar represents $50 \mu \mathrm{m}$. 

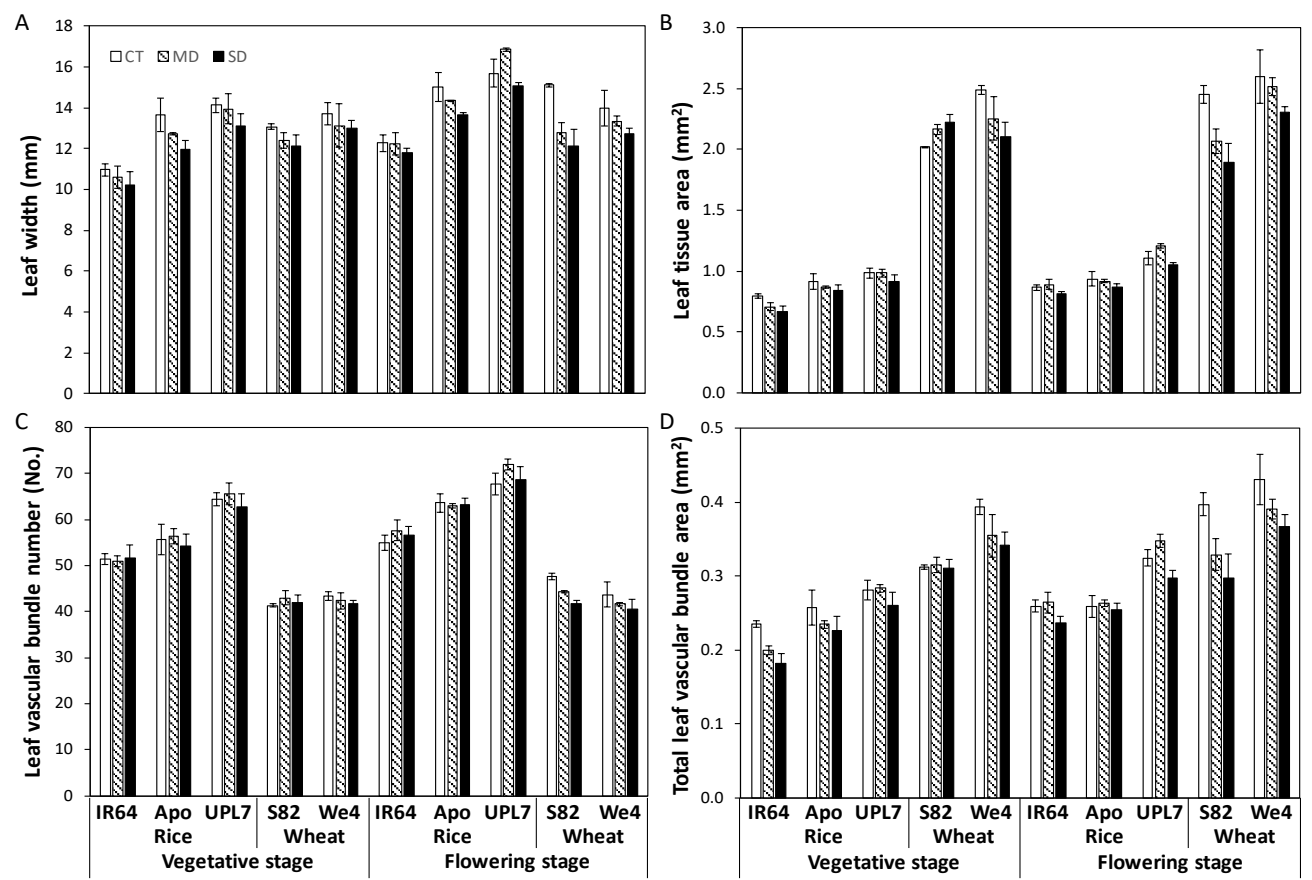

Fig. S4.2 Response of leaf (A) blade width, (B) tissue area, (C) vascular bundle number, and (D) total vascular bundle area of rice and wheat cultivars to water treatments: control (CT), mild drought (MD), and more severe drought (SD). Leaflets were sampled at vegetative stage and flowering stage. Bars represent standard errors of the mean for three replicates. 

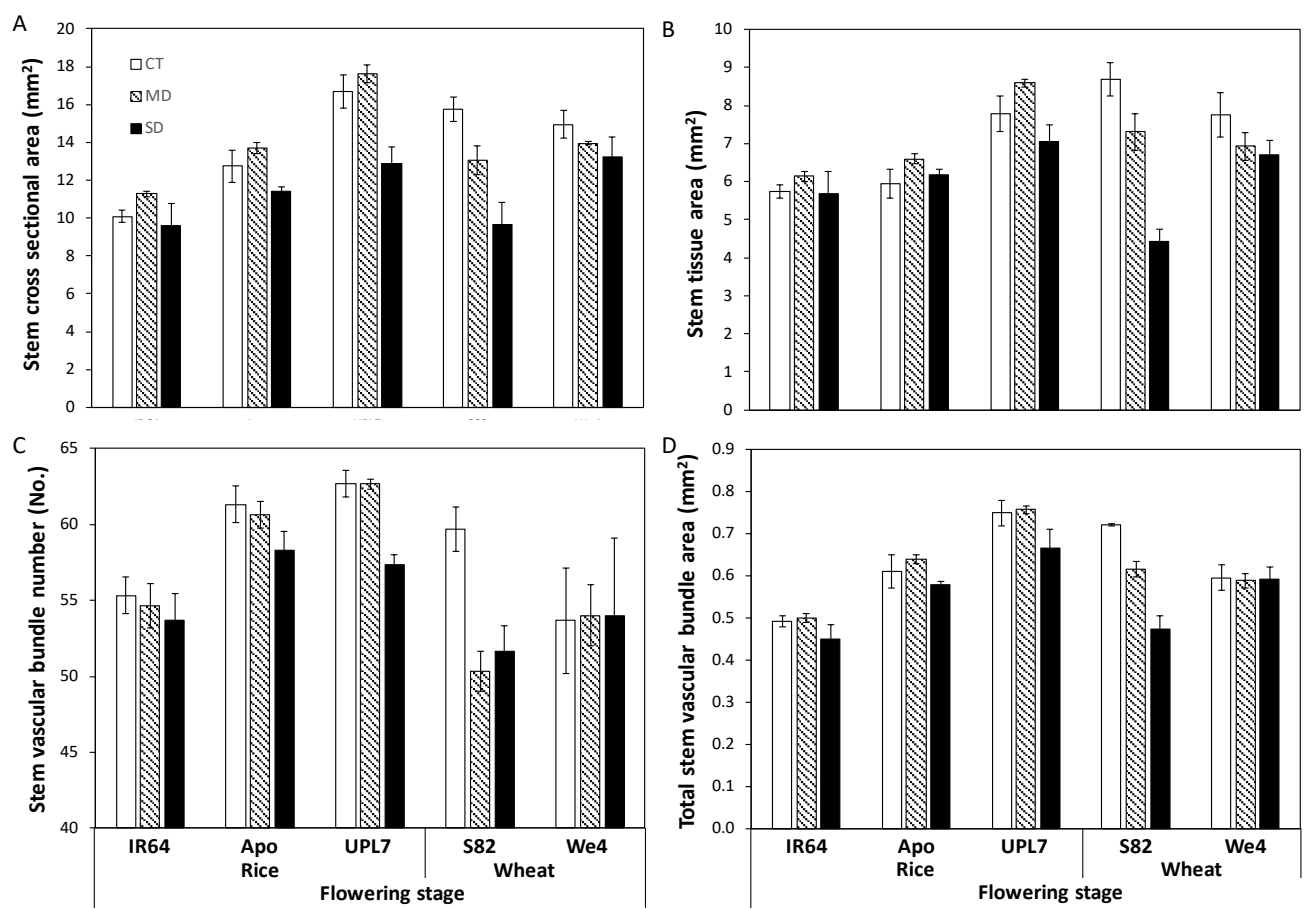

Fig. S4.3 Response of stem (A) cross sectional area, (B) tissue area, (C) vascular bundle number, and (D) total vascular bundle area of rice and wheat cultivars to water treatments: control (CT), mild drought (MD), and more severe drought (SD). Stem sections were sampled at vegetative stage and flowering stage. Bars represent standard errors of the mean for three replicates. 



\title{
Chapter 5
}

\section{Roles of canopy architecture and nitrogen distribution}

\section{in the better performance of an aerobic than}

a lowland rice cultivar under water deficit

\author{
Wenjing Ouyang ${ }^{1}$, Xinyou Yin ${ }^{1}$, Jianchang Yang ${ }^{2}$ and Paul C. Struik ${ }^{1}$ \\ ${ }^{1}$ Centre for Crop Systems Analysis, Wageningen University \& Research, \\ 6700 AK Wageningen, The Netherlands \\ ${ }^{2}$ College of Agriculture, Yangzhou University, \\ 225009 Yangzhou, Jiangsu, China
}




\begin{abstract}
In the wake of declining water availability for agricultural use that will severely disturb the cultivation of irrigated lowland rice (Oryza sativa), aerobic genotypes have been developed allowing rice to grow under drier conditions. However, canopy physiological and morphological characteristics associated with adaptation of aerobic rice to water-limited conditions have so far been understudied. Canopy architectural characters, light and nitrogen distribution parameters (i.e. the extinction coefficient for light, $K_{\mathrm{L}}$; and for nitrogen, $K_{\mathrm{N}}$; and their ratio $K_{\mathrm{N}}: K_{\mathrm{L}}$ ), plant growth and yield were examined in irrigatedlowland (cv. IR64) vs aerobic (cv. Apo) rice genotypes grown under three water regimes. Compared with cv. IR64, cv. Apo allocated less nitrogen to strongly shaded leaves, allowing the vertical nitrogen distribution to better acclimate to light distribution within the canopy. The $K_{\mathrm{N}}: K_{\mathrm{L}}$ ratio increased with increasing water deficit, and cv. Apo (up to $49 \%$ increase) had a higher increase than cv. IR64 (up to $24 \%$ increase). This was attributed to the maintenance of erect leaves at the upper part of the canopy, allocation of less leaf area and less nitrogen to the shaded leaves under water deficit in cv. Apo. The observed differential response in the $K_{\mathrm{N}}: K_{\mathrm{L}}$ ratio partly explained the difference in biomass gain and yield in response to water deficit between the two rice cultivars. We concluded that favourable aboveground architecture and canopy nitrogen profile relative to the light profile contributed greatly to the better performance of cv. Apo than cv. IR64 under dry conditions.
\end{abstract}

Keywords: Canopy light distribution; canopy structure; nitrogen allocation; rice; water deficit 


\subsection{Introduction}

Rice (Oryza sativa L.) is an important food crop that plays a central role in global food security. More than $70 \%$ of the global rice production occurs in intensely managed irrigated lowland systems (continuously inundated paddy fields) which requires large amounts of freshwater (IRRI, 1998). Such cultivation practice is threatened by freshwater scarcity arising from global climate change and increasing water demands by other sectors (Guerra et al., 1998). Various water-saving technologies have been designed to reduce water use by rice, such as alternate wetting and drying irrigation (Bouman and Tuong, 2001), controlled soil drying during grain filling (Yang and Zhang, 2006, 2010), and aerobic cultivation, i.e. growing rice under non-saturated (aerobic) soil without ponded water (Atlin et al., 2006). Water input in aerobic conditions is less than $50 \%$ of that in flooding conditions (Peng et al., 2006). However, rice varieties adapted to irrigated lowland systems are very sensitive to even mild water deficit stress, showing severe yield loss as soon as the soil water content drops below saturation (Bouman and Tuong, 2001; Pantuwan et al., 2002; Centritto et al., 2009). Therefore, special rice varieties suitable for aerobic cultivation, i.e. aerobic rice, have been developed (Bouman et al., 2005). Aerobic rice varieties display a better yield performance under aerobic environment than lowland rice (Bouman et al., 2005; Suralta and Yamauchi, 2008).

Land plants exhibit various growth strategies that allow for acclimatory responses to changing environments. Canopy architecture is important as it determines the interception and distribution of solar radiation, and, thus, has a major influence on the interaction of plants with their environment (Schakel and Hall, 1979; Schittenhelm et al., 2006). Rice ecotypes adapted to different edaphic conditions display diverse canopy architectures, and lowland cultivars are generally shorter and have more tillers than aerobic cultivars (Peng et al., 2000; Lafitte et al., 2002; Venuprasad et al., 2009; Matsuo et al., 2010). However, only limited information is available on differences in effects of water deficit on shoot morphology between aerobic and lowland rice varieties.

Carbon assimilation of a leaf is closely associated with its captured incident light density and nitrogen content (Field, 1983; Evans, 1989; Yin and Struik, 2015). Leaves in canopy at different positions experience very different light environments, i.e. leaves at the lower position are shaded by the upper leaves that intercept most of the incoming solar radiation. Such differences increase when leaf area index (LAI) of the canopy becomes high. Shaded leaves in a full canopy account for more than $70 \%$ of the total leaf area but contribute less than $50 \%$ of the total canopy 


\section{Chapter 5}

photosynthesis, due to the exposure to light-limited conditions (Song et al., 2013). Therefore, it is important to explore avenues to optimize the vertical distribution of light in a crop canopy for improving the whole canopy carbon gain and biomass production, and eventually for improving yield (Yin and Struik, 2015). In fact, this concept has long been proposed as an area to be explored for developing new plant types for rice (Dingkuhn et al., 1991; Virk et al., 2004).

Similar to the light gradient in the canopy, nitrogen distribution among leaf laminae is mostly not uniform at different heights of a vegetative canopy, but declines gradually over its depth (Field, 1983; Evans, 1993). Vertical light and nitrogen distributions in a canopy can be described by an exponential function of the downward cumulative leaf area index with an extinction coefficient for light $\left(K_{\mathrm{L}}\right)$ and for photosynthetically active leaf nitrogen $\left(K_{\mathrm{N}}\right)$. Leaf photosynthetic capacity, depending on the level of photosynthetic enzymes, is highly correlated to leaf nitrogen (Evans, 1989). Therefore, patterns of nitrogen distribution and its effect on canopy carbon gain received much attention (Field, 1983; Anten et al., 1995). The nitrogen distribution along canopy height has often been analyzed through the "optimization" theory (Hirose and Werger, 1987), given that the light-saturated leaf photosynthetic capacity $\left(A_{\max }\right)$ is linearly correlated with leaf nitrogen in most cases (Gu et al., 2012; Yin and Struik, 2015; Tang et al., 2017). This theory suggests that whole canopy photosynthesis would be maximized when nitrogen distribution follows light distribution within a canopy, i.e. $K_{\mathrm{N}}=K_{\mathrm{L}}$ (Goudriaan, 1995). However, the observed nitrogen extinction coefficients within vegetative canopies under favourable growth conditions are generally lower than the optimization theory predicts, i.e. $K_{\mathrm{N}}: K_{\mathrm{L}}<1$ (e.g. Archontoulis et al., 2011).

Under water deficit stress, the light and nitrogen distributions over canopy depth are more complicated than those under non-stressed conditions. A number of structural and physiological characteristics of the canopy, such as leaf area index, leaf angle and canopy nitrogen content are responsible for the variations in $K_{\mathrm{L}}$ and $K_{\mathrm{N}}$ (Hirose and Werger, 1987; Yin et al., 2003) and could be modified by water deficit stress in both dicot (sunflower and kenaf; Archontoulis et al., 2011) and monocot (rice; Okami et al., 2016) crop species. Rice genotypes having different canopy architectures may exhibit different responses of light and leaf nitrogen distribution to water deficit. Little attention has so far been paid to understanding how canopy traits contribute to yield differences between rice ecotypes grown under water-deficit conditions.

In this study, vertical distributions of light and nitrogen in canopies were quantified in relation to canopy structural characteristics in two contrasting rice cultivars with different water-deficit 
tolerance, when grown under water-deficit conditions. The two genotypes, i.e. one lowland cultivar (cv. IR64) and one aerobic cultivar (cv. Apo), were chosen based on our previous extensive studies on their representativeness of the two rice ecotypes (Kadam et al., 2015; Ouyang et al., 2017; Vijayaraghavareddy et al., 2020). We specifically investigated: (1) the effects of prolonged soil water-deficit on $K_{\mathrm{L}}, K_{\mathrm{N}}$ and the $K_{\mathrm{N}}: K_{\mathrm{L}}$ ratio; and (2) how these effects on canopy traits contribute to the genotypic differences in biomass and yield responses to water deficit.

\subsection{Materials and methods}

\subsubsection{Plant materials and treatments}

Two experiments were conducted at the research farm of Yangzhou University, Jiangsu Province, China $\left(32^{\circ} 30^{\prime} \mathrm{N}, 11^{\circ} 25^{\prime} \mathrm{E}\right)$ during the rice growing season (May-October) of 2014. In the first experiment, rice plants were grown as mini-canopy in cuboid cement tanks $(8 \mathrm{~m}$ long, $1.6 \mathrm{~m}$ wide, $0.3 \mathrm{~m}$ high), to test the water-deficit effect primarily on canopy architecture, light and nitrogen distribution in rice genotypes. The second experiment was a field trial (in puddled lowland field) to collect additional data for plant growth, yield and yield components in response to water deficit. The tank experiment was carried out in an open field next to the field trial and tanks were filled with sandy loam soil from the rice field. Both experiments were sheltered from rain by a mobile transparent polyethylene shelter to control soil moisture.

Two cultivars of rice ( $O$. sativa L., subsp. indica) with similar growth duration were chosen based on their sensitivity to water deficit and their morphological traits (Kadam et al., 2015; Ouyang et al., 2017; Vijayaraghavareddy et al., 2020). The lowland rice cultivar IR 64-21 (IR64), considered as highly sensitive to water deficit (Venuprasad et al., 2008), is a semi-dwarf variety with average mature plant height of approximately $100 \mathrm{~cm}$ (Mackill and Khush, 2018). The aerobic rice cultivar NSIC Rc9 (Apo), generally considered as moderately water-deficit tolerant in the reproductive stage (Venuprasad et al., 2007), had an average mature plant height of approximately $130 \mathrm{~cm}$ when grown under inundated condition (Venuprasad et al., 2009). Seeds of both cultivars were obtained from the International Rice Research Institute (IRRI).

Rice seeds were pre-germinated and sown in a seedbed. Twenty-day-old seedlings were transplanted into nine tanks and a paddy field, at a hill spacing of $25 \mathrm{~cm} \times 25 \mathrm{~cm}$ with one seedling per hill. In both experiments, $\mathrm{P}$ (30 $\mathrm{kg} \mathrm{ha}^{-1}$ as single superphosphate) and $\mathrm{K}$ $\left(40 \mathrm{~kg} \mathrm{ha}^{-1}\right.$ as $\left.\mathrm{KCl}\right)$ were applied and incorporated 1 day before transplanting as basal fertilizer. 
Nitrogen $\left(240 \mathrm{~kg} \mathrm{~N} \mathrm{ha}^{-1}\right)$ in the form of urea was applied in portions of $40 \%, 20 \%, 20 \%$ and $20 \%$ as basal fertilizer, topdressing $\sim 7$ days after transplanting, at panicle initiation, and at heading stage, respectively. In the tank experiment, three levels of soil moisture were imposed 15 days after transplanting, i.e. (1) control (CT), keeping 2-5 cm of standing water on soil surface; (2) mild drought (MD), keeping soil water potential between 0 to $-5 \mathrm{kPa}$; and (3) more severe drought (SD), keeping soil water potential between -20 to $-40 \mathrm{kPa}$. For stress treatments, water was drained from the bottom of the tanks, and the required stress level was achieved two and four days after stress imposition for MD and SD, respectively. Two levels of soil moisture were imposed in the field experiment, i.e. CT and SD, and timing and intensity of imposing SD were the same as in the tank experiment, but SD in the field was achieved six days after stress imposition. Soil water potential in stress treatments was monitored with tensiometers (Institute of Soil Sciences, Chinese Academy of Sciences, Nanjing, China) installed in each plot at a depth of $15 \mathrm{~cm}$. For the stress treatments, we checked the tensiometers twice a day, and water was added to bring soil moisture back to the upper limit of the target stress when tensiometer readings reached the lower limit. Once stress was imposed, the target levels were maintained until physiological maturity of the grains. Both tank and field experiments were conducted in a split-plot design, with the CT, MD and SD as the main plots and the cultivars as the split plots, with three replications. The area of each split plot was $6.4 \mathrm{~m}^{2}$ in the tank experiment and 12.5 $\mathrm{m}^{2}$ in the field experiment.

\subsubsection{Vertical light and nitrogen distributions in the canopy}

In the tank experiment, destructive samplings were undertaken at stem-elongating stage (46-51 days after transplanting) and at early flowering stage (66-77 days after transplanting). Before each sampling, the photosynthetically active radiation (PAR) penetrated through the canopy was measured by placing a 1-m linear ceptometer (SunScan System SS1, Delta-T devices, Cambridge, UK) diagonally across two rows. PAR measurements were taken every $20 \mathrm{~cm}$ from the ground upwards and above the canopy, with three to four repeating measurements in each position for each plot. All measurements were restricted to the time period from 11:00 to 13:00 h. Afterwards, leaf angles were measured relative to the vertical line $\left(0^{\circ}\right)$ using a protractor. Measurements were taken on the top three fully-expanded leaves from 3 to 4 randomly selected stems of a plant, and repeated on five plants in a row within the PAR measuring frame in each plot. Values of leaf angle at the same leaf position from the same plot were averaged and treated as one replicate. Subsequently, these plants were cut from the shoot base and brought to an indoor lab, where they were further cut from the base to the top every 
$20 \mathrm{~cm}$ layer thickness to assess the green leaf area index (LAI) and leaf nitrogen per unit area, or called "specific leaf nitrogen (SLN)", of each layer. Leaf area was determined using an area meter (Li-3100; Li-Cor, Lincoln, Nebraska, USA). Leaf dry weight of each layer was assessed after the leaf blades were oven-dried at $70^{\circ} \mathrm{C}$ for at least $72 \mathrm{~h}$. After that, leaf nitrogen concentration ( $\mathrm{mg} \mathrm{N} \mathrm{g}^{-1}$ leaf) was analyzed using an elemental analyzer (Vario Macro cube, Elementar, Germany). Leaf nitrogen per unit area (SLN) was calculated from these data. Then total canopy nitrogen content $\left(\mathrm{N}_{\mathrm{c}}\right)$ and canopy-averaged nitrogen per leaf area $\left(\mathrm{SLN}_{\mathrm{c}}\right)$ were determined.

\subsubsection{Estimation of light and nitrogen extinction coefficients}

The attenuation of PAR through the canopy follows the Beer-Lambert law:

$$
I_{\mathrm{i}}=I_{0} \exp \left(-K_{\mathrm{L}} \mathrm{LAI}_{\mathrm{i}}\right)
$$

where $I_{\mathrm{i}}$ and $I_{0}$ are PAR values on a horizontal level at depth $i$ and above the canopy, respectively; $\mathrm{LAI}_{\mathrm{i}}$ is cumulative $\mathrm{LAI}$ at depth $i$ counted from the top; $K_{\mathrm{L}}$ is the light extinction coefficient. $K_{\mathrm{L}}$ was estimated by fitting Eq. (1) to measured $I_{\mathrm{i}}, I_{0}$ and $\mathrm{LAI}_{\mathrm{i}}$.

Similarly, the vertical gradient of nitrogen in the canopy can be described as:

$$
\mathrm{SLN}_{\mathrm{i}}=\left(\mathrm{SLN}_{0}-\mathrm{SLN}_{\mathrm{b}}\right) \exp \left(-K_{\mathrm{N}} \mathrm{LAI}_{\mathrm{i}}\right)+\mathrm{SLN}_{\mathrm{b}}
$$

where $\mathrm{SLN}_{\mathrm{i}}$ and $\mathrm{SLN}_{0}$ are the $\mathrm{SLN}$ of the $i$ th layer and at the top of the canopy (i.e. at $\mathrm{LAI}_{\mathrm{i}}=0$ ), respectively; $\mathrm{SLN}_{\mathrm{b}}$ is the base value of leaf nitrogen for photosynthesis, which can be regarded as representing non-photosynthetic nitrogen content; a value of $0.3 \mathrm{~g} \mathrm{~N} \mathrm{~m}^{-2}$ for $\mathrm{SLN}_{\mathrm{b}}$ was adopted for rice from Sinclair and Horie (1989) and Yin and van Laar (2005); $K_{\mathrm{N}}$ is the extinction coefficient for the effective leaf nitrogen. $K_{\mathrm{N}}$ and $\mathrm{SLN}_{0}$ were estimated by fitting Eq. (2) to the measured data.

\subsubsection{Plant growth measurements at stem-elongating and flowering stages}

In the tank experiment, tillers of the sampled plants were counted for each sampling. Stem and panicle (flowering stage) dry weights were determined after separately oven drying at $70{ }^{\circ} \mathrm{C}$ for at least $72 \mathrm{~h}$. The summed values of layers for leaf area and dry weight were used for further analysis. In the field experiment, plant shoots of five randomly selected plants were collected at stem-elongating (48-54 days after transplanting) and flowering (72-80 days after transplanting) stages. Leaf area was measured with an area meter (Li-3100; Li-Cor, Lincoln, 


\section{Chapter 5}

Nebraska, USA). Leaf, stem and panicle (flowering stage) were separately oven dried at $70{ }^{\circ} \mathrm{C}$ for $72 \mathrm{~h}$ prior to weighing. Daily average biomass gain between stem-elongating and flowering stages in the tank experiment was calculated as the difference in above-ground dry weight of plants sampled at the two stages divided by the growth duration of each cultivar between the two stages.

\subsubsection{Yield and yield related traits at maturity}

At maturity, yield, yield components, harvest index and total above-ground biomass were determined in the tank and field experiments. The number of spikelets per panicle, filled-grain percentage, and 1000-grain weight were determined from five plants in a central row. Plants were separated into straw, filled grains and unfilled grains, following the procedures of Yoshida et al. (1971). Dry weight of each part was determined after oven drying at $70{ }^{\circ} \mathrm{C}$ for $72 \mathrm{~h}$. The number of spikelets per panicle was calculated as total number of spikelets per replicate divided by the number of panicles per replicate. The filled-grain percentage was defined as the number of filled grains in proportion to total number of spikelets. Harvest index was calculated as the ratio of filled grain weight to above-ground dry weight of the five plants. Grain yield was determined from harvesting all plants from an intact area of $1 \mathrm{~m}^{2}$ in each plot and adjusted to the value at the $14 \%$ moisture. Total above-ground biomass was calculated as $0.86 \times$ yield divided by the harvest index. The number of panicles per $\mathrm{m}^{2}$ was calculated from yield and other yield components.

\subsubsection{Data analysis}

Nonlinear fitting was carried out using the GAUSS method in PROC NLIN of SAS (SAS Institute Inc., Cary, NC, USA) to estimate $K_{\mathrm{L}}$ and $K_{\mathrm{N}}$ in Eqs. (1) and (2). Data were analysed using a general linear model (GLM) to test the significance for the effects of cultivar, treatment, stage and their interactions on each parameter, using the R programme (http:/www.Rproject.org/).

\subsection{Results}

\subsubsection{General plant growth traits}

Under the control condition, growth duration from sowing to maturity was on average 127 and 134 days for cv. IR64 and cv. Apo, respectively. Mild drought (MD) did not induce any change in the growth duration in both cultivars, while more severe drought (SD) increased the growth 


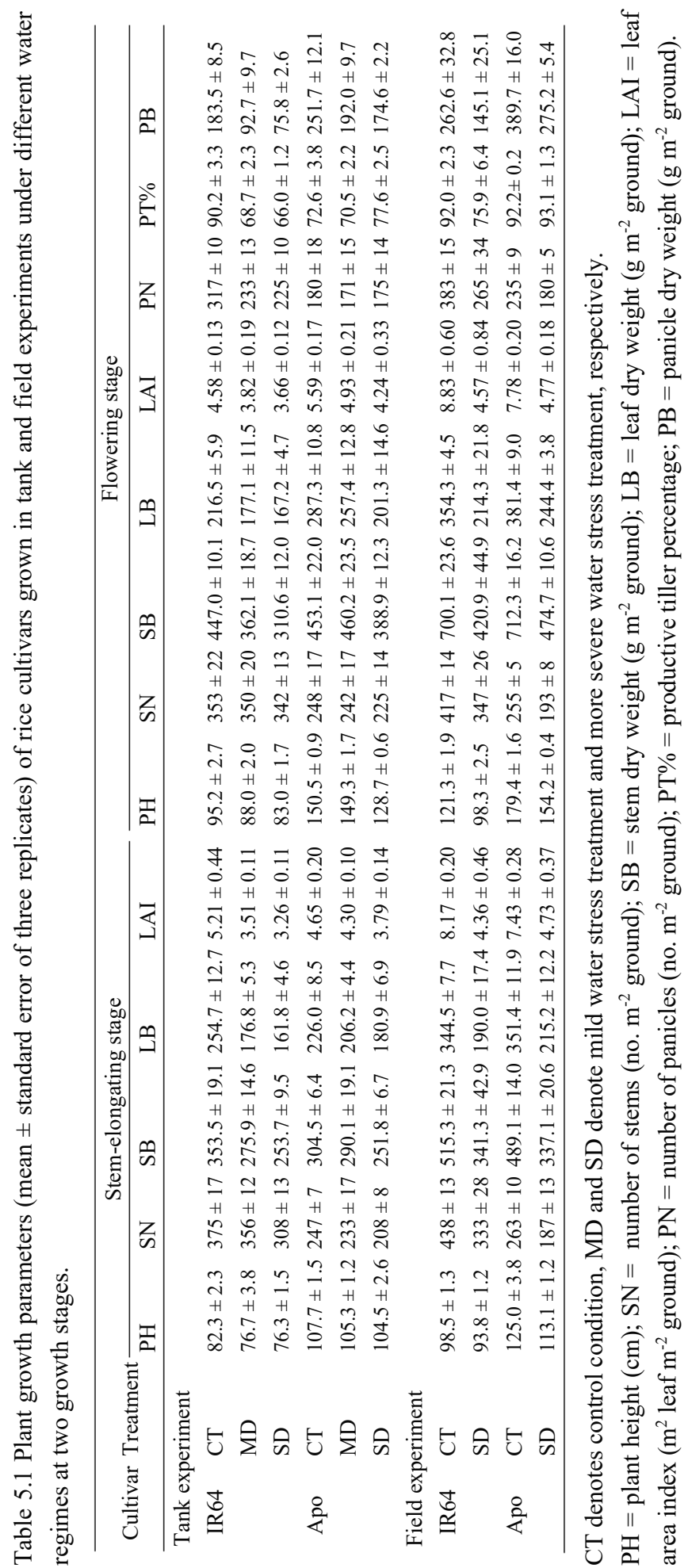




\section{Chapter 5}

duration by 4 days in both cultivars. Overall, water deficit reduced the above-ground plant growth in both cultivars (Table 5.1). Plant height, stem (tiller) number, stem dry weight, leaf dry weight, leaf area index, number of panicles, and panicle dry weight were lower under water deficit treatments than in the control in both cultivars, in both experiments. Nevertheless, variations in response to water deficit of some growth parameters were observed between the two cultivars (Table S5.1). In the tank experiment, only cv. IR64 showed clear decreases in stem $(P<0.05$; up to $22 \%$ decrease), leaf $(P<0.001$; up to $31 \%$ decrease $)$ dry weight and leaf area index (LAI) $(P<0.001$; up to $33 \%$ reduction) under MD conditions. Furthermore, SD decreased stem dry weight by up to $30 \%$ and leaf dry weight by up to $37 \%$ in cv. IR64, whereas these percentages were $17 \%$ and $30 \%$ in cv. Apo. Across stages, water-deficit treatments decreased the number of panicles (at flowering stage) in cv. IR64 $(P<0.001)$, but did not induce a clear change in cv. Apo $(P>0.05)$, resulting in a clearly decreased productive tiller percentage in cv. IR64, but not in cv. Apo. Similarly, decreases in growth parameters in cv. IR64 were higher than those in cv. Apo under SD condition in the field experiment (Table 5.1).

\subsubsection{Yield and yield related traits}

Across experiments and treatments, the grain yield, harvest index and total above-ground biomass at maturity were significantly higher in cv. Apo than in cv. IR64 (Table 5.2). Waterdeficit treatments negatively influenced yield and yield related traits in both cultivars (Table 5.2). In the tank experiment, cv. IR64 and cv. Apo recorded ca $76 \%$ and ca $86 \%$, respectively, of control yield under MD conditions. More severe drought (SD) had similar effects on yield performance in both experiments, with cv. IR64 and cv. Apo having on average 50\% and 64\%, respectively, of control yield under SD conditions. Under CT conditions, cv. IR64 produced $65 \%$ in the tank and $49 \%$ in the field experiment more panicles per $\mathrm{m}^{2}$ than $\mathrm{cv}$. Apo. Waterdeficit treatments reduced this difference, as the decrease of number of panicles in cv. Apo was smaller than that in cv. IR64 under stress conditions. Water-deficit treatments decreased the number of spikelets per panicle and 1000-grain weight in both cultivars in both experiments, and it decreased filled grain\% only in cv. IR64 under SD condition in the tank experiment. In the tank experiment, MD significantly decreased the harvest index in cv. IR64 $(P<0.05 ; 14 \%$ decrease) but not in cv. Apo $(P>0.05 ; 3 \%$ decrease). The decrease in harvest index under SD was slightly higher $(P<0.1)$ in cv. IR64 (25\% decrease) than in cv. Apo ( $19 \%$ decrease) in the tank experiment, but was clearly higher $(P<0.05)$ in cv. IR64 $(18 \%$ decrease) than in Apo (4\% decrease) in the field experiment. The water-deficit effect on total above-ground biomass was significantly stronger $(P<0.05)$ in cv. IR64 (up to 35\% decrease) than in cv. Apo (up to $21 \%$ 


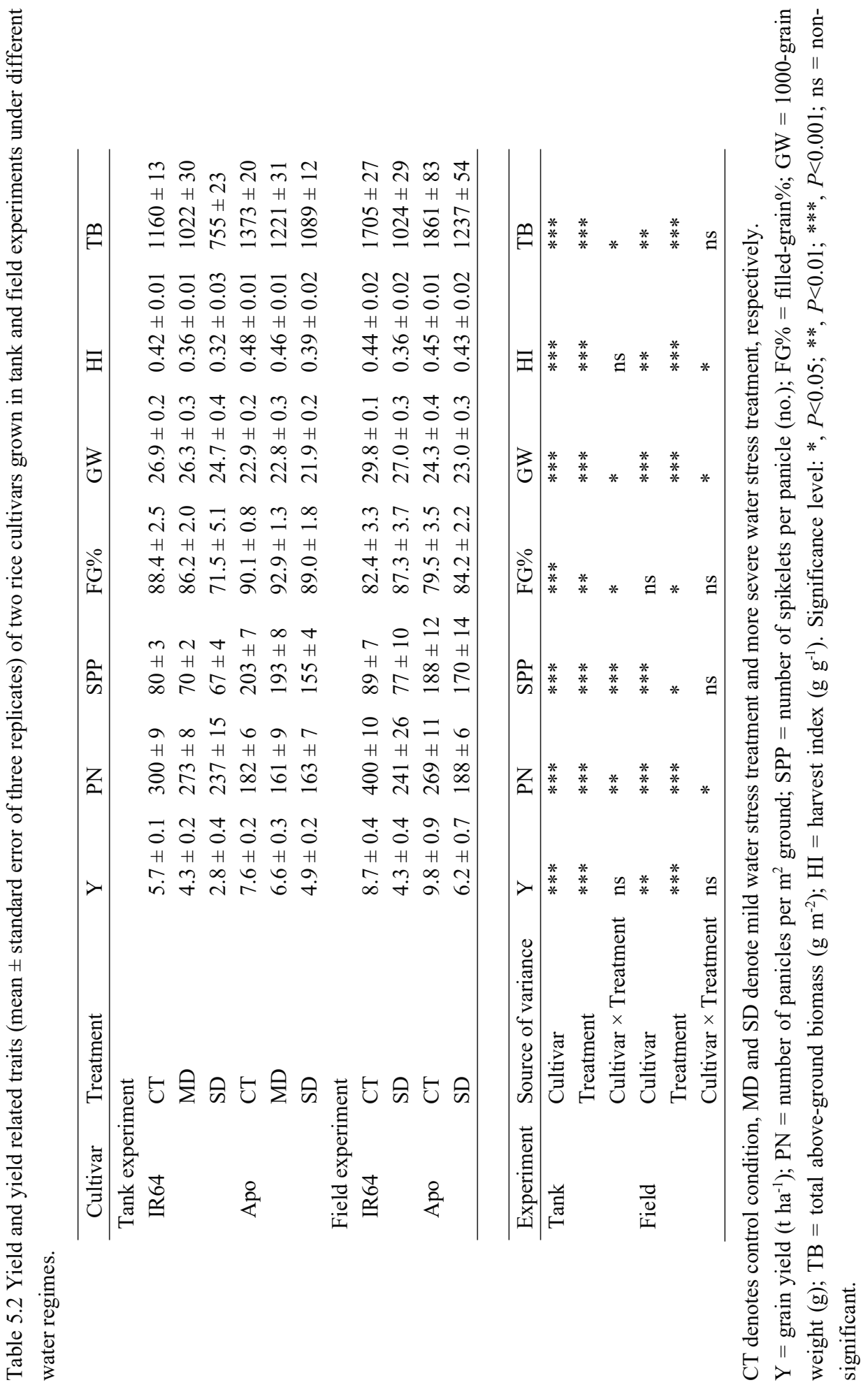




\section{Chapter 5}

decrease) in the tank experiment, while water-deficit induced changes on total above-ground was not significantly different $(P>0.05)$ between cv. IR64 (40\% decrease) and cv. Apo (34\% decrease) in the field experiment.

\subsubsection{Canopy architecture}

Plant height and stem (tiller) number significantly varied between the two cultivars, with cv. IR64 being shorter and producing more stems than cv. Apo (Table 5.1). In general, the canopy structures in terms of leaf area distribution along the plant canopy were similar for the two rice cultivars, with the largest fraction of leaf area being located at the middle of the canopy (Fig. 5.1). Nevertheless, across treatments and stages, the proportion of leaf area located at the bottom (20-40 cm from ground level) of the canopy was significantly higher $(P<0.001)$ in cv. IR64 than in cv. Apo. Water-deficit treatments increased $(P<0.05)$ the allocation of leaf area to the bottom of the canopy in cv. IR64, but did not significantly affect it $(P>0.05)$ in cv. Apo (Fig. $5.1)$.

Small leaf angles indicate more erect leaves. The leaf angles of the top three leaves were smaller in cv. IR64 than in cv. Apo $(P<0.001)$, and the cultivar difference was larger at flowering stage than at stem-elongating stage (Fig. 5.2). At stem-elongating stage, the leaf angle of the uppermost leaf in cv. IR64 was 19\% and 28\% larger under MD and SD conditions compared with CT. The leaf angle of all three upper leaves was increased $(P<0.001)$ under water-deficit conditions in cv. IR64 at flowering stage, with an average increase of $10 \%$ and $30 \%$ by MD and SD, respectively. On the other hand, water deficit did not induce a clear change $(P<0.05)$ on the leaf angle of the upper leaves in cv. Apo (Fig. 5.2).

\subsubsection{Canopy nitrogen content}

Across stages, total canopy nitrogen content $\left(\mathrm{N}_{\mathrm{c}}\right)$ did not significantly $(P>0.05)$ differ between the two cultivars in the control conditions (Table 5.3). A significant cultivar $\times$ treatment interaction $(P<0.01)$ was observed for $\mathrm{N}_{\mathrm{c}}$. Across stages, MD severely decreased $\mathrm{N}_{\mathrm{c}}$ in cv. IR64 ( $P<0.001$; up to $36 \%$ decrease), but only had a mild effect on $\mathrm{N}_{\mathrm{c}}$ in cv. Apo $(P>0.05$; up to $10 \%$ decrease). SD caused up to $42 \%$ and up to $25 \%$ decrease of $\mathrm{N}_{\mathrm{c}}$ in cv. IR64 and in cv. Apo, respectively.

Under control conditions, canopy-averaged nitrogen per leaf area $\left(\mathrm{SLN}_{\mathrm{c}}\right)$ was on average $10 \%$ higher for cv. IR64 compared with cv. Apo $(P<0.001$; Table 5.3). Across stages, water-deficit treatments decreased the $\mathrm{SLN}_{\mathrm{c}}$ in cv. IR64 $(P<0.001)$, with up to $7 \%$ decrease by SD, but did 


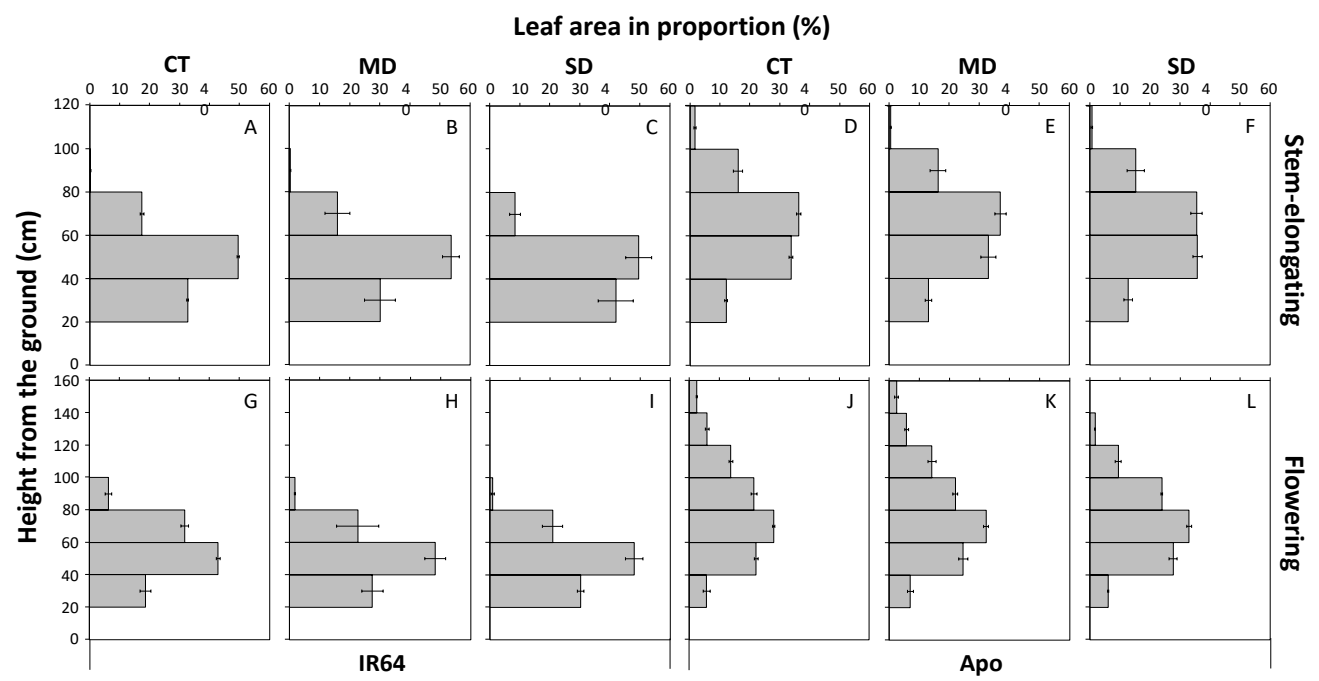

Fig. 5.1 Response of leaf area distribution within IR64 (A-C, G-I) and Apo (D-F, J-L) plant canopies, to water treatments: control (CT; A,D,G,J), mild drought (MD; B,E,H,K), and more severe drought (SD; $\mathrm{C}, \mathrm{F}, \mathrm{I}, \mathrm{L})$. Distribution of leaf area is presented as leaf area at each layer in proportion to total leaf area. Canopy height was measured from the ground level. Measurements were determined at stem-elongation (A-F) and flowering (G-L) stages. Bars represent standard errors of the mean for three replicates.
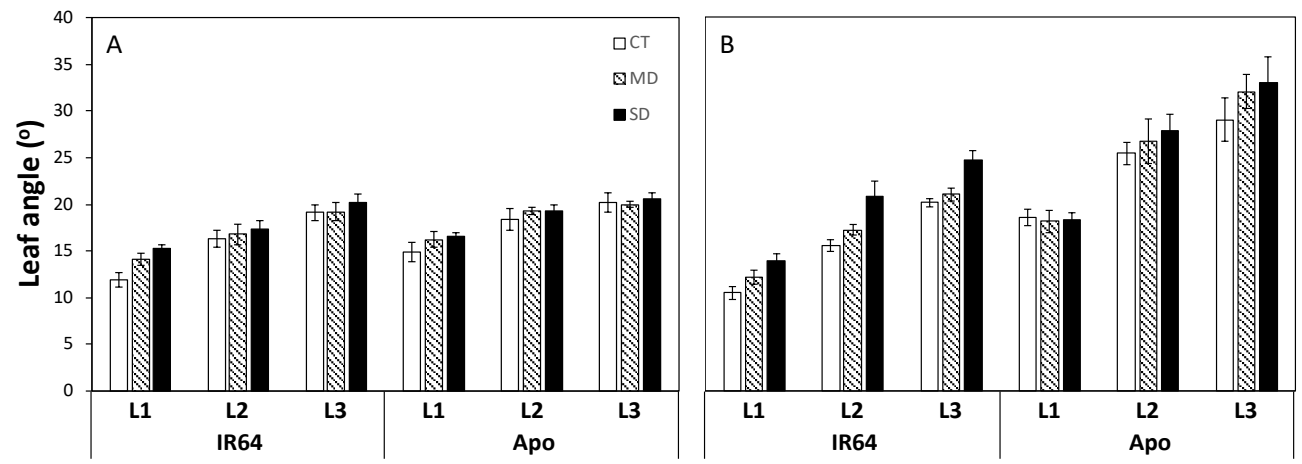

Fig. 5.2 Response of leaf angle of the top three leaves of two rice cultivars to water treatments: control (CT), mild drought (MD), and more severe drought (SD). Leaves counted from the top were marked as L1, L2 and L3, and thus, L1 at flowering stage is the flag leaf. The leaf angles were measured relative to the vertical position of stems at (A) stem-elongating and (B) flowering stages. Bars represent standard errors of the mean for three replicates. 
not significantly affect the $\mathrm{SLN}_{\mathrm{c}}$ in cv. Apo $(P>0.05)$ (Table 5.3). Furthermore, changes in $\mathrm{N}_{\mathrm{c}}$ and $\mathrm{SLN}_{\mathrm{c}}$ under water-deficit conditions did not significantly differ between stages in either cultivar (Table S5.2).

\subsubsection{Light and nitrogen distributions}

Figure 5.3 presents the measured patterns of light distribution in the canopy. Canopy light extinction coefficient $\left(K_{\mathrm{L}}\right)$ estimated from these data significantly differed between the two rice cultivars $(P<0.001)$ (Table 5.3). Under CT conditions, $K_{\mathrm{L}}$ was on average $16 \%$ lower for cv. IR64 than for cv. Apo. Water-deficit treatments increased $K_{\mathrm{L}}$, with a significant interaction between treatment and cultivar $(P<0.001)$ (Table 5.3; Table S5.2). Compared with CT, MD and SD caused on average $17 \%$ and $33 \%$ increases in $K_{\mathrm{L}}$ in cv. IR64, while these percentages were $6 \%$ and $15 \%$ in cv. Apo. Furthermore, the water-deficit effect on $K_{\mathrm{L}}$ was slightly stronger $(P<0.05)$ at flowering stage (up to $35 \%$ decrease) than at stem-elongating stage (up to $31 \%$ decrease). A positive correlation of $K_{\mathrm{L}}$ with the averaged leaf angles of the top three leaves was observed across treatments in each cultivar and when all data were pooled (Fig. 5.4).

Across stages, the value of SLN at the top of the canopy $\left(\mathrm{SLN}_{0}\right)$, estimated from the measured patterns of light distribution in the canopy (Fig. 5.5), did not differ much between cv. IR64 and

Fig. 5.3 Cumulative leaf area index (LAI) calculated from the top of the canopy versus relative photosynthetically active radiation (PAR) penetrated for (A) IR64 and (B) Apo grown under three water treatments: control (CT; circles), mild drought (MD; squares), and more severe drought ( $\mathrm{SD}$; triangles). Measurements were determined at stem-elongating ( $\mathrm{S}$; open symbols) and flowering ( $\mathrm{F}$; filled symbols) stages. Curves are drawn from Eq. (1) with $K_{\mathrm{L}}$ fitted for each treatment of each cultivar, based on data pooled from three replicates.

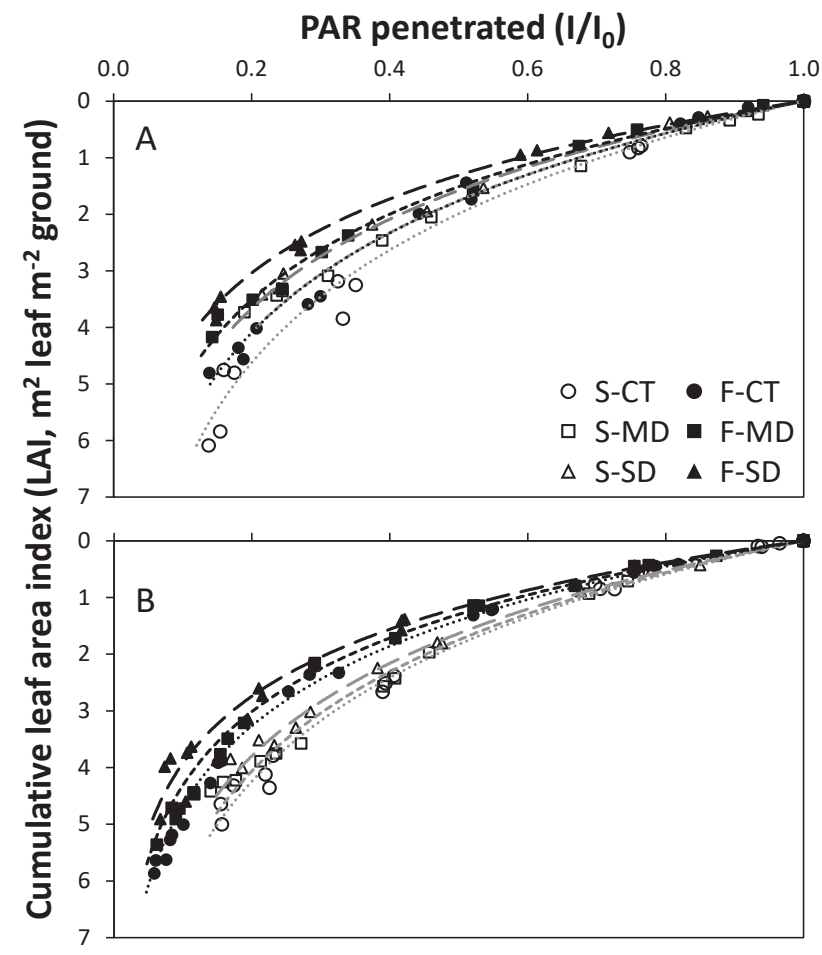




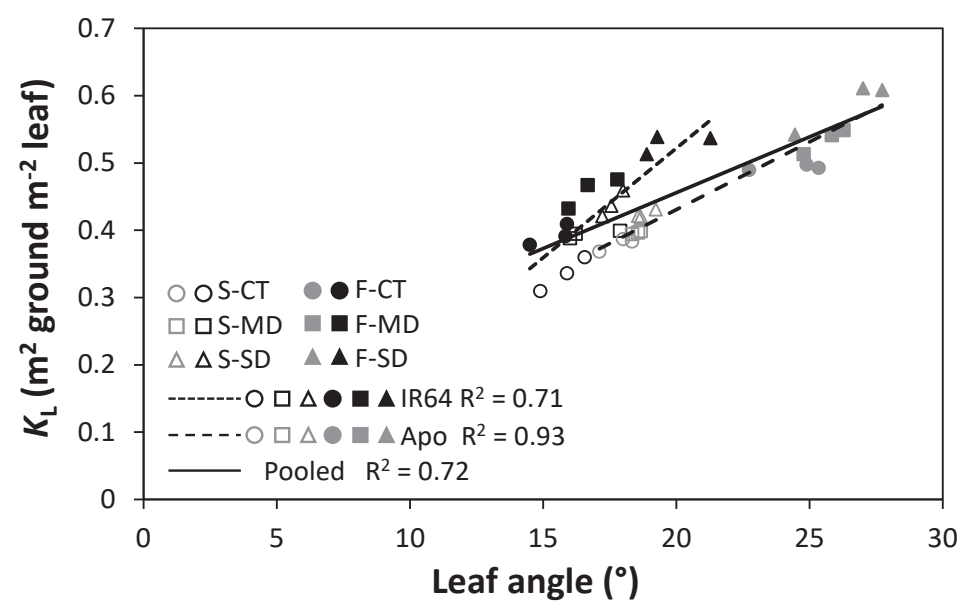

Fig. 5.4 Relationship between canopy light extinction coefficient $\left(K_{\mathrm{L}}\right)$ and leaf angle in IR64 (black) and Apo (grey) grown under three water treatments: control (CT; circles), mild drought (MD; squares), and more severe drought (SD; triangles). Values of leaf angle were averaged from the top three leaves of each replicate. Data was obtained from stem-elongating ( $\mathrm{S}$; open symbols) and flowering (F; filled symbols) stages. Linear regression lines were for each cultivar and overall data.

Fig. 5.5 Cumulative leaf area index (LAI) calculated from the top of the canopy versus the leaf nitrogen content per unit area (SLN) for IR64 (A) and Apo (B) grown under three water treatments: control $(\mathrm{CT}$; circles), mild drought (MD; squares), and more severe drought (SD; triangles). Measurements were determined at stem-elongating ( $\mathrm{S}$; open symbols) and flowering (F; filled symbols) stages. Curves are drawn from Eq. (2) with $\mathrm{SLN}_{0}$ and $K_{\mathrm{N}}$ fitted for each treatment of each cultivar, based on data pooled from three replicates.

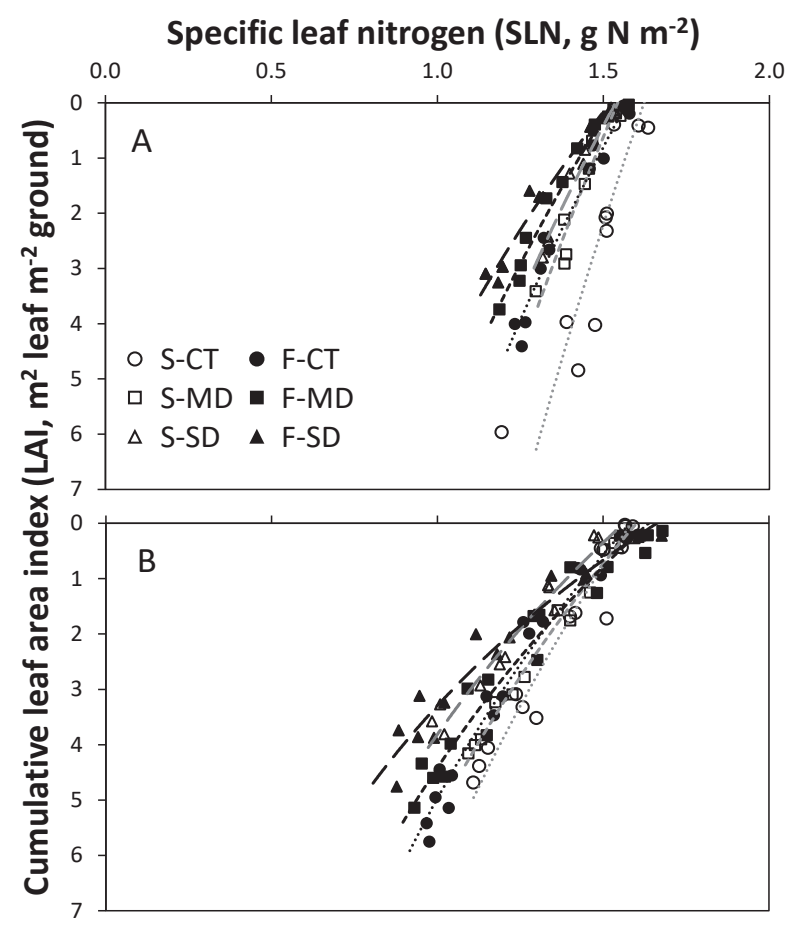




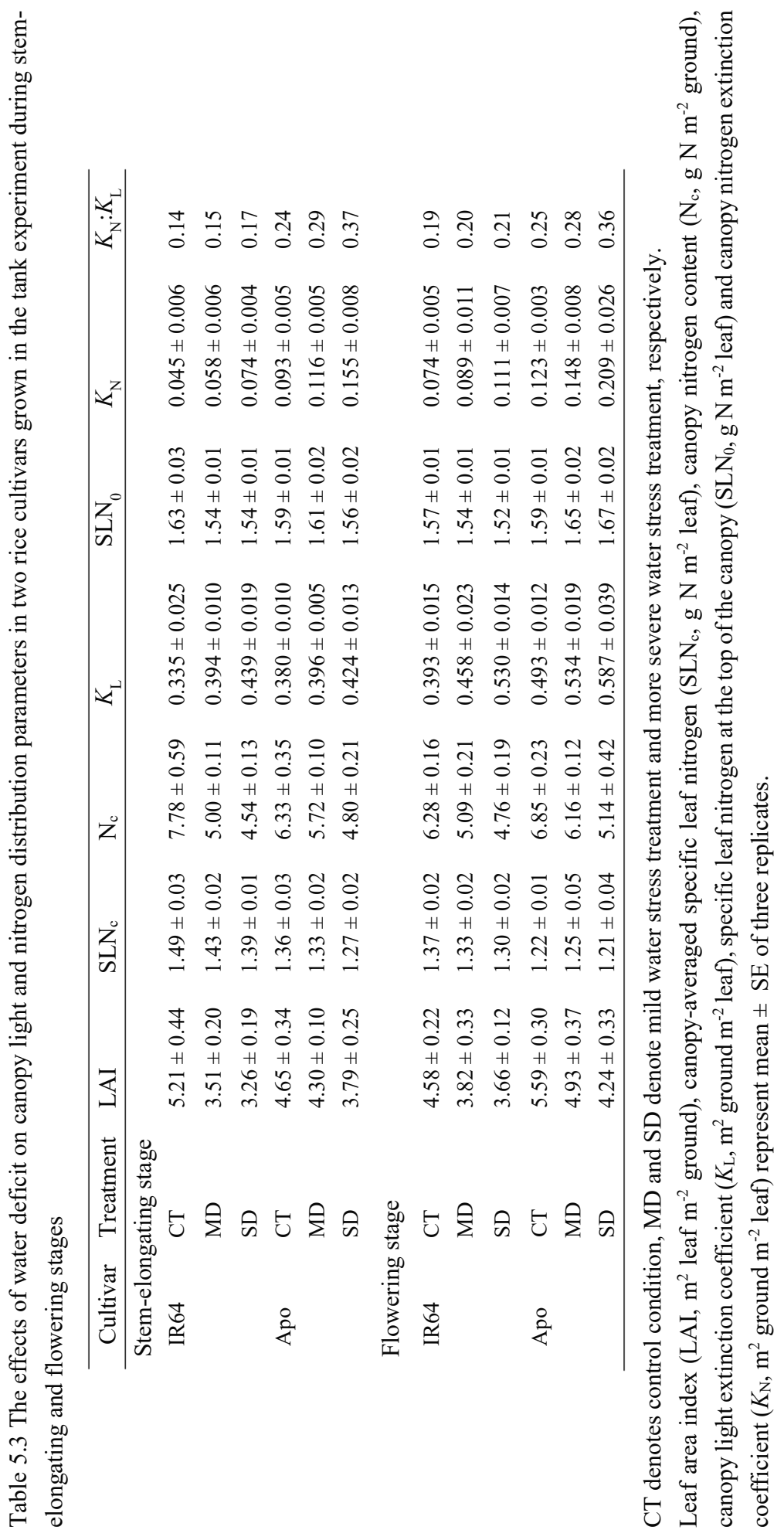


cv. Apo $(P>0.05)$ under CT conditions (Table 5.3). Water-deficit treatments decreased the $\mathrm{SLN}_{0}$ in cv. IR64 ( $P<0.001$; up to $5 \%$ decrease) at both stages, but did not cause a clear change in $\mathrm{SLN}_{0}$ in cv. Apo $(P>0.05)$ at stem-elongating stage and increased its value at flowering stage. The estimated nitrogen extinction coefficient $\left(K_{\mathrm{N}}\right)$ significantly differed between the two rice cultivars $(P<0.001)$ (Table 5.3). Under CT conditions, $K_{\mathrm{N}}$ was on average $46 \%$ lower for cv. IR64 than for cv. Apo. Nevertheless, water deficit increased $K_{\mathrm{N}}$ in both cultivars (Table 5.3). The effects of water-deficit treatments on $K_{\mathrm{N}}$ were stronger $(P<0.001)$ in cv. Apo (up to $70 \%$ increase) than in cv. IR64 (up to $65 \%$ increase). No significant interaction between treatment and stage was observed for $K_{\mathrm{N}}$ (Table S5.2). Positive correlations of $K_{\mathrm{N}}$ with $K_{\mathrm{L}}$ were observed across treatments in each cultivar and when all data were pooled (Fig. 5.6).

Under CT conditions, the $K_{\mathrm{N}}: K_{\mathrm{L}}$ ratio in cv. Apo was 0.24 (stem-elongating stage) and 0.25 (flowering stage), while the ratios were lower in cv. IR64, being 0.14 and 0.19 (Table 5.3). A significant treatment $\times$ cultivar interaction $(P<0.001)$ was observed for the $K_{\mathrm{N}}: K_{\mathrm{L}}$ ratio. In cv. IR64, this ratio was only increased by SD at the stem-elongating stage $(P<0.05)$, with ca. $24 \%$ increase compared with the ratio in $\mathrm{CT}$. On the other hand, the $K_{\mathrm{N}}: K_{\mathrm{L}}$ ratio in cv. Apo was significantly increased by water-deficit treatments at both stages, with up to $19 \%$ and $49 \%$ increase by MD and SD, respectively (Table 5.3).

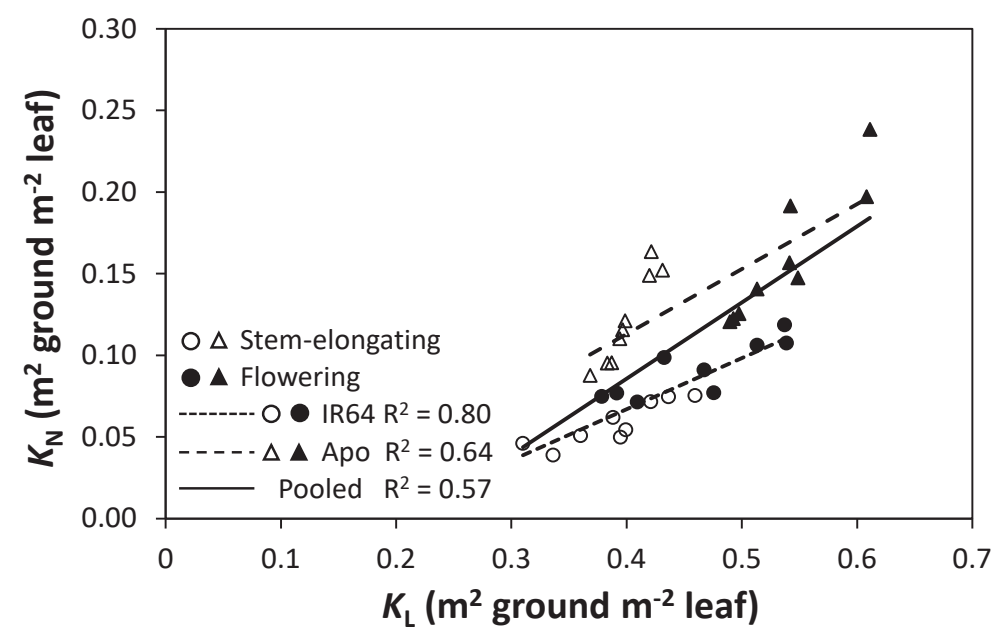

Fig. 5.6 Relationship between canopy nitrogen extinction coefficient $\left(K_{\mathrm{N}}\right)$ and canopy light extinction coefficient $\left(K_{\mathrm{L}}\right)$ in IR64 (circles) and Apo (triangles). Data was obtained from stem-elongating (open symbols) and flowering (filled symbols) stages. Linear regression lines were for each cultivar and overall data. 


\subsubsection{Daily biomass gain in relation to canopy light and nitrogen distribution}

Under CT conditions, the biomass gain between stem-elongating and flowering stage in cv. Apo was almost two times as high as that in cv. IR64 (Table 5.4). The daily average biomass gain during the two growth stages was also higher in cv. Apo than in cv. IR64, and the difference became even higher under water-deficit treatments. Water deficit reduced the daily average biomass gain in both cultivars (Table 5.4). Compared with CT, MD and SD caused ca. 25\% and $52 \%$ decreases in daily average biomass gain in cv. IR64, while these percentages were $10 \%$ and $37 \%$ in cv. Apo. The lower reduction in daily average biomass gain in cv. Apo appeared to be associated with the greater $K_{\mathrm{N}}: K_{\mathrm{L}}$ ratio, compared with cv. IR64. To confirm that, we conducted a regression analysis, where the daily average biomass gain was regressed against the $K_{\mathrm{N}}: K_{\mathrm{L}}$ ratio with treatment categories $(\mathrm{CT}, \mathrm{MD}, \mathrm{SD})$ and canopy nitrogen content $\left(\mathrm{N}_{\mathrm{c}}\right)$ as covariates. Treatments were introduced as a covariate to account for the aforementioned effect of stress levels on daily average biomass gain. Only $\mathrm{N}_{\mathrm{c}}$ was introduced to account for the effect of both canopy nitrogen and LAI on light interception (thus, on biomass gain), because LAI was closely correlated with $\mathrm{N}_{\mathrm{c}}$ (Fig. 5.7) as theoretically expected (Yin et al., 2000). Regression analysis showed that the variation in the $K_{\mathrm{N}}: K_{\mathrm{L}}$ ratio contributed most significantly to the variation in daily average biomass gain between the two rice cultivars, so did the effect of treatment (Table 5.5). $\mathrm{N}_{\mathrm{c}}$ did not significantly contribute to the explanation of the observed variance in daily average biomass gain.

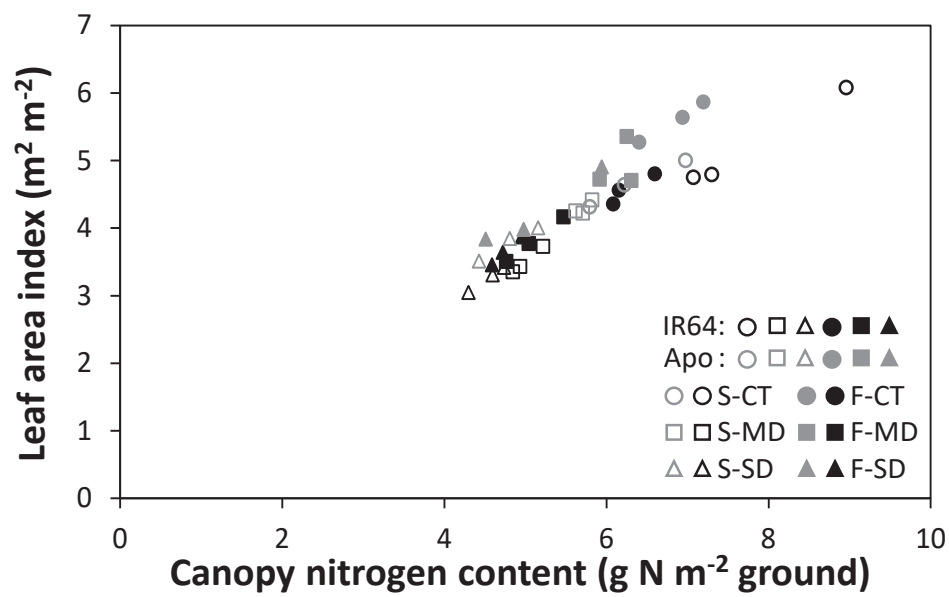

Fig. 5.7 Relationship between leaf area index and canopy nitrogen content for IR64 (black) and Apo (grey) grown under three water treatments: control (CT; circles), mild drought (MD; squares), and more severe drought (SD; triangles). Measurements were determined at stem-elongating (S; open symbols) and flowering (F; filled symbols) stages. 
Table 5.4 The effects of water deficit on biomass gain and daily average biomass gain between stemelongating and flowering stages in two rice cultivars grown in the tank experiment

\begin{tabular}{|c|c|c|c|c|c|c|}
\hline \multirow{2}{*}{ Cultivar } & \multirow{2}{*}{ Treatment } & \multicolumn{2}{|c|}{$\begin{array}{l}\text { Above-ground biomass } \\
\text { (g DM m}{ }^{-2} \text { ground) }\end{array}$} & \multirow{2}{*}{ 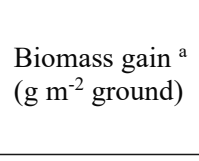 } & \multicolumn{2}{|c|}{ Daily average biomass gain } \\
\hline & & Stem-elongating & Flowering & & $\begin{array}{l}\mathrm{g} \mathrm{m}^{-2} \text { ground } \\
\text { day }^{-1}\end{array}$ & $\begin{array}{l}\begin{array}{l}\% \text { of } \\
\text { control }\end{array} \\
\end{array}$ \\
\hline \multirow[t]{3}{*}{ IR64 } & CT & $608.2 \pm 31.6$ & $846.9 \pm 20.6$ & $238.7 \pm 17.3$ & $11.9 \pm 0.9$ & \\
\hline & MD & $452.7 \pm 17.2$ & $632.0 \pm 27.8$ & $179.3 \pm 18.9$ & $9.0 \pm 0.9$ & 75.1 \\
\hline & SD & $415.5 \pm 14.1$ & $553.6 \pm 10.4$ & $138.0 \pm 14.7$ & $5.8 \pm 0.6$ & 48.2 \\
\hline \multirow[t]{3}{*}{ Apo } & $\mathrm{CT}$ & $530.5 \pm 14.4$ & $992.0 \pm 26.9$ & $461.5 \pm 30.3$ & $17.1 \pm 1.1$ & \\
\hline & MD & $496.3 \pm 23.2$ & $909.6 \pm 45.4$ & $413.3 \pm 58.9$ & $15.3 \pm 2.2$ & 89.6 \\
\hline & SD & $432.6 \pm 13.3$ & $764.8 \pm 26.2$ & $332.2 \pm 27.3$ & $10.7 \pm 0.9$ & 62.7 \\
\hline
\end{tabular}

$\mathrm{CT}$ denotes control condition while MD and SD denote mild water stress treatment and more severe water stress treatment, respectively.

a Biomass gain from the period between stem-elongating and flowering stages was calculated as the above-ground dry matter $(\mathrm{DM})$ (mean \pm standard error of three replicates) differences between the two stages.

b Daily average biomass gain was calculated as the biomass gain from the period between stemelongating and flowering stages divided by the growth duration between the two stages.

Table 5.5 Multiple regression analysis of daily average biomass gain between stem-elongating and flowering stages as a function of treatment (CT, MD, SD), $\mathrm{N}_{\mathrm{c}}$ and $K_{\mathrm{N}}: K_{\mathrm{L}}$ ratio (Daily average biomass gain $=b_{0}+b_{1} \mathrm{CT}+b_{2} \mathrm{MD}+b_{3} \mathrm{SD}+b_{4} \mathrm{~N}_{\mathrm{c}}+b_{5} K_{\mathrm{N}}: K_{\mathrm{L}}$ ), based on data of two rice cultivars. Regressions were made for stem-elongating and flowering stages.

\begin{tabular}{lllllllll}
\hline \multirow{2}{*}{ Stage } & \multirow{2}{*}{ Intercept } & \multicolumn{7}{l}{ Regression coefficient } \\
\cline { 3 - 9 } & $b_{0}$ & $b_{1}{ }^{\S}$ & $b_{2}{ }^{\S}$ & $b_{3}{ }^{\S}$ & $b_{4}$ & $b_{5}$ & $\mathrm{R}^{2}$ & No. of data points \\
\hline Stem-elongating & 13.7 & 0 & $-4.7^{*}$ & $-11.0^{* * *}$ & -0.83 & $35.0^{* * *}$ & 0.85 & 18 \\
Flowering & 2.4 & 0 & -2.4 & $-8.6^{*}$ & 1.0 & $32.5^{*}$ & 0.84 & 18 \\
\hline
\end{tabular}

$\S$ Treatments (CT, MD and SD) as a category variable were quantified by introducing three dummy variables, with the CT as the reference level; so, the regression coefficient $b_{1}$ was nil while values of $b_{2}$ and $b_{3}$ indicate the decrease of daily average biomass gain in MD and SD treatments, respectively, relative to the $\mathrm{CT}$ treatment.

Significance level: * $P<0.05 ; * * *, P<0.001$. 


\subsection{Discussion}

\subsubsection{Growth and yield responded differently to water deficit in two rice cultivars}

Compared with dry land cereals such as wheat and maize, rice is very sensitive to water deficit (Pantuwan et al., 2002; Centritto et al., 2009; Praba et al., 2009). Nevertheless, rice genotypes cultivated for aerobic condition had better adaptation to water-limited conditions than lowland rice cultivars (Bouman et al., 2005; Suralta and Yamauchi, 2008). Our results confirmed this in terms of a smaller decrease of above-ground dry weight, grain yield and harvest index by water deficit in aerobic cultivar cv. Apo compared with lowland cultivar cv. IR64 (Tables 5.1 and 5.2). In general, our results were consistent between the tank and field experiments, although the absolute values of each parameter differed between the two experiments (Tables 5.1 and $5.2)$.

In this study, we aimed to identify the above-ground morphological characteristics that determine the differences in adaptation to aerobic conditions between the two rice cultivars. Thus we did not intend to induce severe drought stress on the rice plants. The mild drought stress (MD; 0 to $-5 \mathrm{kPa}$ ) we imposed to the rice plants was similar to the control treatment used for dryland cereals (Mian and Nafziger, 1994; Bahrun et al., 2002), which is considered to be sufficient for plant growth. However, shoot growth traits in cv. IR64 were strongly inhibited by MD, including decreased stem and leaf dry weight, leaf area and panicle dry weight (Table 5.1). Our previous study suggested that the severely limited shoot growth in rice plants was related to its largely restricted root growth when grown under relatively dry conditions (Ouyang et al., 2021). Nevertheless, the shoot growth was only slightly inhibited by MD in cv. Apo (Table 5.1), while the root growth was also heavily impeded by the same level of treatment (Ouyang et al., 2021). Those results indicated that below-ground tissue only partly accounted for the aboveground biomass accumulation in response to water deficit. Inhibition of shoot growth in response to low water availability is aimed at improving the water balance by limiting water loss, but can lead to yield losses (Claeys and Inzé, 2013). Compared with cv. IR64, the shoot growth in cv. Apo was less affected by water-deficit treatments (Table 5.1). This might be attributed to the fewer tillers and less transpiring leaves in cv. Apo than in cv. IR64 (Table 5.1). Our previous study showed that cv. Apo has fewer stomata, lower stomatal conductance, and higher transpiration efficiency than cv. IR64 (Ouyang et al., 2017). Moreover, the harvest index was also less sensitive to water deficit in cv. Apo than in cv. IR64 (Table 5.2). Therefore, the yield advantage of cv. Apo under water-deficit conditions was attributed to multiple traits that 
enable to maintain biomass production and harvest index under stress.

\subsubsection{Variations in canopy structure, vertical light and nitrogen distribution}

Introducing the semi-dwarf plant type with erect leaves for lowland rice cultivation allows good penetration of light into the lower parts of the canopy (Dingkuhn et al., 1991; Peng et al., 2000). IR64, as a modern lowland rice cultivar, was shorter, had more erect leaf (i.e. smaller leaf angles) at the upper part of the canopy, and more leaf area located at the bottom of plant canopy than cv. Apo (Table 5.1; Figs. 5.1 and 5.2). As a consequence, the vertical light distribution throughout the canopy was relatively more uniform in cv. IR64 than in cv. Apo, as indicated by a smaller $K_{\mathrm{L}}$ in cv. IR64, compared with cv. Apo (Table 5.3). The values of $K_{\mathrm{L}}$ we found here for cv. IR64 and cv. Apo were similar to the values previously reported for other rice cultivars (Okami et al., 2016; Gu et al., 2017). Both rice cultivars showed non-uniform nitrogen distributions within the canopy $\left(K_{\mathrm{N}}>0\right)$, particularly at the flowering stage (Table 5.3; Fig. 5.5). The non-uniformity of nitrogen within the canopy has been reported for many crops (Bertheloot et al., 2008; Archontoulis et al., 2011; Gu et al., 2017). The gradient of SLN is triggered by the light environment within a canopy and leaf aging (Hirose and Werger, 1987; Okami et al., 2016). Our results supported this by viewing a positive correlation between $K_{\mathrm{N}}$ and $K_{\mathrm{L}}$ (Fig. 5.6). Thus, the steeper SLN gradient in cv. Apo (i.e. a higher $K_{\mathrm{N}}$ ) was associated with a more attenuated light climate within the canopy (i.e. a higher $K_{\mathrm{L}}$ ), compared with cv. IR64. Furthermore, the variation in canopy nitrogen distribution between cv. IR64 and cv. Apo was mainly resulted from the difference in the nitrogen content in the lower leaf layers (Fig. 5.5), as SLN at the top of the canopy $\left(\mathrm{SLN}_{0}\right)$ was not much different between the two cultivars under control condition (Table 5.3). In addition, cv. Apo had low leaf area portioned to the lowest canopy layer where there is low light intensity (Figs. 5.1 and 5.3).

\subsubsection{Cultivars differed in light and nitrogen distributions within the canopy in response to water deficit}

Water-deficit stress occurring during canopy development will modify many of the canopy characteristics in comparison with well-watered plants (Pantuwan et al., 2002; Archontoulis et al., 2011). In our study, canopy structures in terms of plant height, leaf angle and leaf area distribution were affected by water-deficit treatments (Figs. 5.1 and 5.2; Table 5.1). Among those structural traits, leaf angle was reported to be most important in determining $K_{\mathrm{L}}$ (Yin and van Laar, 2005; Archontoulis et al., 2011). Reported effects of water deficit on leaf angle were not consistent across species or even within species (Werner et al., 1999; Lonbani and Arzani, 
2011). Lonbani and Arzani (2011) observed both increase and decrease in flag leaf angle under water-deficit stress in different wheat cultivars. This different response may arise, depending on whether leaf angle is adjusted to contribute to reduced levels of photoinhibition under stress. This contribution did not seem to be relevant to our experiment because cv. Apo had larger leaf angles (Fig. 5.2; thus presumably had stronger photoinhibition), yet had more biomass accumulation than cv. IR64 (Table 5.5). Nevertheless, larger leaf angle on the upper part of the canopy would intercept more light and create light deprivation of the lower leaves, therefore resulting in higher $K_{\mathrm{L}}$ (Archontoulis et al., 2011). Our results support this latter view given the positive correlations between $K_{\mathrm{L}}$ and leaf angle (Fig. 5.4). The leaf angles of the three upper leaves in cv. Apo were less affected by water deficit, therefore resulting in a smaller increase of $K_{\mathrm{L}}$ for cv. Apo than for cv. IR64 (Table 5.3; Fig. 5.2).

We observed an increased $K_{\mathrm{N}}$ under water-deficit treatments (Table 5.3). The lower SLN at the lower part of the canopy under water deficit was not related to low nitrogen availability, as the reduction of canopy nitrogen content under water-deficit treatments was mainly caused by the heavily reduced leaf area, but not the canopy averaged nitrogen content (Table 5.3). Therefore, the change in $K_{\mathrm{N}}$ could be triggered by the higher $K_{\mathrm{L}}$ within the canopy (Hirose and Werger, 1987; Okami et al., 2016) and faster ageing of the leaves at the lower part of the canopy (Hikosaka et al., 1994) under water-deficit treatments. Still, water-deficit treatments increased the difference in nitrogen distribution between cv. Apo and cv. IR64, resulting in a more strongly increased value of $K_{\mathrm{N}}$ under water deficit in cv. Apo than in cv. IR64 (Fig. 5.5; Table 5.3). Our results indicate that there are genotypic variations in plant architecture and leaf nitrogen distribution in response to water deficit between the two rice cultivars.

\subsubsection{Associations of daily average biomass gain with canopy nitrogen vs light profiles}

Theoretically, the nitrogen content in an specific leaf was positively correlated with its photosynthetic rate, as it determines several photosynthetic capacity parameters (Harley et al., 1992; Yin et al., 2009; Gu et al., 2012). However, such relationship only applies when the leaf is exposed to saturating light, as leaf nitrogen affects little the net photosynthesis under low light conditions (such as in shaded leaves) (Field, 1983). According to an optimization theory, within a dense canopy, the canopy photosynthesis can be maximized if the leaf $\mathrm{N}$ distribution follows the light distribution, i.e. $K_{\mathrm{N}}: K_{\mathrm{L}}=1$ (Hirose and Werger, 1987; Anten et al., 1995; Goudriaan, 1995; Sands, 1995). In our study, across stages, the averaged value for the $K_{\mathrm{N}}: K_{\mathrm{L}}$ ratio in control conditions was 0.21 (Table 5.3), indicating the vertical distributions of nitrogen 
in the two rice cultivars were far from the optimized. Such phenomenon was also observed in other rice cultivars (Gu et al., 2017), and in other monocots (Anten et al., 1995). Nevertheless, the nitrogen distribution in $\mathrm{cv}$. Apo exhibited a better acclimation to light distribution by showing a higher $K_{\mathrm{N}}: K_{\mathrm{L}}$ ratio than cv. IR64 (Table 5.3). A higher $K_{\mathrm{N}}: K_{\mathrm{L}}$ ratio indicated a more efficient use of nitrogen at the whole plant level, in terms of the whole canopy photosynthetic carbon assimilation (Field, 1983; Anten et al., 1995). Therefore, the possibility of enhancing canopy photosynthesis and biomass production by increasing $K_{\mathrm{N}}: K_{\mathrm{L}}$ ratio should be considered, if no other factors are involved. Our study supported this idea in view of a higher daily average biomass gain between stem-elongating and flowering stages in cv. Apo than in cv. IR64 in control conditions (Table 5.4), even though the above-ground dry weight, canopy nitrogen content and leaf area index at the stem-elongating stage was higher in cv. IR64 than in cv. Apo (Tables 5.3 and 5.4).

Changes in the relationship between nitrogen and light have been related to leaf area index and nitrogen status (Dreccer et al., 2000; Yin et al., 2003; Shiratsuchi et al., 2006; Gu et al., 2017). Lötscher et al. (2003) reported that low internal nitrogen availability is the main factor that increases the $K_{\mathrm{N}}: K_{\mathrm{L}}$ ratio. However, our results indicated that nitrogen availability was only partly responsible to the response of the $K_{\mathrm{N}}: K_{\mathrm{L}}$ ratio to water deficit. Increases in the $K_{\mathrm{N}}: K_{\mathrm{L}}$ ratio under water-deficit treatments were observed in both cultivars, yet, average canopy nitrogen content $\left(\mathrm{SLN}_{\mathrm{c}}\right)$ was affected by water-deficit treatments only in cv. IR64 but not in cv. Apo (Table 5.3). The development of vertical nitrogen distributions in the canopy are viewed as plastic responses that optimize nitrogen utilization with respect to canopy carbon assimilation (Dreccer et al., 2000; Bertheloot et al., 2008). Thus, the increase of the $K_{\mathrm{N}}: K_{\mathrm{L}}$ ratio indicates an improvement of nitrogen distribution by water deficit in rice canopy. Furthermore, our results indicated that the differential responses of daily average biomass gain to water-deficit treatments in two rice cultivars was most significantly associated with the variable response in the $K_{\mathrm{N}}: K_{\mathrm{L}}$ ratio (Table 5.5). Cv. Apo exhibited a better adaptation to water deficit than cv. IR64 by showing a higher increased value of the $K_{\mathrm{N}}: K_{\mathrm{L}}$ ratio under water deficit treatments (Table 5.3). Interestingly, yield under all treatments were higher in cv. Apo than in cv. IR64 (Table 5.2). As grain yield depends mainly on assimilate accumulation during the grain-filling phase, higher yield in cv. Apo suggests that the higher $K_{\mathrm{N}}: K_{\mathrm{L}}$ ratio favourable for canopy carbon assimilation may have continued for a large part of the post-flowering phase. 


\subsection{Conclusions}

The aerobic and lowland rice cultivars displayed distinct canopy architecture, canopy nitrogen and light profile parameters, i.e. the extinction coefficients for nitrogen $\left(K_{\mathrm{N}}\right)$ and for light $\left(K_{\mathrm{L}}\right)$, and their ratio $\left(K_{\mathrm{N}}: K_{\mathrm{L}}\right)$. Differences in leaf angle were responsible for the variation in light profile between the two cultivars. Under the control condition, differences in the $K_{\mathrm{N}}: K_{\mathrm{L}}$ ratio between the two rice cultivars appeared to be responsible for the differences in their daily average biomass gain and yield although the aerobic cultivar (cv. Apo) had low number of tillers and low biomass at the late vegetative stage. Associated with its partitioning of less nitrogen to the shaded leaves, the $K_{\mathrm{N}}: K_{\mathrm{L}}$ ratio of cv. Apo, compared with the lowland cultivar (cv. IR64), was higher, resulting in a more efficient use of nitrogen at the canopy scale in the aerobic cultivar. Under water deficit, cv. Apo maintained erect leaves at the upper part of the canopy. "Apo" also allocated less nitrogen to the shaded leaves and this resulted in a higher $K_{\mathrm{N}}: K_{\mathrm{L}}$ ratio than under the control condition. Such adjustment allowed a better optimizing of nitrogen utilization over the canopy and therefore minimized the impact of water-deficit stress on biomass gain and yield in cv. Apo. Our results suggest that improving above-ground architecture and nitrogen allocation pattern in the canopy are needed to improve biomass gain and yield performance of rice under declining water availability. Further studies are needed to verify the relationship between the canopy traits and biomass gain using more genotypes. Nevertheless, our results suggest that besides the $K_{\mathrm{L}}$-determining above-ground architecture that has previously been attended to in rice ideotype breeding (Dingkuhn et al. 1991; Peng et al., 2000; Virk et al. 2004), the nitrogen allocation pattern in the canopy $\left(K_{\mathrm{N}}\right)$ and the $K_{\mathrm{N}}: K_{\mathrm{L}}$ ratio are also very important for improving biomass production and yield of rice, especially under water-deficit conditions.

\section{Acknowledgements}

This work was supported by an anonymous private donor who financed, via Wageningen University Fund, the first author's PhD fellowship. The experimental work was financed by the College of Agriculture, Yangzhou University. We thank IRRI for providing rice seeds, Mrs Zhiqin Wang and Mr. Zhenxiang Zhou for assistance during experimentation, and Dr C.G. van der Linden, Dr P.S. Bindraban and Dr Krishna S.V. Jagadish for valuable support.

\section{References}

Anten NPR, Schieving F, Werger MJA. 1995. Patterns of light and nitrogen distribution in 
relation to whole canopy carbon gain in $\mathrm{C}_{3}$ and $\mathrm{C}_{4}$ mono- and dicotyledonous species. Oecologia 101, 504-513.

Archontoulis SV, Vos J, Yin X, Bastiaans L, Danalatos NG, Struik PC. 2011. Temporal dynamics of light and nitrogen vertical distributions in canopies of sunflower, kenaf and cynara. Field Crops Research 122, 186-198.

Atlin GN, Lafitte HR, Tao D, Laza M, Amante M, Courtois B. 2006. Developing rice cultivars for high-fertility upland systems in the Asian tropics. Field Crops Research 97, 43-52.

Bahrun A, Jensen CR, Asch F, Mogensen VO. 2002. Drought-induced changes in xylem pH, ionic composition, and ABA concentration act as early signals in field-grown maize (Zea mays L.). Journal of Experimental Botany 53, 251-263.

Bertheloot J, Martre P, Andrieu B. 2008. Dynamics of light and nitrogen distribution during grain filling within wheat canopy. Plant Physiology 148, 1707-1720.

Bouman BAM, Tuong TP. 2001. Field water management to save water and increase its productivity in irrigated lowland rice. Agricultural Water Management 49, 11-30.

Bouman BAM, Peng S, Castaneda AR, Visperas RM. 2005. Yield and water use of irrigated tropical aerobic rice systems. Agricultural Water Management 74, 87-105.

Centritto M, Lauteri M, Monteverdi MC, Serraj R. 2009. Leaf gas exchange, carbon isotope discrimination, and grain yield in contrasting rice genotypes subjected to water deficits during the reproductive stage. Journal of Experimental Botany 60, 2325-2339.

Claeys H, Inzé D. 2013. The agony of choice: how plants balance growth and survival under water-limiting conditions. Plant Physiology 162, 1768-1779.

Dingkuhn M, Penning de Vries FWT, De Datta SK, Van Laar HH. 1991. Concepts for a new plant type for direct seeded flooded tropical rice. In Direct seeded flooded rice in the tropics. International Rice Research Institute, Los Baños, Philippines, 1991, 17-38.

Dreccer MF, van Oijen M, Schapendonk AHCM, Pot CS, Rabbinge R. 2000. Dynamics of vertical leaf nitrogen distribution in a vegetative wheat canopy. Impact on canopy photosynthesis. Annals of Botany 86, 821-831.

Evans JR. 1989. Photosynthesis and nitrogen relationships in leaves of $\mathrm{C}_{3}$ plants. Oecologia 78, $9-19$.

Evans JR. 1993. Photosynthetic acclimation and nitrogen partitioning within a Lucerne canopy. II. Stability through time and comparison with a theoretical optimum. Functional Plant Biology 20, 69-82.

Field C. 1983. Allocating leaf nitrogen for the maximization of carbon gain: leaf age as a control 


\section{Chapter 5}

on the allocation program. Oecologia 56, 341-347.

Goudriaan J. 1995. Optimization of nitrogen distribution and of leaf area index for maximum canopy photosynthesis rate. In Nitrogen Management Studies in Irrigated Rice. 85-97. Thiyagarajan TM, ten Berge HFM, Wopereis MCS (eds). International Rice Research Institute, Los Baños, Philippines.

Guerra LC, Bhuiyan SI, Tuong TP, Barker R. 1998. Producing more rice with less water from irrigated systems. SWIM Paper 5. IWMI/IRRI, Colombo, Sri Lanka, 24.

Gu J, Chen Y, Zhang H, Li Z, Zhou Q, Yu C, Kong X, Liu L, Wang Z, Yang J. 2017. Canopy light and nitrogen distributions are related to grain yield and nitrogen use efficiency in rice. Field Crops Research 206,74-85.

Gu J, Yin X, Stomph TJ, Wang H, Struik PC. 2012. Physiological basis of genetic variation in leaf photosynthesis among rice (Oryza sativa L.) introgression lines under drought and wellwatered conditions. Journal of Experimental Botany 63, 5137-5153.

Harley PC, Thomas RB, Reynolds JF, Strain BR. 1992. Modelling photosynthesis of cotton grown in elevated $\mathrm{CO}_{2}$. Plant, Cell \& Environment 15, 271-282.

Hirose T, Werger MJA. 1987. Maximizing daily canopy photosynthesis with respect to the leaf nitrogen allocation pattern in the canopy. Oecologia 72, 520-526.

Hikosaka K, Terashima I, Katoh S. 1994. Effects of leaf age, nitrogen nutrition and photon flux density on the distribution of nitrogen among leaves of a vine (Ipomoea tricolor Cav.) grown horizontally to avoid mutual shading of leaves. Oecologia 97, 451-457.

IRRI. 1998. Rice Almanac. Manila, The Philippines : International Rice Research Institute.

Kadam NN, Yin X, Bindraban PS, Struik PC, Jagadish KS. 2015. Does morphological and anatomical plasticity during the vegetative stage make wheat more tolerant of water deficit stress than rice? Plant Physiology 167, 1389-1401.

Lafitte HR, Courtois B, Arraudeau M. 2002. Genetic improvement of rice in aerobic systems: progress from yield to genes. Field Crops Research 75, 171-190.

Lonbani M, Arzani A. 2011. Morpho-physiological traits associated with terminal drought stress tolerance in triticale and wheat. Agronomy Research 9, 315-329.

Lötscher M, Stroh K, Schnyder H. 2003. Vertical leaf nitrogen distribution in relation to nitrogen status in grassland plants. Annals of Botany 92, 679-688.

Mackill DJ, Khush GS. 2018. IR64: a high-quality and high-yielding mega variety. Rice 11, 18. Matsuo N, Ozawa K, Mochizuki T. 2010. Physiological and morphological traits related to 
water use by three rice (Oryza sativa L.) genotypes grown under aerobic rice systems. Plant and Soil 335, 349-361.

Mian MAR, Nafziger ED. 1994. Seed size and water potential effects on germination and seedling growth of winter wheat. Crop Science 34, 169-171.

Okami M, Kato Y, Yamagishi J. 2016. Canopy architecture and leaf nitrogen distribution of rice (Oryza sativa L.) under chronic soil water deficit. Journal of Agronomy and Crop Science 202, 464-471.

Ouyang W, Struik PC, Yin X, Yang J. 2017. Stomatal conductance, mesophyll conductance, and transpiration efficiency in relation to leaf anatomy in rice and wheat genotypes under drought. Journal of Experimental Botany 68, 5191-5205.

Ouyang W, Yin X, Yang J, Struik PC. 2021. Do shoot anatomical characteristics allow rice to grow well under water deficit? Journal of Agronomy and Crop Science. https://doi.org/10.1111/jac.12509.

Pantuwan G, Fukai S, Cooper M, Rajatasereekul S, O’Toole JC. 2002. Yield response of rice (Oryza sativa L.) genotypes to different types of drought under rainfed lowlands: Part 1. Grain yield and yield components. Field Crops Research 73, 153-168.

Peng S, Laza RC, Visperas RM, Sanico AL, Cassman KG, Khush GS. 2000. Grain yield of rice cultivars and lines developed in the Philippines since 1966. Crop Science 40, 307-314.

Peng S, Bouman B, Visperas RM, Castañeda A, Nie L, Park HK. 2006. Comparison between aerobic and flooded rice in the tropics: agronomic performance in an eight-season experiment. Field Crops Research 96, 252-259.

Praba ML, Cairns JE, Babu RC, Lafitte HR. 2009. Identification of physiological traits underlying cultivar differences in drought tolerance in rice and wheat. Journal of Agronomy and Crop Science 195, 30-46.

Sands PJ. 1995. Modelling canopy production. I. Optimal distribution of photosynthetic resources. Functional Plant Biology 22, 593-601.

Schakel KA, Hall AE. 1979. Reversible leaflet movements in relation to drought adaptation of cowpeas, Vigna unguiculata (L.) Walp. Functional Plant Biology, 6, 265-276.

Schittenhelm S, Sourell H, Löpmeier FJ. 2006. Drought resistance of potato cultivars with contrasting canopy architecture. European Journal of Agronomy 24, 193-202.

Song Q, Zhang G, Zhu XG. 2013. Optimal crop canopy architecture to maximise canopy photosynthetic $\mathrm{CO}_{2}$ uptake under elevated $\mathrm{CO}_{2}-$ a theoretical study using a mechanistic model of canopy photosynthesis. Functional Plant Biology 40, 108-124. 


\section{Chapter 5}

Shiratsuchi H, Yamagishi T, Ishii R. 2006. Leaf nitrogen distribution to maximize the canopy photosynthesis in rice. Field Crops Research 95, 291-304.

Sinclair TR, Horie T. 1989. Leaf nitrogen, photosynthesis, and crop radiation use efficiency: a review. Crop Science 29: 90-98.

Suralta RR, Yamauchi A. 2008. Root growth, aerenchyma development, and oxygen transport in rice genotypes subjected to drought and waterlogging. Environmental and Experimental Botany 64, 75-82.

Tang K, Struik PC, Amaducci S, Stomph TJ, Yin X. 2017. Hemp (Cannabis sativa L.) leaf photosynthesis in relation to nitrogen content and temperature: implications for hemp as a bioeconomically sustainable crop. GCB Bioenergy 9, 1573-1587.

Venuprasad R, Lafitte HR, Atlin GN. 2007. Response to direct selection for grain yield under drought stress in rice. Crop Science 47, 285-293.

Venuprasad R, Cruz MS, Amante M, Magbanua R, Kumar A, Atlin GN. 2008. Response to two cycles of divergent selection for grain yield under drought stress in four rice breeding populations. Field Crops Research 107, 232-244.

Venuprasad R, Dalid CO, Del Valle M, Zhao D, Espiritu M, Cruz MS, Amante M, Kumar A, Atlin GN. 2009. Identification and characterization of large-effect quantitative trait loci for grain yield under lowland drought stress in rice using bulk-segregant analysis. Theoretical and Applied Genetics 120, 177-190.

Vijayaraghavareddy P, Yin X, Struik PC, Makarla U, Sreeman S. 2020. Responses of lowland, upland and aerobic rice genotypes to water limitation during different phases. Rice Science 27, 345-354.

Virk PS, Khush GS, Peng S. 2004. Breeding to enhance yield potential of rice at IRRI: the ideotype approach. International Rice Research Notes 29, 5-9.

Werner C, Correia O, Beyschlag W. 1999. Two different strategies of Mediterranean macchia plants to avoid photoinhibitory damage by excessive radiation levels during summer drought. Acta Oecologica 20, 15-23.

Yang J, Zhang J. 2006. Grain filling of cereals under soil drying. New Phytologist 169, 223 236.

Yang J, Zhang J. 2010. Crop management techniques to enhance harvest index in rice. Journal of Experimental Botany 61: 3177-3189.

Yin X, Lantinga EA, Schapendonk AH, Zhong X. 2003. Some quantitative relationships between leaf area index and canopy nitrogen content and distribution. Annals of Botany 91, 
893-903.

Yin X, Struik PC. 2015. Constraints to the potential efficiency of converting solar radiation into phytoenergy in annual crops: from leaf biochemistry to canopy physiology and crop ecology. Journal of Experimental Botany 66, 6535-6549.

Yin X, van Laar HH. 2005. Crop systems dynamics: an ecophysiological simulation model of genotype-by-environment interactions. Wageningen Academic Publishers.

Yin X, Schapendonk AHCM, Kropff MJ, van Oijen M, Bindraban PS. 2000. A generic equation for nitrogen-limited leaf area index and its application in crop growth models for predicting leaf senescence. Annals of Botany 85: 579-585.

Yin X, Struik PC, Romero P, Harbinson J, Evers JB, Van Der Putten PE, Vos J. 2009. Using combined measurements of gas exchange and chlorophyll fluorescence to estimate parameters of a biochemical $\mathrm{C}_{3}$ photosynthesis model: a critical appraisal and a new integrated approach applied to leaves in a wheat (Triticum aestivum) canopy. Plant, Cell \& Environment 32, 448464.

Yoshida S, Forno DA, Cock JH. 1971. Laboratory Manual for Physiological Studies of Rice. International Rice Research Institute. Los Baños. Philippines. 


\section{Supplementary materials in Chapter 5}

Table S5.1 Analysis of variance results for plant growth parameters in rice cultivars.

\begin{tabular}{|c|c|c|c|c|c|c|c|c|c|c|c|c|c|c|c|c|}
\hline \multirow{2}{*}{ Source of variation } & \multicolumn{8}{|c|}{ Tank experiment } & \multicolumn{8}{|c|}{ Field experiment } \\
\hline & $\mathrm{PH}$ & SN & SB & LB & LAI & $\mathrm{PN}$ & $\mathrm{PT} \%$ & PB & $\mathrm{PH}$ & $\mathrm{SN}$ & SB & LB & LAI & $\mathrm{PN}$ & $\mathrm{PT} \%$ & PB \\
\hline Cultivar (C) & $* * *$ & $* * *$ & $*$ & $* * *$ & $* * *$ & $* * *$ & ns & $* * *$ & $* * *$ & $* * *$ & ns & $*$ & $\mathrm{~ns}$ & $* * *$ & * & $* * *$ \\
\hline Treatment $(\mathrm{T})$ & $* * *$ & $*$ & $* * *$ & $* * *$ & $* * *$ & $* *$ & $* * *$ & $* * *$ & $* * *$ & $* * *$ & $* * *$ & $* * *$ & $* * *$ & $* *$ & $*$ & $* * *$ \\
\hline Stage (S) & $* * *$ & ns & $* * *$ & $* *$ & $* *$ & - & - & - & $* * *$ & $\mathrm{~ns}$ & $* * *$ & $*$ & ns & - & - & - \\
\hline Cultivar $\times$ Treatment & $*$ & ns & $* *$ & $*$ & ns & $* *$ & $* * *$ & ns & $*$ & ns & ns & ns & $*$ & $*$ & $*$ & ns \\
\hline Cultivar $\times$ Stage & $* * *$ & ns & $* * *$ & $* * *$ & $*$ & - & - & - & $* * *$ & ns & ns & ns & ns & - & - & - \\
\hline Treatment $\times$ Stage & $* * *$ & ns & ns & ns & ns & - & - & - & $* * *$ & ns & $*$ & ns & ns & - & - & - \\
\hline $\mathrm{C} \times \mathrm{T} \times \mathrm{S}$ & $*$ & ns & ns & $*$ & $*$ & - & - & - & $\mathrm{ns}$ & $\mathrm{ns}$ & $\mathrm{ns}$ & ns & $\mathrm{ns}$ & - & - & - \\
\hline
\end{tabular}

$\mathrm{PH}=$ plant height; $\mathrm{SN}=$ number of stems; $\mathrm{SB}=$ stem dry weight; $\mathrm{LB}=$ leaf dry weight; $\mathrm{LAI}=$ leaf area index; $\mathrm{PN}=$ number of panicles; $\mathrm{PT} \%=$ productive tiller percentage; $\mathrm{PB}=$ panicle dry weight. Significance level: *, $P<0.05 ; * *, P<0.01 ; * * *, P<0.001 ; \mathrm{ns}=$ non-significant.

Table S5.2 Analysis of variance results for canopy light and nitrogen distribution parameters in rice cultivars.

\begin{tabular}{llllllll}
\hline Source of variation & $\mathrm{LAI}$ & $\mathrm{SLN}_{\mathrm{c}}$ & $\mathrm{N}_{\mathrm{c}}$ & $K_{\mathrm{L}}$ & $\mathrm{SLN}_{0}$ & $K_{\mathrm{N}}$ & $K_{\mathrm{N}}: K_{\mathrm{L}}$ \\
\hline Cultivar & $* * *$ & $* * *$ & $\mathrm{~ns}$ & $* * *$ & $* * *$ & $* * *$ & $* * *$ \\
Treatment & $* * *$ & $* * *$ & $* * *$ & $* * *$ & $\mathrm{~ns}$ & $* * *$ & $* * *$ \\
Stage & $* *$ & $* * *$ & $\mathrm{~ns}$ & $* * *$ & $\mathrm{~ns}$ & $* * *$ & $* *$ \\
Cultivar $\times$ Treatment & $*$ & $\mathrm{~ns}$ & $* *$ & $* *$ & $* *$ & $* * *$ & $* * *$ \\
Cultivar $\times$ Stage & $* *$ & $\mathrm{~ns}$ & $* *$ & $* * *$ & $* *$ & $\mathrm{~ns}$ & $* * *$ \\
Treatment $\times$ Stage & $\mathrm{ns}$ & $\mathrm{ns}$ & $\mathrm{ns}$ & $*$ & $\mathrm{~ns}$ & $\mathrm{~ns}$ & $\mathrm{~ns}$ \\
Cultivar $\times$ Treatment $\times$ Stage & $*$ & $\mathrm{~ns}$ & $*$ & $\mathrm{~ns}$ & $\mathrm{~ns}$ & $\mathrm{~ns}$ & $\mathrm{~ns}$ \\
\hline
\end{tabular}

$\mathrm{LAI}=$ leaf area index; $\mathrm{SLN}_{\mathrm{c}}=$ canopy-averaged specific leaf nitrogen; $\mathrm{N}_{\mathrm{c}}=$ canopy nitrogen content; $K_{\mathrm{L}}=$ canopy light extinction coefficient; $\mathrm{SLN}_{0}=$ specific leaf nitrogen at the top of the canopy; $K_{\mathrm{N}}=$ canopy nitrogen extinction coefficient. Significance level: *, $P<0.05$; **, $P<0.01$; ***, $P<0.001$; ns $=$ non-significant. 


\section{Chapter 6}

General discussion 
The high water requirements for rice cultivation make rice much more prone to the predicted increase in agricultural freshwater scarcity than dryland cereals. Due to the importance of rice in global food security, reducing water use in rice cultivation while obtaining high yield remains essential. The evolution of various rice cultivation systems (see Chapter 1) has triggered the development of rice genotypes with different degrees of water deficit tolerance, which makes the crop unique in terms of its inherent variability available for water deficit tolerance. Lowland rice is much more sensitive to water deficit, while aerobic and upland rice have relatively higher water deficit tolerance. Yet, our knowledge of the mechanisms underlying the variation in water deficit tolerance between various rice types is poor. To support breeding strategies to produce water deficit tolerant rice varieties, there is a need for better understanding why rice cannot perform similar as dryland cereals (wheat in this dissertation) in terms of its high water deficit sensitivity.

My main aim was to unravel and understand which anatomical, morphological, and physiological characteristics are important for the evolutionary and adaptive patterns of rice types and wheat to their growth environments. In order to achieve this aim, I firstly outlined several candidate mechanisms at various scales in Chapter 1. Then, those candidate mechanisms were tested in various types of rice and wheat, at leaf level (Chapter 2), at plant level (Chapters 3 and 4), and at canopy and crop level (Chapter 5) under three water regimes. This dissertation shows that during evolutionary adaptation to their growth environments, wet and dry, respectively, rice and wheat have developed their specific strategies to cope with their growth environments. Rice plants possess several constraints to grow under water deficit.

In this Chapter, main findings of each preceding chapter will be presented in Section 6.1 and their implications will be addressed in Sections 6.2 and 6.3. Thereafter, the current state and future prospects of improving rice water deficit tolerance will be discussed in Section 6.4. Finally, this chapter will be completed by some concluding remarks (Section 6.5).

\subsection{Research findings of this dissertation}

\subsubsection{Leaf anatomical traits are important for improving leaf water use efficiency in rice}

Transpiration efficiency (TE) refers to the physiological definition of water use efficiency (WUE) at the leaf level, which is the moles of carbon gained in photosynthesis $\left(A_{\mathrm{n}}\right)$ in exchange for water used in transpiration $(T)$, i.e. $A_{\mathrm{n}} / T$. Aerobic and upland $O$. sativa cultivars and O. glaberrima genotypes can grow under drier soil conditions than lowland $O$. sativa cultivars, 
but very little effort has been devoted to investigating the difference in TE between those rice types. In Chapter 2, I assessed the genotypic variability in TE among six rice cultivars (lowland, aerobic, upland), one African rice genotype (O. glaberrima), and two wheat cultivars (Triticum aestivum) under long-term water stress; I evaluated the diffusion components that are responsible for the variations in TE; and I investigated the anatomical determinants for those components.

Combined gas exchange and chlorophyll fluorescence data were collected to assess the $A_{\mathrm{n}}, T$, and the diffusive conductances (i.e. stomatal conductance $g_{\mathrm{s}}$ and mesophyll conductance $g_{\mathrm{m}}$ ) (Chapter 2). Lowland cultivars had lower TE than other rice types. Wheat cultivars did not show superiority over the water deficit tolerant rice cultivars in terms of TE, because high $A_{\mathrm{n}}$ was accompanied by high $T$ in wheat. Causal analysis indicated that variations in TE were well explained by combined $g_{\mathrm{s}}$ and $g_{\mathrm{m}}$, the $g_{\mathrm{s}} / g_{\mathrm{m}}$ ratio to be precise. Subsequently, Chapter 2 showed that variations in $g_{\mathrm{s}}$ resulted from the differences in stomatal development (stomatal density and size), while variations in $g_{\mathrm{m}}$ arose from different leaf mesophyll structure and anatomical properties (cell wall thickness and proportion of mesophyll exposed to intercellular airspace covered by chloroplasts).

\subsubsection{Morphological and anatomical attributes have a strong impact on water transport in rice}

Before water reaches transpiring leaves, it must first pass through a series of cell layers into the root xylem and then move up into the shoot. Water movement from the soil into the root stele (where root xylem locates) can be treated as fluid flow through a complex structure: epidermis, exodermis, central cortex, and endodermis (Steudle and Peterson, 1998). By comparing the root morphology, root cross-sectional structures, stem and leaf anatomy between rice and wheat, several features specific for rice were revealed in Chapter 3 and Chapter 4.

Chapter 3 revealed that the anatomical and histochemical attributes of root structures were highly variable between rice and wheat, between water treatments, and even along the length of an individual root. Visible changes in anatomical (endodermal tertiary thickened walls) and histochemical (suberization and lignification of endodermis) properties revealed evident apoplastic barrier formation in rice roots under water deficit (Chapter 3). Furthermore, rice roots have an extensive aerenchym but a much smaller stele and much smaller xylem vessels than wheat roots (Chapter 3), while the xylem area in stem and leaf was higher in rice than in wheat 
(Chapter 4). Different from wheat, rice cultivars tend to decrease their root system investments under water deficit, as indicated by the heavily decreased root length and lateral root branching (Chapter 3) and decreased root biomass partitioning (Chapter 4). Relatively, the shoot growth in rice was less affected by treatments (Chapter 4). Those different effects on root and shoot during water deficit therefore disturbed the whole-plant water balance in rice, and negatively influenced plant water status, showing as a clear decrease in leaf water potential $\left(\Psi_{\text {leaf }}\right)$. In conclusion, root and shoot anatomical and morphological attributes play important roles in response to water deficit in rice plant. To grow rice in a drier condition, it is necessary not only to increase root growth, but also to modify leaf anatomy in rice.

\subsubsection{Contribution of above-ground architectural characteristics to water deficit tolerance}

Plant canopies are spatially and temporally variable. Descriptions of canopy structure have long been recognized as being essential to provide an understanding of plant processes in response to a specific environment (Norman and Campbell, 1989). In Chapter 5, canopy architectural characteristics, light and nitrogen distribution parameters (i.e. the extinction coefficient for light, $K_{\mathrm{L}}$; and that for effective leaf nitrogen, $K_{\mathrm{N}}$; and their ratio $K_{\mathrm{N}}: K_{\mathrm{L}}$ ) were compared between one irrigated-lowland (cv. IR64) and one aerobic (cv. Apo) rice genotype, which clearly differed in above-ground morphological attributes. Furthermore, the effects of prolonged soil water-deficit on those canopy traits and how these effects contributed to the genotypic differences in biomass and yield responses of two cultivars to water deficit were presented.

Compared with cv. Apo, cv. IR64 exhibited a relatively more uniform vertical light distribution throughout the canopy (indicated by a lower $K_{\mathrm{L}}$ ) but a less steep nitrogen gradient along canopy height (indicated by a lower $K_{\mathrm{N}}$ ). The variation in biomass gain was best explained by the difference in the $K_{\mathrm{N}}: K_{\mathrm{L}}$ ratio. Results indicated that cv. Apo maintained a favourable aboveground architecture and canopy nitrogen profile (the higher $K_{\mathrm{N}}: K_{\mathrm{L}}$ ratio) under water deficit, leading to a better performance in the biomass gain and yield than cv. IR64. Those results indicated the importance of rice architectural characteristics and canopy nitrogen distribution profile for water deficit adaptation.

\subsection{The sensitivity of rice to water deficit}

An important aim of this dissertation is to understand why rice cannot perform as well as other dryland cereals when growing under relatively dry conditions. Therefore, water deficit stresses 
were imposed from seedling establishment (5 leaves in Chapters 2, 3 and 4; 15 days after transplanting in Chapter 5) until flowering (Chapters 2 and 3) or physiological maturity of the grains (Chapters 4 and 5); and the stress levels were not as severe as in many drought studies. For rice, the target setting of mild stress (MD) was to keep the soil water potential between 0 to $-5 \mathrm{kPa}$, where the soil state is viewed as the optimal condition for dryland plant growth; and the highest stress level imposed to rice (SD; soil water potential between -20 and $-40 \mathrm{kPa}$ ) was similar to, or slightly stronger than, the one in aerobic cultivation (Kato and Okami, 2011).

Yield performance of two $O$. sativa cultivars (cv. IR64 and cv. Apo) in the field condition were presented in Chapter 5 to verify the results obtained from the tank experiment. In the same field trial, yield performance of other four $O$. sativa cultivars used in Chapter 2 (Table 2.1) were also tested to assess the water deficit effect on grain yield in rice, and the data are given here in Table 6.1. The experimental details for field trial were described in Chapter 5. Even for the most tolerant cultivar (Sal), yield loss exceeded 20\% under SD condition when compared with those grown under inundated field. The most severe yield loss was observed in lowland cultivars, with an average decrease of $47 \%$ under SD conditions compared with the control. The varying degrees in the sensitivity of grain yield to water deficit among rice cultivars can be linked with the variable responses to water deficit in total above-ground biomass $(P<0.001)$; panicle number $(P<0.01)$; and harvest index $(P<0.05)$. It has been demonstrated that the determinant for grain yields under water deficit depends on the developmental phase, during which the stress is imposed (Boyer and Westgate, 2004). The strong dependence of grain yield on both total above-ground biomass and harvest index could be because water deficit treatments were imposed from early tillering stage throughout the whole plant growth duration in this dissertation.

In Chapters 3 and 4, the plant growth was examined in three rice cultivars (one cultivar from each cultivation system) at two stages. Water deficit decreased the growth in all plant organs with varying degrees. In particular, root development was more impeded by water deficit than shoot organs were, as indicated by the changes in ratios of dry mass fractions (Chapter 4). The hazard of decrease in root dry mass fraction in rice is aggravated by the changes in root morphology and architecture. Water deficit strongly restrained the total root length and lateral root branching in all rice cultivars (Chapter 3), and therefore would impede the water acquisition capacity of root system in rice under water limited conditions (Courtois et al., 2009; Smith and De Smet, 2012). Further analysis of root anatomical and histochemical properties 


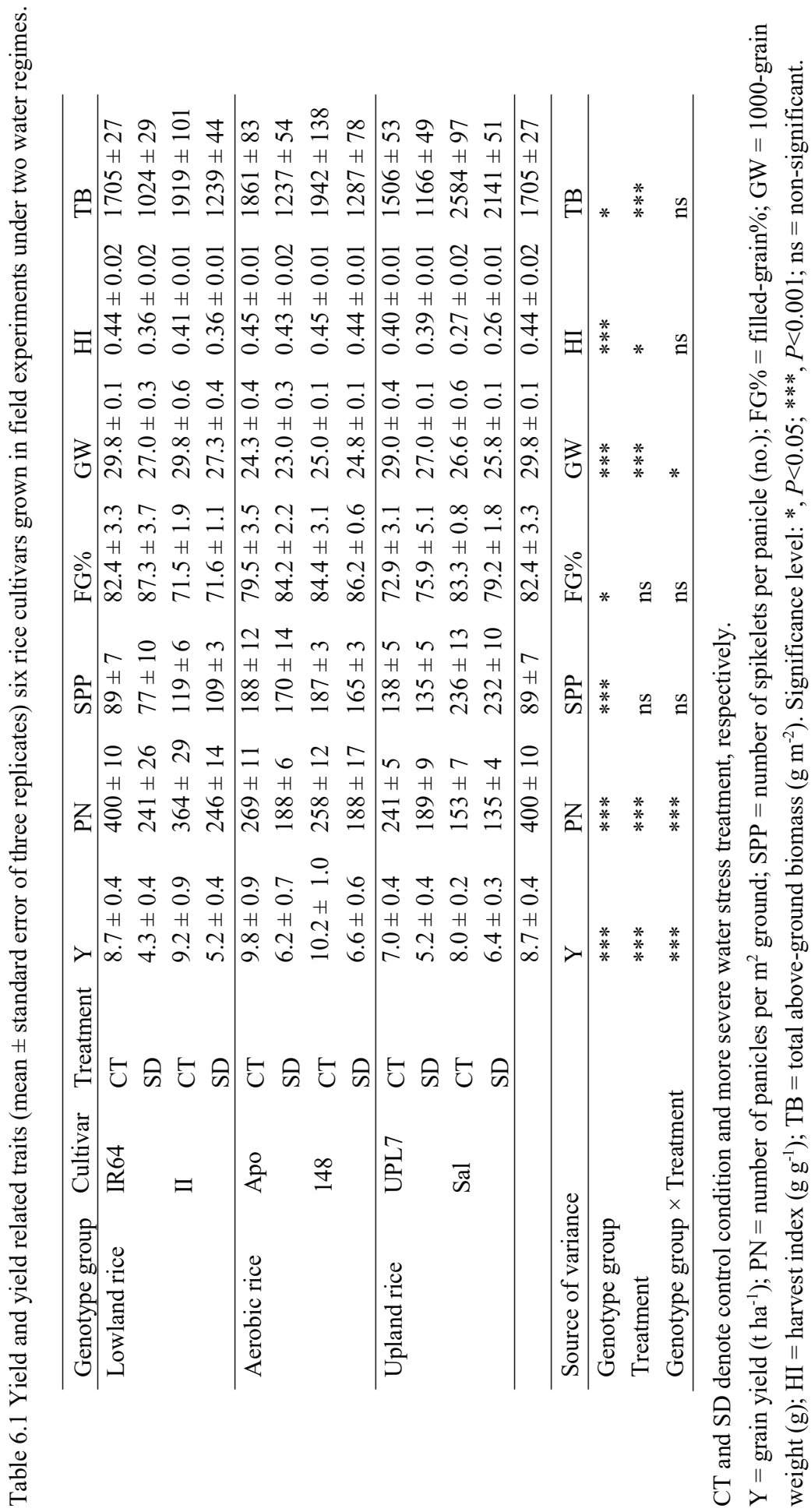


revealed that the radial water transport would be impeded in rice plants grown under water deficit due to the thickened cell walls and accelerated suberization and lignification of the endodermis (Chapter 3 ). These changes are viewed as adaptations to increased soil dryness (for a review, see Enstone et al., 2002), indicating that rice roots are very sensitive to very mild water deficit and appear to respond to aerobic conditions. In the meantime, the photosynthetic capacity in the rice leaf was weakened by water deficit (Chapter 2). The decrease in lightsaturated photosynthetic rate was found to be correlated with the declined $\mathrm{CO}_{2}$ diffusion conductances, i.e. $g_{\mathrm{s}}$ and $g_{\mathrm{m}}$, which was associated with the structural adaptations of stomata and leaf mesophyll to pro-longed water deficit. Modifications in stomatal density and size, mesophyll cell wall thickness and the ratio of chloroplast to the exposed mesophyll cell walls were detected (Chapter 2). Those structural rearrangements were viewed as adaptive strategy for leaves grown under drought (Tosens et al., 2012; Giuliani et al., 2013; Hughes et al., 2017).

\subsection{The identified targets for improving rice water deficit tolerance}

Because of its semi-aquatic origin, rice must have evolved unique physiological, morphological and anatomical adaptations to cultivation in a flooded soil. However, whether those attributes that facilitate growth under flooded conditions would become obstacles for rice growth under dryland conditions is not clear. The comparison of morphological and anatomical properties between rice and wheat made it possible to identify traits determining the differences in water requirement between rice and wheat. Findings from this dissertation indicate that not single traits but suites of morphological and anatomical features are responsible for the adaptive capacity of rice plant to water deficit. Several constraints need to be overcome if rice is to grow under drier conditions.

\subsubsection{Increasing photosynthetic capacity}

Photosynthesis is the basis of plant growth. It is not only important for biomass accumulation during vegetative stage but also plays a major role in determining yield at post-flowering stages. At the leaf level, mesophyll conductance for $\mathrm{CO}_{2}$ diffusion $\left(g_{\mathrm{m}}\right)$ was considered to be even more important than stomatal conductance $\left(g_{\mathrm{s}}\right)$ in determining leaf photosynthesis due to the high internal resistance to $\mathrm{CO}_{2}$ transfer (Flexas et al., 2012). The internal diffusion of $\mathrm{CO}_{2}$ depends on leaf structural components such as leaf mesophyll thickness, fraction of mesophyll exposed to internal airspace, exposed chloroplast surface area, and cell wall thickness (for a review, see Evans, 2021). Although some genetic variation within rice has been observed, those structural 
attributes in rice leaves were less optimized when compared with those in wheat leaves (Chapter 2). The thin leaf mesophyll, low fraction of mesophyll exposed to internal airspace, low exposed chloroplast surface area and thick mesophyll cell walls in rice leaf, leading to a low efficient internal conductance for $\mathrm{CO}_{2}$, presented as a low $g_{\mathrm{m}}$ and ultimately led to low photosynthesis. To increase the $\mathrm{CO}_{2}$ concentration inside the chloroplasts, plant must compensate this low internal conductance for $\mathrm{CO}_{2}$ by a high $g_{\mathrm{s}}$, but at the cost of a large amount of water loss through transpiration. This would result a low TE, as shown in the lowland rice cultivars. The combination of high $g_{\mathrm{s}}$ and low $g_{\mathrm{m}}$ would not be favourable for maintaining photosynthesis under water shortage as the $\mathrm{CO}_{2}$ concentration in the intercellular air spaces largely declined due to decreased $g_{\mathrm{s}}$ through stomatal adjustments. Nevertheless, alleviation of adverse impact of water deficit in $g_{\mathrm{m}}$ resulting from certain anatomical feature was observed in tolerant rice cultivars and wheat, indicating the possibility of improving $g_{\mathrm{m}}$ under water deficit through modifying leaf anatomy. Therefore, the $g_{\mathrm{m}}$-related leaf anatomical structures in rice leaves need to be modified to improve the internal diffusion of $\mathrm{CO}_{2}$, leaf photosynthesis and TE under water deficit. This is especially true for lowland cultivars.

At the canopy level, the canopy nitrogen profile, the light profile and their relationship are important for canopy productivity (Yin and Struik, 2015; Gu et al., 2017). In a canopy, the gradient of leaf nitrogen contributes to an efficient use of nitrogen at the whole-plant level, as photosynthesis of a leaf increases with increasing nitrogen at high irradiance but is less dependent at low irradiance (Field, 1983; Hikosaka and Terashima, 1995). Theoretical studies have suggested that canopy photosynthesis would be maximized if a vertical nitrogen distribution follows the light gradient within the canopy, i.e. $K_{\mathrm{N}}: K_{\mathrm{L}}=1$ (Field, 1983; Goudriaan 1995). However, the nitrogen gradients in actual canopies have been shown to be less steep than the optimal gradients (Yin et al., 2003; Archontoulis et al., 2011), and the $K_{\mathrm{N}}: K_{\mathrm{L}}$ ratio was found to be around 0.35 in Gramineae species (Hikosaka et al., 2016). Variation in the $K_{\mathrm{N}}: K_{\mathrm{L}}$ ratio has been observed among rice cultivars in previous studies (Okami et al., 2016; Gu et al., 2017). Chapter 5 revealed an averaged value of 0.18 and 0.30 for $K_{\mathrm{N}}: K_{\mathrm{L}}$ ratio in a lowland (cv. IR64) and an aerobic (cv. Apo) rice genotypes. The very low $K_{\mathrm{N}}: K_{\mathrm{L}}$ ratio discovered in cv. IR64 was mainly due to the low $K_{\mathrm{N}}$, which was attributed to the allocating of much nitrogen in shaded leaves, indicating a low nitrogen use efficiency at the canopy level in cv. IR64. In addition, the development of vertical light distributions in canopy of cv. IR64 became less optimal under pro-longed water deficit, due to the increased leaf angles (relative to the vertical) at the upper part of the canopy. Yet, the nitrogen content was evenly reduced within the canopy by water 
deficit in cv. IR64. On the contrary, the more tolerant cultivar, cv. Apo, showed a better adjustment in canopy nitrogen usage by allocating less nitrogen to the shaded leaves under water deficit. Those results suggest that there is a need to improve the nitrogen distribution pattern in the lowland cultivar cv. IR64 under water deficit.

\subsubsection{Enhancing the balance between water acquisition and transpiration demand}

A large proportion of the cross-sectional area in rice roots was occupied by cortical aerenchyma (Chapter 3), which is associated with oxygen transport to roots when a plant grows under inundated conditions (McDonald et al. 2002). Nonetheless, regardless of rice genotypes and positions along different root zones, extensive aerenchyma formation has been observed in rice roots under water deficit treatments, although to a lesser extent than under inundated conditions (Chapter 3). This confirms aerenchyma formation is actually prevalent in rice roots (Suralta and Yamauchi 2008). Such tissue is essential for rice growth under inundated conditions but restricts radial water transport in rice root (Yang et al., 2012), therefore not favourable for rice growing under water shortage. Furthermore, when rice plants are grown under water deficit, there is considerable formation of apoplastic barriers, including thickened cell walls and additional deposition of suberin and lignin (Chapter 3). These modifications can block the hydraulic route, and therefore markedly and irreversibly decrease the cell wall permeability to water. These modifications are considered as a protecting measure to restrict water loss to dry soil yet readily permitting water uptake when soil moisture is restored (North and Nobel, 1992; De Micco and Aronne, 2012). Different degrees of endodermal suberization along root length were observed in drought-stressed barley (Kreszies et al., 2019) and in wheat (Chapter 3), with highly suberized endodermis at the basal part of the root but not in the younger root zones near the apex. In this way, the backflow of water to the drier environment is minimised near the soil surface and meanwhile the radial water transport at the apical part of the roots is not restricted to the deeper wet soil layers. However, such a phenomenon was not observed in rice root. In water deficit stressed rice roots, modifications of endodermal cell wall have been detected at all sectioning positions, and very remarkable near the root apex (Chapter 3 ). Hence, the radial water transport capacity along the whole root would be largely restricted in rice by those anatomical modifications since the apoplastic pathway is considered to play a major role for water transport in rice roots (Ranathunge et al., 2004). Moreover, the adverse effect of the longterm water deficit stress on water acquisition in rice is also reflected by the greatly decreased root growth and lateral root formation (Chapter 3). Lateral roots make up a large part of total root length, and are of major importance in regulating water acquisition from deeper soil 
(Pallant et al., 1993; Segal et al., 2008; Knipfer et al., 2011). Those results imply that the water acquisition ability in rice root is impeded by water deficit.

In contrast to maintaining the massive aerenchyma in rice root, the space for the vascular transport system has been pushed to a limited area, as the stele accounts only $6 \%$ of the crosssectional area in rice root, while this number reached $20 \%$ in wheat (Chapter 3 ). The much smaller xylem in rice roots will lead to a much lower axial water transport ability in rice compared with wheat, since the hydraulic conductance of xylem vessels varies with the fourth power of the vessel diameter (Tyree and Ewers, 1991). On the other hand, rice had a high proportion of vascular area to leaf mesophyll area (Chapter 4) and high density of stomata on both surfaces of its leaves (Chapter 2). These attributes ensure a high transpiration demand when rice plants grow under inundated conditions, but become burdens when the water acquisition ability of root is highly impeded. Such unbalanced state was reflected as obvious decrease in leaf water potential (Chapter 4) and in $g_{\mathrm{s}}$ (Chapter 2), with the impact being most apparent in lowland rice cultivars. Therefore, improvement of the balance in xylem system between root and leaf would be required if rice is to grow under drier conditions.

\subsection{Opportunities for future research}

In this dissertation, I evaluated the effect of long-term water deficit stress on rice morphology and anatomy at organ, plant and canopy level. It appears that rice plant experiences drought stress when growing under aerobic cultivation. Several morphological and anatomical traits that are responsible for the adaptive capacity of the rice plant to drier conditions have been identified in this dissertation. Nevertheless, new questions have been raised from the findings of this study and these remain to be addressed.

Water deficit evokes a multitude of cellular responses at different parts of the plant. Visible modifications on structural properties in leaves (Chapter 2 ) and roots (Chapter 3) were observed in the rice plant under water deficit. Results indicated that the water deficit induced anatomical changes in the rice leaves impeded the internal $\mathrm{CO}_{2}$ transport, resulting in a decrease in mesophyll conductance $\left(g_{\mathrm{m}}\right)$. However, the functions of certain biochemical components such as aquaporins should not be discarded. Evidences implied that aquaporins in leaves could be involved in $g_{\mathrm{m}}$ for $\mathrm{CO}_{2}$ by acting at several points along the $\mathrm{CO}_{2}$ path, and are most likely responsible for the dynamic $g_{\mathrm{m}}$ changes (Hanba et al., 2004; Flexas et al., 2006). Actually, aquaporins are a group of channel-forming membrane proteins present in different plant tissues 
(Johansson et al., 2000). Root-specific aquaporins are located in the plasma membrane and in the vacuolar membrane and facilitate the passive water transport in the cell-to-cell pathway. As introduced in Chapter 1, the radial water transport in roots involves apoplastic and cell-to-cell pathways. While the apoplastic pathways is impeded by the additionally formed physical barriers (Chapter 3), the cell-to-cell pathway could be important under water limited conditions.

The total root length in rice was largely decreased by water deficit in Chapter 3, but the maximum root length and the proportion of root mass in the soil depth was not examined. In most cases, the topsoil dries stronger and faster than the subsoil. It has been proposed that the susceptibility of rice to drought is attributed to its shallow root system, which has a limited ability to extract water from deeper soil layers (Kondo et al., 2003; Gowda et al., 2011). Nevertheless, evidences suggested that rice genotypes with deeper roots had higher biomass productivity and grain yield under short-term water limitation than the shallow-rooting genotypes (Lilley and Fukai, 1994; Venuprasad et al., 2002; Kato et al., 2007; Uga et al., 2013). Therefore, investigation into the difference in rooting habit among various types of rice, between rice and other dry land cereals, and how these differences affect the response of water uptake under long-term water deficit could be interesting.

Lateral roots, which comprise a greater proportion of the root system in total length and number (Yamauchi et al., 1987, Harada and Yamazaki, 1993), are responsible for the greatest amount of water and nutrient absorption (Yoshida et al., 1982). Lateral root plasticity is a variable trait in plant adaptation to water deficit. The decrease in lateral root formation was presented as the decreased fine root length and lateral root length per nodal root length in Chapter 3. However, the response of the number and branching patterns of lateral roots to water deficit was not covered. Furthermore, root traits related to water transport across and along roots were only examined in nodal roots. It is uncertain whether the structural changes found in nodal root under water deficit can represent lateral root or not. Therefore, the morphology and anatomy of lateral root under long-term water deficit are interesting to study.

Results from Chapter 4 indicated that stem anatomy did not have a direct contribution to the plant water status. The stem provides support to the aerial parts of the plant and conducts the exchange of water, nutrients, signalling molecules and carbohydrates between aerial organs and underground organs (Dickison et al., 2000). Another important role of the stem for cereal crops is to store the accumulated water-soluble carbohydrates (WSC) that are subsequently mobilized to grain. Under stress conditions, the accumulation of WSC in the stem may be much less due 
to restrained photosynthesis (Johnson et al., 1981). When photosynthetic activity is depressed by drought, grain filling becomes more dependent on mobilized stem reserves (Bell and Incoll, 1990; Davidson and Chevalier, 1992). Therefore, stem anatomy might play an important role in nutrient mobilization during grain filling.

In Chapter 5, the canopy architectural characteristics, light and nitrogen distribution parameters were only examined in two rice genotypes, one from lowland (cv. IR64) and one from aerobic (cv. Apo) rice. Compared with cv. Apo, the leaf nitrogen content was found to be less efficiently distributed along the canopy in cv. IR64. In general, the difference in above-ground architecture between lowland rice and cultivars from other cultivation regimes is evident (Peng et al., 2000; Lafitte et al., 2002; Venuprasad et al., 2009; Matsuo et al., 2010). However, it is not certain if the light and nitrogen distribution patterns found in the two cultivars can represent the genotypes from their own cultivation regimes. Therefore, the canopy characteristics, light and nitrogen distribution of more cultivars from the same rice type should be investigated in future studies. Furthermore, data was only collected at stem-elongating and flowering stages in Chapter 5. As grain yield also depends on assimilate accumulation during the grain-filling phase, it is necessary to assess the potential impact of water deficit on the architecture, light and nitrogen profiles, and canopy photosynthesis at post-flowering stage.

\subsection{Concluding remarks}

Despite the above discussed further research needs, this dissertation already identified several promising targets for improving rice performance under water deficit. With the aim of providing leads for growing rice like dryland cereals, comprehensive studies have been conducted to assess the anatomical, morphological, and physiological attributes that are responsible for differences in adaptive abilities to water deficit among different rice types, and between rice and wheat. Although some genetic variation within rice has been observed, those attributes were mostly variable between rice and wheat. The results suggested:

(1) rice leaf photosynthesis and TE could be improved by increasing the internal diffusion of $\mathrm{CO}_{2}$ via modulating mesophyll structural traits;

(2) the balance between water acquisition and transpiration demand in a rice plant can be enhanced by increasing root growth, improving the radial and axial water transport in roots, and modifying leaf anatomy. 
Moreover, the results for canopy physiological and morphological characteristics in two rice genotypes suggested that the biomass gain and yield in the susceptible rice genotype could be improved through optimizing canopy architectural characters and nitrogen profile within the canopy. These findings provide traits that are highly relevant for developing rice genotypes for growing under dry conditions.

\section{References}

Archontoulis SV, Vos J, Yin X, Bastiaans L, Danalatos NG, Struik PC. (2011). Temporal dynamics of light and nitrogen vertical distributions in canopies of sunflower, kenaf and cynara. Field Crops Research 122, 186-198.

Bell CJ, Incoll LD. 1990. The redistribution of assimilate in field-grown winter wheat. Journal of Experimental Botany 41, 949-960.

Boyer JS, Westgate ME. 2004. Grain yields with limited water. Journal of Experimental Botany 55, 2385-2394.

Courtois B, Ahmadi N, Khowaja F, Price AH, Rami JF, Frouin J, Hamelin C, Ruiz M. 2009. Rice root genetic architecture: meta-analysis from a drought QTL database. Rice 2, 115-128.

Davidson DJ, Chevalier PM. 1992. Storage and remobilization of water-soluble carbohydrates in stems of spring wheat. Crop Science 32, 186-190.

De Micco V, Aronne G. 2012. Morpho-Anatomical Traits for Plant Adaptation to Drought. In Plant Responses to Drought Stress. 37-61, Springer, Berlin, Heidelberg.

Dickison WC. 2000. Integrative plant anatomy. Academic press. San Diego, CA, USA.

Enstone DE, Peterson CA, Ma F. 2002. Root endodermis and exodermis: structure, function, and responses to the environment. Journal of Plant Growth Regulation 21, 335-351.

Evans JR. 2021. Mesophyll conductance: walls, membranes and spatial complexity. New Phytologist 229, 1864-1876.

Field C. 1983. Allocating leaf nitrogen for the maximization of carbon gain: leaf age as a control on the allocation program. Oecologia 56, 341-347.

Flexas J, Barbour MM, Brendel O, Cabrera HM, Carriquí M, Diaz-Espejo A, Douthe C, Dreyer E, Ferrio JP, Gago J, Gallé A. 2012. Mesophyll diffusion conductance to CO2: an unappreciated central player in photosynthesis. Plant Science 193, 70-84.

Flexas J, Ribas-Carbó M, Hanson DT, Bota J, Otto B, Cifre J, McDowell N, Medrano H, Kaldenhoff R. 2006. Tobacco aquaporin NtAQP1 is involved in mesophyll conductance to 
CO2in vivo. The Plant Journal 48, 427-439.

Giuliani R, Koteyeva N, Voznesenskaya E, Evans MA, Cousins AB, Edwards GE. 2013. Coordination of leaf photosynthesis, transpiration, and structural traits in rice and wild relatives (genus Oryza). Plant Physiology 162, 1632-1651.

Gowda VRP, Henry A, Yamauchi A, Shashidhar HE, Serraj R. 2011. Root biology and genetic improvement for drought avoidance in rice. Field Crops Research 122, 1-13.

GoudriaanJ. 1995. Optimization of nitrogen distribution and of leaf area index for maximum canopy assimilation rate. In Nitrogen management studies in irrigated rice. 85-97. Thiyagarajan TM, ten Berge HFM, Wopereis MCS, eds. Los Baños, Philippines: International Rice Research Institute.

Gu J, Chen Y, Zhang H, Li Z, Zhou Q, Yu C, Kong X, Liu L, Wang Z, Yang J. 2017. Canopy light and nitrogen distributions are related to grain yield and nitrogen use efficiency in rice. Field Crops Research 206, 74-85.

Hanba YT, Shibasaka M, Hayashi Y, Hayakawa T, Kasamo K, Terashima I, Katsuhara M. 2004. Overexpression of the barley aquaporin HvPIP2;1 increases internal $\mathrm{CO}_{2}$ conductance and $\mathrm{CO}_{2}$ assimilation in the leaves of transgenic rice plants. Plant and Cell Physiology 45, 521529.

Harada J, Yamazaki K. 1991. Morphological aspects of root system in rice plants. In Developments in Agricultural and Managed Forest Ecology. 456-462. Elsevier.

Hikosaka K, Anten NP, Borjigidai A, Kamiyama C, Sakai H, Hasegawa T, Oikawa S, Iio A, Watanabe M, Koike T, Nishina K. 2016. A meta-analysis of leaf nitrogen distribution within plant canopies. Annals of Botany 118, 239-247.

Hikosaka K, Terashima I. 1995. A model of the acclimation of photosynthesis in the leaves of C3 plants to sun and shade with respect to nitrogen use. Plant, Cell and Environment 18, 605618.

Hughes J, Hepworth C, Dutton C, Dunn JA, Hunt L, Stephens J, Waugh R, Cameron DD, Gray JE. 2017. Reducing stomatal density in barley improves drought tolerance without impacting on yield. Plant Physiology 174, 776-787.

Johnson RC, Witters RE, Ciha AJ. 1981. Daily Patterns of Apparent Photosynthesis and Evapotranspiration in a Developing Winter Wheat Crop 1. Agronomy Journal 73, 414-418.

Johansson I, Karlsson M, Johanson U, Larsson C, Kjellbom P. 2000. The role of aquaporins in cellular and whole plant water balance. Biochimica et Biophysica Acta (BBA)Biomembranes 1465, 324-342. 
Kato Y, Kamoshita A, Yamagishi J, Imoto H, Abe J. 2007. Growth of rice (Oryza sativa L.) cultivars under upland conditions with different levels of water supply 3. Root system development, soil moisture change and plant water status. Plant Production Science 10, 3-13.

Kato Y, Okami M. 2011. Root morphology, hydraulic conductivity and plant water relations of high-yielding rice grown under aerobic conditions. Annals of Botany 108, 575-583.

Knipfer T, Fricke W. 2011. Water uptake by seminal and adventitious roots in relation to wholeplant water flow in barley (Hordeum vulgare L.). Journal of Experimental Botany 62, 717-733.

Kondo M, Pablico PP, Aragones DV, Agbisit R, Abe J, Morita S, Courtois B. 2003. Genotypic and environmental variations in root morphology in rice genotypes under upland field conditions. In Roots: the dynamic interface between plants and the earth. 189-200. Springer, Dordrecht.

Kreszies T, Shellakkutti N, Osthoff A, Yu P, Baldauf JA, Zeisler-Diehl VV, Ranathunge K, Hochholdinger F, Schreiber L. 2019. Osmotic stress enhances suberization of apoplastic barriers in barley seminal roots: analysis of chemical, transcriptomic and physiological responses. New Phytologist 221, 180-194.

Lafitte HR, Courtois B, Arraudeau M. 2002. Genetic improvement of rice in aerobic systems: progress from yield to genes. Field Crops Research 75, 171-190.

Lilley JM, Fukai S. 1994. Effect of timing and severity of water deficit on four diverse rice cultivars. I. Rooting pattern and soil water extraction. Field Crops Research 37, 205-213

Matsuo N, Ozawa K, Mochizuki T. 2010. Physiological and morphological traits related to water use by three rice (Oryza sativa L.) genotypes grown under aerobic rice systems. Plant and Soil 335, 349-361.

McDonald MP, Galwey NW, Colmer TD. 2002. Similarity and diversity in adventitious root anatomy as related to root aeration among a range of wetland and dryland grass species. Plant, Cell \& Environment 25, 441-451.

Norman JM, Campbell GS. 1989. Canopy structure. In Plant Physiological Ecology. 301-325. Springer, Dordrecht.

North GB, Nobel PS. 1992. Drought-induced changes in hydraulic conductivity and structure in roots of Ferocactus acanthodes and Opuntia ficus-indica. New Phytologist 120, 9-19.

Okami M, Kato Y, Yamagishi J. 2016. Canopy architecture and leaf nitrogen distribution of rice (Oryza sativa L.) under chronic soil water deficit. Journal of Agronomy and Crop Science 202, 464-471.

Pallant E, Holmgren RA, Schuler GE, McCracken KL, Drbal B. 1993. Using a fine root 
extraction device to quantify small diameter corn roots $(\geq 0.025 \mathrm{~mm})$ in field soils. Plant and Soil 153, 273-279.

Peng S, Laza RC, Visperas RM, Sanico AL, Cassman KG, Khush GS. 2000. Grain yield of rice cultivars and lines developed in the Philippines since 1966. Crop Science 40, 307-314.

Ranathunge K, Kotula L, Steudle E, Lafitte R. 2004. Water permeability and reflection coefficient of the outer part of young rice roots are differently affected by closure of water channels (aquaporins) or blockage of apoplastic pores. Journal of Experimental Botany 55, 433 447.

Segal E, Kushnir T, Mualem Y, Shani U. 2008. Water uptake and hydraulics of the root hair rhizosphere. Vadose Zone Journal 7, 1027-1034.

Smith, S, De Smet I. 2012. Root system architecture: insights from Arabidopsis and cereal crops. Philosophical Transactions of the Royal Society B 367, 1441-1452.

Steudle E, Peterson CA. 1998. How does water get through roots? Journal of Experimental Botany 49, 775-788.

Suralta RR, Yamauchi A. 2008. Root growth, aerenchyma development, and oxygen transport in rice genotypes subjected to drought and waterlogging. Environmental and Experimental Botany 64, 75-82.

Tosens T, Niinemets U, Vislap V, Eichelmann H, Castro Diez P. 2012. Developmental changes in mesophyll diffusion conductance and photosynthetic capacity under different light and water availabilities in Populus tremula: how structure constrains function. Plant, Cell \& Environment 35, 839-856.

Tyree MT, Ewers FW. 1991. The hydraulic architecture of trees and other woody plants. New Phytologist 119, 345-360.

Uga Y, Yamamoto E, Kanno N, Kawai S, Mizubayashi T, Fukuoka S. 2013. A major QTL controlling deep rooting on rice chromosome 4. Scientific Reports 3, 1-6.

Venuprasad R, Dalid CO, Del Valle M, Zhao D, Espiritu M, Cruz MS, Amante M, Kumar A, Atlin GN. 2009. Identification and characterization of large-effect quantitative trait loci for grain yield under lowland drought stress in rice using bulk-segregant analysis. Theoretical and Applied Genetics 120, 177-190.

Venuprasad R, Shashidhar HE, Hittalmani S, Hemamalini GS. 2002. Tagging quantitative trait loci associated with grain yield and root morphological traits in rice (Oryza sativa L.) under contrasting moisture regimes. Euphytica 128, 293-300.

Yamauchi A, Kono Y, Tatsumi J. 1987. Comparison of root system structures of 13 species of 
cereals. Japanese Journal of Crop Science 56, 618-631.

Yang X, Li Y, Ren B, Ding L, Gao C, Shen Q, Guo S. 2012. Drought-induced root aerenchyma formation restricts water uptake in rice seedlings supplied with nitrate. Plant and Cell Physiology 53, 495-504.

Yin X, Struik PC. 2015. Constraints to the potential efficiency of converting solar radiation into phytoenergy in annual crops: from leaf biochemistry to canopy physiology and crop ecology. Journal of Experimental Botany 66, 6535-6549.

Yin X, Lantinga EA, Schapendonk AHCM, Zhong X. 2003. Some quantitative relationships between leaf area index and canopy nitrogen content and distribution. Annals of Botany 91: 893-903.

Yoshida S, Bhattacharjee DP, Cabuslay GS. 1982. Relationship between plant type and root growth in rice. Soil Science and Plant Nutrition 28, 473-482. 



\section{Summary}

Cultivated rice, derived from its semi-aquatic ancestor, is most productive when grown under irrigated lowland conditions even though it can grow in rainfed or upland environments. Irrigated lowland rice production requires massive amounts of fresh water, and, thus, is most vulnerable to the increasing water scarcity. Moreover, increasing water deficit stress, arising from climate changes, poses a serious threat to the sustainability of rice production in all cultivation systems. Hence, it is important to explore avenues for developing rice genotypes that can maintain high productivity under drier conditions. To better understand why rice cannot perform well like dryland cereals, basic anatomical, morphological and related physiological responses of rice to water deficit need to be explored.

The evolution of rice in adapting to various ecological habitats, from wetland to dryland, allows the development of rice genotypes with different degrees of water deficit tolerance. Aerobic and upland Oryza sativa cultivars are relatively more tolerant to water deficit than lowland $O$. sativa cultivars, while Oryza glaberrima genotypes are moderately to highly tolerant. Nevertheless, rice is highly susceptible to water deficit stress compared with dryland cereals such as wheat (Triticum aestivum). On the basis of background and research questions presented in Chapter 1, in this thesis, I compared the effect of long-term water deficit stress on the morphological, anatomical and physiological characteristics in rice and wheat at leaf (Chapter 2) and plant (Chapters 3 and 4) level. In addition, water deficit effects on canopy physiological and morphological characteristics were investigated in two contrasting rice cultivars (Chapter 5).

Photosynthesis plays a central role in plant performance under water deficit. Transpiration efficiency (TE), the ratio of photosynthetic rate $\left(A_{\mathrm{n}}\right)$ to transpiration, illustrates water use efficiency at the leaf level. In Chapter 2, the genotypic variability in photosynthesis and TE were evaluated among six O. sativa rice cultivars (lowland, aerobic, upland), one African rice genotype (O. glaberrima), and two wheat cultivars under three water regimes. To explore avenues for improving $\mathrm{TE}$ in rice, variations in $\mathrm{CO}_{2}$ diffusion components (i.e. stomatal conductance $g_{\mathrm{s}}$ and mesophyll conductance $g_{\mathrm{m}}$ ) and their anatomical determinants were further investigated. The variability in $A_{\mathrm{n}}$ among species and within $O$. sativa was closely associated with the variation in $g_{\mathrm{s}}$ and $g_{\mathrm{m}}$, while the genotypic variation in TE was highly related to the $g_{\mathrm{m}} / g_{\mathrm{s}}$ ratio. Water deficit tolerant groups, i.e. O. glaberrima, upland rice, and wheat, exhibited 
higher TE sensitivity in response to $g_{\mathrm{m}} / g_{\mathrm{s}}$ ratio than lowland and aerobic rice. In particular, the results indicated that simultaneously sustaining photosynthesis and increasing TE under water deficit can be achieved by minimizing the decrease in $g_{\mathrm{m}}$. Moreover, the variations of $g_{\mathrm{s}}$ and $g_{\mathrm{m}}$ were strongly determined by certain leaf anatomical traits. By analysing the water deficit effect on each of these leaf anatomical traits, I found that leaves with lower stomata density and smaller stomata leading to lower $g_{\mathrm{s}}$ were more suitable for dryer environments; high proportions of chloroplasts covering the mesophyll cell walls that are exposed to the intercellular airspace could be beneficial for maximization of $g_{\mathrm{m}}$, especially under water deficit conditions. These findings demonstrated that the improvement of TE in rice plants can be achieved by increasing the $g_{\mathrm{m}} / g_{\mathrm{s}}$ ratio, which could be achieved through modifying anatomical traits.

Under water deficit conditions, maintaining plant water status is not only determined by regulating stomatal conductance, but also by the water acquisition and transport capacity in root and shoot. Therefore, I further evaluated the morphological and anatomical traits that affect water acquisition and transport in root (Chapter 3) and shoot (Chapter 4) in three O. sativa rice cultivars and two wheat cultivars. These three rice cultivars were selected as representatives of the lowland, aerobic and upland rice groups based on their performance in Chapter 2, while the two wheat cultivars were the same as those used in Chapter 2. In Chapter 3, I compared the water-deficit effect on root morphology, root anatomical and histochemical attributes among rice genotypes and between rice and wheat, while in Chapter 4, I analyzed the water-deficit effect on biomass partitioning, leaf water potential, anatomical traits in leaf and stem in the same genotypes. Although the data reflected a certain degree of phenotypic plasticity in response to water deficit among rice genotypes, the general trends of each morphological, anatomical and histochemical trait in response to water deficit were similar among rice genotypes but differed greatly between rice and wheat. Compared with wheat roots, rice roots formed an extensive aerenchyma but a much smaller stele and smaller xylem vessels; rice roots thickened endodermal cell walls with additional deposition of suberin and lignin when grown under water deficit. Those attributes of rice led to a potentially low axial conductance and formed strong barriers for radial water transport into the stele. On the other hand, rice had a higher demand of water usage in leaves (transpiration) as the total leaf xylem area and the proportion of leaf xylem area to leaf mesophyll area were much higher in rice than in wheat (Chapter 4). Furthermore, the root growth and lateral root formation in rice was strongly impeded by water deficit, while the above-ground growth of rice was relatively less affected. These results indicated an imbalance between water acquisition and transpiration demand in 
rice plant when grown under water deficit. As a result, compared with wheat, rice had a higher reduction of leaf water potential and a more severe loss of yield under water deficit. Therefore, in order to improve rice performance under drier conditions, it is necessary to modify the anatomical and histochemical traits of rice root, improve root growth and modify leaf anatomy of the rice plant.

Water deficit limits plant growth and development. To this end, my studies have been focused on the important factors limiting rice growth at leaf and plant level in the previous chapters. On the other hand, plant canopy structure plays major roles in determining the adaptative capability of plant to different environments. Rice varieties adapted to different edaphic conditions were found having diverse canopy architectures in previous reports and in those experiments conducted for the previous chapters. In Chapter 5, one lowland cultivar (cv. IR64) and one aerobic cultivar (cv. Apo) were selected from the six rice cultivars that were used in Chapter 2 to investigate how canopy physiological and morphological characteristics contribute to differences in water-deficit adaptability between rice genotypes grown under water deficit. Compared with cv. IR64, cv. Apo displayed a closer association between nitrogen distribution and light distribution in the canopy, which was reflected in a higher ratio of the extinction coefficients for nitrogen $\left(K_{\mathrm{N}}\right)$ to that for light $\left(K_{\mathrm{L}}\right): K_{\mathrm{N}}: K_{\mathrm{L}}$. The higher $K_{\mathrm{N}}: K_{\mathrm{L}}$ ratio of cv. Apo was mainly associated with the lower partitioning of nitrogen to the shaded leaves of lower canopy positions, indicating a more efficient use of nitrogen at the canopy scale than in cv. IR64. Under water deficit conditions, cv. Apo maintained erect leaves at the upper part of the canopy and allocated less nitrogen to the shaded leaves, resulting in a higher $K_{\mathrm{N}}: K_{\mathrm{L}}$ ratio than under the control condition. Those adjustments allowed a better optimizing of nitrogen utilization over the canopy and therefore minimized the impact of water-deficit stress on biomass gain and yield in cv. Apo. These results suggest that improving above-ground architecture and nitrogen allocation pattern in the canopy are very important for improving biomass production and yield of rice, especially under water-deficit conditions.

Chapter 6 responds to the research objectives (Chapter 1) and presents reflections on the comprehensive insights of this dissertation. This chapter summarized and discussed the main findings obtained in Chapters 2-5. In conclusion, comparative studies on anatomy, morphology and physiology of rice and wheat, and of contrasting types within rice in response to water deficit led to the identification of several traits that can be exploited for developing rice varieties suitable for growing under dry conditions. 



\section{Acknowledgements}

"PhD, Doctor of Philosophy, is an earned research degree." - excerpted from Wikipedia.

The completion of my journey as a $\mathrm{PhD}$ candidate could not have been possible without the contribution and support of many people. Therefore, I would like to express my gratitude to those who have inspired, encouraged and helped me during this memorable journey.

First and foremost, I am grateful to an anonymous private donor who provided financial support to my PhD study. I would like to extend my appreciation to the College of Agriculture in Yangzhou University for the financial support of the research work reported in this dissertation.

I would like to express my sincere gratitude to my supervision team: Prof. Paul C. Struik [Centre for Crop System Analysis (CSA), Wageningen University \& Research (WUR)], Dr. Xinyou Yin (CSA), and Prof. Jianchang Yang [College of Agriculture, Yangzhou University (YZU)]. Dear Paul, thank you very much for offering me this challenging and interesting work. I still can recall the day that you interviewed me. You picked me up at the entrance of Radix and kindly guided me to CSA. Your kind manner eased my nervousness during that interview. Your door is always open and you always make time not only to any research related doubts but also to my personal confusions, no matter how busy you are. You encouraged me and gave compliments no matter how small progress I had during this PhD journey. Thank you for your patience and never-ending support.

Dear Xinyou, I remember you told me during the first day when I seated in CSA, "you can just knock on my door without appointment if you have any question". That is also what I did. Sometimes I even could see "who is this?" in your eyes during the first second when I interrupted you. But you would be fully concentrated on my projects in the next second. I was very lucky to have you as my daily supervisor. You provided constant and efficient support to me throughout my academic training process. I really appreciate all the inspiring discussions with you at each phase of my writing, which have led me to the final completion of this thesis. I would also like to express my gratitude to your wife, Yarong, for her kindness and hospitality. Dear Prof. Yang, thank you very much for accepting me as part of your group and providing excellent working facilities during my study in Yangzhou University. I am also grateful for your kind hospitality when I first arrived in Yangzhou. I truly appreciate your constructive suggestions on experimental designs and valuable advice on the research chapters. I also express 
my sincere gratitude to your wife, Zhiqin Wang, who provided me great help in arranging the experimental equipment, in field management and data collection. Without her support, I could not have completed my experiments.

This PhD project is one of the components of the "Growing Rice Like Wheat" (GRLW) programme, which was carried out by five $\mathrm{PhD}$ students working from four countries. I am very grateful to the other supervisor members of the GRLW team for their inspiring comments and suggestions, constant support and encouragement: Dr. Prem Bindraban, Dr. C. Gerard van der Linden, Prof. Harro Bouwmeester, Dr. S.V. Krishna Jagadish, Dr. Caroline Ruyter-Spira, Dr. M.S. Sheshashayee, and Dr. Nataraja Karaba. I am thankful to Niteen, Giovanni, Ashwini and Preethi, with whom I enjoyed many meaningful discussions. Beatriz, thank you for the enjoyable lunches, coffees and encouragement.

I would like to express my earnest thanks to Peter E.L. van der Putten (CSA). Peter, I will never forget how much help you gave me in the greenhouse experiment during the first year of my PhD. Thank you very much for your support in arranging the experimental facilities, communicating with the staff of Unifarm, and also contacting with experts in the department of Plant Cell Biology and Microscopy. The experiences I gained in that experiment provided a solid foundation for my further research in China. Thank you for all the nice talks during coffee break and lunch time.

As a sandwich PhD student, I have spent over two and half years in the Crop Physiology group of the Agricultural College of Yangzhou University. I would like to particularly mention three persons. Prof. Hao Zhang, I express my special thanks to you for providing me great help in arranging accommodation before I arrived in Yangzhou and giving me valuable advices in the management of the field experiments. Prof. Junfei $\mathrm{Gu}$, thank you for your constructive suggestions on experimental protocols and your guidance on gas-exchange measurements. Prof. Lijun Liu, I am very grateful to you and your wife for making it possible for me to run the field experiment in the last year I stayed in Yangzhou. All your generous supports were crucial for the completion of my experiments and data collection. I also thank the other members of the Crop Physiology group in Yangzhou for providing an enjoyable working environment: Tingting Chen, Guang Chu, Yunji Xu, Chenxin Ji, Weiyang Zhang, Jie Liu, Daojian Gu, Jinlong Bian and Yiwei Xiong.

During my stay at Yangzhou University, I have conducted four pot experiments, one tank 
experiment and two field experiments. Those experiments were laborious. I would never have been able to finish those on my own and I want to thank all the people that supported me with experiment implementation and data collection. Especially Qun Zhou (College of Agriculture, YZU) and Zhenxiang Zhou (who later became a PhD student of CSA) contributed a lot to the field and experimental work, while Yiqi Mao (College of Agriculture, YZU) contributed to the lab work. I am very grateful for all your hard work and kind help. Qun Zhou, many thanks for your patience during the seemingly endless gas-exchange measurements and root washing. Zhenxiang Zhou, thank you for managing the field experiments and providing the necessary help in the lab. Yiqi Mao, thank you very much for your assistance on root staining and microscopic photographing. I also want to thank Tiny Franssen-Verheijen (Laboratory of Virology, WUR), Joke Oosterkamp (Horticulture and Product Physiology, WUR), Dr. André van Lammeren (Laboratory of Cell Biology, WUR), Dongliang Li (College of Bioscience and Biotechnology, YZU) and Xurun Yu (College of Bioscience and Biotechnology, YZU) for their valuable guidance of my microscopy work and discussing the protocols. I also appreciate Ying Chen, Zhikang Li, Qixing Dai, Dong Yan and Wenxun Huang from College of Agriculture of YZU for their assistance during the experimental work.

I want to thank all the previous and current members of CSA for their direct or indirect support. I would like to express my gratitude to Sjanie van Wetten, Nicole Wolffensperger, Petra Rozema and Alex-Jan de Leeuw. Sjanie, thank you for being a supportive friend. Your encouragement and motivation helped me when I went through a tough 2016. Petra, thank you for helping me to arrange all formalities during the last two years. Nicole, I am very thankful for your assistance to format this thesis. Your suggestions were very clear and helpful. I am very grateful for this. I am very grateful to Dr. Tjeerd-Jan Stomph for his valuable advice on data analysis. I want to thank Dr. Herman N.C. Berghuijs for the brainstorm sessions that we had when I came back to WUR. Those sessions helped me to further develop Chapter 2 in this thesis. I also thank you for being a good friend. I want to thank Alejandro Morales Sierra for helping me program in $\mathrm{R}$, which saved me a lot of time during data analysis.

I would also like to thank many PhD fellows and friends: Luuk van Dijk, Giovani Theisen, Dennis Tippe, Ali Elhakeem, Ambra Tosto, Phuong Thi Nguyen, Thomas Awio, Wenfeng Li, Shuangwei Li, Qi Wang, Liping Shao, Shenghao Gu, Na Wang, Bei Dong, Panpan Fan, Liang Fang, Chunfeng Gu, Qian Li, Hongyu Sun, Dong Wang, Jin Wang, Zishen Wang, Zhuo Xu, Zhenxiang Zhou and Qingyue Zhao. Thank you very much for organizing scientific seminars, 
$\mathrm{PhD}$ meetings, lunch discussions, international dinners, Thursday drinks and outdoor activities. Special thanks go to Wanju Shi, Kailei Tang, Fang Gou, Yuyun Wang, Chen Feng, Uta Priegnitz and Marcelo Labra Fernández. Your company, endless support and encouragement gave me strength to persevere with this challenging journey. Zishen and Zhenxiang, thank you for being my paranymphs.

Last but by no means least, I would like to express my deepest gratitude to my family, especially my parents for their unconditional love, care and support. They took care of me when I stayed in Yangzhou and travelled two times in a year for another two years between China and Netherlands to give me full support to pursue my career. Thank you!

Wenjing Ouyang

Wageningen, The Netherlands,

September, 2021 


\section{List of Publications}

Ouyang W, Yin X, Yang J, Struik PC. 2021. Roles of canopy architecture and nitrogen distribution in the better performance of an aerobic than a lowland rice cultivar under water deficit. Field Crops Research 271, 108257.

Ouyang W, Yin X, Yang J, Struik PC. 2021. Do shoot anatomical characteristics allow rice to grow well under water deficit? Journal of Agronomy and Crop Science, online (https://doi.org/10.1111/jac.12509).

Ouyang W, Yin X, Yang J, Struik PC. 2020. Comparisons with wheat reveal root anatomical and histochemical constraints of rice under water-deficit stress. Plant and Soil 452, 547-568.

Ouyang W, Struik PC, Yin X, Yang J. 2017. Stomatal conductance, mesophyll conductance, and transpiration efficiency in relation to leaf anatomy in rice and wheat genotypes under drought. Journal of Experimental Botany 68, 5191-5205.

Kip N, Ouyang W, van Winden J, Raghoebarsing A, van Niftrik L, Pol A, ..., and Op den Camp, HJ. 2011. Detection, isolation, and characterization of acidophilic methanotrophs from Sphagnum mosses. Applied and Environmental Microbiology 77, 5643-5654. 



\section{PE\&RC Training and Education Statement}

With the training and education activities listed below the $\mathrm{PhD}$ candidate has complied with the requirements set by the C.T. de Wit Graduate School for Production Ecology and Resource Conservation (PE\&RC) which comprises of a minimum total of 32 ECTS (= 22 weeks of activities)

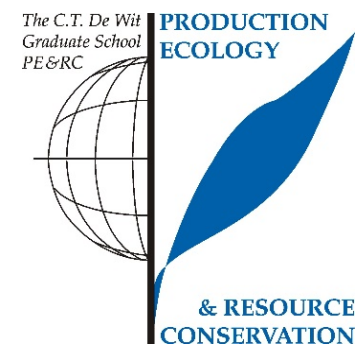

\section{Review of literature (6 ECTS)}

- Anatomical and physiological traits to improve drought tolerance in rice

\section{Writing of project proposal (4.5 ECTS)}

- Morphological, anatomical and physiological differences between different types of rice and wheat under water deficit conditions

\section{Post-graduate courses (3.2 ECTS)}

- Common statistical software; College of Agriculture, Yangzhou University, China (2014)

- Introduction to R for statistical analysis; PE\&RC (2016)

- Mixed linear models; PE\&RC (2017)

\section{Laboratory training and working visits (4.5 ECTS)}

- Microtome and microscopy training; College of Agriculture, Yangzhou University, China (2013)

- Rice and wheat root morphological study; International Rice Research Institute, Philippines (2015)

Deficiency, refresh, brush-up courses (2.4 ECTS)

- Design of experiments; College of Agriculture, Yangzhou University, China (2014)

- $\quad$ Basic statistics; Biometris (2016)

\section{Competence strengthening / skills courses (1.9 ECTS)}

- Scientific publishing; WGS (2016)

- Brain training; WGS (2016)

- Efficient writing strategies; Wageningen in’to Languages (2016)

PE\&RC Annual meetings, seminars and the PE\&RC weekend (1.2 ECTS)

- PE\&RC Introduction weekend (2012)

- PE\&RC Day (2016) 


\section{Discussion groups / local seminars or scientific meetings (7.5 ECTS)}

- Monthly seminars College of Agriculture; Yangzhou University, China (2013-2015)

- Lunch seminars; Wageningen University (2016-2019)

- Photosynthesis discussion group; Wageningen University (2016)

\section{International symposia, workshops and conferences (4.4 ECTS)}

- Symposium on crop productivity and food security in China and ASEAN; Yangzhou, China (2013)

- The growing rice like wheat workshop; IRRI (2015)

\section{MSc thesis supervision (6 ECTS)}

- The effect of water deficit on photosynthesis in rice

- Leaf anatomy of rice and wheat 


\section{Curriculum vitae}

Wenjing Ouyang was born on $23^{\text {rd }}$ January, 1984 in Hubei Province, China. She grew up in Wuhan, a beautiful city that lies in the eastern Jianghan Plain. In 2006, she obtained her Bachelor of Science (BSc) degree in Biotechnology at Huazhong University of Science and Technology, China. In 2008, she received a fellowship from Radboud Scholarship Programme to pursue her Master of Science (MSc) study in Radboud University Nijmegen, the Netherlands, in Molecular Life Science. During her MSc study, she conducted research for two theses, and her second thesis was on Plant Genetics, from which her research interest shifted to Plant Science. In 2012, she started her PhD study at the Crop Physiology group of the Centre for Crop Systems Analysis at Wageningen University \& Research, in collaboration with the College of Agriculture, Yangzhou University. Her PhD project, as a component of the "Growing Rice Like Wheat" (GRLW) programme, has focused on understanding the anatomical, morphological and physiological differences between different types of rice and wheat under water deficit conditions. 


\section{Funding}

This PhD study was funded by an anonymous private donor who provided financial support, via Wageningen University Fund. The experimental work was financed by the College of Agriculture, Yangzhou University. 



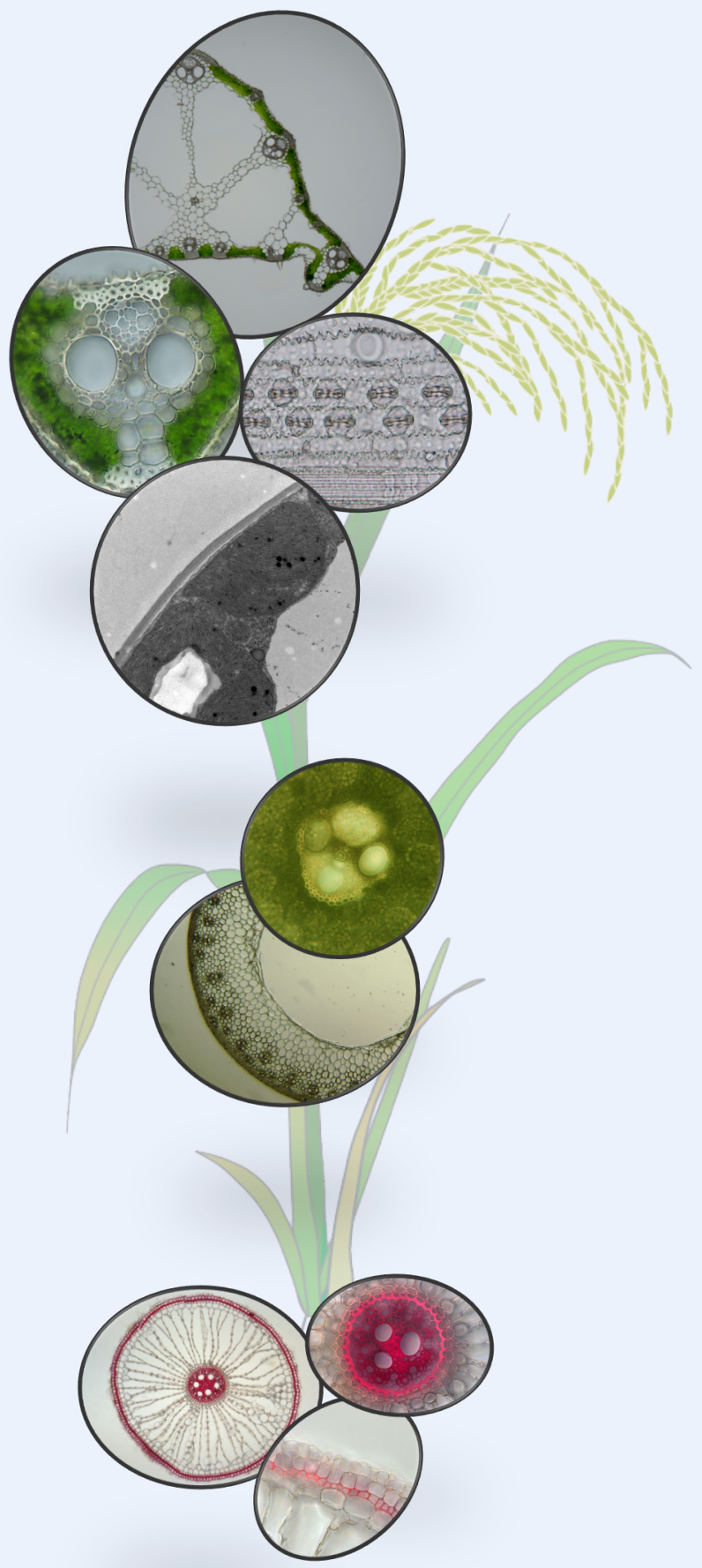

